INVOLVEMENT OF CYTOCHROME P450 1A IN THE TOXICITY OF ARYL

HYDROCARBON RECEPTOR AGONISTS: ALTERATION OF ARACHIDONIC ACID

\title{
METABOLISM AND PRODUCTION OF REACTIVE OXYGEN SPECIES
}

\author{
by \\ Jennifer Joy Schlezinger \\ B.S. Biology \\ Boston College, Chestnut Hill, MA, 1992 \\ SUBMITTED IN PARTIAL FULFLLMENT OF THE REQUIREMENTS FOR THE \\ DEGREE OF DOCTOR OF PHLOSOPHY \\ at the
MASSACHUSETTS INSTITUTE OF TECHNOLOGY
and the
WOODS HOLE OCEANOGRAPHIC INSTITUTION \\ August, 1998 \\ (C) Jennifer Joy Schlezinger \\ All rights reserved. \\ The author hereby grants to M.I.T. and W.H.O.I. permission to reproduce and \\ distribute copies of this thesis document in whole or in part.
}

Signature of Author

Joint Program in Biological Oceanography

Massachusetts Institute of Technology/Woods Hole Oceanographic Institution

Certified by

John J. Stegeman, Thesis Supervisbr

Accepted by

Mark E. Hahn, Chair

Joint Committee for Biological Oceanography,

Massachusetts Institute of Technology/Woods Hole Oceanographic Institution

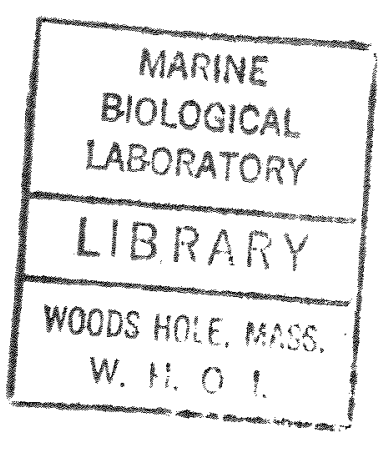




\title{
Involvement of Cytochrome P450 1A in the Toxicity of Aryl Hydrocarbon
}

\author{
Receptor Agonists: Alteration of Arachidonic Acid Metabolism and \\ Production of Reactive Oxygen Species
}

\author{
By \\ Jennifer Joy Schlezinger
}

submitted in partial fulfillment of the requirements for the degree of Doctor of Philosophy

\begin{abstract}
Two cytochrome P4501A-dependent mechanisms of aryl hydrocarbon receptor (AhR) agonist toxicity were examined in the marine teleost scup (Stenotomus chrysops), alteration of arachidonic acid (AA) metabolism and production of reactive oxygen species (ROS).

In scup hepatic microsomes, cytochrome P450s including CYP1A and CYP2B-like proteins catalyzed regioselective metabolism of $\mathrm{AA}$ to eicosatrienoic and hydroxyeicosatetraenoic acids. Benzo[a]pyrene (BP) treatment induced liver microsomal AA metabolism, but that effect varied with season. Endogenous AA epoxides were recovered from scup liver, heart, and kidney, and their composition in the liver was altered by treatment with $\mathrm{BP}$ or 2,3,7,8-tetrachlorodibenzo- $p$-dioxin.

In scup and mammals, the formation of ROS was stimulated by binding of 3,3',4,4-tetrachlorobiphenyl (TCB) to CYP1A, apparently CYP1A1. Attack of that ROS inactivated scup CYP1A. ROS release and inactivation of CYP1A were stimulated only by substrates of CYP1A that are slowly metabolized. In vivo, 3,3',4,4',5pentachlorobiphenyl (PeCB) potently induced CYP1A mRNA, protein and catalytic activity at low doses (0.01-0.1 mg/kg), suppressed induction of CYP1A protein and catalytic activity at a high dose $(1 \mathrm{mg} / \mathrm{kg})$ and transiently induced oxidative stress in scup liver. The suppression of CYP1A induction was organ-dependent, with hepatic CYP1A being most susceptible to inactivation. The results suggest that ROS could be involved in the in vivo suppression of scup liver CYP1A by planar halogenated aromatic hydrocarbons.

The reactive oxygen sensitive transcription factor, nuclear factor- $\kappa \mathrm{B}(\mathrm{NF}-\kappa \mathrm{B})$, was characterized in scup. An NF- $\mathrm{KB}$ consensus binding sequence bound specifically to 3 proteins in scup liver, heart and kidney. One protein was recognized by an antibody to mammalian $\mathrm{p} 50$. Injection alone appeared to activate $\mathrm{NF}-\mathrm{kB}$. BP did not increase the activation of NF- $\kappa B$, and PeCB activated NF- $\kappa B$ in only 1 of 2 experiments.

Last, CYP1A induction in endothelial cells of the American eel (Anguilla rostrata), a site which may be particularly susceptible to alterations in AA metabolism and ROS production, was described. Eel liver CYP1A responded to BP, $\beta$-naphthoflavone and TCB in a dose-dependent fashion, and induction was correlated with hepatic inducer concentration. Endothelial CYP1A was inducible in a number of organs and was metabolically active. In the rete mirabile, penetration of endothelial CYP1A induction increased with increasing dose of AhR agonists, corresponding with an increase in inducer concentration. A transition from endothelial to epithelial staining occurred in the gill, heart and kidney at high inducer doses.
\end{abstract}

Thesis Supervisor: John J. Stegeman. Title: Senior Scientist, WHOI 



\section{ACKNOWLEDGMENTS}

First and foremost, I must thank my advisor, John Stegeman. While we did not always agree on the best course of action, he allowed me the freedom to follow the data along the most interesting path. John Waterbury kindly participated in my thesis proceedings as the chairperson of both my proposal defense and my thesis defense. Peter Dedon was not only an enthusiastic member of my committee, a somewhat rare commodity in MIT faculty members, but also a thought provoking member. Mark Hahn's office door was always open, and he was always willing to chat about enzyme kinetics. I must thank Judy McDowell for providing some environmental perspective to my thesis work.

Not all of my research took place in Redfield, and I need to thank a number of people in the MBL/WHOI community at large, as well as a few others from a bit farther afield. Jim Craddock saved me from having to put my arm in garbage pails full of salp goo to retrieve my mid-water fish and more importantly identified those fish for me. Rita Garrick imparted much important information on the culture of endothelial cells. Colleen Hurter hunted down hundreds of references for me. Michelle McCafferty was an absolute artist when it came down to embedding retes in paraffin. Vicki Starczak introduced me to the evils of pseudo-replication and helped me to plan both logisticaily-possible and statistically-correct experiments. And, Julia Westwater was always a source of helpful information in the Education office. At the National Institute of Environmental Health Sciences, Darryl Zeldin was kind enough to teach me the ropes of arachidonic acid metabolism and to allow me free use of his extensive HPLC systems. Cindy Moomaw and Carol Parker both provided essential technical support and helped me survive Hurricane Fran. At Boston University, Koren Mann made the NF- $\mathrm{kB}$ work possible by teaching me the secrets of gel shift assays, and Dave Sherr let me run amuck in his lab with my fish samples.

I have had the privilege to work with a wonderful (and at times crazy) group of people in the Stegeman and Hahn labs. In particular, Bruce was always ready to help me through a crisis (and believe me, I had plenty!). He was always ready to inject more fish, dissect more fish and correct more dilutions! And, he always did it with a smile, with a joke and usually with a song. Eli, Margie and Wade provided plenty of constructive criticism on my manuscripts and my science. Afonso taught me the ins and outs of antioxidant enzymes with his Brazilian flair. Renee provided me with the know-how to pick up where she had left off, and Rachel provided the moral support for those last few months of thesis writing hell! The help of several summer students, Courtney, DJ and 
Jennifer, increased my productivity dramatically. Other laboids along the way included Agnes, Brenda, Carolyn, Celine, Connie, Diana, Heather, Howie, Joanna, Liz, Malin, Michael \#1, Michael \#2, Shannon, Sibel, Stephanie \#1, Stephanie \#2 and Sue.

I would not be the person or the scientist I am today without the love and support of my family and friends. Mom and Dad not only provided the scientific genes but also an environment where I was free to chose whomever I wanted to be. Brian has been everything a big brother should be. The Schlezingers welcomed me into their family and made me one of their own. I thank Eli and Shannon for many evenings of entertainment, and Brenda for many discussions about the Future. For those who got me through that first summer in Woods Hole (Carolyn, Diane and Doug) and that first semester at MIT (Liz and Melissa) - thank you!

Finally, I must thank my wonderful husband - David (aka LD). Your love gave me the confidence to fulfill a lifelong dream. It was through your support, your humor and I think most of all your patience that we got through these challenging times.

My research was supported in part by the Lyons Fellowship, the MIT/WHOI Joint program, the Rinehart Coastal Research Center, NIH grant P42-ES07381, EPA grant R823890 and the Air Force Office of Scientific Research grant F40620-94-1039.

This thesis is dedicated, in loving memory, to my grandmother Sophie. 
Abstract

Acknowledgments 5

List of Tables $\quad 9$

$\begin{array}{ll}\text { List of Figures } & 11\end{array}$

$\begin{array}{ll}\text { Abbreviations } & 15\end{array}$

$\begin{array}{ll}\text { CHAPTER 1. Introduction and Background } & 17\end{array}$ Introduction

Structure, Function and Regulation of Cytochromes P450

Cytochromes P450 in Teleost Fish

Polychlorinated Biphenyls

Reactive Oxygen Species

Arachidonic Acid

Endothelium

Specific Objectives

CHAPTER 2. Arachidonic Acid Metabolism in the Marine Fish Stenotomus chrysops (Scup) and the Effects of Cytochrome P450 1A Induction Abstract

Introduction

Materials and Methods

Results

Discussion

CHAPTER 3. Oxidative Inactivation of Cytochrome P450 1A Stimulated

51 by 3,3',4,4'-Tetrachlorobiphenyl: Production of Reactive Oxygen Species by Vertebrate CYP1As
Abstract
Introduction
Materials and Methods
Results
Discussion

CHAPTER 4. Structure-Activity Relationships in the Stimulation of Reactive Oxygen Production and Cytochrome P450 1A Inactivation by

Halogenated Aromatic Hydrocarbons

Abstract

Introduction

Materials and Methods

Results

Discussion 
CHAPTER 5. Inactivation of Cytochrome P450 1A by 3,3',4,4',5-Penta-

chlorobiphenyl In Vivo and its Potential Relationship to Oxidative

Stress
Abstract
Introduction
Materials and Methods
Results
Discussion

CHAPTER 6. Characterization of the Reactive Oxygen Sensitive Transcription

Factor Nuclear Factor- $\kappa B$ in the Marine Fish Stenotomus chrysops and Examination of its Activation by Aryl Hydrocarbon Receptor Agonists
Abstract
Introduction
Materials and Methods
Results
Discussion

CHAPTER 7. Tissue Distribution of and Induction of Cytochrome P450 1A of Endothelial CYP1A on AhR Agonist Pharmacokinetics
Abstract
Introduction
Materials and Methods
Results
Discussion

CHAPTER 8. Summary and Conclusions

Arachidonic Acid Metabolism

Planar Halogenated Aromatic Hydrocarbon-Stimulated CYP1A Inactivation

Planar Halogenated Aromatic Hydrocarbon-Stimulated ROS

Production

NF-KB in a Teleost

CYP1A and Endothelium

APPENDIX A. 3,3',4,4'-Tetrachlorobiphenyl Metabolism in Fish, Bird and Reptile Species and its Relationship to Cytochrome P450 1A

Inactivation and Reactive Oxygen Production

Abstract

Introduction

Materials and Methods

Results

Discussion

References 
Table I. Induction of selected P450 gene subfamilies. 23

Table II. Chlorination patterns and IUPAC numbers for select PCBs. 27

Table III. Oxygen species and their reactivity. 31

Table IV. Antioxidant defenses. 33

CHAPTER 2:

Table I. Characterization of P450 in liver microsomes 43

Table II. Regioselectivity of HETE formation by liver microsomes from 45 untreated and BP-treated scup.

Table III. Antibody inhibition of scup liver microsomal metabolism of 46 arachidonic acid.

Table IV. Endogenous EET content in scup liver following treatment with $\quad 47$ CYP1A inducers.

Table V. Endogenous EET content of scup heart and kidney. 48

CHAPTER 3:

Table I. Loss of scup liver P450 stimulated by TCB and NADPH. 62

Table II. Effect of catalase inhibitors on TCB-stimulated CYP1A inactivation. 66

Table III. Effect of $\mathrm{H}_{2} \mathrm{O}_{2}$ on TCB-stimulated CYP1A inactivation. 67

Table IV. Effects of antioxidants and iron concentrations on TCB-stimulated 68 inactivation of CYP1A.

Table V. Comparison of scup and rat liver microsomal enzyme activities and $\quad 74$ CYP1A inactivation.

\section{CHAPTER 4:}

Table I. In vitro inhibition and inactivation of EROD by CB congeners in scup 98 liver microsomes.

Table II. NADPH oxidation in scup liver microsomes.

CHAPTER 7:

Table I. Total spectral P450 and cytochrome b5 content in eels treated with $\mathrm{BNF}, \mathrm{BP}$ and TCB.

Table II. Comparison of the efficacy of BNF, BP and TCB in inducing CYP1A 172 in eel liver.

Table III. Characterization of CYP1A protein and activity in liver microsomes from eels collected from differentially polluted sites. 
CHAPTER 7 cont.

Table IV. Quantification of CYP1A content and activity in eel heart and rete mirabile following treatment with model AhR agonists.

Table V. Characterization of CYP1A protein and activity in heart and rete mirabile microsomes from eels collected from differentially polluted sites.

Table VI. Immunohistochemical analysis of CYP1A induction following treatment with BNF, BP and TCB in the rete mirabile of eels.

\section{APPENDIX A:}

Table I. Comparison of CYP1A content, EROD activity and TCB metabolism in liver microsomes from bird, fish and reptile species. 
Figure 1. The catalytic cycle of cytochrome P450. 21

Figure 2. Generalized PCB structure. 26

Figure 3. Oxygen chemistry. 30

Figure 4. P450-mediated metabolites of arachidonic acid. 34

Figure 5. Anguilla rostrata. 38

Figure 6. Stenotomus chrysops. 38

CHAPTER 2:

Figure 1. Immunodetection of CYP1A in scup liver microsomes. 43

Figure 2. Reverse-phase HPLC chromatograms of the organic soluble 44 arachidonic acid metabolites generated by scup liver microsomes.

Figure 3. Seasonal and sex differences in scup liver microsomal metabolism 45 of arachidonic acid.

Figure 4. Effect of BP and TCDD treatment on scup liver microsomal 46 metabolism of arachidonic acid.

\section{CHAPTER 3:}

Figure 1. TCB-stimulated inactivation of scup liver CYP1A (EROD activity). $\quad 59$

Figure 2. TCB concentration dependent inactivation of scup liver CYP1A. 60

Figure 3. Effect of cytochrome $c$ on TCB-stimulated scup liver CYP1A 64 inactivation.

Figure 4. Effects of azide (A) and $\mathrm{H}_{2} \mathrm{O}_{2}$ (B) on TCB-stimulated scup liver 65 CYP1A inactivation.

Figure 5. ROS production in liver microsomes from control and BP-treated scup. 70

Figure 6. Effect of TCB and NADPH on the capacity of scup liver CYP1A to 72 produce ROS.

Figure 7. ROS production in liver microsomes from control and Aroclor-treated 75 rats.

Figure 8. ROS production in microsomes from insect cells expressing human $\quad 76$ CYP1A1 and CYP1A2.

\section{CHAPTER 4:}

Figure 1. Effect of $\mathrm{CB}$ congeners and $\mathrm{BP}$ on ROS production in scup liver microsomes. 
CHAPTER 4 cont.

Figure 2. Inhibition and inactivation of scup liver CYP1A stimulated by BP and CBs 52, 77, 105, 126 and 169.

Figure 3. Loss of spectral P450 in the presence of CBs and NADPH.

Figure 4. Concentration dependent inhibition and inactivation of CYP1A stimulated by CBs 105 (A), 126 (B) and 169 (C).

Figure 5. Effect of azide on CB-stimulated CYP1A inactivation in scup liver microsomes.

Figure 6. Effect of $\mathrm{H}_{2} \mathrm{O}_{2}$ on CB-stimulated inactivation in scup liver microsomes.

Figure 7. Effect of cytochrome $c$ on CB-stimulated CYP1A inactivation in scup liver microsomes.

CHAPTER 5:

Figure 1. Effect of PeCB on hepatic microsomal cytochrome P450 (A) and cytochrome b5 (B).

Figure 2. Effect of PeCB on CYP1A mRNA expression in scup liver.

Figure 3. Effect of PeCB on hepatic microsomal CYP1A content (A) and catalytic activity (EROD - B; MROD - C).

Figure 4. Correlation of CYP1A content with total P450 and EROD activity. $\quad 120$

Figure 5. Effect of PeCB on hepatic microsomal P450A (A) and P450B (B). 121

Figure 6. Effect of PeCB on the potential of hepatic microsomes to produce 123 ROS.

Figure 7. Effect of PeCB on hepatic cytosolic catalase activity (A), glutathione peroxidase activity (B), glutathione reductase activity $(\mathrm{C})$ and superoxide dismutase activity (D).

Figure 8. Effect of PeCB on extra-hepatic microsomal CYP1A content.

Figure 9. Effect of PeCB on extra-hepatic microsomal CYP1A catalytic activity (EROD).

CHAPTER 6:

Figure 1. Effect of BP on scup hepatic microsomal CYP1A content (A) and catalytic activity (EROD - B).

Figure 2. Binding of an NF- $\mathrm{KB}$ consensus sequence to liver nuclear proteins from control and BP-treated scup. 
CHAPTER 6 cont.

Figure 3. Effect of PeCB on scup hepatic microsomal CYP1A content (A) and catalytic activity (EROD - B).

Figure 4. Quantification of NF- $\mathrm{kB}$ activation in liver of control and PeCBtreated scup

Figure 5. Nuclear proteins from scup liver bound an NF- $\mathrm{kB}$ consensus sequence but not $\mathrm{AP}-1$ or Oct1 consensus sequences.

Figure 6. Specific competition of binding of an NF- $\mathrm{kB}$ consensus sequence to scup liver nuclear proteins.

Figure 7. Binding of an NF- $\mathrm{KB}$ consensus sequence to at least 3 scup liver nuclear proteins.

Figure 8. Specific binding of an NF- $\mathrm{kB}$ consensus sequence to scup kidney (A) and heart (B) nuclear proteins.

Figure 9. Binding of an NF- $\mathrm{KB}$ consensus sequence to at least 3 scup kidney (A) 154 and heart (B) nuclear proteins.

\section{CHAPTER 7:}

Figure 1. Distributions of ${ }^{3} \mathrm{H}-\mathrm{BP}$ and ${ }^{14} \mathrm{C}-\mathrm{TCB}$ in eels injected IP.

Figure 2. CYP1A protein expression in liver microsomes from eels treated with BNF, BP and TCB.

Figure 3. Quantification of liver CYP1A protein and activity in eels treated with BNF, BP and TCB.

Figure 4. Correlation of BP and TCB concentration in eel liver with CYP1A induction.

Figure 5. Immunodetection of CYP1A in rete mirabile microsomes from eels treated with BNF, BP and TCB.

Figure 6. Immunohistochemical analysis of CYP1A protein in endothelium of eels treated with BNF, BP and TCB.

Figure 7. CYP1A immunostained sections of rete mirabile from eels treated with BNF.

\section{CHAPTER 8:}

Figure 1. An alignment between CYP1A sequences demonstrating similarities and differences between amino acids in the vicinity of the active site. 
APPENDIX A: $\quad$ Page

Figure 1. TCB-stimulated inactivation of hepatic microsomal CYP1A (EROD 208 activity).

Figure 2. Correlation of TCB metabolism with inactivation of CYP1A catalytic activity.

Figure 3. TCB-stimulated ROS production in liver microsomes.

Figure 4. Correlation of ROS production with CYPIA catalytic activity. 


\begin{tabular}{|c|c|c|}
\hline \multicolumn{3}{|c|}{ ABBREVIATIONS } \\
\hline 4-OH-TCB & - & 4-Hydroxy-3,3',4,5-tetrachlorobiphenyl \\
\hline 5-OH-TCB & - & 5-Hydroxy-3,3',4,4'-tetrachlorobiphenyl \\
\hline $\mathrm{AA}$ & - & Arachidonic acid \\
\hline $\mathrm{AHH}$ & - & Aryl hydrocarbon hydroxylase \\
\hline AhR & - & Aryl hydrocarbon receptor \\
\hline ANF & - & $\alpha$-Naphthoflavone \\
\hline AP-1 & - & Activator protein- 1 \\
\hline ARNT & - & Aryl hydrocarbon receptor nuclear translocator \\
\hline ATA & - & 3-Amino-1,2,4-triazole \\
\hline BNF & - & B-Naphthoflavone \\
\hline BP & - & Benzo[a]pyrene \\
\hline BSA & - & Bovine serum albumin \\
\hline cat & - & Chloramphenicol acetyltransferase \\
\hline CB & - & Chlorobiphenyl \\
\hline CPR & - & Cytochrome $\mathrm{P} 450$ reductase \\
\hline CYP & - & Cytochrome P450 \\
\hline DCF & - & 2',7'-Dichlorofluorescein \\
\hline DCDFDA & - & 2',7'-Dichlorodihydrofluorescein diacetate \\
\hline DHET & - & Dihydroxyeicosatrienoic acid \\
\hline DMBA & - & 7,12-Dimethylbenz[a]anthracene \\
\hline DRE & - & Dioxin response element \\
\hline DTPA & - & Diethylenetriaminepenta-acetic acid \\
\hline DTT & - & Dithiothrietol \\
\hline EET & - & Epoxyeicosatrienoic acid \\
\hline EMSA & - & Electrophoretic mobility shift assay \\
\hline EPA & - & Eicosapentaenoic acid \\
\hline EROD & - & Ethoxyresorufin O-deethylation \\
\hline ETCP & - & 1,2-Epoxy-3,3,3-tricloropropane \\
\hline GH & - & Growth hormone \\
\hline GSI & - & Gonadosomatic index \\
\hline $\mathrm{HA}$ & - & Hydroxylamine \\
\hline $\mathrm{HAH}$ & - & Halogenated aromatic hydrocarbon \\
\hline HBSS & - & Hank's buffered salt solution \\
\hline
\end{tabular}




\begin{tabular}{|c|c|c|}
\hline $\mathrm{HE}$ & - & Dihydroethidium \\
\hline HETE & - & Hydroxyeicosatetraenoic acid \\
\hline HIV-1 & - & Human immunodeficiency virus type 1 \\
\hline IHC & - & Immunohistochemistry \\
\hline IP & - & Intra-peritoneal \\
\hline $\mathrm{MC}$ & - & 3-Methylcholanthrene \\
\hline MROD & - & Methoxyresorufin O-demethylation \\
\hline $\mathrm{NBH}$ & - & New Bedford Harbor \\
\hline $\mathrm{NBT} / \mathrm{BCIP}$ & - & Nitro blue tetrazolium/5-bromo-4-chloro-3-indoyl-phosphate \\
\hline NF-KB & - & Nuclear factor- $\kappa B$ \\
\hline PAEC & - & Porcine aorta endothelial cells \\
\hline PAH & - & Polynuclear aromatic hydrocarbons \\
\hline PB & - & Phenobarbital \\
\hline PCB & - & Polychlorinated biphenyl \\
\hline $\mathrm{PeCB}$ & - & $3,3^{\prime}, 4,4^{\prime}, 5$-Pentachlorobiphenyl \\
\hline PFB & - & Pentafluorobenzyl \\
\hline pHAH & - & Planar halogenated aromatic hydrocarbon \\
\hline PLC & - & Peritoneal lavage cells \\
\hline PLHC & - & P. lucida hepatoma cells \\
\hline PMA & - & Phorbol 12-myristate 13-acetate \\
\hline PMSF & - & Phenylmethylsulfonyl fluoride \\
\hline ROS & - & Reactive oxygen species \\
\hline SOD & - & Superoxide dismutase \\
\hline TCB & - & 3,3',4,4'-Tetrachlorobiphenyl \\
\hline TCDD & - & $2,3,7,8$-Tetrachlorodibenzo-p-dioxin \\
\hline TCDF & - & 2,3,7,8-Tetrachlorodibenzofuran \\
\hline TEF & - & TCDD equivalency factor \\
\hline
\end{tabular}




\section{CHAPTER 1}

Introduction and Background 


\section{INTRODUCTION}

The overall goal of this research was to investigate mechanisms of toxicity of aryl hydrocarbon receptor agonists, with particular emphasis on planar halogenated aromatic hydrocarbons (pHAH). These studies explored two potential cytochrome P450 1Amediated mechanisms of toxicity, alteration of arachidonic acid metabolism and production of reactive oxygen species. Further, cytochrome P450 1A induction in a sensitive cell type, endothelium, was examined following either experimental or environmental exposure.

Polychlorinated biphenyls (PCB) are ubiquitous contaminants of the global environment. Produced mainly for the electrical industry from the 1940's to the 1970's, their production now is banned. PCBs, along with dioxins and dibenzofurans, comprise the group of compounds know as halogenated aromatic hydrocarbons (HAH). The planar HAH congeners are considered to be the most toxic. While the toxicity of planar HAHs $(\mathrm{pHAH})$ is recognized and thought mainly to be a function of their interaction with the aryl hydrocarbon receptor (AhR), the mechanisms of this toxicity are unclear.

Mono-oxygenase enzymes, particularly cytochrome P450s, are considered to be one of the major defense mechanisms against the toxicity of xenobiotic compounds. Cytochromes P450 (CYP), a superfamily of enzymes, is responsible for the synthesis and degradation of many endogenous compounds, as well as for the metabolism of many foreign compounds. These enzymes catalyze a wide range of reactions including aromatic and aliphatic hydroxylation, epoxidation, $\mathrm{N}, \mathrm{O}$, and $\mathrm{S}$ dealkylation and $\mathrm{N}, \mathrm{S}$, and $\mathrm{P}$ oxidation. In general the addition of oxygen to xenobiotic compounds increases their water-solubility and thus allows for increased excretion. Most xenobiotics are metabolized by CYPs in families 1-4. In particular, cytochrome P4501A (CYP1A) has been characterized for its induction and regulation by foreign chemicals via the AhR.

Paradoxically, the interaction of substrates with CYP1A also may result in increasing the toxicity of these chemicals. First, oxidative metabolism by CYP contributes to toxicity by activating promutagens and procarcinogens such as benzo[a]pyrene or aflatoxin $B_{1}$. Second, studies in fish and mammals have suggested that treatment with CYP1A inducers increases the metabolism of arachidonic acid (AA) in vivo. These metabolites have a variety of diverse physiological functions, and alteration of AA metabolism following CYP1A induction may have important physiological consequences. Third, pHAH treatment is associated with AhR-dependent oxidative stress. Binding of

slowly metabolized substrates by CYP1A may uncouple the catalytic cycle, resulting 
release of reactive oxygen species (ROS) that could attack any member of the cellular machinery. Thus CYP1A may contribute to toxicity by activating chemicals, modifying metabolism of endogenous signaling molecules and producing reactive oxygen.

CYP1A is found in a wide range of tissues and cell types. It is thought that most metabolism of xenobiotic compounds is carried out in the liver by CYP1A. However, studies have shown that endothelium in vertebrates from fish to mammals is a ubiquitous site of very strong induction of CYP1A by halogenated and non-halogenated aromatic hydrocarbons. CYP1A found in endothelial cells may represent a significant proportion of CYP1A found in organisms as a whole. Because the endothelial cells line all blood vessels and actually form the capillaries, it raises the question of what significance induction of CYP1A in these cells may have. 


\section{STRUCTURE, FUNCTION AND REGULATION OF CYTOCHROMES P450}

The cytochromes P450 are a superfamily of mono-oxygenase enzymes. CYPs are found in a wide variety of life forms, including bacteria, fungi and plants, as well as animals. There are 115 gene families, 37 of which occur in animals (Nelson, 1997). CYPs with less than $40 \%$ amino acid sequence identity are placed in different gene families; those with $40-55 \%$ identity are placed in different subfamilies. The diversity of this gene superfamily is reflected by the vast array of chemicals, endogenous and exogenous in origin, which are substrates for these enzymes.

In general, CYPs are hydrophobic, membrane bound, heme proteins found in the endoplasmic reticulum of many cell types. The orientation of CYP in the membrane is still debated. Studies agree that the protein is localized toward the cytoplasmic face. Nelson and Strobel (Nelson and Strobel, 1988) hypothesized that a CYP is held in the membrane by an amino terminal hairpin loop, with the globular part of the protein extending into the cytoplasm. The substrate binding site faces the membrane in this model with the heme oriented parallel to the membrane. Edwards et al. (Edwards et al., 1991) proposed a model in which there is only a single stranded anchor of 20-30 residues with the globular portion of the protein in the cytoplasm, the heme being perpendicular or near perpendicular to the membrane. They also suggest that a portion of the globular protein may rest on the membrane itself. Still others suggest that there are four transmembrane domains and that the active site is within the membrane (Black and Coon, 1986).

The CYP active site contains one iron protoporphyrin IX prosthetic group formed by four pyrole rings and one iron atom. This is where the dioxygen molecule is bound, reduced and activated (McMurry and Groves, 1986). Unlike other hemoproteins, the CYP heme has a 5th ligand, a cysteine-thiolate (Black and Coon, 1986). This 5th ligand causes the unusual absorbance maximum at $450 \mathrm{~nm}$. When the thiolate bond is distupted, P450 is converted to the inactive P420 form (Parkinson, 1996). Knowledge of active site structure is limited because of the inability to crystallize membrane-bound proteins; however, the stereospecific nature of substrate oxidation suggests that the substrate orientation is constrained within the active site (Miwa and Lu, 1986). 


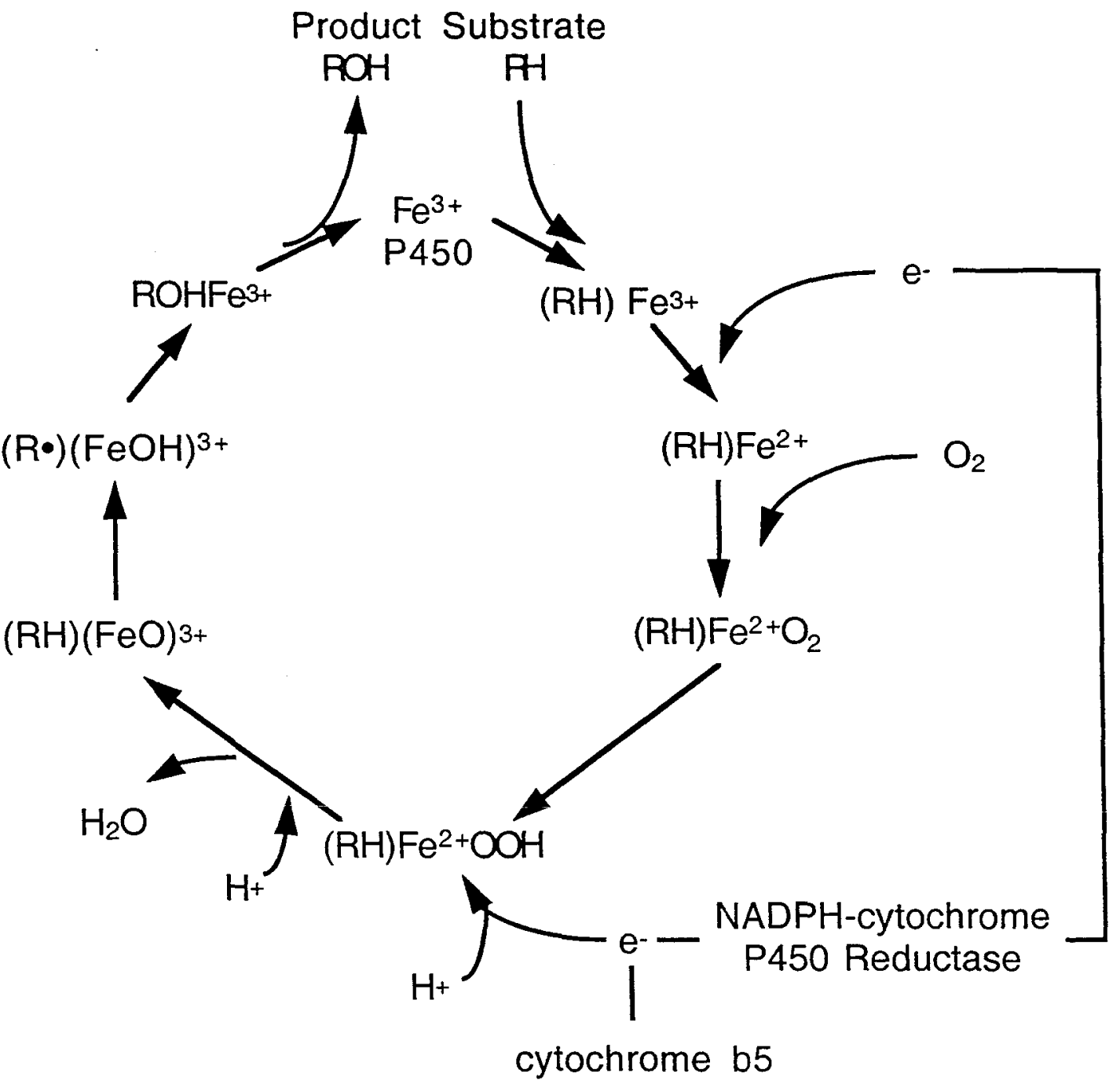

Figure 1: The catalytic cycle of cytochrome P450. From: (Parkinson, 1996).

The reaction mechanism of CYP consists of a series of interactions with oxygen and a substrate (Figure 1). In the resting state, the heme iron of the prosthetic group is in a low spin state $\left(\mathrm{Fe}^{3+}\right)$. Once the substrate is bound, the iron is converted to a high spin state and to a redox potential that favors reduction. Substrate binding is probably the first step in most CYP cycles; however, rapid CYP reduction also can occur in the absence of substrate (Guengerich and Johnson, 1997). The iron is reduced by electron transport from the flavoprotein NADPH-cytochrome P450 reductase. Oxygen binds. Addition of a proton and a second electron converts the complex to a peroxide. Donation of the second 
electron is the rate limiting step in the mechanism. The oxygen-oxygen double bond is cleaved by the introduction of a second proton. A substrate radical is formed, hydroxylated and released (Stegeman and Hahn, 1994). Therefore, one oxygen atom oxidizes the substrate while the other atom is reduced with two electrons to form water.

Electron transfer is essential to CYP function. Because NADPH is the major source of electrons and is a two electron donor, the electron transfer enzyme must be able to accept two electrons but donate only one electron at a time to CYP. NADPHcytochrome P450 reductase is a membrane-bound flavoprotein which contains equimolar amounts of FAD and FMN and donates the first, if not both, electrons to CYPs. FAD is located close to the NADPH binding site and accepts the electron from NADPH. FMN is located near the CYP interaction site and passes the electron to CYP (Kurzban and Strobel, 1986). The rate of reduction of CYP can be increased 5-10 fold upon substrate binding (Ingelman-Sundberg, 1986). The second electron also may be donated to CYP by cytochrome b5, through cytochrome b5 reductase and NADH (Ortiz de Montellano, 1986).

Cytochrome P450 enzymes form two different regulatory classes. One class metabolizes endogenous substrates and the other metabolizes exogenous substrates, including xenobiotics. As a result there is a fundamental difference in the way that these two classes of enzymes are regulated. Constitutively expressed CYPs may be induced by endogenous or exogenous compounds; however, enzyme levels are generally maintained optimally for the maintenance of a particular function (Waterman et al., 1986). Constitutively expressed CYPs include CYP1A2, CYP2A6, CYP2B6, CYP2C, CYP2D6, CYP2E1 and CYP3A (Gonzalez and Lee, 1996). Those CYPs which metabolize exogenous compounds are inducible and respond to inducers with increased protein levels and catalytic activities. These changes in protein level are usually a result of changes in mRNA levels. These CYPs are induced by a wide variety of compounds (Table I).

CYPs can be regulated transcriptionally or post-transcriptionally. 3Methylcholanthrene (MC) induction of CYP1A2 is associated with mRNA stabilization (Kimura et al., 1986). Phenobarbital (PB) induces transcription of CYP2B1 and CYP2B2 (Waxman and Azaroff, 1992). Increases in CYP2E1 mRNA following diabetes occur due to mRNA stabilization (Porter and Coon, 1991). However, following exposure to acetone, CYP2E1 protein stabilization occurs because of phosphorylation prevention (Song et al., 1986; Eliasson et al., 1990). CYP3A can be induced either by transcriptional activation with dexamethasone (Schuetz et al., 1984) or by protein stabilization with macrolide antibiotics (Watkins et al., 1986). Clofibrate induces transcriptional activation of CYP4A; 
this may be mediated by the peroxisome-proliferator-activated receptor (Hardwick et al., 1987). Thus, regulation is inducer-, as well as, CYP- specific.

\section{TABLE I}

Induction of selected CYP gene subfamilies (From: Stegeman and Hahn, 1994)

\begin{tabular}{|c|c|c|c|c|}
\hline $\begin{array}{c}\text { Gene family } \\
\text { and } \\
\text { subfamily }\end{array}$ & $\begin{array}{l}\text { Selected } \\
\text { Protein } \\
\text { members }\end{array}$ & Prominent substrates & Common Inducers & Mechanisms \\
\hline CYP1A & $1 \mathrm{Al}$ & $\begin{array}{l}\text { PAH, planar PCB, } \\
\text { 7-ethoxyresorufin } \\
\text { Acetanilide, estradiol, } \\
\text { caffeine }\end{array}$ & $\begin{array}{c}\text { PAHs, planar PCBs, } \\
\text { BNF, chlorinated dioxins } \\
\text { and furans } \\
\text { PAHs, planar PCBs, } \\
\text { BNF, chlorinated dioxins } \\
\text { and furans, ISF }\end{array}$ & $\begin{array}{c}\text { Mostly } \\
\text { transcriptional } \\
\text { Transcriptional, post- } \\
\text { transcriptional }\end{array}$ \\
\hline CYP2B & 2B1 & Barbiturates, steroids & $\begin{array}{c}\text { Barbiturates, non-planar } \\
\text { PCBs, DDT }\end{array}$ & Transcriptional \\
\hline CYP2E & $2 \mathrm{E} 1$ & $\begin{array}{l}\text { Ethanol, } \\
\text { alkylnitrosamines }\end{array}$ & $\begin{array}{l}\text { Ethanol, ketones, } \\
\text { starvation, diabetes }\end{array}$ & $\begin{array}{c}\text { Transcriptional, post- } \\
\text { transcriptional }\end{array}$ \\
\hline CYP3A & $3 \mathrm{Al}$ & $\begin{array}{c}\text { Steroids } \\
\text { (6B-hydroxylase) }\end{array}$ & $\begin{array}{c}\text { PCN, DEX, macrolide } \\
\text { antibiotics }\end{array}$ & $\begin{array}{c}\text { Transcriptional, post- } \\
\text { transcriptional }\end{array}$ \\
\hline CYP4A & $4 \mathrm{~A} 1$ & $\begin{array}{c}\text { Lauric acid, arachidonic } \\
\text { acid }\end{array}$ & $\begin{array}{c}\text { Clofibrate, phthalates, } \\
\text { PCBs }\end{array}$ & Transcriptional \\
\hline
\end{tabular}

Abbreviations:

$\begin{array}{llll}\text { BNF } & \text { B-naphthoflavone } & \text { DEX } & \text { dexamethasone } \\ \text { DDT } & \text { dichlorodiphenyltrichloroethane } & \text { ISF } & \text { isosafrole } \\ \text { PAH } & \text { polynuclear aromatic hydrocarbon } & \text { PB } & \text { phenobarbital } \\ \text { PCB } & \text { polychlorinated biphenyl } & \text { PCN } & \text { pregnenolone-a-carbonitrile }\end{array}$

TCDD 2,3,7,8-tetrachlorodibenzo-p-dioxin 
For CYP1A1, induction is a receptor-mediated process. The aryl hydrocarbon receptor (AhR) is a cytosolic protein containing a ligand binding subunit and two heat shock proteins. Recently, the hepatitis B virus X-associated protein 2 also has been shown to be associated with the unliganded AhR (Meyer et al., 1998). Agonist binding to the AhR initiates CYP1A1 induction. The sequence of events is as follows (Hankinson, 1995). 1. The inducer diffuses into the cell. 2. The inducer binds to the AhR protein. 3. The ligand receptor complex is converted to a DNA binding form via the dissociation of the heat shock proteins, translocation to the nucleus, association with the AhR nuclear translocator (ARNT) protein and phosphorylation. 4. The ligand, receptor, ARNT complex binds to the enhancer DNA, known as the dioxin response element (DRE). Multiple DREs may be present in the promoter region of CYP1A (Lusska et al., 1993). 5. The enhancer DNA is activated. The enhancer is activated by several possible mechanisms, including altered DNA configuration, histone modification, or recruitment of additional proteins. 6. The nucleosome is disrupted allowing increased accessibility of the transcriptional promoter. The transcription factor binds to the promoter and enhances mRNA and protein synthesis. This sequence of reactions leads to increased levels of CYP1A in the cell.

CYPs may be regulated by physiological parameters, as well. In mammals, the CYP2A, CYP2C, CYP3A, and CYP4A subfamilies are expressed in a sexually differentiated fashion (Sundseth et al., 1992a; Sundseth and Waxman, 1992b). The differences in expression have been attributed to the pulsatile versus continuous release of growth hormone in males and females. Suppression of hepatic P450 content and activity during gonadal development in females, and release of that suppression after spawning, occurs in many teleost species (Pajor et al., 1990; Gray et al., 1991; Andersson and Forlin, 1992; Elskus et al., 1992). CYP1A, CYP2B-like and CYP3A-like proteins are suppressed by estradiol treatment or during natural maturation of female fish (Pajor et al., 1990; Gray et al., 1991). Estradiol regulates CYP1A at a pre-transcriptional level (Elskus et al., 1992). Sexually differentiated expression of CYP2K mRNA and protein also has been attributed to hormonal regulation (Buhler et al., 1994).

Even environmental factors, such as temperature, can influence CYP content. In some species, cold acclimatized fish have higher CYP metabolic rates than warm acclimatized fish (Carpenter et al., 1990). In killifish (Fundulus heteroclitus), warm acclimatized fish have higher CYP1A content and EROD activity; however, cold acclimatized fish maintain elevated CYP1A mRNA and protein levels for longer periods of 
time. The data suggest that it is a post-transcriptional temperature affect (Kloepper-Sams and Stegeman, 1992). The regulation of CYPs is not directed simply by inducers, but is influenced by a large variety of internal and external variables.

\section{CYTOCHROMES P450 IN TELEOST FISH}

While this study focuses on the CYP1A subfamily, it is important to note that other CYP gene families exist in fish. Procedures including protein purification, immunological reactivity and amino acid sequencing have been used to identify and classify different CYP genes in fish. This has lead to the description of fish CYP genes in subfamilies 1-4: 1(A), 2(B,E,K,M,N,P), 3(A), 4(T) (Stegeman, 1987; Kaplan et al., 1991; Stegeman, 1993; Buhler et al., 1994; Yang et al., 1996; Falckh et al., 1997; Oleksiak et al., 1998a; Oleksiak et al., 1998b). CYP from the 11(A), 17, 19, and 26 subfamilies also have been identified in fish (Sakai et al., 1992; Tanaka et al., 1992; Takahashi et al., 1993; White et al., 1996). Most of these CYP forms have been isolated in rainbow trout (Oncorhynchus mykiss); however, several subfamilies have been described in scup (Stenotomus chrysops), cod (Gadus morhua) and killifish as well. In particular, CYP1A has been found in all fish species that have been examined to date (Stegeman and Hahn, 1994).

While the CYP1A subfamily in mammals is represented by two members, CYP1A1 and CYP1A2, most fish are thought to have only one CYP1A subfamily member. In mammals, CYP1A1 metabolizes polynuclear aromatic hydrocarbons (PAH), and CYP1A2 metabolizes aromatic amines (Parke et al., 1991). Scup CYP1A expressed in Chinese hamster V-79 cells has catalytic properties of both mammalian CYP1A1 and CYP1A2, consistent with the hypothesis that teleost CYP1As represent a type ancestral to both of the mammalian genes (Morrison et al., 1995; Stegeman et al., 1996). The scup CYP1A amino acid sequence is $57-59 \%$ similar to mammalian CYP1A1 representatives and 52-55\% similar to CYP1A2 representatives. Scup CYP1A has an 78-82\% amino acid sequence similarity to CYP1As from rainbow trout, toadfish (Ospanus tau), plaice (Plueronectes platessa), and tomcod (Microgadus tomcod) (Morrison et al., 1995; Morrison et al., 1998).

Biochemical evidence also supports the conclusion that scup P450E, rainbow trout P450LM4 and cod P450c are orthologous proteins and that these teleost proteins are closely related to mammalian CYP1A1 (see (Stegeman and Kloepper-Sams, 1987; Stegeman, 1989)). The scup, trout and cod proteins are all induced by polynuclear aromatic hydrocarbons, PCBs and $\beta$-naphthoflavone and are inhibited by $\alpha$ naphthoflavone. When reconstituted with epoxide hydrolase all produce high percentages 
of benzo-ring dihydrodiols. All of the proteins are primary catalysts for ethoxyresorufin and aryl hydrocarbon hydroxylase (AHH) activity and have similar spectral properties (a maximum at $447 \mathrm{~nm}$ when reduced and $\mathrm{CO}$-ligated). Antibodies raised against the purified form of each protein cross-reacts with each of the other proteins, and scup CYP1A shares 21 of 25 amino acids in the $\mathrm{N}$-terminal sequence with the trout protein. Finally, scup and rat CYP1As are immunologically related. Although, only 1 of 9 antibodies raised against scup CYP1A recognize rat CYP1A1, and 2 of 10 antibodies raised against rat CYP1A1 recognize scup CYP1A (Klotz et al., 1986).

Recently, two unique CYP1A genes were found to be expressed in MC treated rainbow trout (Berndtson and Chen, 1994). This gene is the result of a duplication after the divergence of fish from other vertebrates.

\section{POLYCHLORINATED BIPHENYLS}

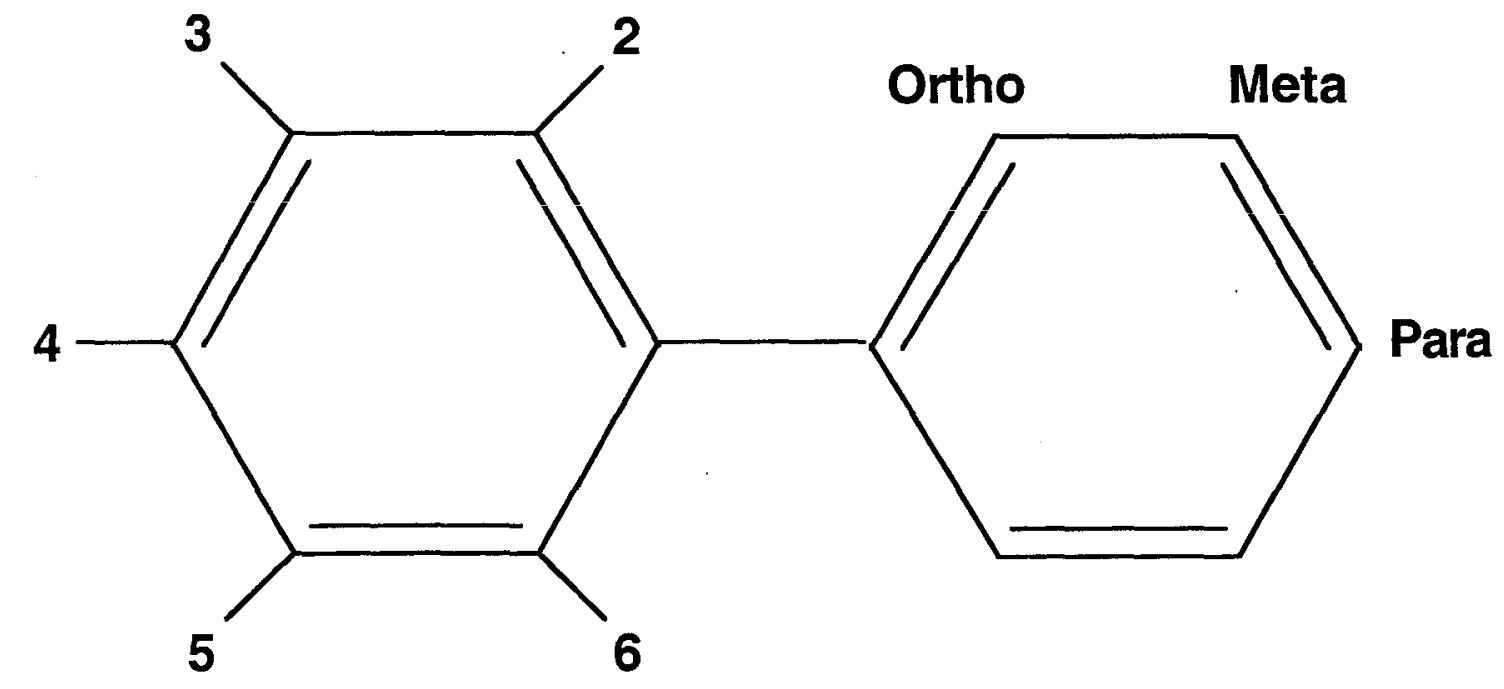

Figure 2. Generalized structure of polychlorinated biphenyls.

Polychlorinated biphenyls (PCB) are compounds composed of two phenyl rings connected by a single carbon-carbon bond with various patterns of chlorine substitution. Chlorines can be substituted in the 2-6 and 2'-6' positions, resulting in 209 possible congeners (Figure 2, Table II). 


\section{TABLE II}

Chlorination patterns and IUPAC numbers for select PCBs

\begin{tabular}{|c|c|}
\hline Structure & IUPAC No. \\
\hline \multicolumn{2}{|l|}{ 3-Methylcholanthrene-Type } \\
\hline 3,3',4,4'-tetrachlorobiphenyl & 77 \\
\hline 3,4,4',5-tetrachlorobiphenyl & 81 \\
\hline 3,3',4,4',5-pentachlorobiphenyl & 126 \\
\hline $3,3^{\prime}, 4,4^{\prime}, 5,5^{\prime}$-hexachlorobiphenyl & 169 \\
\hline . & \\
\hline \multicolumn{2}{|l|}{ Phenobarbital-Type } \\
\hline 2,2'-dichlorobiphenyl & 4 \\
\hline $2,2^{\prime}, 4,4^{\prime}$-tetrachlorobiphenyl & 47 \\
\hline 2,2',5,5'-tetrachlorobiphenyl & 52 \\
\hline $2,2^{\prime}, 4,5,5^{\prime}$-pentachlorobiphenyl & 101 \\
\hline $2,2^{\prime}, 3,3^{\prime}, 4,4$-hexachlorobiphenyl & 128 \\
\hline $2,2^{\prime}, 3,4,4^{\prime}, 5$-hexachlorobiphenyl & 138 \\
\hline $2,2^{\prime}, 4,4^{\prime}, 5,5^{\prime}$-hexachlorobiphenyl & 153 \\
\hline $2,2^{\prime}, 4,4 ', 6,6$-hexachlorobiphenyl & 155 \\
\hline 2,3,3',4,4',5-hexachlorobiphenyl & 156 \\
\hline 2,3,3',4',5,6-hexachlorobiphenyl & 163 \\
\hline $2,2^{\prime}, 3,4^{\prime}, 5,5^{\prime}, 6$-heptachlorobiphenyl & 187 \\
\hline \multicolumn{2}{|l|}{ Mixed-Type } \\
\hline $2,3,3^{\prime}, 4,4^{\prime}$-pentachlorobiphenyl & 105 \\
\hline $2,3^{\prime}, 4,4^{\prime}, 5$-pentachlorobiphenyl & 118 \\
\hline 2,3,3',4,4',5-hexachlorobiphenyl & 156 \\
\hline
\end{tabular}

Several properties lend PCBs to many uses; they are inflammable, chemically stable and miscible with organic compounds. PCBs were used as organic diluents, plasticizers, pesticide extenders, adhesives, dust reducing agents, cutting oils, flame retardants, heat transfer fluids, dielectric fluids for transformers and capacitors, hydraulic lubricants, sealants, and in carbonless copy paper (Safe, 1994). Of the 1.5 million metric tons of PCBs that were produced, $65 \%$ is land-locked, $31 \%$ has been released into the environment and $4 \%$ has been degraded or incinerated (Tanabe, 1985). Reports of PCB residues in the environment began in the 1960's (Jensen, 1966; Risebrough et al., 1968). PCB residues have been found in every component of the global ecosystem, including the 
atmosphere, rivers, lakes, soil, marine sediment, open ocean, and fish, wildlife and human adipose tissue, blood and milk (Safe et al., 1985; Tanabe, 1985). Of the environmental load, 97\% can be found in coastal sediments and open ocean (Tanabe, 1985).

PCBs regulate CYPs on multiple levels. Individual chlorobiphenyl (CB) congeners can be grouped structurally by their induction of different CYP isoforms. $\mathrm{CB}$ congeners with no ortho substitutions induce CYP1A1, CYP1A2 and CYP2A1 and are called MCtype inducers (Parkinson et al., 1980; Parkinson et al., 1980). The most potent inducers have chlorine substitutions at both para positions and at least two meta positions (i.e. CBs $77,81,126,169$ ) (Poland and Glover, 1977; Kafafi et al., 1993). Structurally diverse CB congeners induce CYP2B1/2B2, but all effective PB-type inducers have two or more ortho substitutions (Parkinson et al., 1980; Parkinson et al., 1980). The two most potent CYP2B1/2B2 inducers are CBs 163 and 187 (Connor et al., 1995). CB congeners with a mono-ortho substitution induce all five CYP forms and are called mixed-type inducers (Parkinson et al., 1980; Parkinson et al., 1980). Mixed-type CB congeners are less potent at inducing CYPs than the type-specific congeners (see (Safe, 1994)).

The structure activity relationships seen in fish differ somewhat from those seen in mammals. A number of studies in a range of fish species have demonstrated that CB 77 (Franklin et al., 1980; Melancon and Lech, 1983; Gooch et al., 1989; Monosson and Stegeman, 1991; Tyle et al., 1991; Lindstrom-Seppa et al., 1994; Newsted et al., 1995; Otto and Moon, 1995; Huuskonen et al., 1996; Sleiderlink and Boon, 1996; White et al., 1997a), CB 126 (Engwall et al., 1994; Newsted et al., 1995; Huuskonen et al., 1996; Palace et al., 1996) and CB 169 (James and Little, 1981; Miranda et al., 1990; Newsted et al., 1995) induce CYP1A in fish. Several studies have found that no P450 induction occurs in fish following treatment with PB-type congeners (i.e. CBs 52, 128, 138, 153) (Forlin and Lidman, 1978; James and Little, 1981; Gooch et al., 1989). However, two studies have suggested that AHH activity is increased following treatment with PB-type congeners (i.e. CBs 101 and 153) (Gruger et al., 1976; Da Costa and Curtis, 1995), and one study showed an increase in total P450 and $p$-nitroanisole O-demethylation following CB 153 treatment (Forlin and Lidman, 1978). There is contradictory evidence as to whether mixed-type congeners are effective CYP inducers in fish. CB 105 was ineffective at inducing CYP1A in scup, rainbow trout and cod (Gooch et al., 1989; Bernhoft et al., 1994; Newsted et al., 1995). CB 118 did not induce CYP1A in scup but did induce CYP1A in rainbow trout (Gooch et al., 1989; Skaare et al., 1991). CB 156 significantly 
induced CYP1A in flounder (Platichthys flesus L.) (Beyer et al., 1997). The reasons for the relative insensitivity of fish to PB-and mixed-type congeners is unknown.

Following induction, CBs can inhibit CYP catalytic activities. CB 77 is a competitive inhibitor of ethoxyresorufin O-deethylation (EROD), a CYP1A catalytic activity, in scup liver microsomes. The mono-ortho CB 156 has a limited capacity to inhibit EROD in scup liver microsomes as well (Gooch et al., 1989). In rat liver microsomes, CB 77 is a mixed-type inhibitor of EROD (DeMatteis et al., 1989), and CB 169 is a noncompetitive inhibitor of estradiol 2-hydroxylase activity, a CYP1A2 catalytic activity (Voorman and Aust, 1987). Furthermore, treatment with high doses of non-ortho $\mathrm{CB}$ congeners results in a decrease in CYP1A catalytic activity in vivo (Melancon and Lech, 1983; Voorman and Aust, 1988; Miranda et al., 1990; Monosson and Stegeman, 1991; Lindstrom-Seppa et al., 1994) or in cultured cells (Sawyer and Safe, 1982; Rodman et al., 1989; Hahn et al., 1993; Kennedy et al., 1993; Lorenzen et al., 1997). In rat liver microsomes, CBs 4, 52 and 155 all inhibit O-demethylation of $p$-nitroanisole, a CYP2B catalytic activity, with inhibitory capacity decreasing with increasing chlorination (Hesse and Wolff, 1977).

CB 77 and other planar CB congeners that are AhR agonists also stimulate inactivation of CYP1A. While CYP1A mRNA remains elevated in rainbow trout exposed to high doses of $\mathrm{CB} 77$ or 126 and in scup exposed to high doses of CB 77, CYP1A activity and protein both decrease at high doses (Gooch et al., 1989; Newsted et al., 1995; White et al., 1997a). Similar results have been described in studies of cultured chick embryo hepatocytes and porcine aorta endothelial cells exposed to high doses of CB 77 (Lambrecht et al., 1988; Sinclair et al., 1989; Stegeman et al., 1995; Lorenzen et al., 1997). In scup, the CB 77-dependent decrease in CYP1A was shown to be posttranscriptional and hypothesized to result from oxidative modification of the protein (White et al., 1997a).

The environmental significance of a $\mathrm{CB}$ congener can be determined by assessing its potential for toxicity, its frequency of occurrence in the environment and its relative abundance in animal tissues (McFarland and Clark, 1989). Exposure to PCBs can result in hepatocellular carcinoma, immunotoxicity, wasting syndrome and reproductive, endocrine and developmental toxicity (see (Safe, 1994)). The most toxicologically active congeners are those having chlorine substitutions at both para positions and at least two meta positions but no chlorine substitutions at the ortho positions (Safe et al., 1985). By comparing the TCDD equivalency factors (TEF) of CB congeners, the coplanar congeners are most potent 
in eliciting toxic effects in fish (Janz and Metcalfe, 1991; Walker and Peterson, 1991; Newsted et al., 1995) and mammals (Safe, 1990; Tillitt et al., 1991). While these coplanar CB congeners occur at extremely low concentrations in environmental samples, their potential toxicity ranks them as the congeners of highest environmental concern (McFarland and Clark, 1989). Mixed-type inducers are considered the next most toxic group of congeners, and they are relatively abundant. PB-type inducers are most abundant in environmental samples but are considered to have limited toxic potential.

\section{REACTIVE OXYGEN SPECIES}

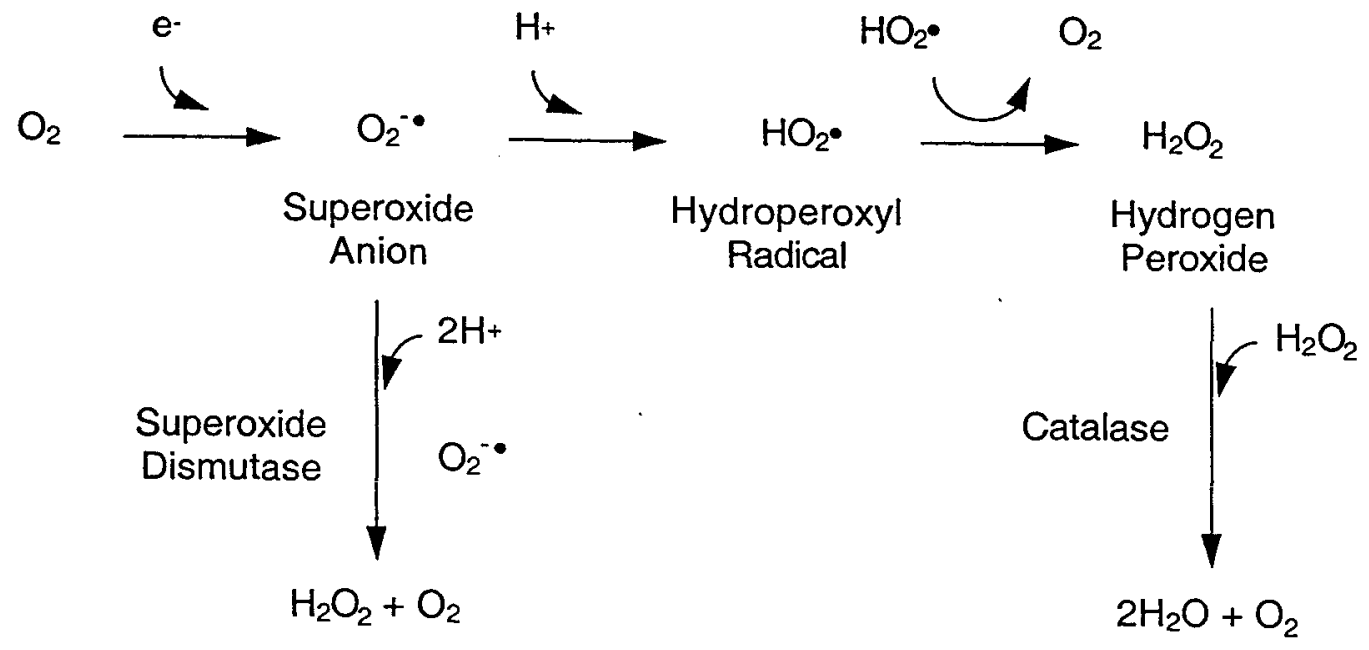

Figure 3. Oxygen chemistry.

Reactive oxygen species (ROS) are free radical species containing an unpaired electron in an outer orbital resulting in an unstable electron configuration. Technically, molecular oxygen is a bi-radical, as it has two unpaired electrons in the outer orbitals in the ground state. Molecular oxygen oxidizes by accepting two electrons; however the electrons must have parallel spins. This spin restriction is advantageous to aerobic organisms because it slows oxygen reactions but is disadvantageous because it allows one electron transfers. Reduction of molecular oxygen results in the formation of the superoxide radical $\left(\mathrm{O}_{2}^{-\bullet}\right)$, which is a good reductant but a poor oxidant. Protonation of $\mathrm{O}_{2}^{-\bullet}$ to the perhydroxyl radical $\left(\mathrm{HO}_{2}{ }^{\bullet}\right)$ increases the oxidizing potential. Addition of a second electron to oxygen results in the formation hydrogen peroxide $\left(\mathrm{H}_{2} \mathrm{O}_{2}\right)$, which is also a product of $\mathrm{O}_{2}{ }^{-\bullet}$ dismutation. Addition of a third electron to oxygen forms the hydroxyl radical $(\mathrm{OH} \bullet)$, the most reactive oxygen species. $\mathrm{OH} \cdot$ are formed by the interaction of $\mathrm{H}_{2} \mathrm{O}_{2}$ with either 
reduced iron (Fenton reaction, $\mathrm{Fe}^{2+}+\mathrm{H}_{2} \mathrm{O}_{2}------>\mathrm{Fe}^{3+}+\mathrm{OH} \bullet+\mathrm{OH}^{-}$) or with $\mathrm{O}_{2}^{-\bullet}$ (Haber Weiss reaction, $\mathrm{O}_{2}^{-\bullet}+\mathrm{H}_{2} \mathrm{O}_{2}----->\mathrm{O}_{2}+\mathrm{OH} \cdot+\mathrm{OH}^{-}$).

Both singlet oxygen and $\mathrm{H}_{2} \mathrm{O}_{2}$ are considered to be ROS, but are not radicals. Singlet oxygen, a powerful oxidizer, is produced by an electron rearrangement, with electrons in non-parallel spin or in the same orbital. While $\mathrm{H}_{2} \mathrm{O}_{2}$ is not reactive enough to oxidize in an aqueous environment, it is biologically important because it forms $\mathrm{OH} \cdot$, diffuses readily and crosses biological membranes.

\section{TABLE III}

Oxygen species and their reactivity (From: Yu, 1994)

\begin{tabular}{|c|c|c|c|}
\hline Species & $\begin{array}{l}\text { Chemical } \\
\text { Symbol }\end{array}$ & $\begin{array}{c}\text { Half Life } \\
\text { at } 37^{\circ} \mathrm{C}(\mathrm{Sec}) \\
\end{array}$ & Properties \\
\hline Molecular Oxygen & ${ }^{3} \mathrm{O}_{2}$ & $>10^{2}$ & \\
\hline Singlet Oxygen & ${ }^{1} \mathrm{O}_{2}$ & $1 \cdot 10^{-6}$ & Powerful oxidizing agent \\
\hline Superoxide & $\mathrm{O}_{2}-$ & $1 \cdot 10^{-6}$ & Good reductant, poor oxidant. \\
\hline Hydroxyl & $\mathrm{OH} \cdot$ & $1 \cdot 10^{-9}$ & Extremely reactive, very low diffusion distance. \\
\hline Perhydroxyl & $\mathrm{HO}_{2}$ & & Stronger oxidant, more lipid soluble than $\mathrm{O}_{2}^{-\bullet}$. \\
\hline Alkoxyl & RO. & $1 \cdot 10^{-6}$ & $\begin{array}{l}\text { Intermediate in its reactivity with lipid between } \\
\qquad \mathrm{ROO} \cdot \text { and } \mathrm{HO} \cdot\end{array}$ \\
\hline Peroxyl & ROO• & $1 \cdot 10^{-2}$ & $\begin{array}{l}\text { Low oxidizing ability relative to HO• but } \\
\text { greater diffusibility. }\end{array}$ \\
\hline Hydrogen peroxide & $\mathrm{H}_{2} \mathrm{O}_{2}$ & & $\begin{array}{l}\text { Oxidant, but reactions with organic substrates } \\
\text { very slow, very diffusable. }\end{array}$ \\
\hline
\end{tabular}

Both exogenous and endogenous sources of ROS are present in cells. Exogenous sources include radiation, ozone and hyperoxia (see (Freeman and Crapo, 1982)). A major endogenous source of $\mathrm{ROS}$ is $\mathrm{O}_{2}^{-\bullet}$ produced during leakage of electrons by mitochondria (see (Freeman and Crapo, 1982)). Other endogenous sources include lipid breakdown (Girotti, 1985), production of $\mathrm{O}_{2}^{-\bullet}$ during inflammatory response (Baboir, 1978), oxidative metabolism by oxidases such as monoamine oxidase (Cohen, 1985), NADPH oxidase (Shatwell and Segal, 1996) and xanthine oxidase (McCord and Fridovich, 1968), peroxisomes (see (Mannaerts and Veldhoven, 1993)) and CYP. Interruption of the CYP catalytic cycle after passage of the first electron results in $\mathrm{O}_{2}^{-\bullet}$ release and after passage of 
the second electron results in $\mathrm{H}_{2} \mathrm{O}_{2}$ release (Parkinson, 1996). O $2^{-\bullet}$ also can be produced by cytochrome $\mathrm{P} 450$ reductase (Aust et al., 1972; Morehouse et al., 1984).

ROS can initiate radical damage to lipids, proteins and DNA (Kappus, 1987). Oxidative damage to lipids results in a loss of membrane fluidity, a reduction in membrane potential and an increase in ion permeability (Bagchi et al., 1989; Simonian and Coyle, 1996). Oxidation of amino acids, particularly those that are unsaturated and sulfurcontaining (i.e. tryptophan, tyrosine, phenylalanine, histidine, methionine and cysteine), can lead to gross structural modification of proteins (Kyle et al., 1989), can result in crosslinking and aggregate formation (Davies, 1987; Davies et al., 1987) and can mark proteins for proteolysis (Davies et al., 1987). ROS oxidize nucleotides and cause singleand double- strand breaks (Floyd et al., 1988; Simonian and Coyle, 1996).

ROS regulate both gene transcription and post-translational activation of certain proteins involved in signal transduction. The tumor suppresser $\mathrm{p} 53$ inhibits growth and suppresses transformation by blocking the cell cycle and preventing gene amplification (Baker et al., 1990; Lane, 1992). Binding of p53 to DNA is controlled post-translationally by the redox status of cysteine residues at the zinc and DNA binding regions (Rainwater et al., 1995). Activator protein 1 (AP-1) is a complex of oncogene proteins from the Fos and Jun families which are intermediary transcriptional regulators in signal transduction processes leading to proliferation and transformation (Angel and Karin, 1991). Both $\mathrm{H}_{2} \mathrm{O}_{2}$ and the antioxidant pyrrolidine dithiocarbamate induce c-fos and c-jun expression (Meyer et al., 1994). However, $\mathrm{H}_{2} \mathrm{O}_{2}$ only moderately activates AP-1 DNA binding while antioxidants strongly activate binding (Meyer et al., 1994). Nuclear factor- $\kappa B(N F-\kappa B)$ is a complex of homo- or heterodimers (e.g. p50 and p65) of members of the Rel family of transcriptional activator proteins. NF- $\mathrm{KB}$ resides in the cytoplasm complexed with an inhibitor $\mathrm{I} K \mathrm{~B}$, and degradation of $\mathrm{I} \kappa \mathrm{B}$ is required to allow translocation and DNA binding (see (Piette et al., 1997)). Degradation of IKB has been suggested to involve ROS, as antioxidants block NF- $\mathrm{KB}$ activation, and potent $\mathrm{NF}-\mathrm{KB}$ activators such as tumor necrosis factor- $\alpha$, interlukin-1, phorbol 12-myristate 13-acetate (PMA), lipopolysaccharide and okadaic acid all elevate ROS levels (Schreck et al., 1991; Schreck et al., 1992). Redox regulation also has been suggested for the c-myb protooncogene (Guehmann et al., 1992), Ets transcription factor (Wasylyk and Wasylyk, 1993), SP-1 transcription factor (Knoepfel et al., 1994), glucocorticoid receptor (Esposito et al., 1995), early growth response-1 transcription factor (Huang and Adamson, 1993), thyroid transcription factors (Civitareale et al., 1994; Arnone et al., 1995), upstream stimulatory transcription factor (Pognonec et 
al., 1992), aryl hydrocarbon receptor (Ireland et al., 1995), and estrogen receptor (Hayashi et al., 1997). Oxidants also may stimulate signal transduction by altering $\mathrm{Ca}^{2+}$-flux and protein phosphorylation (see (Suzuki et al., 1997)).

An antioxidant defense system has evolved to lower the steady state cellular concentrations of ROS and to repair damage caused by ROS. Primary antioxidant defenses include: 1) ROS scavenging compounds, both lipid- and water-soluble and 2) antioxidant enzyme systems (Table IV) (see (Freeman and Crapo, 1982; Yu, 1994)). Secondary defenses include lipolytic enzymes, phospholipases, proteolytic enzymes, proteases, peptidases, DNA repair enzymes, endonucleases, exonucleases and ligase (Davies, 1986).

\section{TABLE IV}

Antioxidant defenses (From: Yu, 1994)

\begin{tabular}{|c|c|c|}
\hline Category & Primary Tissue Site & Actions \\
\hline \multicolumn{3}{|l|}{ Enzyme Systems } \\
\hline $\mathrm{Cu} / \mathrm{Zn} \mathrm{SOD}$ & Cytosol & Dismutation of $\mathrm{O}_{2}-\bullet$ to $\mathrm{H}_{2} \mathrm{O}_{2}$. \\
\hline $\mathrm{Mn}$ SOD & Mitochondria & Dismutation of $\mathrm{O}_{2}^{-\bullet}$ to $\mathrm{H}_{2} \mathrm{O}_{2}$. \\
\hline $\mathrm{Cu} S O D$ & Plasma & Dismutation of $\mathrm{O}_{2}^{-\bullet}$ to $\mathrm{H}_{2} \mathrm{O}_{2}$. \\
\hline Catalase & Peroxisomes & $\begin{array}{l}\text { Dismutation of } \mathrm{H}_{2} \mathrm{O}_{2} \text {, reduces methyl and ethyl } \\
\text { hydroperoxides. }\end{array}$ \\
\hline \multicolumn{3}{|l|}{ GSH Redox Cycle } \\
\hline GSH Peroxidase & Cytosol & Reduction of $\mathrm{H}_{2} \mathrm{O}_{2}$ and other hydroperoxides. \\
\hline GSH reductase & Cytosol & Reduction of low molecular weight disulfides. \\
\hline \multicolumn{3}{|c|}{ Lipid-Soluble Compounds } \\
\hline Vitamin $\mathrm{E}$ & Lipid membranes & $\begin{array}{l}\text { Converts } \mathrm{O}_{2} \cdot \bullet, \mathrm{OH} \bullet \text { and lipid } \mathrm{ROO} \cdot \text { to less reactive } \\
\text { forms, breaks lipid peroxidation chain reactions. }\end{array}$ \\
\hline$\beta$-Carotene & Lipid Membranes & Scavenges $\mathrm{O}_{2}^{-\bullet}$, reacts with $\mathrm{ROO} \cdot$. \\
\hline Bilirubin & Bloodstream & Chain-breaking anti-oxidant. Reacts with ROO. \\
\hline \multicolumn{3}{|c|}{ Water-soluble Compounds } \\
\hline Vitamin C & Wide distribution & Scavenges $\mathrm{O}_{2}^{-} \cdot$ and $\mathrm{OH} \cdot$. \\
\hline Uric Acid & Wide distribution & $\begin{array}{l}\text { Scavenges } \mathrm{O}_{2}^{-} \bullet, \mathrm{OH} \bullet \text {, oxoheme oxidants and } \\
\text { ROO•. }\end{array}$ \\
\hline Glucose & Wide distribution & Scavenges $\mathrm{OH} \bullet$. \\
\hline Cysteine & Wide distribution & Reduces organic compounds. \\
\hline GSH & Wide distribution & $\begin{array}{l}\text { Reacts directly with } \mathrm{O}_{2} \cdot \bullet, \mathrm{OH} \bullet \text { and organic free } \\
\text { radicals. }\end{array}$ \\
\hline
\end{tabular}




\section{ARACHIDONIC ACID}

Arachidonic acid (AA) is both a structural component of membranes and a functional participant in signaling cascades. Following release from membranes by phospholipase $\mathrm{A} 2, \mathrm{AA}$ is metabolized through three major pathways: cyclooxygenase, lipoxygenase or cytochrome P450 (Needleman et al., 1986). CYP can metabolize AA to three types of products (Figure 4). Allylic oxidation forms mid-chain conjugated dienols, or mid-chain hydroxyeicosatetraenoic acids (5-, 8-, 9-, 11-, 12-, or 15-HETE). $\omega$ Terminal hydroxylation forms $\mathrm{C}_{16}$ - through $\mathrm{C}_{20}$-alcohols of AA (16-, 17-, 18-, 19, or 20HETE). Olefin epoxidation forms epoxyeicosatrienoic acids (5,6-, 8,9-, 11,12- and 14,15-EET). Mammalian CYP in families 1-4 metabolize AA (Figure 4).

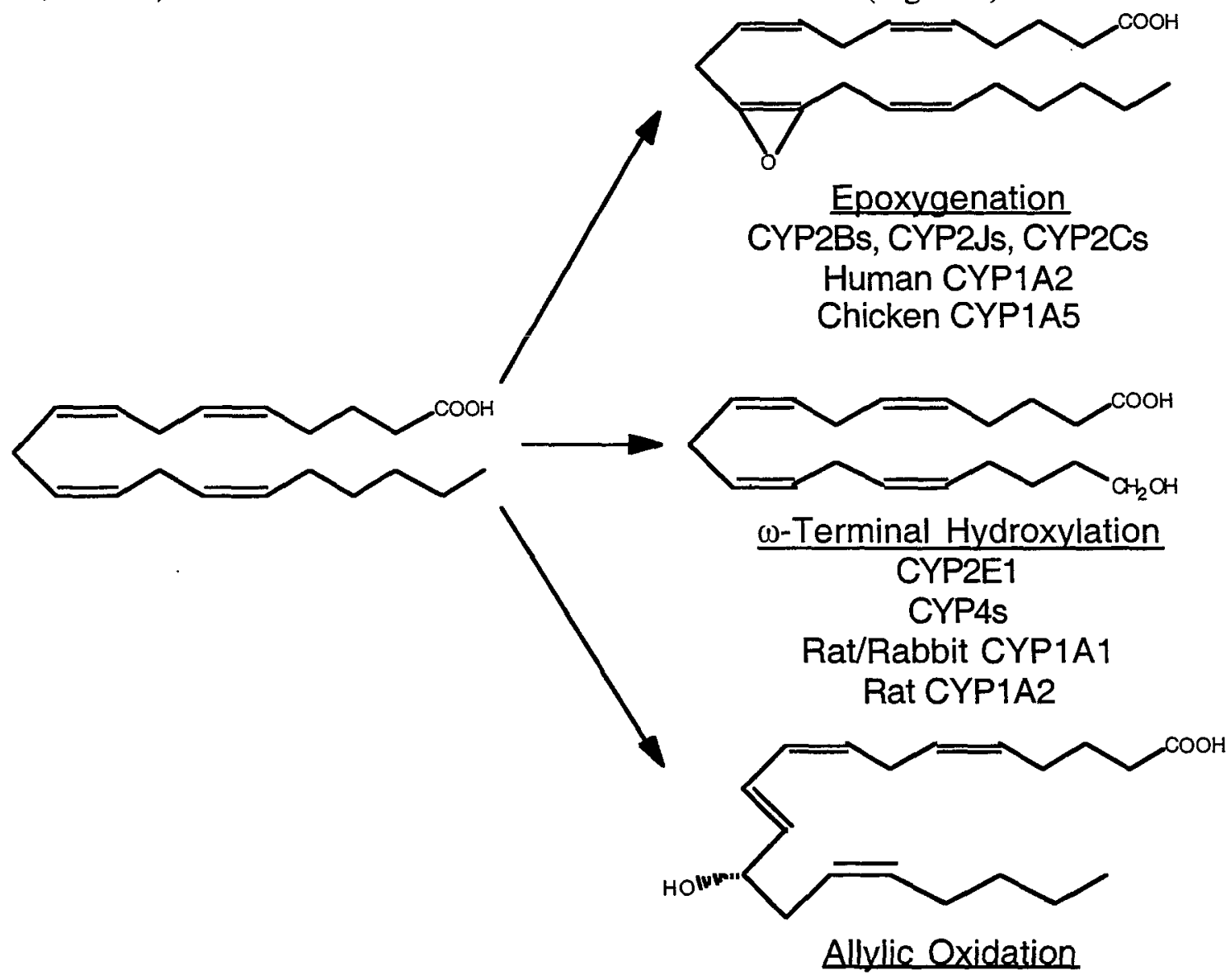

Figure 4. CYP-mediated arachidonic acid metabolism and the specific CYP isoforms which favor those reactions (Oliw et al., 1982; Capdevila et al., 1990; Laethem et al., 1993; Rifkind et al., 1994; Capdevila et al., 1995; Rifkind et al., 1995; Zeldin et al., 1995; Wu et al., 1996; Wu et al., 1997; Zhang et al., 1997) . 
CYP-mediated AA metabolites can promote potent biological activities including inhibition of platelet aggregation, neutrophil aggregation and cyclooxygenase activity (Proctor et al., 1989), alteration of endothelial cell permeability, vascular tone, and cellular ion flux (Schwartzman et al., 1987; Ohnishi et al., 1992; Harder et al., 1995; Campbell et al., 1996), and stimulation of angiogenesis and peptide hormone release (Falck et al., 1983; Harder et al., 1995). EETs, particularly 5,6- and 14,15-EET, stimulate a wide range of effects from vasoconstriction, to vasodilation, to alteration of $\mathrm{Ca}^{2+}$ homeostasis, to inhibition of $\mathrm{Na}^{+} / \mathrm{K}^{+}$-ATPases, to stimulation of peptide hormone release (see (Fitzpatrick and Murphy, 1989)). Other physiologically relevant CYP-mediated AA metabolites include 12(R)-HETE which inhibits $\mathrm{Na}^{+} / \mathrm{K}^{+}$-ATPases in the cornea (Schwartzman et al., 1987) and 19- and 20-HETE which modulate renal $\mathrm{Na}^{+} / \mathrm{K}^{+}$-ATPases (Escalante et al., 1990).

Investigations of AA metabolism in fish have focused on prostaglandin and HETE formation. A variety of fish tissues have been shown to metabolize AA to prostaglandins and hydroxy metabolites, including gills (Strivastava and Mustafa, 1984; Van Praag et al., 1987; Beckman and Mustafa, 1992), heart (Herman et al., 1979; Strivastava and Mustafa, 1984; Brown and Bucknall, 1986), red blood cells (Cagen et al., 1983), skin (Anderson et al., 1981), kidney, liver and stomach (Bandyopadhyay et al., 1982; Henderson et al., 1985). Studies in gills have demonstrated that both lipoxygenases and cyclooxygenases contribute to AA metabolism (Van Praag et al., 1987; Beckman and Mustafa, 1992). In fish, prostaglandins may participate in the regulation of cardiovascular function (Brown and Bucknall, 1986), hormone release (Chang et al., 1993; Hsu and Goetz, 1993; Wade and Van Der Kraak, 1993), ovulation (Goetz et al., 1982), nervous system function (Mustafa and Strivastava, 1989), fluid and electrolyte balance in gills and kidney (Wales and Gaunt, 1985; Brown and Bucknall, 1986; Beckman and Mustafa, 1992) and immune response (Rowley et al., 1995). It is likely then that CYP-mediated AA metabolism plays an important role in the production of biologically active metabolites. However, CYPmediated AA metabolism has been examined only in killifish, scup, and skate (Raja erinacea) (Zacharewski et al., 1996; Oleksiak et al., 1998a; Oleksiak et al., 1998b).

\section{ENDOTHELIUM}

Endothelial cells are those cells which line all of the blood and lymphatic vessels of the body. In the large arteries and veins, the endothelium forms only a one-cell layer thick lining. Endothelial cells themselves form the smallest of the blood vessels, the capillaries. Endothelial cells can be classified on the basis of their continuity. Continuous 
endothelium, found in the brain, retina, muscle, lung and adipose tissue, forms continuous tight junctions with no breaks in the vessel wall. Discontinuous endothelium, found in the liver, spleen and bone marrow, has gaps between cells. Fenestrated endothelium, found in the endocrine glands, renal glomeruli and tubules and the intestinal villi, is characterized by specialized intracellular pores that are important to transport and filtration (Gerritsen, 1987). Also, while large and small vessels share many common features, there is evidence for differences in their nutritional requirements, in their responses to growth and migration stimuli and in their metabolism of signaling compounds (Zetter, 1981; Gerritsen, 1987).

The functions of endothelial cells are many and diverse. First, they provide a physical lining of the heart and blood vessels which maintains the fluidity of the blood. Second, they maintain and control blood vessel tone. Mammalian endothelial cells produce several vasoactive substances including the vasodilators, nitric oxide, endothelium derived hyperpolarizing factor, and prostacyclin and the vasoconstrictor endothelin (Thiemermann, 1991; Hecker et al., 1994). They also metabolize other vasoactive compounds including angiotensin and bradykinin (Hornig and Drexler, 1997). Some of these substance, such as nitric oxide, actively maintain tone in the normal circulation, while others such as prostacyclin, are more important in damage response (Vane et al., 1990). Shear stress is an important signal that controls production of these vasoactive compounds (Ando and Kamiya, 1993). Third, the ability of endothelial cells to relax or contract allows them to control microvascular permeability (Crone, 1986; Miller and Sims, 1986). Fourth, they regulate platelet clumping and clotting (Vander et al., 1990), and lymphocyte traffic (Pearson, 1991). Last, these cells are responsible not only for repair of damaged blood vessels but also angiogenesis (Alberts et al., 1989). Endothelial cells provide a diversity of functions and may be referred to more appropriately as an "organ."

Considering the amount of endothelium in the body, endothelial CYP1A could contribute significantly to total bodily CYP1A induction (Stegeman et al., 1989). Endothelial cells can constitute between 0.5 and $1.5 \%$ of body weight depending on the species. In comparison, the liver can constitute between 1 and $1.5 \%$ of body weight. Liver is considered the major site of induction of CYP1A; however, endothelial CYP1A has been shown to be strongly inducible in mammalian and fish endothelial cells (Dees et al., 1982; Miller et al., 1989; Stegeman et al., 1989; Smolowitz et al., 1991; Farin et al., 1994; Thirman et al., 1994; Stegeman et al., 1995). Considering the numerous and important functions of endothelial cells and the potential for CYP1A induction, the effect of CYP1A induction on endothelial cells is an important area of investigation. 


\section{OBJECTIVES OF THESIS RESEARCH}

While the toxicity of planar halogenated aromatic hydrocarbons (pHAH) has been recognized for many years, the mechanisms of their toxicity are uncertain. The toxicity of these compounds has been linked to AhR mediated processes; however the processes directly involved in pHAH toxicity are unknown. Considering the ubiquitous presence of these compounds in the environment, investigation of their mechanisms of toxicity is of utmost importance. I have examined two potential CYP1A-dependent mechanisms of AhR agonist toxicity in the marine teleost Stenotomus chrysops, alteration of AA metabolism (Chapter 2) and production of ROS (Chapters 3-6). The oxidative inactivation of scup, rat and human CYP1As stimulated by CB 77 in vitro and its relationship to ROS production is demonstrated (Chapter 3). The relationship of substrate structure to the oxidative inactivation of CYP1A was investigated by comparing the effects of ortho and non-ortho substituted PCBs in vitro (Chapter 4). Further, the ability of CB 126 to mediate inactivation of CYP1A and oxidative stress was investigated in vivo (Chapter 5). The reactive oxygen sensitive transcription factor, $\mathrm{NF}-\mathrm{KB}$, was characterized in scup, and its activation by BP and CB 126 was examined (Chapter 6). Last, I have described CYP1A induction in endothelial cells in the American eel (Anguilla rostrata)(Chapter 7). Endothelium is a site which may be particularly susceptible to alterations in AA metabolism and ROS production

The majority of this research was conducted in two teleost species, Stenotomus chrysops (scup) (Figure 5), and Anguilla rostrata (American eel)(Figure 6). Scup are marine teleosts that migrate along the Eastern coast of the United States (Morse, 1978). This is a well characterized species that is extremely sensitive to both CYP1A induction and inactivation. The American eel is a catadromous fish, that spawns in the Sargasso Sea and spends the majority of its life in estuaries and rivers (Fahay, 1978). Eels may be particularly useful for the study of in vivo induction of endothelial CYP1A because they have a rete mirabile, a counter-current vascular structure, composed entirely of capillaries, which increases the partial pressure of oxygen to aid its secretion into the swim bladder (Krogh, 1959). 


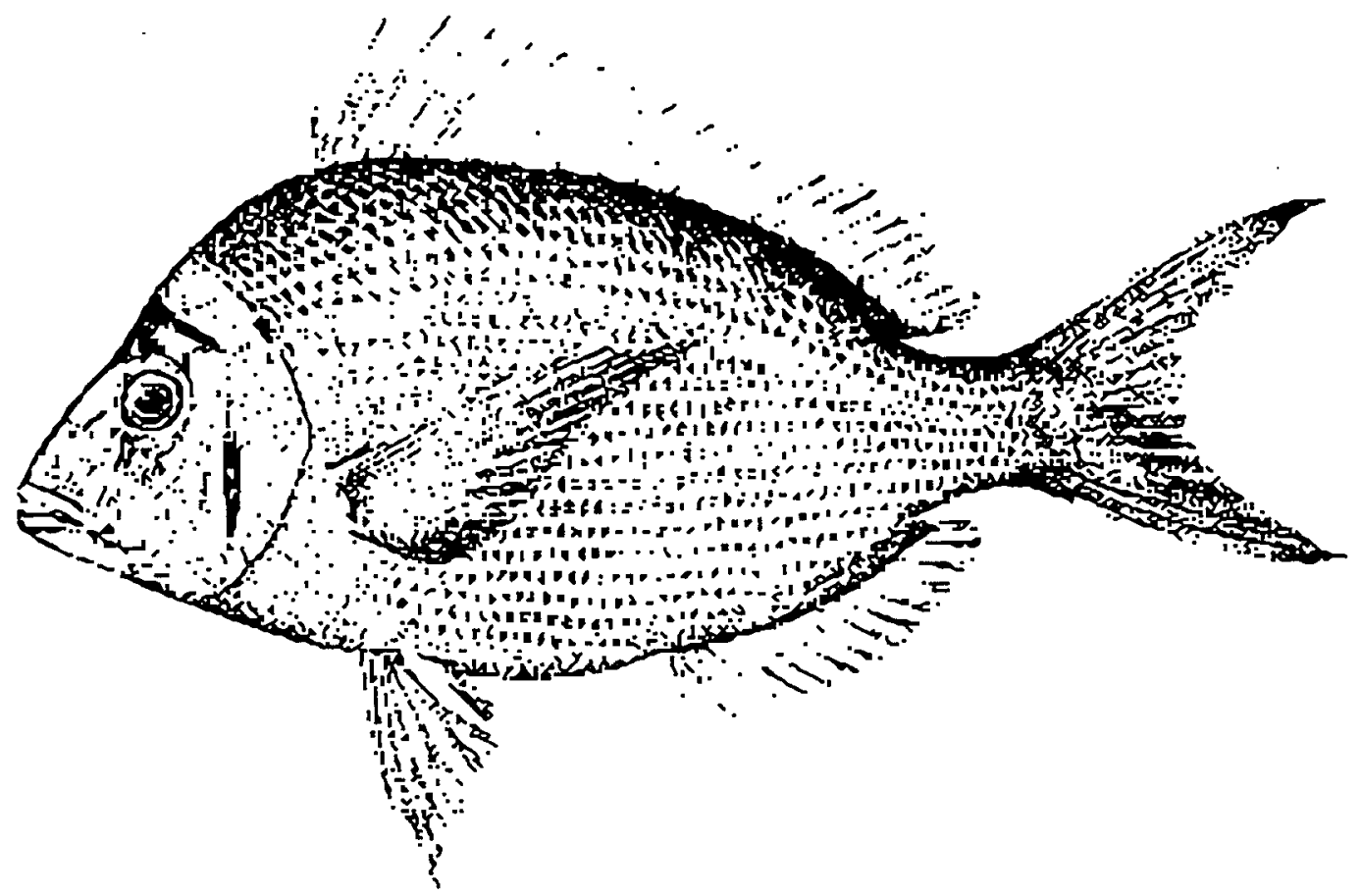

Figure 5. Stenotomus chrysops. Actual adult size: $12-22 \mathrm{~cm}$.

From: (www.wh.whoi.edu/photos/lineart/)

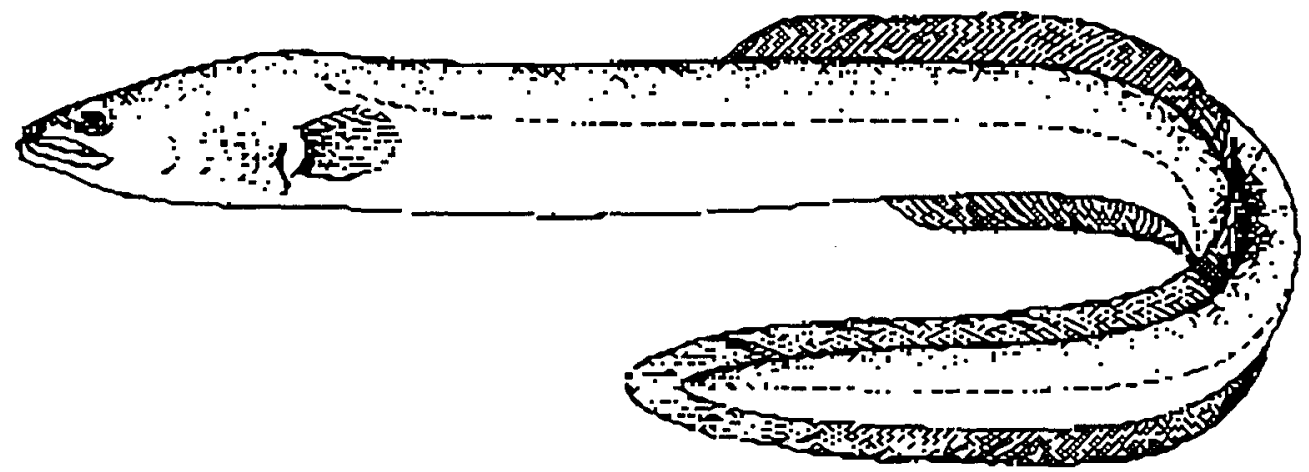

Figure 6. Anguilla rostrata. Actual adult size: $61-107 \mathrm{~cm}$.

From: (www.wh.whoi.edu/photos/lineart/) 


\section{CHAPTER 2}

Arachidonic Acid Metabolism in the Marine Fish Stenotomus chrysops (scup) and the Effects of Cytochrome P4501A Induction 


\title{
Arachidonic Acid Metabolism in the Marine Fish Stenotomus chrysops (Scup) and the Effects of Cytochrome P450 1A Inducers
}

\author{
Jennifer J. Schlezinger, ${ }^{*}$ Carol Parker, $†$ Darryl C. Zeldin, $\dagger$ and John J. Stegeman,1 \\ ${ }^{*}$ Biology Department, Woods Hole Oceanographic Institution, Woods Hole, Massachusetts 02543; and \\ $\dagger$ Laboratory of Pulmonary Pathobiology, National Institute of Environmental Health Sciences, \\ Research Triangle Park, North Carolina 27709
}

Received November 24, 1997, and in revised form February 19, 1998

Cytochrome P450-mediated arachidonic acid (AA) metabolism was investigated in the marine fish scup, Stenotomus chrysops. Liver microsomes incubated with AA and NADPH produced epoxyeicosatrienoic acids (EETs) and their hydration products (dihydroxyeicosatrienoic acids, DHETs), midchain conjugated dienols (midchain HETEs), and $\mathrm{C}_{16^{-}}$through $\mathrm{C}_{20^{-}}$ alcohols of AA (a-terminal HETEs), all identified by HPLC and GC/MS. Gravid females had 4-fold lower AA metabolism rates than males but identical metabolite profiles. The 5,6-EET (inferred from stable metabolites) was most abundant (47\% of total EETs) followed by $14,15-, 11,12-$, and $8,9-E E T ~(27,13$, and $13 \%$, respectively). The 12-HETE represented $25 \%$ of total HETEs followed in abundance by 16-, 15-, 11-, 19-, 20-, 8-, and 9-HETE. Antibodies against scup CYP1A and a scup CYP2B-like protein inhibited liver microsomal AA metabolism by 30 and $46 \%$, respectively. GC/MS analysis revealed EETs and DHETs as endogenous constituents in scup liver; the predominant EETs were 8,9- and 14,15-EET, followed by a lesser amount of 11,12-EET. Chiral analysis showed a preference for the S,R-enantiomers of endogenous 8,9-, 11,12-, and 14,15-EET (optical purities 80,64 , and $64 \%$, respectively). Treatment of scup with the CYP1A inducer benzo( $a$ )pyrene (BP) increased liver microsomal formation of EETs and HETEs by 2.7-fold in spring and 1.7-fold in summer. BP treatment did not affect microsomal EET regioselectivity, but shifted hydroxylation in favor of 19-HETE and induced 17-HETE formation. 2,3,7,8-Tetrachlorodibenzo-p-dioxin (TCDD) treatment in summer did not induce liver microsomal AA metabolism rates, yet BP and TCDD both increased endogenous EET content of

\footnotetext{
${ }^{1}$ To whom correspondence should be addressed. Fax: 508-457 2169. E-mail: jstegeman@whoi.edu.
}

liver (5- and 3-fold, respectively), with a shift to 14,15 EET. BP treatment increased the selectivity for the S,R-enantiomers of endogenous $8,9-, 11,12-$, and 14,15EET (optical purities 91, 84, and $83 \%$, respectively). Kidney, gill, and heart microsomes all metabolized AA, at rates 10 - to 30 -fold less than liver microsomes. Similar amounts of endogenous 8,9- and 14,15-EET and less 11,12-EET were detected in heart and kidney, and there was a strong enantioselectivity for $8(\mathrm{R}), 9(\mathrm{~S})$-EET in heart (optical purity $78 \%$ ) but not in kidney. BP treatment did not alter the total EET content in these organs but did shift the regiochemical profile in heart to favor 14,15-EET. Thus, scup liver and extrahepatic organs metabolize AA via multiple cytochrome $\mathbf{P 4 5 0}$ (CYP) forms to eicosanoids in vitro and in vivo. BP or TCDD induced endogenous AA metabolism in liver, altering EET regioselectivity and, with $\mathrm{BP}$, stereoselectivity. While AhR agonists alter metabolism of AA in early diverging vertebrates expressing both CYP1A and $A h R$, the magnitude of effects may depend upon the type of inducer. O 1998 Academic Press

Key Words: arachidonic acid; cytochrome P450 1A; Stenotomus chrysops.

Metabolism of free arachidonic acid $\left(\mathrm{AA}^{2}\right)$ released from cell membranes by phospholipase $\mathrm{A}_{2}$ is catalyzed by cyclooxygenases, lipoxygenases, and cytochrome

\footnotetext{
${ }^{2}$ Abbreviations used: AA, arachidonic acid; AhR, aryl hydrocarbon receptor, BNF, $\beta$-naphthoflavone; $\mathrm{BP}$, benzo( $a$ )pyrene; CYP, $\mathrm{P} 450$, cytochrome P450; DHET, dihydroxyeicosatrienoic acid; EET, epoxyeicosatrienoic acid; EROD, ethoxyresorufin $O$-deethylase; ETCP, 1,2-epoxy3,3,3-trichloropropane; HETE, hydroxyeicosatetraenoic acid; NBT-BCIP, nitroblue tetrazolium/5-bromo-4-chloro-3-indoyl-phosphate; $\mathrm{PeCB}$, $3,3^{\prime}, 4,4^{\prime}, 5$-pentachlorobiphenyl; PFB, pentafluorobenzyl; TCDD, 2,3,7,8tetrachlorodibenzo- $p$-dioxin; TMS, trimethylsilyl.
} 
P450 (P450 or CYP) monooxygenases (1). P450s can metabolize AA to three types of products (2). Allylic oxidation forms midchain conjugated dienols or midchain hydroxyeicosatetraenoic acids (5-, 8-, 9-, 11-, 12-, or 15-HETE). w-Terminal hydroxylation forms $\mathrm{C}_{16^{-}}$ through $\mathrm{C}_{20^{-}}$-alcohols of AA (16-, 17-, 18-, 19-, or 20HETE). Olefin epoxidation forms epoxyeicosatrienoic acids (5,6-, 8,9-, 11,12-, and 14,15-EET), which are metabolized to dihydroxyeicosatrienoic acids (DHET) by epoxide hydrolases. In mammals, these AA metabolites have potent biological activities including inhibition of platelet aggregation, neutrophil aggregation, and cyclooxygenase activity (3); alteration of endothelial cell permeability, vascular tone, and cellular ion fluxes (4-6); and stimulation of angiogenesis (7) and peptide hormone release (8).

$P 450$ s in gene families 1-4 have been shown to metabolize AA, and the product profile depends on the CYP isoform. CYP2B, CYP2J2, and CYP2C proteins are primarily epoxygenases $(9,12)$, CYP2E1 and CYP4A are primarily $\omega$-terminal hydroxylases $(13,14)$, while CYP2J3 and CYP2J4 catalyze both activities $(15,16)$. CYP1A proteins show varied patterns of AA metabolism. Purified rabbit or rat CYP1A1 and rat CYP1A2 form primarily 16- through 20-HETE and form lesser amounts of midchain HETEs and EETs $(10,17)$. In contrast, recombinant human CYP1A2 and chicken CYP1A5 are primarily epoxygenases $(9,18)$. The regio- and stereochemical selectivity of EET formation also varies with the CYP1A protein catalyzing the reaction. Thus, the major epoxide formed by rat CYP1A1 is 14,15 -EET (10), that formed by rat and human CYP1A2 is 11,12-EET $(9,10)$, and that formed by chicken CYP1A5 is 8,9-EET (18). Rat CYP1A1 favors production of $8(\mathrm{~S}), 9(\mathrm{R})$-, $11(\mathrm{~S}), 12(\mathrm{R})$-, and 14(R),15(S)-EET enantiomers (10). Rat CYP1A2 and chicken CYP1A5 favor 8(S),9(R)-, 11(R),12(S)-, and 14(R),15(S)-EET $(10,18)$.

Consistent with observations that CYPIAs can metabolize AA, treatment of mammals or birds with aryl hydrocarbon receptor (AhR) agonists (CYP1A inducers) alters microsomal AA metabolism. However, the response to treatment differs among species. In chick embryos, 2,3,7,8-tetrachlorodibenzo-p-dioxin (TCDD) or $\beta$-naphthoflavone (BNF) induced liver microsomal metabolism of AA to 8,9-and 11,12-EET by 6 - to 10 -fold (19). In rabbits, 3-methylcholanthrene and BNF induce 19- and 20-HETE formation by renal and hepatic microsomes by 2 -fold (20). Similarly, in guinea pigs BNF induced a 3-fold increase in formation of 19- and 20HETEs by lung microsomes (21), and 3,3',4,4',5-pentachlorobiphenyl (PeCB) induced hepatic microsomal 20 HETE formation by 2 -fold (22). In rats, BNF and PeCB decreased liver microsomal EET formation but increased 16- through 19-HETE formation $(10,22,23)$. The inconsistent effects of CYP1A induction on AA metabolism in vitro by different tissues and species make it difficult to determine the significance of AhR agonist effects on AA metabolism. Moreover, although it has been suggested that such effects in vivo could modulate or contribute to the toxicity of TCDD (19), we are unaware of studies that have examined effects on endogenous EET formation.

In this study we consider whether multiple P450s catalyze AA metabolism, and the identity of metabolic products, in fish, the earliest diverging vertebrate group. We also address the hypothesis that AhR agonists affect AA metabolism in fish. Fish possess AhRs, and testing this hypothesis is important in determining whether effects on AA metabolism are involved in AhR agonist toxicity generally. Preliminary studies indicated that BNF treatment of the marine teleost fish scup (Stenotomus chrysops) and the elasmobranch skate (Raja erinacea) induced microsomal AA metabolism in those species (24). Here we examine the in vitro metabolism of AA by hepatic and extrahepatic microsomes of male and female scup, both untreated and treated with CYP1A inducers. Regiospecific and stereospecific metabolism of endogenous $\mathrm{AA}$ is described, providing the first demonstration that in vivo metabolism of $A A$ is altered by benzo( $(a)$ pyrene (BP) and TCDD. The results indicate that endogenous AA metabolism can be altered to a greater extent than suggested by microsomal rates measured in vitro.

\section{MATERIAIS AND METHODS}

Materials. 1,2-Epoxy-3,3,3-trichloropropane was kindly provided by Dr. Bruce Hammock (U.C. Davis). Benzo(a)pyrene, triphenylphosphine, $\alpha$-bromo-2,3,4,5,6-pentafluorotoluene, $N, N$-diisopropylethylamine, and $N, N$-dimethylformamide were purchased from Aldrich (Milwaukee, WI). Purified rabbit IgG was purchased from Cappel (Durham, NC). 8-, 9-, 12-, and 15-HETEs were purchased from Cayman Chemical Co. (Ann Arbor, MI). $\left[1-{ }^{14} \mathrm{C}\right]$ Arachidonic acid was purchased from DuPont-New England Nuclear (Boston, MA). 7-Ethoxyresorufin was purchased from Molecular Probes (Eugene, OR). 2,3,7,8-Tetrachlorodibenzo( $p$ )dioxin was purchased from Ultra Scientific (North Kingstown, RI). All other chemicals and reagents were purchased from Sigma (St. Louis, MO).

Animals. S. chrysops (scup) were purchased from the Marine Biological Laboratory (Woods Hole, MA). The fish were originally wild-caught and had been depurated for 6 months prior to use. Fish were held in flow-through seawater tanks at $14^{\circ} \mathrm{C}$ and maintained on a diet of Purina Trout Chow. The studies were performed in accordance with principles and procedures outlined in the NIH Guide for the Care and Use of Laboratory Animals.

Treatment of fish. Experimental animals ranged in size from 104 to $452 \mathrm{~g}$. Experiments took place in March and May (spring) and July (summer). Fish were injected intraperitoneally with corn oil (1 ml $\mathrm{kg})$ or with solutions of BP (10 mg/kg) or TCDD $(1 \mu \mathrm{g} / \mathrm{kg})$ in corn oil. These doses were selected based on previous work that has demonstrated the greater potency of TCDD for CYP1A induction [see (25)]. Each fish was kept in a separate tank postinjection. Three days following injection, the fish were killed by severing the spinal cord. Body and gonad weights were recorded and used to calculate the percent of total body weight represented by the gonads. Livers, hearts, kidneys, and gills were harvested. Portions of organs for endogenous metabolite assays were frozen immediately and stored in liquid $\mathrm{N}_{2}$. 
Microsome preparation and assays. Microsomes were prepared from freshly collected tissue by differential centrifugation (26). Microsomes were prepared from individual livers. Equivalent portions of kidney, heart, and gill tissue from each of the fish used in the spring induction study were pooled before microsomes were prepared. Microsomes were resuspended in $0.15 \mathrm{M} \mathrm{KCl}$ following the initial sedimentation and resedimented. Pellets were resuspended in buffer (50 mM Tris-Cl, pH 7.4, I mM dithiothreitol, $1 \mathrm{mM}$ EDTA, $20 \%$ glycerol) and frozen in liquid $\mathrm{N}_{2}$ until use. Protein content was determined using the bicinchoninic acid method, with bovine serum albumin as a standard (27). Ethoxyresorufin $O$-deethylase (EROD) activity was determined fluorometrically as previously described (28). Dithionite-difference spectra of CO-treated microsomes were obtained as previously described (29).

Western blotting. Immunoblotting procedures used here were modified from those previously described (30). Briefly, microsomal proteins (10-80 $\mu$ g/ane) were resolved on 12\% SDS-PAGE gels and transferred to either nitrocellulose or nylon membrane. The primary antibodies were mouse monoclonal antibody 1-12-3 (31) against scup CYP1A (32) and rabbit polyclonal antibody 7-94 against scup P450B (a CYP2B-like protein) (33). PAb 7-94 does not cross-react with purified CYP1A (33) but does cross-react weakly with CYP2N and CYP2P from the fish Fundulus heteroclitus. ${ }^{3}$ The secondary antibody to MAb 1-12-3 was goat anti-mouse alkaline phosphatase and to PAb 7-94 was goat anti-rabbit alkaline phosphatase (Schleicher and Schuell, Keene, NH). Immunoreactive proteins were visualized with nitroblue tetrazolium and 5-bromo 4-chloro-3-indoyl-phosphate (NBT-BCIP) or enhanced chemiluminescence (Tropix, Bedford, MA). CYP1A- and CYP2B-like proteins detected were quantified by video image analysis by comparison to scup standards of known concentration.

Analysis of microsomal metabolites and antibody inhibition studies. Duplicate reaction mixtures containing $0.5 \mathrm{IU} / \mathrm{ml}$ isocitrate dehydrogenase, $2.0 \mathrm{mg} / \mathrm{ml}$ microsomal protein, and $\left[1{ }^{14} \mathrm{C}\right] \mathrm{AA}(55-57 \mu \mathrm{Ci}$ $\mu \mathrm{mol} ; 50-70 \mu \mathrm{M}$, final concentration) were shaken constantly at $30^{\circ} \mathrm{C}$. After a 5-min temperature equilibration, NADPH ( $1 \mathrm{mM}$, final concentration) was added to initiate the reaction. At various time points, the reactions were stopped by the addition of ethyl ether, and the organic soluble products were extracted three times. Samples were dried under a $\mathrm{N}_{2}$ stream, separated by reverse-phase HPLC, and quantified by on-line liquid scintillation using a Radiomatic Flo-One $\beta$-detector (Radiomatic Instruments, Tampa, FL) as previously described (2). Determination of the regiochemistry of epoxidation required greater reverse-phase separation and was performed as previously described (34). Formation of each regioisomer was calculated as the sum of the EET and the DHET and, in the case of the 5,6-olefin, the $\delta$-lactone as well. For antibody inhibition experiments, microsomes from freshly caught fish obtained in fall were used. These fish had appreciable levels of CYP1A and higher levels of CYP2B-like protein than did the fish used in the treatment experiments. Normal rabbit IgG, the polyclonal antibody 118 against scup CYP1A (30), or the polyclonal antibody 7-94 against scup P450B (33) were added to the reaction mixtures at a protein/total $P 450$ ratio of 4,8 , or $16 \mathrm{mg}$ total $\mathrm{IgG} / \mathrm{nmol}$ of $\mathrm{P} 450$. After $15 \mathrm{~min}$ at $30^{\circ} \mathrm{C},\left[1-{ }^{14} \mathrm{C}\right] \mathrm{AA}$ was added, and the reaction was initiated with NADPH. Metabolites were extracted, resolved, and quantified as before (2). To determine EET chirality, $1 \mathrm{mM}$ 1,2-epoxy-3,3,3-trichloropropane (ETCP), an epoxide hydrolase inhibitor, was included in the incubation, and the samples were resolved into individual regioisomers and enantiomers by HPLC as described $(35,36)$. To resolve the hydroxylation products, fractions corresponding to minutes $15-23$ on reverse-phase HPLC were collected batchwise, dried under $\mathrm{N}_{2}$, and separated by normal-phase HPLC as described $(23,37)$. A UV detector (Waters Model 990) monitored the HETE standards at $234 \mathrm{~nm}(12-, 15-, 11-$, 9-, and 5-HETEs) and $210 \mathrm{~nm}(16-, 17-, 19-$, and 20-HETEs). The

\footnotetext{
${ }^{3}$ M. F. Oleksiak and J. J. Stegeman, unpublished observations.
}

microsomal $\left[1{ }^{14} \mathrm{C} \mid \mathrm{HETEs}\right.$ were monitored by a Radiomatic Flo-One B-detector.

Quantification of endogenous EETs and DHETs in scup tissues. Methods used to quantify endogenous EETs and DHETs in scup tissues were similar to those used with rat and human tissues $(12,36)$. Bricfly, frozen tissues were homogenized in $15 \mathrm{ml}$ phosphate-buffered saline containing the peroxide-reducing agent triphenylphosphine $(5-10 \mathrm{mg})$. The homogenates were extracted twice, under acidic conditions, with 2 volume of chloroform/methanol (2:1) and once with an equal volume of chloroform. The combined organic phases were neutralized and evaporated in tubes containing mixtures of $\left[1-{ }^{14} \mathrm{C}\right] 8,9-, 11,12$, and $14,15-\mathrm{EET}$ $\left(55-57 \mu \mathrm{Ci} / \mu \mathrm{mol}, 80 \mathrm{ng}\right.$ each) or $\left[1{ }^{14} \mathrm{C}\right] 8,9-, 11,12-$, and $14,15-\mathrm{DHET}$ (55-57 $\mu \mathrm{C} \mathrm{j} / \mu \mathrm{mol}, 20 \mathrm{ng}$ each) internal standards. Saponification to recover phospholipid-bound EETs and DHETs was followed by $\mathrm{SiO}_{2}$ column purification. The eluent, containing a mixture of radiolabeled internal standards and total endogenous EETs and DHETs, was resolved into individual regioisomers and enantiomers by HPLC as described $(35,36)$. Individual EET pentafluorobenzyl (PEB) esters were dissolved in dodecane and analyzed by GC/MS on a VG TRIO-1 quadrupole mass spectrometer (Fisons/VG, Altrincham, United Kingdom) operating under negative-ion chemical ionization conditions (source temperature, $100^{\circ} \mathrm{C}$; ionization potential, $70 \mathrm{eV}$; filament current, 500 $\mu \mathrm{A})$ at unit mass resolution and using methane as a bath gas. Quantifications were made by selected ion monitoring of $\mathrm{m} / 2319$ (loss of PFB from endogenous EET-PFB) and $m / z 321$ (loss of PFB from $\left[1{ }^{14} \mathrm{C}\right]-$ EET-PFB internal standard). Aliquots of individual DHET-PFB-trimethylsilyl (TMS) ether derivatives were dissolved in dodecane and analyzed by GC/MS as described (12). Quantifications were made by selected ion monitoring of $\mathrm{m} / \mathrm{z} 481$ (loss of PFB from endogenous DHET-PFB-TMS) and $\mathrm{m} / 2 \mathrm{z} 33$ (loss of PFB from $\left[1{ }^{14} \mathrm{C}\right.$ ]DHET-PFB-TMS internal standard). EET-PFB/(1- $\left.{ }^{14} \mathrm{C}\right] \mathrm{EET}-\mathrm{PFB}$ and DHET-PFBTMS/[1-14C]DHET-PFB-TMS ratios were calculated from the integrated values of the corresponding ion current intensities.

Other methods. $\left[1-{ }^{14} \mathrm{ClEET}\right.$ internal standards were synthesized from $\left[1-{ }^{14} \mathrm{C}\right] \mathrm{AA}(55-57 \mu \mathrm{Ci} / \mu \mathrm{mol})$ by nonselective epoxidation as previously described (38). DHET and $\left[1-{ }^{14} \mathrm{C}\right] \mathrm{DHET}$ internal standards were prepared by chemical hydration of EETs and $\left[1-{ }^{14} \mathrm{C}\right]$ EETs (39). The w-terminal HETEs were synthesized as previously described $(23,40)$. All synthetic EETs, DHETs, and HETEs were purified by reverse-phase HPLC (2). Methylations were performed using an ethereal solution of diazomethane (41). PFB esters were formed by reaction with pentafluorobenzyl bromide as described (36). TMS ethers were prepared using $25 \%(\mathrm{v} / \mathrm{v})$ bis(trimethylsilyl)trifluoroacetamide in anhydrous pyridine (42).

Statistics. Statistics were calculated using SuperAnova (Abacus Concepts, Inc., Berkeley, CA) for Macintosh. Student's $t$ test and single-factor ANOVAs in combination with the Tukey-Kramer multiple comparisons test were used to determine significance. All data are reported as means $\pm \mathrm{SE}$.

\section{RESULTS}

\section{Characterization of Scup Liver Microsomes}

Prior to use in AA metabolism studies, liver microsomes from variously treated fish were characterized. Levels of total spectral P450, immunoreactive CYP1A protein, and CYP1A catalytic activity (EROD) in liver microsomes of control male and female fish are shown in Table I. In spring, control female fish had less total P450, CYP1A, and EROD activity than did males; these values increased in summer (Table I). The content of the major protein recognized by anti-P450B (putative CYP2B) also was less in females than in 
SCHLEZINGER ET AL.

TABLE I

Characterization of $\mathrm{P} 450$ in Liver Microsomes

\begin{tabular}{|c|c|c|c|c|c|}
\hline Treatment & $n$ & $\operatorname{Sex}$ & $\begin{array}{c}\text { Total spectral P450 } \\
\text { (nmol/mg) }\end{array}$ & $\begin{array}{c}\text { CYP1A } \\
\text { (pmol/mg) }\end{array}$ & $\begin{array}{l}\text { EROD activity } \\
\text { (pmol/min/mg) }\end{array}$ \\
\hline \multicolumn{6}{|l|}{ Spring } \\
\hline \multirow[t]{2}{*}{ Control } & 3 & Male & $0.410 \pm 0.180$ & $1 \pm 1$ & $175 \pm 112$ \\
\hline & 4 & Female & $0.122 \pm 0.034$ & nd & $90 \pm 18$ \\
\hline \multicolumn{6}{|l|}{ Summer } \\
\hline \multirow[t]{2}{*}{ Control } & 4 & Male & $0.404 \pm 0.065$ & $12 \pm 3$ & $736 \pm 157$ \\
\hline & 3 & Female & $0.212 \pm 0.028$ & $5 \pm 0$ & $168 \pm 44$ \\
\hline \multirow[t]{2}{*}{$\mathrm{BP}$} & 5 & Male & $0.902 \pm 0.031^{*}$ & $321 \pm 13^{*}$ & $8973=163^{*}$ \\
\hline & 3 & Female & $0.596 \pm 0.123^{*}$ & $222 \pm 46^{*}$ & $7364 \pm 919^{*}$ \\
\hline \multirow[t]{2}{*}{ TCDD } & 5 & Male & $0.725 \pm 0.100^{*}$ & $237 \pm 40^{*}$ & $8090 \pm 960^{*}$ \\
\hline & 2 & Female & $0.321,0.428^{a}$ & 130,133 & $4668,5995^{*}$ \\
\hline
\end{tabular}

Note. Scup liver microsomes were characterized for their total P450 content, CYP1A content, and CYP1A catalytic activity (EROD) as described under Materials and Methods. Values are means \pm SE. Spring and summer indicate the season in which experiments took place and fish were killed. Low levels of CYPIA detected in control fish are consistent with the fact that these fish had depurated for only 6 months. Longer times result in a further decrease of signal. Microsomes from these fish were used to determine rates of AA metabolism and the distribution of products. nd, not detectable.

- Individual values.

* Significantly different from control ( $P<0.05$, Tukey-Kramer).

males in spring $(P<0.05,417 \pm 81$ vs density units $/ \mathrm{mg}$ microsomal protein $876 \pm 95$ density units/mg microsomal protein), but not in summer. Gonad-body weight ratios were significantly different in spring and summer ( $P<0.002$, spring: $3.8 \pm 0.5, n=7$; summer: $2.3 \pm 0.2, n=22$ ). The trend of the relationship between gonad size, P450 levels, and CYP1A activity in females is consistent with previous observations that gonadal status affects $\mathrm{P} 450$ s and their activity in scup liver (43).

Treatment of male scup with either BP $(10 \mathrm{mg} / \mathrm{kg})$ or TCDD $(1 \mu \mathrm{g} / \mathrm{kg})$ resulted in significant increases in total P450 (1.8- to 2.2-fold), corresponding to the increase in CYP1A content (20- to 27-fold) (Fig. 1 and Table I). EROD activity increased 11- to 12-fold following treatment with either BP or TCDD (Table I). BP or TCDD induced total P450 content, CYP1A immunore-

\section{Lane$$
\begin{array}{lllllll}
1 & 2 & 3 & 4 & 5 & 6 & 7
\end{array}
$$

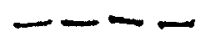

FIG. 1. Immunodetection of CYP1A in scup liver microsomes. Liver microsomal fractions prepared from scup treated with corn oil ( 80 $\mu \mathrm{g} / \mathrm{lane}$ ), BP (10 $\mu \mathrm{g} / \mathrm{lane})$, or TCDD (10 $\mu \mathrm{g} / \mathrm{lane})$ were electrophoresed, transferred to nitrocellulose, and immunoblotted with $\mathrm{MAb}$ 1-12-3 against scup CYP1A. Lanes 1-3, corn oil; lanes 4 and 5 , BP-treated; lanes 6 and 7, TCDD-treated. Visualization by NBTBCIP. active protein, and EROD activity also in female scup (Table I). The amounts of CYP2B-like protein were not increased and if anything were decreased by treatment (control, $1110 \pm 161 ; \mathrm{BP}, 725 \pm 170$; TCDD, $669 \pm 135$ density units/mg protein).

\section{Liver Microsomal AA Metabolism}

Hepatic microsomes prepared from control male and female fish incubated with $\left[1-{ }^{14} \mathrm{C}\right] \mathrm{AA}, \mathrm{NADPH}$, and an NADPH-regenerating system formed EETs, DHETs, midchain HETEs, and $\omega$-terminal HETEs (Fig. 2). Identity of the metabolites was verified by coelution with authentic standards on reverse-phase and normal-phase HPLC and by GC/MS analysis (2, 37). Epoxygenase metabolites (EETs and DHETs) were the major products, accounting for $44 \pm 2 \%$ of total metabolites formed by both male or female liver microsomes, regardless of season. Lesser amounts of midchain HETEs, $\omega$-terminal HETEs, and polar metabolites were produced $(26 \pm 2,13 \pm 1$, and $11 \pm 2 \%$ of total metabolites, respectively). Metabolite formation was NADPH-dependent and increased linearly with time and protein concentration (data not shown). The reaction rate was temperature dependent, with the maximum reaction rate occurring at $30^{\circ} \mathrm{C}$ (data not shown), as with other scup liver $\mathrm{P} 450$ reactions (26).

Microsomal epoxidation of AA was highly regioselective, with a strong preference for epoxidation at the 5,6-olefin ( $47 \pm 2 \%$ of total EETs, $n=3$ summer males). Epoxidation at the 14,15-, 11,12-, and 8,9-olefins occurred less often $(27 \pm 1,13 \pm 1$, and $13 \pm 1 \%$, 

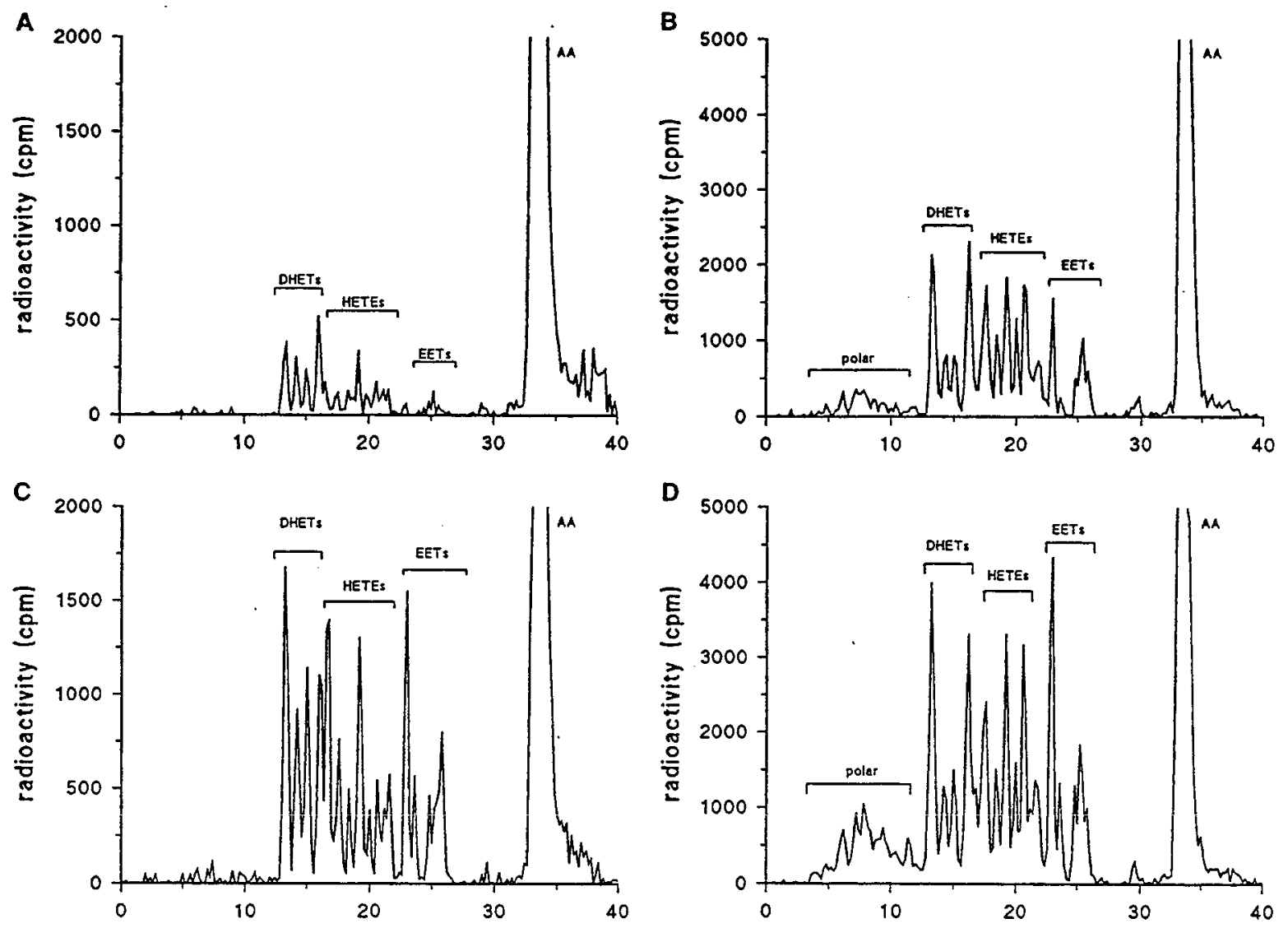

FIG. 2. Reverse-phase HPLC chromatograms of the organic soluble arachidonic acid metabolites generated by scup liver microsomes. (A) Untreated female scup. (B) BP-treated female scup. (C) Untreated male scup. (D) BP-treated male scup. Scup liver microsomes (2 mg/ml protein) were incubated with [1 $\left.-^{14} \mathrm{C}\right] \mathrm{AA}(50-70 \mu \mathrm{M}), \mathrm{NADPH}$, and an NADPH-regenerating system at $30^{\circ} \mathrm{C}$ for $1 \mathrm{~h}$. Products were extracted, dried under a $\mathrm{N}_{2}$ stream, separated by reverse-phase HPLC, and quantified by on-line liquid scintillation as under Methods (2). Products were identified based on coelution with authentic standards. A similar amount of radioactivity was injected onto the column in each case. Data are from the spring experiment. Ordinate, radioactivity in cpm; abscissa, time in minutes.

respectively; $n=3$ ). We were unable to determine the stereochemistry of the epoxides as they were hydrated to DHETs by microsomal epoxide hydrolase (17). Addition of ETCP did not completely block the activity; DHETs still represented $24-49 \%$ of epoxygenase metabolites in reactions containing ETCP. Hydroxylation of AA also occurred in a regioselective manner (Table II). 12-HETE was produced in the greatest amount (23\% of total HETEs) followed by lesser amounts of 19 , 15-, 20-, 11-, 8-, 9-, and 17-HETE.

Hepatic microsomal AA metabolism differed by 4.2fold $(P<0.05)$ between sexes in fish sampled in spring (Figs. 2 and 3 ). In summer, the rates increased in females, and they were not significantly different from rates in males $(135 \pm 18 \mathrm{pmol} / \mathrm{min} / \mathrm{mg}$ vs $180 \pm 18$ $\mathrm{pmol} / \mathrm{min} / \mathrm{mg}$, respectively).
To investigate the contribution of individual $\mathrm{P} 450 \mathrm{~s}$ to scup liver microsomal metabolism of AA, we performed inhibition studies using PAb 118 against scup CYP1A and PAb 7-94 against scup P450B (Table III). Metabolism was inhibited progressively by increasing amounts of either antibody (Table III). Addition of the anti-CYP1A and anti-P450B antibodies together resulted in approximately additive inhibition, up to $70 \%$ of microsomal AA metabolism (Table III). Epoxygenase and hydroxylase reactions were inhibited similarly.

The results above suggest that CYP1A contributes in part to AA metabolism in scup liver. To investigate further a role for teleost CYP1A, we examined the effects of CYP1A induction on microsomal metabolism of AA. In male and female scup, BP treatment significantly increased the total rate of formation of AA me- 
TABLE II

Regioselectivity of HETE Formation by Liver Microsomes from Untreated and BP-Treated Scup

\begin{tabular}{ccc}
\hline & \multicolumn{2}{c}{$\begin{array}{c}\text { Distribution (\%) of HETE formation } \\
\text { in microsomes from }\end{array}$} \\
\cline { 2 - 3 } HETE & Control scup & BP-treated scup \\
\hline $8-$ & $6 \pm 2$ & $1 \pm 1$ \\
$9-$ & $4 \pm 2$ & $2 \pm 2$ \\
$11-$ & $11 \pm 4$ & $16 \pm 1$ \\
$12-$ & $23 \pm 4$ & $19 \pm 3$ \\
$15-$ & $12 \pm 4$ & $12 \pm 7$ \\
$16-$ & $19 \pm 3$ & $21 \pm 2$ \\
$17-$ & $1 \pm 1$ & $5 \pm 3$ \\
$19-$ & $13 \pm 4$ & $21 \pm 6$ \\
$20-$ & $12 \pm 4$ & $4 \pm 2$ \\
\hline
\end{tabular}

Note. Scup liver microsomes ( $2 \mathrm{mg} / \mathrm{ml}$ protein) were incubated with $\left\{1-{ }^{14} \mathrm{ClAA}(50-70 \mu \mathrm{M}), \mathrm{NADPH}\right.$, and a NADPH-regenerating system at $30^{\circ} \mathrm{C}$ for $1 \mathrm{~h}$. Fractions corresponding to minutes $15-23$ on reversephase HPLC were collected batchwise, dried under $\mathrm{N}_{2}$, and resolved into individual regioisomers by normal-phase HPLC $(23,37)$. Minimal amounts of 5-HETE were detected. Data are from fish in sum mer experiments. Values are means $\pm \mathrm{SE}(n=3-5)$. Rate of total HETE formation was $35 \pm 14 \mathrm{pmol} / \mathrm{min} / \mathrm{mg}(\mathrm{N}=8)$ by control scup liver microsomes and $63 \pm 10 \mathrm{pmol} / \mathrm{min} / \mathrm{mg}(\mathrm{N}=8)$ by liver microsomes from BP-treated scup.

tabolites, by 2.7-fold in spring and 1.7-fold in summer (Fig. 4). Comparable increases occurred in EETs, HETEs, and unidentified polar metabolites (Fig. 2). Treatment did not alter significantly the regioselectivity for AA-epoxide formation by liver microsomes (data not shown). BP-treated animals in summer showed a 2 -fold induction in the formation of 19-HETE and a 5 -fold induction of 17-HETE (a minor metabolite) (Table II). In contrast to BP, TCDD treatment in summer did not significantly induce microsomal metabolism of AA (Fig. 4), despite significant increases in total P450, CYP1A protein, and activity (Table I).

\section{Endogenous EET and DHET Content of Scup Liver}

EETs and DHETs were detected as endogenous constituents of scup liver. Control fish livers contained $61 \pm$ $5 \mathrm{ng} \mathrm{EET/g} \mathrm{tissue} \mathrm{(Table} \mathrm{IV)} \mathrm{and} 14 \pm 3 \mathrm{ng}$ DHET/g tissue. The predominant EETs recovered from untreated fish liver were 8,9- and 14,15-EET, followed by a lesser amount of 11,12-EET (Table IV). The labile 5,6-EET could not be quantified. BP treatment resulted in a fivefold increase in total liver EETs with a disproportionate increase in the amount of 14,15-EET recovered, from 31 to $64 \%$ of the total (Table IV). TCDD treatment resulted in a threefold increase in total liver EETs, with a lesser shift in favor of the 14,15-EET (Table IV). In liver from untreated fish the S,R-enantiomers of 8,9-, 11,12-, and 14,15-EET were predominant (optical purity 80, 64, and
$64 \%$, respectively) (Table IV). Importantly, treatment with BP significantly increased the selectivity for the S,R-enantiomer of the three endogenous EETs measured in scup liver (Table IV).

\section{Metabolism of AA in Extrahepatic Scup Tissues}

AA metabolism by heart, kidney, and gill was examined using microsomal preparations of tissues from control and BP-treated fish. Microsomes from these tissues when incubated with $\left[1-{ }^{14} \mathrm{C}\right] \mathrm{AA}, \mathrm{NADPH}$, and an NADPH-regenerating system formed EETs, DHETs, midchain HETEs, and w-terminal HETEs. HPLC analysis of EETs and DHETs indicated epoxidation at the 5,6-, 8,9-, 11,12-, and 14,15-olefins by heart, gill, and kidney microsomes. Individual HETEs could not be identified because the radioactivity was too low for further normal-phase separation. The overall rates were 10 - to 30 -fold less than those observed with liver microsomes (activity in heart ranged from 9.9 to $10.6 \mathrm{pmol} / \mathrm{min} / \mathrm{mg}$; in gill, 2.8 to $3.9 \mathrm{pmol} / \mathrm{min} /$ $\mathrm{mg}$; and in kidney, 4.7 to $7.2 \mathrm{pmol} / \mathrm{min} / \mathrm{mg}$ ). Extrahepatic microsomal AA metabolism rates were not induced by BP (data not shown). To confirm that AA metabolism occurs in vivo in scup extrahepatic organs and to examine the effects of BP, endogenous EETs were measured in heart and kidney. In the summer experiment, heart and kidney from untreated fish contained moderate amounts of 8,9-, 11,12-, and 14,15EET (Table V). 8,9-EET was the most prominent regioisomer in heart (42\% of total EETs), and 14,15-EET was the most prominent regioisomer in kidney ( $43 \%$ of total EETs). BP treatment did not significantly alter the concentration of total EETs present in heart or

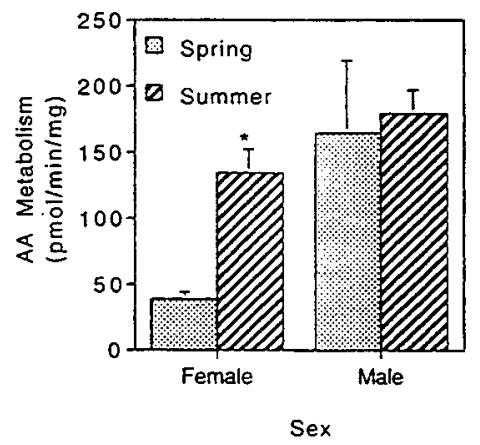

FIG. 3. Seasonal and sex differences in scup liver microsomal metabolism of arachidonic acid. Scup liver microsomes $(2 \mathrm{mg} / \mathrm{ml}$ protein) were incubated with $\left[1-{ }^{14} \mathrm{C}\right] \mathrm{AA}(50-70 \mu \mathrm{M}), \mathrm{NADPH}$, and an NADPH-regenerating system at $30^{\circ} \mathrm{C}$ for $1 \mathrm{~h}$. Products were processed, identified, and quantified as described in the legend to Fig. 2. Spring includes March and May. Data are means \pm SE. *Significantly different from spring $(P<0.01$, Student's $t$ test). Ordinate, AA metabolism in pmol product formed/min/mg microsomal protein; abscissa, gender and seasonal group. 


\section{P450 ARACHIDONIC ACID METABOLISM IN FISH}

TABLE III

Antibody Inhibition of Scup Liver Microsomal Metabolism of Arachidonic Acid

\begin{tabular}{|c|c|c|c|c|c|c|}
\hline \multirow[b]{3}{*}{ Metabolites } & \multicolumn{6}{|c|}{ \% Inhibition } \\
\hline & \multicolumn{2}{|c|}{ Anti-CYP1A } & \multicolumn{2}{|c|}{ Anti-P450B } & \multicolumn{2}{|c|}{ Anti-CYP1A + anti-P450B } \\
\hline & $\begin{array}{c}4 \mathrm{mg} / \mathrm{nmol} \\
\mathrm{P450}\end{array}$ & $\begin{array}{c}8 \mathrm{mg} / \mathrm{nmol} \\
\mathrm{P450}\end{array}$ & $\begin{array}{c}4 \mathrm{mg} / \mathrm{nmol} \\
\mathrm{P450}\end{array}$ & $\begin{array}{c}8 \mathrm{mg} / \mathrm{nmol} \\
\text { P450 }\end{array}$ & $\begin{array}{c}4 \mathrm{mg} \text { each/nmol } \\
\text { P450 }\end{array}$ & $\begin{array}{c}8 \mathrm{mg} \mathrm{each} / \mathrm{nmol} \\
\text { P450 }\end{array}$ \\
\hline $\begin{array}{l}\text { Total } \\
\text { EET/DHET } \\
\text { HETE }\end{array}$ & $\begin{array}{l}21,6 \\
24,0 \\
16,5\end{array}$ & $\begin{array}{l}44,21 \\
49,17 \\
37,20\end{array}$ & $\begin{array}{l}44,8 \\
49,3 \\
37,7\end{array}$ & $\begin{array}{l}48,44 \\
50,43 \\
44,34\end{array}$ & $\begin{array}{l}34 \\
30 \\
32\end{array}$ & $\begin{array}{l}70 \\
67 \\
65\end{array}$ \\
\hline
\end{tabular}

Note. Normal rabbit IgG, the polyclonal antibody 118 against scup CYP1A, or the polyclonal antibody 7-94 against scup P450B was added to microsomal reaction mixtures at protein/total P450 ratios of 4,8 , or $16 \mathrm{mg}$ total $\mathrm{IgG} / \mathrm{nmol}$ of P450. After $15 \mathrm{~min}$ at $30^{\circ} \mathrm{C},\left[1-^{14} \mathrm{C}\right] \mathrm{AA}(50-70$ $\mu \mathrm{M})$ was added, and the reaction was initiated with NADPH. Metabolites were extracted, resolved, and quantified as before (2). \% Inhibition was calculated by comparing the metabolism by microsomes in incubations with specific antibodies to that by microsomes incubated under identical conditions with the same concentration of normal rabbit IgG. Data represent metabolism in a single individual. One individual had a greater amount of CYP1A than the other, but both had similar amounts of P450B. Microsomes from a third individual were incubated with $2.5,5$, and $10 \mathrm{mg}$ anti-CYP1A/nmol P450; increasing inhibition of AA metabolism also was seen.

kidney (Table V). However, the relative concentration of 14,15-EET tended to increase in heart of BP-treated fish (Table V).

The stereochemical composition of endogenous EETs in scup heart and kidney was determined from a pooled sample of three organs from control animals (Table V). In kidney, the $8(\mathrm{~S}), 9(\mathrm{R})$ - and $11(\mathrm{~S}), 12(\mathrm{R})$-EETs were recovered in excess ( 79 and $69 \%$, respectively). In heart, the $11(\mathrm{~S}), 12(\mathrm{R})$ - and $14(\mathrm{~S}), 15(\mathrm{R})$-EETs were recovered in excess (65 and $77 \%$, respectively). In contrast to those EETs and to the liver and kidney, the 8,9-EET showed a strong preference for the $8(\mathrm{R}), 9(\mathrm{~S})$ enantiomers (78\% optical purity). The stereochemistry of EETs formed in extrahepatic organs of BP-treated fish was not determined.

\section{DISCUSSION}

Metabolism of $\mathrm{AA}$ by cytochromes $\mathrm{P} 450$ results in products that are physiologically active, affecting a variety of functions including peptide hormone release (8), platelet aggregation (3), fluid electrolyte transport (44), and vascular tone [as reviewed in (5)]. Alteration in the expression of specific CYP isoforms may affect these biological processes. A general understanding of the importance of P450-derived eicosanoids in controlling physiological processes may be aided by examining AA metabolism in early vertebrate species and identifying the CYP isoforms involved.' Here we determined that $\mathrm{P} 450$ s including CYP1A- and 2B-like proteins in hepatic microsomes of the marine fish scup (S. chrysops) catalyze regioselective metabolism of AA to EETs and HETEs. Recovery of endogenous AA epoxides from scup liver, heart, and kidney establishes that fish $\mathrm{P} 450$ s metabolize $\mathrm{AA}$ in vivo. $\mathrm{BP}$ treatment induced rates of liver microsomal $A A$ metabolism, but that ef- fect varied with season. Endogenous AA epoxide content, particularly in liver, was significantly elevated by $B P$ even when microsomal rates were only slightly induced. The effects of TCDD on endogenous metabolism were qualitatively similar to those of BP.

\section{Hepatic Metabolism of AA}

Untreated scup liver microsomes metabolized AA predominantly to EETs and also to HETEs. Similarly, rat, rabbit, and human liver microsomes all favor ep-

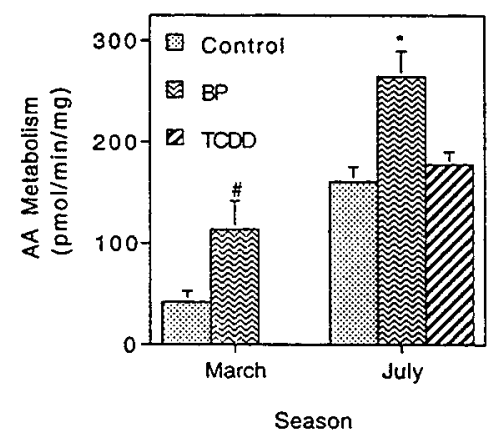

FIG. 4. Effect of BP and TCDD treatment on scup liver microsomal metabolism of arachidonic acid. Scup liver microsomes $(2 \mathrm{mg} / \mathrm{ml}$ protein) were incubated with $\left[1{ }^{14} \mathrm{C}\right] \mathrm{AA}(50-70 \mu \mathrm{M}), \mathrm{NADPH}$, and an NADPH-regenerating system at $30^{\circ} \mathrm{C}$ for $1 \mathrm{~h}$. Products were processed, identified, and quantified as described in the legend to Fig. 2. In the March experiment, each dose group consisted of two females and one male. In the July experiment, each dose group contained seven to eight fish of mixed sex. Data are means $\pm \mathrm{SE}$. \#Significantly different from control $(P<0.1$, Student's $t$ test). *Significantly different from control $(P<0.05$, Tukey-Kramer). Ordinate, AA metabolism in $\mathrm{pmol}$ product formed $/ \mathrm{min} / \mathrm{mg}$ microsomal protein; Abscissa, treatment group. 
oxidation of AA $(9,10,17,45)$. In contrast, chick embryo liver microsomes favor w-terminal hydroxylation of AA (18). Scup liver microsomes had lower rates of AA metabolism (0.1-0.2 nmol $/ \mathrm{min} / \mathrm{mg}$ microsomal protein) than did rat, chicken, or human liver microsomes $(0.5,1.3$, and $0.6 \mathrm{nmol} / \mathrm{min} / \mathrm{mg}$, respectively) $(9,10,18$, 45). However, the rate obtained with scup was similar to that measured in liver microsomes of another fish, $F$. heteroclitus $(0.2 \mathrm{nmol} / \mathrm{min} / \mathrm{mg}) .{ }^{4}$ Similarly, the concentration of endogenous EETs in scup liver was six- to eightfold less than that seen in human or rat liver but was comparable to that in $F$. heteroclitus liver (41). ${ }^{5}$ Both the regio- and stereochemistry of scup liver endogenous EETs differ from that found in $F$. heteroclitus, rat, and human liver $(36,41,45) .^{5}$

Species differences in the amount of endogenous eicosanoids recovered may reflect differences in the amount of AA present endogenously in cell membranes. Marine fish contain less $\mathrm{AA}$ and greater amounts of $\mathrm{n}-3$ fatty acids (e.g., eicosapentaenoic acid) than do mammals or freshwater fish (46), presumably due to differences in diet and in ability to elongate fatty acids (47). However, differences in the identity and abundance of specific metabolites will depend more on the P450 isoforms involved. The results here and those of Oleksiak et al. ${ }^{4,5}$ establish that multiple teleost P450s metabolize AA. Antibody inhibition indicated that CYPLA and a CYP2B-like protein contribute to AA metabolism in scup liver microsomes and may account for $70 \%$ of total AA metabolism. Members of two new subfamilies in the CYP2 gene family, CYP2N and CYP2P, recently identified in the fish $F$. heteroclitus, also catalyze AA epoxygenase and hydroxylase reactions. ${ }^{4,5}$ Homologues of CYP2N and CYP2P have been identified in scup liver ${ }^{3}$ and likely contribute to AA metabolism in this species. CYP4 genes occur in fish (48), but homologues of CYP2C, prominent AA epoxygenases and hydroxylases in mammalian liver (45), have not been identified in fish. Having established that there are multiple CYP involved in AA metabolism in fish provides a foundation for determining the regulation of metabolite formation by $\mathrm{P} 450$ pathways in these early vertebrates and their relationship to P450-mediated AA metabolism in mammalian systems.

\section{Sex and Seasonal Differences in Hepatic AA Metabolism}

Microsomal AA metabolism in scup showed seasonally dependent sex differences that could result from hormonal regulation of $\mathrm{P} 450$ gene expression. In control fish in spring (i.e., during gonadal development), females had lower AA metabolism rates than males. In

M. F. Oleksiak, S. Wu, C. Parker, J. J. Stegeman, and D. C. Zeldin, in preparation.

${ }^{5}$ M. F. Oleksiak, S. Wu, C. Parker, D. C. Zeldin, and J. J. Stegeman, in preparation.
TABLE TV

Endogenous EET Content in Scup Liver Following Treatment with CYP1A Inducers

\begin{tabular}{|c|c|c|c|c|}
\hline \multirow[b]{2}{*}{ Regioisomer } & \multirow{2}{*}{$\begin{array}{c}\text { EET } \\
\text { concentration } \\
(\mathrm{ng} / \mathrm{g})\end{array}$} & \multirow{2}{*}{$\begin{array}{l}\text { Distribution } \\
\text { of EET } \\
(\%)\end{array}$} & \multicolumn{2}{|c|}{$\begin{array}{c}\text { Enantioselectivity } \\
\text { of EET } \\
\end{array}$} \\
\hline & & & $(\% \mathrm{R}, \mathrm{S})$ & $(\% S, R)$ \\
\hline \multicolumn{5}{|l|}{ Control } \\
\hline 14,15 & $19 \pm 1$ & 31 & $36 \pm 6$ & $64 \pm 6$ \\
\hline $11,12-$ & $13 \pm 1$ & 21 & $36 \pm 2$ & $64 \pm 2$ \\
\hline $8,9-$ & $29 \pm 5$ & 48 & $20 \pm 3$ & $80 \pm 3$ \\
\hline Total & $61 \pm 5$ & 100 & & \\
\hline \multicolumn{5}{|l|}{ BP } \\
\hline 14,15 & $208 \pm 62^{*}$ & 64 & $17 \pm 5$ & $83 \pm 5$ \\
\hline $11,12-$ & $39 \pm 7^{*}$ & 12 & $16 \pm 2$ & $84 \pm 2$ \\
\hline 8,9 & $77 \pm 13^{*}$ & 24 & $9 \pm 0$ & $91 \pm 0$ \\
\hline Total & $324 \pm 81^{*}$ & 100 & & \\
\hline \multicolumn{5}{|l|}{ TCDD } \\
\hline 14,15 & $93 \pm 8^{* * * *}$ & 51 & ND & ND \\
\hline 11,12 & $32 \pm 3^{* *}$ & 18 & ND & ND \\
\hline 8,9 & $59 \pm 7^{* * *}$ & 31 & ND & ND \\
\hline Total & $184 \pm 17^{* * *}$ & 100 & & \\
\hline
\end{tabular}

Note. Endogenous scup liver 14,15-, 11,12-, and 8,9-EET were extracted, purified, and quantified as described under Materials and Methods. Data are from male fish in the summer experiment. $\mathrm{Fe}$ males and the spring experiment with BP gave similar results. Concentration values are means $\pm \mathrm{SE}(n=3-4)$. ND, not determined.

* Significantly different from control ( $P<0.01$, Tukey-Kramer)

** Significantly different from control $(P<0.05$, Tukey-Kramer $)$.

*** Significantly different from control $(P<0.03$, Student's $t$ test; $P<0.1$, Tukey-Kramer).

summer (i.e., post-spawning), there was no significant sex difference in the rates of AA metabolism. CYP1A and CYP2B- and CYP3A-like proteins are suppressed by estradiol treatment or during natural maturation of female fish $(43,49)$. The lesser amounts of CYP1A and putative CYP2B in female scup in spring indicate that at least two CYPs may contribute to the sex differences in AA metabolism in scup liver. However, expression of hepatic CYP2P and CYP2N, homologues of which occur in scup, does not differ between sexes of $F$. heteroclitus. ${ }^{4,5}$ In rats, CYP2A, CYP2C, and CYP4A genes show sex differences in expression $(50,51)$; there might be sex differences in AA metabolism in rats. The physiological significance of sex-linked differences in hepatic AA metabolism in any species is not known.

\section{Extrahepatic Metabolism of AA}

P450-mediated AA metabolism also was demonstrated in scup heart, gill, and kidney, organs in which AA metabolites might be expected to be of physiological importance. Similar to human and rat kidney cortex $(36,52)$, the 14,15 - and 8,9-EETs predominate in scup kidney. Interestingly, concentrations of endogenous EETs were as high in scup kidney as they were in liver, 
P450 ARACHIDONIC ACID METABOLISM IN FISH

TABLE V

Endogenous EET Content of Scup Heart and Kidney

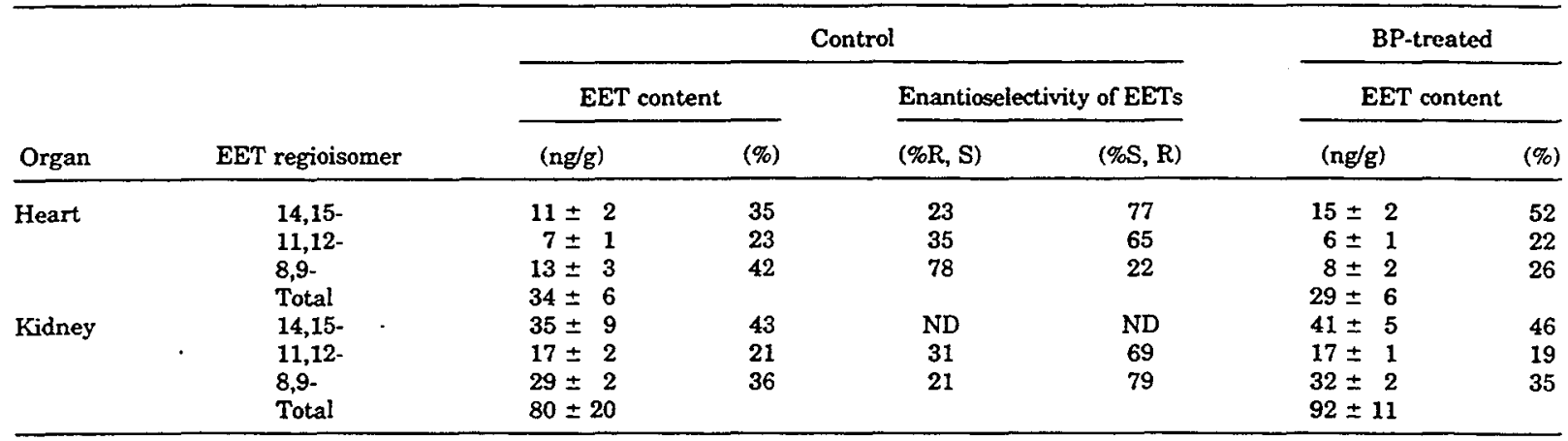

Note. Endogenous scup heart and kidney 14,15-, 11,12-, and 8,9-EET were extracted, purified, and quantified as described under Materials and Methods. Data are from fish in summer experiments. Concentration values for EETs are means \pm SE from three pools of two to three individuals. $\mathrm{ND}$, not determined because the ${ }^{14} \mathrm{C} /{ }^{12} \mathrm{C}$ ratio was too low for quantification.

suggesting that P450-derived EETs may be important to kidney function in fish. In mammalian kidney, EETs and HETEs modulate $\mathrm{Na}^{+} / \mathrm{K}_{+}$-ATPase, alter $\mathrm{Ca}^{2+}$ flux, affect proximal tubule sodium transport, and have vasoactive effects [see (44)].

The regioisomeric distribution of EETs in scup heart was similar to that in liver and kidney; however, the enantiomeric selectivity was different. In contrast to scup liver and to human and rat heart $(12,15)$, the $8(\mathrm{R}), 9(\mathrm{~S})$-EET predominated in scup heart. Oleksiak et al. ${ }^{5}$ determined that CYP2N2 cloned from $F$. heteroclitus heart forms $8(\mathrm{R}), 9(\mathrm{~S})-\mathrm{EET}$; thus, a CYP2N2 homologue might contribute to the enantioselectivity seen in scup heart. EETs have been shown to modulate mammalian cardiac physiology $(15,53)$, and their presence in scup heart may indicate a physiological role for these AA metabolites in fish heart as well.

\section{CYP1A and AA Metabolism}

Following BP treatment of scup, total hepatic microsomal AA metabolism increased 2-fold, with comparable increases occurring in hydroxylase and epoxygenase reactions. The regiochemistry of EETs was unaffected by treatment, but hydroxylation shifted in favor of 17- and 19-HETE. This is similar to results with some, but not all, other species treated with AhR agonists. In rats, $B N F$ and $P e C B$ decrease total hepatic $A A$ metabolism, mainly resulting from a suppression of EET formation, while formation of 16- through 19HETE increases $(22,23)$. In guinea pig and rabbit, AhR agonists increase total hepatic AA metabolism 2-fold, with increases mainly in HETE formation $(20,22)$. In chick embryo liver, AhR agonists increase total AA metabolism and formation of EETs 6- to 10-fold (19).

A major question concerns whether effects on AA metabolism contribute to AhR agonist toxicity (19) and whether this involves induction of CYP1A. Several results support a hypothesis that $A h R$ agonists affect $A A$ metabolism in scup, possibly through CYP1A induction. (i) Specific antibodies to CYP1A inhibited AA metabolism in scup liver microsomes. (ii) Treatment of scup with the CYP1A inducer BP produced an expected strong induction of CYP1A in liver and increased liver microsomal AA metabolism, in both epoxygenase and hydroxylase reactions. (iii) Treatment with BP or TCDD increased endogenous hepatic EET content. (iv) Both the regio- and stereochemical profiles of liver EETs were altered following BP treatment, favoring the 14,15-EET and the S,R-enantiomers of all three EETs. (v) TCDD also caused a shift favoring the 14,15EET in liver. (vi) The regiochemical EET profile in heart shifted in favor of 14,15-EET following treatment with BP. On the other hand, BP treatment did not alter the total endogenous EET content in scup kidney or heart and did not alter the regiochemical profile of $A A$ metabolites in the kidney; CYP1A is strongly induced in those organs by $\mathrm{BP}$ (unpublished observations). Also, treatment of scup with TCDD did not alter rates of liver microsomal AA metabolism. While the antibody inhibition results and inducer effects on endogenous EETs suggest that CYP1A catalyzes AA metabolism in scup, the TCDD and extrahepatic data are not fully consistent with this conclusion.

TCDD effects on scup liver AA metabolism were qualitatively similar to those of $\mathrm{BP}$, but were less strong, even though both compounds elicited similar induction of hepatic CYP1A. A difference in AA metabolism could occur if BP and TCDD induced different $\mathrm{P} 450$ s in scup liver. In chick embryo there are two CYP1As which have different efficiencies for AA metabolism (18). Phylogenetic analysis of CYP1A genes (32) suggests that many fish, including scup, have a 


\section{SCHLEZINGER ET AL.}

single CYP1A gene. (Multiple CYP1A genes in trout represent a very recent divergence (32), distinct from the divergence in birds and mammals.] Scup CYP1A expressed in Chinese hamster V-79 cells has catalytic properties of both mammalian CYP1A1 and CYP1A2, consistent with the hypothesis that teleost CYPIAs represent a type ancestral to both of the mammalian genes (54); however, we cannot rule out that scup have an inducible CYP not yet identified. Also, BP, but not TCDD, might induce CYP1A through binding to glycine $N$-methyltransferase (55) present in scup (56). Whether different induction processes affect CYP1A expression in fish is unknown.

To our knowledge, these are the first observations of effects of TCDD or BP on endogenous AA metabolism. While CYP1A may be involved, alteration of AA metabolism in vivo by BP or TCDD might occur through processes additional to CYP1A induction, perhaps involving effects on membrane structure. TCDD causes a loss of membrane fluidity, possibly by stimulation of lipid peroxidation (57), and a decrease in 20:5 and 22:5 polyunsaturated fatty acids (58). BP causes a transition in membranes from the gel to liquid crystal state (59), although the effect of this transition on AA availability is not known. That effects of BP and TCDD cannot be ascribed solely to their action as AhR agonists is indicated, for example, by effects of BP but not TCDD on expression of epidermal growth factor receptors, transforming growth factor $\beta-1$ and $c-m y c$ in human placental choriocarcinoma cells (60), and evidence for an AhR-independent induction of fos and jun genes by TCDD (61).

Effects of BP treatment on extrahepatic AA metabolism also are not entirely consistent with CXP1A being a catalyst of AA metabolism in scup. CYP1A is strongly induced in the heart and kidney by AhR agonists (62) and is the dominant P450 in heart of induced scup (63). However, induction of CYP1A did not affect cardiac microsomal AA metabolism, although there was a modest increase in endogenous 14,15EET of BP-treated fish. CYP2N2 is highly expressed in heart of some fish, ${ }^{5}$ and a CYP2N homologue might be a dominant AA metabolizing enzyme in scup heart. It will be important to determine whether CYP1A contributes to AA metabolism in heart in vivo, given that CYP1A-derived AA metabolites have been shown to possess potent cardioactive $(15,53)$ and vasoactive effects $(64)$. Neither the total endogenous EET content nor the regiochemical profile of EETs in scup kidney was altered by treatment with BP. In contrast, CYP1A inducers have been shown to alter renal microsomal AA metabolism in the rabbit (20). Proteins in the CYP2C subfamily may dominate AA metabolism in mammalian kidney (65). CYP2C homologues have not been identified in fish, but certainly some isoforms other than CYP1A are contributing to AA metabolism in teleost kidney.

In summary, the results here demonstrate that the marine fish scup metabolizes AA in a regio- and stereospecific fashion in vivo and in vitro, producing eicosanoids in organs including liver, heart, and kidney.
Physiological roles for cyclooxygenase- and lipooxygenase-derived AA metabolites have been demonstrated in fish $(66,67)$. Our results and those of Oleksiak et al..$^{4.5}$ demonstrate that P450s are members of the AA metabolic cascade in teleosts; P450-derived AA metabolites may play physiological roles in fish, as they do in mammals. Given the greater content of $n-3$ fatty acids in some fish, it will be important to determine whether they also are metabolized to biologically active metabolites by teleost P450s. Treatment with AhR agonists produced variable though generally weak effects on microsomal metabolism of $\mathrm{AA}$, but they had stronger effects on the extent of metabolism of endogenous AA and affected the regio- and stereospecificity of that metabolism. The alterations in AA metabolism following BP or TCDD treatment leave open the possibility that such changes may be involved in toxicity of $\mathrm{AhR}$ agonists in early vertebrates, although whether such metabolism might act in a protective way cannot be ruled out.

\section{ACKNOWLEDGMENTS}

This research was supported in part by the Rinehart Coastal Research Center, NIH Grant P42-ES07381, EPA Grant R823890, the Air Force Office of Scientific Research (AFOSR) (F40620-941039), and a Mellon Award. We gratefully acknowledge Cindy Moomaw and Bruce Woodin for technical assistance. Drs. Margie Oleksiak, Mark Hahn, and Eli Hestermann made helpful comments on the manuscript. This is Contribution No. 9609 of the Woods Hole Oceanographic Institution.

\section{REFERENCES}

1. Needleman, P., Turk, J., Jakschik, B. A., Morrison, A. R., and Lefkowith, J. B. (1986) Annu. Rev. Biochem. 55, 69-102.

2. Capdevila, J. H., Falck, J. R., Dishman, E., and Karara, A. (1990) Methods Enzymol. 187, 385-394.

3. Proctor, K. G., Capdevila, J. H., Flack, J. R., Fitzpatrick, F. A., Mullane, K. M., and McGiff, J. C. (1989) Blood Vessels 26, 53-64.

4. Ohnishi, T., Posner, J. B., and Shapiro, W. R. (1992) Neurosurgery 30, 545-551.

5. Harder, D. R., Campbell, W. B., and Roman, R. J. (1995) J. Vasc. Res. 32, 79-92.

6. Schwartzman, M. L., Balazy, M., Masferrer, J., Abraham, N. G., McGiff, J. C., and Murphy, R. C. (1987) Proc. Natl. Acad. Sci. USA 84, 8125-8129.

7. Murphy, R. C., Falck, J. R., Lumin, S., and Yadagiri, P. (1988) J. Biol. Chem. 263, 17917-17202.

8. Falck, J. R., Manna, S., Moltz, J., Chacos, N., and Capdevila, J. (1983) Biochem. Biophys. Res. Commun. 114, 743-749.

9. Rifkind, A. B., Lee, C., Chang, T. K. H., and Waxman, D. J. (1995) Arch. Biochem. Biophys. 320, 380-389.

10. Capdevila, J. H., Karara, A., Waxman, D. J., Martin, M. V., Falck, J. R., and Guengerich, F. P. (1990) J. Biol. Chem. 265, 10865-10871.

11. Zeldin, D. C., Plitman, J. D., Kobayashi, J., Miller, R. F., Snapper, J. R., Falck, J. R., Szarek, J. L., Philpot, R. M., and Capdevila, J. H. (1995) J. Clin. Invest. 95, 2150-2160.

12. Wu, S., Moomaw, C. R., Tomer, K. B., Falck, J. R., and Zeldin, D. C. (1996) J. Biol. Chem. 271, 3460-3468

13. Laethem, R. M., Balazy, M., Falck, J. R., Laethem, C. L., and Koop, D. R. (1993) J. Biol. Chem. 268, 12912-12918. 


\section{P450 ARACHIDONIC ACID METABOLISM IN FISH}

14. Capdevila, J. H., Zeldin, D., Makita, K., Karara, A., and Falck, J. R. (1995) in Cytochrome P450: Structure, Mechanism, and Biochemistry (Ortiz de Montellano, P., Ed.), pp. 443-471, Plenum Press, New York.

15. Wu, S., Weina, C., Murphy, E., Gabel, S., Tomer, K. B., Foley, J., Steenbergen, C., Falck, J. R., Moomaw, C. R., and Zeldin, D. C. (1997) J. Biol. Chem. 277, 1-9.

16. Zhang, Q.Y., Ding, X., and Kaminsky, L. S. (1997) Arch. Biochem. Biophys., 340, 270-278.

17. Oliw, E. H., Guengerich, F. P., and Oates, J. A. (1982) J. Biol. Chem. 257, 3771-3781.

18. Rifkind, A. B., Kanetoshi, A., Orlinick, J., Capdevila, J. H., and Lee, C. (1994) J. Biol. Chem. 269, 3387-3396.

19. Rifkind, A. B., Gannon, M., and Gross, S. S. (1990) Biochem. Biophys. Res. Commun. 172, 1180-1188.

20. Schwartzman, M. L., Abraham, N. G., Carroll, M. A., Levere, R. D., and McGiff, J. C. (1986) Biochem. J. 238, 283-290.

21. Knickle, L. C., and Bend, J. R. (1994) Mol. Pharmacol. 45, 1273-1280.

22. Huang, S., and Gibson, G. G. (1991) Toxicol. Appl. Pharmacol. 108, 86-95.

23. Falck, J. R., Lumin, S., Blair, I., Dishman, E., Martin, M. V., Waxman, D. J., Guengerich, F. P., and Capdevila, J. H. (1990) J. Biol. Chem. 265, 10244-10249.

24. Zacharewski, T. R., McCallum, G. P., Stegeman, J. J., and Bend, J. R. (1996) in Environmental Toxicology and Risk Assessment: Transboundary Issues in Pollution-Air, Surface, and Groundwater (LaPoint, T. W., Price, F. T., and Little, E. E., Eds.), pp. 165-187, Am. Soc. Testing Materials, Philadelphia.

25. Hahn, M. E., and Stegeman, J. J. (1994) Toxicol. Appl. Pharmacol. 127, 187-198.

26. Stegeman, J. J., Binder, R. L., and Orren, A. (1979) Biochem. Pharmacol. 28, 3431-3439.

27. Smith, P. K., Krohn, R. I., Hermanson, G. T., Mallia, A. K. Gartner, F. H., Provenzano, M. D., Fujimoto, E. K., Goeke, N. M., Olson, B. J., and Klenk, D. C. (1985) Anal. Biochem. 150, 76-85.

28. Hahn, M. E., Lamb, T. M., Schultz, M. E., Smolowitz, R. M., and Stegeman, J. J. (1993) Aquat. Toxicol. 26, 185-208.

29. Bonkovsky, H. L., Healey, J. F., Bement, W. J., Sinclair, P. R., Sinclair, J. F., and Shedlovsky, S. F. (1984) Biochem. Pharmacol. 33, 499-502.

30. Kloepper-Sams, P. J., Park, S. S., Gelboin, H. V., and Stegeman, J. J. (1987) Arch. Biochem. Biophys. 253, 268-278.

31. Park, S. S., Miller, H., Klotz, A. V., Kloepper-Sams, P. J., Stegeman, J. J., and Gelboin, H. V. (1986) Arch. Biochem. Biophys. 249, 339-350.

32. Morrison, H. G., Oleksiak, M. F., Cornell, N. W., Sogin, M. L., and Stegeman, J. J. (1995) Biochem. J. 308, 97-104.

33. Gray, E. S. (1988) in Sexual Patterns of Monooygenase Functions in the Liver of Marine Teleosts and the Regulation of Activity by Estradiol, pp. 154, MIT/WHOI, Woods Hole, MA.

34. Zeldin, D., Foley, J., Goldsworthy, S., Cook, M., Boyle, J., Ma, J., Moomaw, C., Tomer, K., Steenbergen, C., and Wu, S. (1997) Mol. Pharmacol. 51, 931-943.

35. Hammonds, T. D., Blair, I. A., Falck, J. R., and Capdevila, J. H (1989) Anal. Biochem. 182, 300-303.

36. Karara, A., Dishman, E., Blair, I., Falck, J. R., and Capdevila, J. H. (1989) J. Biol. Chem. 264, 19822-19827.

37. Capdevila, J. R., Yadagiri, P., Manna, S., and Falck, J. R. (1986) Biochem. Biophys. Res. Commun. 141, 1007-1011.

38. Falck, J. R., Yagagiri, P., and Capdevila, J. H. (1990) Methods Enzymol. 187, 357-364.
39. Zeldin, D. C., Kobayashi, J., Falck, J. R., Winder, B. S., Hammock, B. D., Snapper, J. R., and Capdevila, J. H. (1993) J. Biol. Chem. 268, 6402-6407.

40. Manna, S., Falck, J. R., Chacos, N., and Capdevila, J. H. (1983) Tetrahedron Lett. 24, 33-36.

41. Capdevila, J. H., Pranamik, B., Napoli, J. L., Manna, S., and Falck, J. R. (1986) Arch. Biochem. Biophys. 231, 511-517.

42. Porter, N. A., Logan, J., and Konotoyianidou, V. (1979) J. Org. Chem. 44, 3177-3181.

43. Gray, E. S., Woodin, B. R., and Stegeman, J. J. (1991) J. Exp. Zool. 259, 330-342.

44. McGiff, J. C., Quilley, C. P., and Carroll, M. A. (1993) Steroids $58,573-579$.

45. Zeldin, D. C., Moomaw, C. R., Jesse, N., Tomer, K. B., Beetham, J., Hammock, B. D., and Wu, S. (1996) Arch. Biochem. Biophys. 330, 87-96.

46. Innis, S. M., Rioux, F. M., Auestad, N., and Ackman, R. G. (1995) J. Nutr. 125, 2286-2293.

47. Kissil, G. W., Youngson, A., and Cowey, C. B. (1987) J. Nutr. 117, 1379-1384.

48. Falckh, P. H. J., Wu, Q. K, and Ahokas, J. P. (1997) Biochem. Biophys. Res. Commun. 236, 302-305.

49. Pajor, A. M., Stegeman, J. J., Thomas, P., and Woodin, B. R. (1990) J. Exp. Zool. 253, 51-60.

50. Sundseth, S. S., and Waxman, D. J. (1992) J. Biol. Chem. 267, 3915-3921.

51. Sundseth, S. S., Alberta, J. A., and Waxman, D. J. (1992) J. Biol. Chem. 267, 3907-3914.

52. Katoh, T., Takahashi, K, Capdevila, J., Karara, A., Falck, J. R. Jacobson, H. R., and Badr, K. F. (1991) Am. J. Physiol. 261, F578-F586.

53. Moffat, M. P., Ward, C. A., Bend, J. R., Mock, T., Farhangkhoee, P., and Karmazyn, M. (1993) Am. J. Physiol. 264, H1154-H1160.

54. Stegeman, J. J., Morrison, H. G., Soballa, V., Jacob, J., and Doehmer, J. (1996) in XIth International Symposium on Microsomes and Drug Oxidations, Los Angeles.

55. Raha, A., Joyce, T., Gusky, S., and Bresnick, E. (1995) Arch. Biochem. Biophys. 322, 395-404.

56. Barton, H. A., and Marletta, M. A. (1988) J. Biol. Chem. 263, 5825-5832.

57. Alsharif, N. Z., Gandjean, C. J., Murray, W. J., and Stohs, S. J. (1990) Xenobiotica 20, 979-988.

58. Pohjanvirta, R., Snakari, S., Kulju, T., Yhinen, M., and Tuomisto, J. (1990) Pharmacol. Toxicol. 66, 399-408

59. Sanioto, D. L., and Schreier, S. (1975) Biochem. Biophys. Res. Commun. 67, 530-537.

60. Zhang, L., and Shiverick, K. T. (1997) Biochem. Biophys. Res. Commun. 231, 117-120.

61. Hoffer, A., Chang, C. Y., and Puga, A. (1996) Toxicol. Appl. Pharmacol. 141, 238-247.

62. Smolowitz, R. M., Hahn, M. E., and Stegeman, J. J. (1991) Drug Metab. Dispos. 19, 113-123.

63. Stegeman, J. J., Miller, M. R., and Hinton, D. E. (1989) Mol. Pharmacol. 36, 723-729.

64. Pinto, A., Abraham, N. G., and Mullane, K. M. (1987) J. Pharmacol. Exp. Ther. 240, 856-863.

65. Capdevila, J. H., Wei, S., Yan, J., Karara, A., Jacobson, H. R. Falck, J. R., Guengerich, F. P., and DuBois, R. N. (1992) J. Biol. Chem. 267, 21720-21726.

66. Beckman, B., and Mustafa, T. (1992) Fish Physiol. Biochem. 10, 213-222.

67. Rowley, A. F., Knight, J., Lloyd-Evans, P., Holland, J. W., and Vickers, P. J. (1995) Fish Shellfish Immunol. 5, 549-567. 


\section{CHAPTER 3}

Oxidative Inactivation of Cytochrome P450 1A Stimulated by 3,3',4,4'Tetrachlorobiphenyl: Production of Reactive Oxygen by Vertebrate CYP1As 


\section{ABSTRACT}

Microsomal cytochrome P450 1A (CYP1A) in a vertebrate model (teleost fish scup (Stenotomus chrysops)) recently was shown to be inactivated by the planar aryl hydrocarbon receptor agonist 3,3',4,4'-tetrachlorobiphenyl (TCB) (Biochem. Pharmacol. 53, 1029-1040 (1997)). Here, the mechanism of CYP1A inactivation and its relationship to substrate-dependent generation of reactive oxygen species (ROS) were examined in liver microsomes from scup and rat. Initially we confirmed that inactivation of scup CYP1A activity (7-ethoxyresorufin O-deethylation (EROD)) by TCB was time- and NADPHdependent. This loss of EROD activity, equated with CYP1A inactivation, was irreversible and dependent upon molecular oxygen. Microsomal NADPH oxidation rates increased upon addition of TCB, and CYP1A inactivation was lessened by addition of cytochrome $c$. Loss of EROD activity was accompanied by a loss of spectral P450, by a variable loss of heme and by a variable appearance of P420. Rates of TCB metabolism were $<0.5$ $\mathrm{pmol} / \mathrm{min} / \mathrm{mg}$, indicating that inactivation did not proceed via a TCB metabolite. Addition of non-heme iron chelators (diethylenetriaminepenta-acetic acid and deferoxamine), antioxidant enzymes (catalase and superoxide dismutase), and ROS scavenging compounds (ascorbate, mannitol and tocopherol) had no influence on the inactivation. Added $\mathrm{H}_{2} \mathrm{O}_{2}$ enhanced the inactivation, but only the enhanced loss of activity could be eliminated by addition of catalase. TCB-dependent CYP1A inactivation was accelerated by azide but not by hydroxylamine or aminotriazole. TCB stimulated the formation of ROS when added to microsomes with induced levels of CYP1A but not microsomes from untreated animals. Moreover, as native CYP1A was lost due to TCB-dependent inactivation, there was a concurrent reduction in ROS formation. TCB-stimulated inactivation of CYP1A also was identified in rat liver microsomes. Liver microsomes from Aroclor-treated rats also showed an increased ROS production when incubated with TCB. TCB stimulated ROS formation by baculovirus expressed human CYP1A1 but not CYP1A2. The results indicate that slow metabolism of TCB uncouples electron transfer to and monooxygenation by CYP1A, resulting in inactivation due to the formation and attack of ROS within the CYP1A1 active site. ROS formed by CYP1A bound with planar halogenated aromatic hydrocarbons may contribute to the toxic effects of these compounds. Species differences in the metabolism of and the inactivation by TCB also suggest differences in the topology of the substrate access channels or the active sites of homologous CYP1As. 


\section{INTRODUCTION}

Mechanisms by which planar halogenated aromatic hydrocarbons (pHAH) (2,3,7,8-tetrachlorodibenzo-p-dioxin - TCDD, non-ortho polychlorinated biphenyls PCBs) exert toxicity are not understood fully. PHAH, polycyclic aromatic hydrocarbons, and natural products are agonists of the aryl hydrocarbon receptor (AhR), a basic-helixloop-helix/PAS protein that is a ligand activated transcription factor (Hankinson, 1995). AhR activation leads to altered expression of drug metabolizing enzymes (cytochrome P450 $1 \mathrm{~A}$, glutathione S-transferase, UDP glucuronosyl transferase) and genes involved in cell growth control (e.g. transforming growth factors- $\alpha$ and $-B, B-J u n$, Jun-D) (Hankinson, 1995). Mice rendered AhR deficient by locus-specific homologous recombination are resistant to TCDD toxicity, indicating that toxicity of pHAH is dependent upon the AhR (Fernandez-Salguero et al., 1996). The occurrence of oxidative damage in animals or cells exposed to pHAH (Stohs et al., 1990; Buchmann et al., 1991; Toborek et al., 1995; Park et al., 1996) suggests that toxicity of some AhR agonists might involve reactive oxygen species (ROS).

Uncoupling of electron transfer and oxygen reduction from monooxygenation by cytochromes P450 (CYP) can result in the release of ROS $\left(\mathrm{O}_{2}^{-\bullet}\right.$ and $\left.\mathrm{H}_{2} \mathrm{O}_{2}\right)$. Gillette et al. (1957) first demonstrated microsomal NADPH-dependent generation of $\mathrm{H}_{2} \mathrm{O}_{2}$ by rabbit liver microsomes. $\mathrm{O}_{2}^{-\bullet}, \mathrm{H}_{2} \mathrm{O}_{2}$ and/or $\mathrm{OH} \bullet$ also are formed by human or rat liver microsomes in the presence of NADPH (Rashba-Step and Cederbaum, 1994; Reinke et al., 1994). NADPH-stimulated formation of ROS by liver microsomes can be decreased by the inhibitor SKF525A (Bondy and Naderi, 1994), implying CYP involvement. CYP forms including CYP2E1, CYP2B4 and CYP3A have been shown to release ROS, usually upon substrate binding, which accelerates electron transfer to CYP heme (Kuthan and Ullrich, 1982; Ekstrom et al., 1986; Ahmed et al., 1995). However, for most CYP, the degree to which uncoupling occurs and the conditions that might favor uncoupling are not known. This study considers uncoupling of and ROS formation by CYP1As.

Suggestions that CYP1A can produce ROS initially came from studies of microsomal oxidation of uroporphyrinogen and bilirubin. That oxidation was suggested to occur as a result of ROS formed during uncoupling of the CYP1A catalytic cycle by nonortho PCBs (Sinclair et al., 1986; DeMatteis et al., 1991). Oxidative damage correlated with CYP1A induction following treatment of cells with pHAH (Toborek et al., 1995; Park et al., 1996) further suggests uncoupling of CYP1A. To our knowledge, there has been no direct demonstration that pHAHs stimulate ROS production by CYP1A. 
One effect of ROS generated by CYP1A may be inactivation of the enzyme. 3,3',4,4'-Tetrachlorobiphenyl (TCB) and other planar PCBs not only induce CYP1A but also can elicit sharp declines in CYP1A activity and content following exposure to high doses (Gooch et al., 1989; Sinclair et al., 1989; Hahn et al., 1993; Stegeman et al., 1995). In the fish model, scup (Stenotomus chrysops), the TCB-dependent decrease in CYP1A was shown to be post-transcriptional, and studies in microsomes showed that TCB can inactivate as well as inhibit scup CYP1A (White et al., 1997a). TCB is a ligand for scup CYP1A but is metabolized slowly (Gooch et al., 1989; White et al., 1997b). Therefore, it was speculated that inactivation may be due to uncoupling of CYP1A and formation of ROS (White et al., 1997a). A number of enzymes (CYP2B, Cu,Zn-superoxide dismutase (SOD), Fe-SOD, lactoperoxidase, myeloperoxidase, xanthine oxidase) that use or produce $\mathrm{H}_{2} \mathrm{O}_{2}$ and that contain a metal ion undergo oxidative auto-inactivation (Loosemore et al., 1980; Matheson and Travis, 1985; Beyer and Fridovich, 1987; Jenzer et al., 1987; Karuzina and Archakov, 1994).

In this paper we examine the nature of non-ortho PCB-stimulated inactivation of CYP1A and its relationship to ROS formation in uncoupled catalytic cycles of CYP1A. We examine this process using TCB as a model pHAH in liver microsomes from the marine fish scup, a system in which the phenomenon of CYP1A inactivation was identified and where it is quite strong. The results indicate that inactivation of CYP1A is a result of uncoupling and provide the first direct demonstration that CYP1A in the native state bound with a pHAH is a source of ROS. Similar studies were conducted using rat liver microsomes and expressed human CYP1As. In the mammals, as in scup, the formation of ROS was linked to binding of TCB to CYP1A, apparently CYP1A1. However, inactivation of mammalian CYP1As was less strong than in scup, suggesting differences in the active sites of the CYP1A homologues in these species.

\section{MATERIALS AND METHODS}

Chemicals: Benzo[a]pyrene was purchased from Aldrich (Milwaukee, WI). 2',7'Dichloro-dihydrofluorescein diacetate, dihydroethidium, 7-ethoxyresorufin and 7 methoxyresorufin were purchased from Molecular Probes (Eugene, OR). 3,3',4,4'tetrachlorobiphenyl and 3,3',4,4'-tetrachlorobiphenyl-Ring-UL-14 $\mathrm{C}(52.1 \mathrm{mCi} / \mathrm{mmol})$ were purchased from Pathfinder (St. Louis, MO). Analysis of the ${ }^{14} \mathrm{C}-3,33^{\prime}, 4,4^{\prime}-\mathrm{TCB}$ by GC/ECD and GC/MS revealed no hydrophobic contaminants (>99\% pure); small amounts of polar contaminants were removed by dissolving the TCB in hexane and extracting twice 
with $\mathrm{NaOH}$. Hydroxylamine was purchased from Fisher (Pittsburgh, PA). Catalase was purchased from Sigma, contained less than $0.1 \%$ thymol and was determined to have the manufacturer specified activity. All other reagents were purchased from Sigma (St. Louis, $\mathrm{MO})$.

Animals: Scup (Stenotomus chrysops ) were caught by angling in Vineyard Sound, MA in 1992, 1994 and 1996. Fish were held in flow-through seawater tanks at $14^{\circ} \mathrm{C}$ and maintained on a diet of Purina Trout Chow. Experimental animals ranged in size from 165 to $358 \mathrm{~g}$. Control fish received no treatment. To induce CYP1A, fish were injected intra-peritoneally with a solution of benzo[a]pyrene (BP) $(10 \mathrm{mg} / \mathrm{kg})$ in corn oil. $\mathrm{BP}$ was used because it is a potent inducer, is rapidly metabolized, and does not cause uncoupling of scup CYP1A (unpublished results). Three days following injection the fish were killed by severing the spinal cord. The livers were harvested, and microsomes were made immediately. Eleven microsomal pools were prepared with livers from 3 to 6 fish per pool.

Microsome preparation: Hepatic microsomal fractions were prepared by differential centrifugation (Stegeman et al., 1979). Following the initial sedimentation, microsomes were washed by resuspending in $0.15 \mathrm{M} \mathrm{KCl}$ and sedimenting again. Microsomes also were prepared from post-mitochondrial supernatants from livers of untreated rats and rats treated with Aroclor 1254 (Molecular Toxicology, Inc., Annapolis, MD). Pellets were resuspended in buffer (50 mM TRIS, pH 7.4, $1 \mathrm{mM}$ dithiothrietol, $1 \mathrm{mM}$ EDTA, 20\% glycerol) and frozen in liquid $\mathrm{N}_{2}$ until use. Microsomes from baculovirus-infected insect cells expressing human NADPH cytochrome P450 reductase together with either human CYP1A1 or CYP1A2 were purchased from Gentest Corp. (Boston, MA). Protein content was determined by the bicinchoninic acid method (Smith et al., 1985), using bovine serum albumin (BSA) as a standard.

Western blotting for CYP1A quantification: Immunoblotting procedures were modified from those previously described (Kloepper-Sams et al., 1987). Microsomal proteins $(10 \mu \mathrm{g} / \mathrm{lane})$ were resolved on $12 \%$ SDS-PAGE gels and electrophoretically transferred to $0.1 \mu \mathrm{m}$ nitrocellulose membrane. The primary antibodies were the mouse monoclonal antibody 1-12-3 (Park et al., 1986), raised against scup P450E (CYP1A; (Morrison et al., 1995)) and the polyclonal antibody Rye, raised against mouse CYP1A2 (Stegeman et al., 1995). MAb 1-12-3 is highly specific for CYP1A in fish and CYP1A1 in mammals. The secondary antibodies were alkaline phosphatase linked goat anti-mouse IgG and goat anti-rabbit IgG (Biorad, Hercules, CA). The immunoreactive bands were 
visualized using nitro blue tetrazolium and 5-bromo-4-chloro-3-indoyl-phosphate and quantified by video image analysis (NIH Image 1.60b5) by comparison to scup standards of known concentration. Where appropriate, the CYP1A1 values for rat are relative, reported as scup CYP1A equivalents.

Enzyme assays: Microsomal ethoxyresorufin O-deethylation (EROD) and methoxyresorufin O-demethylation (MROD) were determined fluorometrically (Hahn et al., 1993), using a Cytofluor 2300 (Millipore) multiwell plate reader. NADPH-dependent cytochrome $c$ reductase activity was measured at room temperature from the increase in absorbance at $550 \mathrm{~nm}$ using a Shimadzu 210 difference spectrophotometer (Stegeman et al., 1982). NADPH oxidation was determined at room temperature from the decrease in absorbance at $340 \mathrm{~nm}$ (Imai, 1979). TCB metabolism was assessed using the methods of White et al. (1997b). Radioactivity was determined by liquid scintillation counting on a Beckman LS5000TD counter.

In vitro studies of CYPIA inhibition and inactivation: The procedure followed that of White et al. (1997a). Microsomes were incubated at $0.1 \mathrm{mg} / \mathrm{ml}$ in buffer $(50 \mathrm{mM}$ TRIS, $0.1 \mathrm{mM}$ EDTA, $\mathrm{pH} 7.6$ ) at a final volume of $1 \mathrm{ml}$ in glass test tubes at $30^{\circ} \mathrm{C}$. The following chemicals were added in various combinations at the final concentrations indicated: acetone $(0.5 \%)$, ascorbate $(1 \mathrm{mM})$, 3-amino-1,2,4-triazole $(0.1 \mathrm{mM})$, azide (0.01-1 $\mathrm{mM})$, catalase (800 units $/ \mathrm{ml})$, cytochrome $c(10 \mu \mathrm{M})$, deferoxamine $(1 \mathrm{mM})$, DTPA (1 mM), Fe-EDTA (1 mM), $\mathrm{H}_{2} \mathrm{O}_{2}(1 \mathrm{mM})$, hydroxylamine $(0.1 \mathrm{mM})$, mannitol (1 $\mathrm{mM})$, NADPH (1.8 mM), SOD (400 units/ml), TCB $(0.017-17 \mu \mathrm{M})$ and tocopherol (1 $\mathrm{mM})$. Aliquots were removed from the reaction mixtures at times zero, 10, 20 and 30 minutes and then were assayed as above for the rate of EROD or MROD over 5 minutes (White et al., 1997a). Inhibition was calculated by comparing EROD activity at 10 minutes in control reaction mixtures to that in reaction mixtures containing TCB alone. Inactivation was calculated by comparing EROD activity at 30 minutes in reaction mixtures containing $\mathrm{TCB}$ alone to that in reaction mixtures containing TCB+NADPH. Curve fitting was performed using Sigma Plot for Macintosh (SSPS Inc., Chicago, II). For inhibition, the IC50 was determined directly from the plot of TCB concentration and activity loss. The method of (Cha, 1975) was used to convert the IC50 to a $\mathrm{K}_{i}$, considering TCB as a tight binding inhibitor. To remove TCB from reaction mixtures, microsomes were sedimented, resuspended (50 mM TRIS, $\mathrm{pH} 7.4,0.15 \mathrm{M} \mathrm{KCl}, 0.1 \mathrm{mM} \mathrm{BSA}$ ), incubated 6 minutes at $37^{\circ} \mathrm{C}$, sedimented and resuspended. 
Some incubations were performed under anaerobic conditions. Hungate techniques were used to prepare reaction mixtures as these techniques completely purge the experimental system of oxygen (Hungate, 1969). Reaction mixtures were prepared in stoppered serum bottles. Oxygen was purged from the bottles by bubbling argon gas through the bottles for 30 minutes while they were on ice. The argon had been rendered free of oxygen by passage through a hot, reduced copper column. An NADPH solution was purged in the same manner. NADPH was added to the appropriate reaction mixtures using a syringe repeatedly purged of oxygen by filling it with the argon gas and evacuating it. Aliquots of reaction mixtures also were withdrawn using an argon purged syringe. Otherwise, sampling and analysis procedures were as described above.

Spectral P450 and heme assays: To determine if there was a loss of P450 or heme, microsomes $(0.4 \mathrm{mg}$ protein $/ \mathrm{ml})$ were incubated in buffer ( $50 \mathrm{mM}$ TRIS, $0.1 \mathrm{mM}$ EDTA, $\mathrm{pH} 7.6)$ at $30^{\circ} \mathrm{C}$. The following chemicals were added in various combinations at the final concentrations indicated: acetone $(0.5 \%)$, TCB $(17 \mu \mathrm{M})$, and NADPH $(0.7 \mathrm{mM})$. Following a 30 minute incubation, total P450 concentration was determined by bubbling reaction mixtures with $\mathrm{CO}$ and obtaining the dithionite-difference spectra (Bonkovsky et al., 1984). Heme was determined in reaction mixtures using the pyridine hemochrome assay (Omura and Sato, 1964).

Peroxide and superoxide formation: The production of $\mathrm{H}_{2} \mathrm{O}_{2}$ was determined by measuring the formation of formaldehyde from the oxidation of methanol by the catalase I complex (Rashba-Step and Cederbaum, 1994). The SOD-sensitive rate of adrenochrome formation was measured by the absorption change at $485 \mathrm{~nm}$ (Misra and Fridovich, 1972).

$\mathrm{H}_{2} \mathrm{O}_{2}$ and $\mathrm{O}_{2}^{-\bullet}$ formation also were determined simultaneously using two fluorescent dyes. The oxidation of 2',7'-dichlorodihydrofluorescein diacetate (DCDFDA) and dihydroethidium (HE) to fluorescent products was used to measure $\mathrm{H}_{2} \mathrm{O}_{2}$ and $\mathrm{O}_{2}$ production, respectively. The method is a modification of those by Bondy and Naderi (1994) and Robinson et al. (1994). In a 48-well plate, $0.1 \mathrm{mg}$ of microsomal protein was diluted to $160 \mu \mathrm{l}$ with Hank's buffered salt solution (HBSS) $(120 \mathrm{mM} \mathrm{NaCl}, 2.5 \mathrm{mM}$, $\mathrm{KCL}, 1.2 \mathrm{mM} \mathrm{NaH} 2 \mathrm{PO}_{4}, 0.1 \mathrm{mM} \mathrm{MgCl} 2,5.0 \mathrm{mM} \mathrm{NaHCO}_{3}, 6.0 \mathrm{mM}$ glucose, $1.0 \mathrm{mM}$ $\mathrm{CaCl}_{2}$ and $10 \mathrm{mM}$ HEPES) containing $5 \mu \mathrm{M} \mathrm{DCDFDA}$ and $7.5 \mu \mathrm{M} \mathrm{HE}$ (final concentrations). Following a 15 minute pre-incubation at $30^{\circ} \mathrm{C}$, either acetone $(5 \mu \mathrm{l})$ or TCB (1.7 nmol in acetone) was added. In some cases 200 units of SOD then were added. Reactions were initiated with NADPH (1.4 mM) and fluorescence was monitored over 10 
minutes with $485 \mathrm{~nm}$ excitation and $530 \mathrm{~nm}$ and $625 \mathrm{~nm}$ emission filters for DCDFDA and $\mathrm{HE}$, respectively. 2',7'-Dichlorofluorescein and ethidium bromide were used as standards.

The capacity for formation of ROS during in vitro inactivation of CYP1A was determined as follows. Reaction mixtures were prepared as for the inactivation assay. Aliquots were removed from the reaction mixtures at 10,20 and 30 minutes. $\mathrm{O}_{2}^{-\bullet}$ production was assessed as described above except that $50 \mu \mathrm{l}$ aliquots were combined with $100 \mu \mathrm{l} \mathrm{HBSS}$ and HE $(15 \mu \mathrm{M})$. NADPH $(1.4 \mathrm{mM})$ was added to those aliquots taken from reaction mixtures that did not contain NADPH. Ethidium production rates were monitored fluorometrically over 5 minutes as described above.

Statistics: Statistics were calculated using SuperAnova for Macintosh (Abacus Concepts, Inc., Berkeley, CA). Two-factor ANOVAs (microsomal pool and treatment) were used to analyze the spectral P450, inactivation and ROS time course experiments. One factor ANOVAs were used to analyze the cytochrome $c$ experiments and ROS determinations. The Tukey-Kramer and Dunnett's multiple-comparisons tests were used to determine differences between incubation conditions.

\section{RESULTS}

Inactivation of scup liver CYP1A: Initially we sought to confirm that TCB+NADPH could inactivate microsomal CYP1A, using methods employed previously (White et al., 1997a). Incubating liver microsomes from BP-treated scup with acetone or with NADPH over 30 minutes did not alter their capacity to catalyze EROD (Figure 1). Incubating liver microsomes with TCB alone resulted in an immediate 50\% inhibition of EROD, but the activity did not decline further over time (Figure 1). That inhibition of EROD was TCB concentration-dependent, and the $\mathrm{K}_{\mathrm{i}}$ was $0.16 \mu \mathrm{M}$ (Figure 2). In contrast, when hepatic microsomes were incubated with both TCB and NADPH there were both an immediate inhibition and a progressive loss of activity (Figure 1). Liver microsomes incubated with TCB and NADPH for 30 minutes had $63 \pm 6 \%$ less capacity to catalyze EROD activity than did microsomes incubated with TCB alone. As with inhibition, the progressive loss of EROD activity also was TCB concentration-dependent (Figure 2). This inactivation of EROD did not occur when microsomes were incubated with TCB and NADH instead of NADPH (data not shown). 


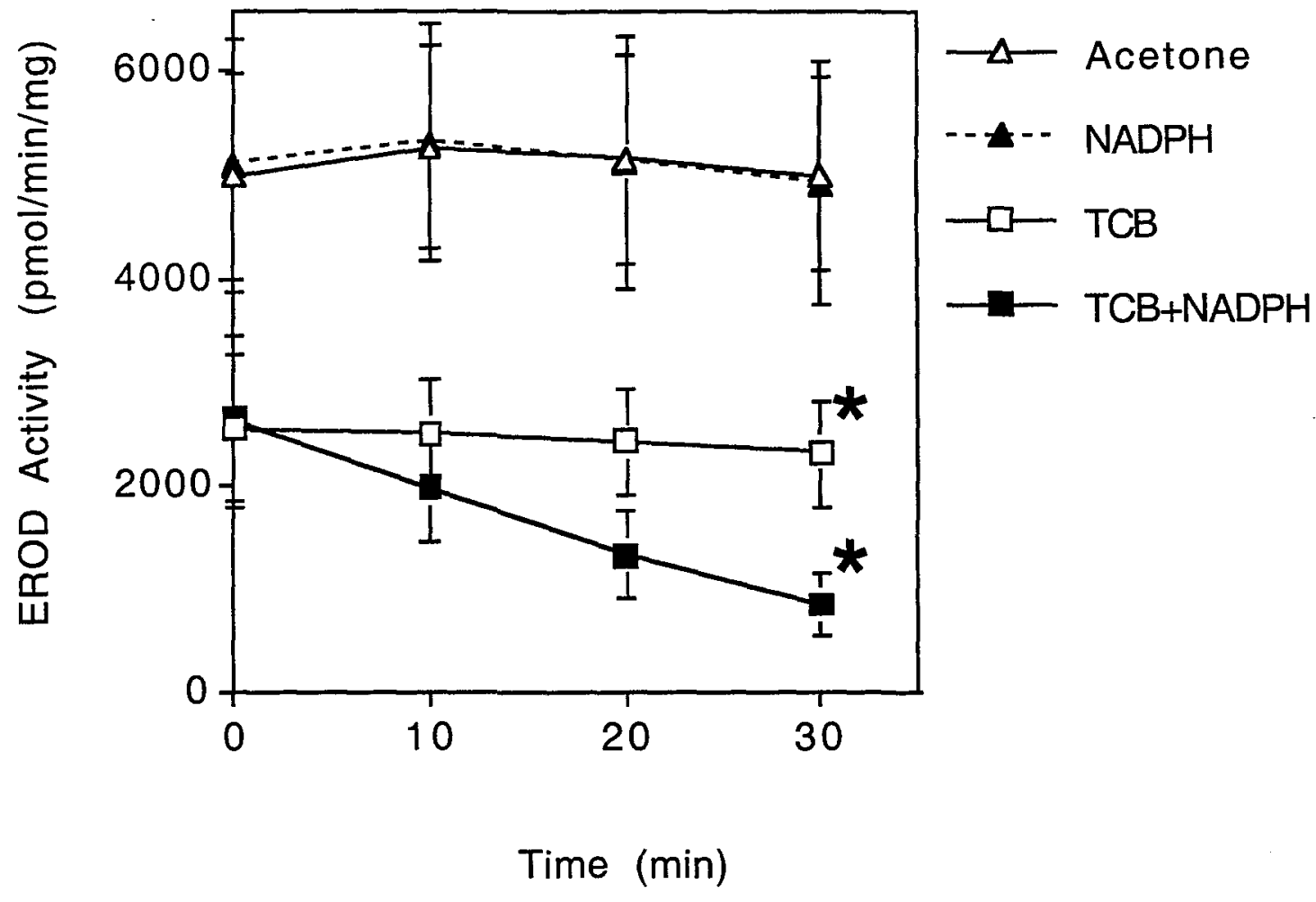

Figure 1. TCB-stimulated inactivation of scup liver CYP1A (EROD activity). Microsomes $(0.1 \mathrm{mg}$ protein $/ \mathrm{ml}$ with $380 \pm 150 \mathrm{pmol} \mathrm{CYP} 1 \mathrm{~A} / \mathrm{mg}$ ) were incubated in buffer $(50 \mathrm{mM}$ TRIS, $0.1 \mathrm{mM}$ EDTA, pH 7.6) at a final volume of $1 \mathrm{ml}$ in glass test tubes at $30^{\circ} \mathrm{C}$. The following chemicals were added in various combinations at the final concentrations indicated: acetone (5\%), NADPH $(1.8 \mathrm{mM})$, and TCB in acetone $(1.7 \mu \mathrm{M})$. Aliquots were removed from the reaction mixtures at times zero, 10, 20 and 30 minutes and then were assayed fluorometrically for the rate of EROD over 5 minutes. Complete inactivation of EROD occurred within 1 hour. Data are means \pm SD from 11 pools of microsomes. *Statistically different from all other incubation conditions analyzed at 30 minutes $(p<0.01$, Tukey-Kramer). 


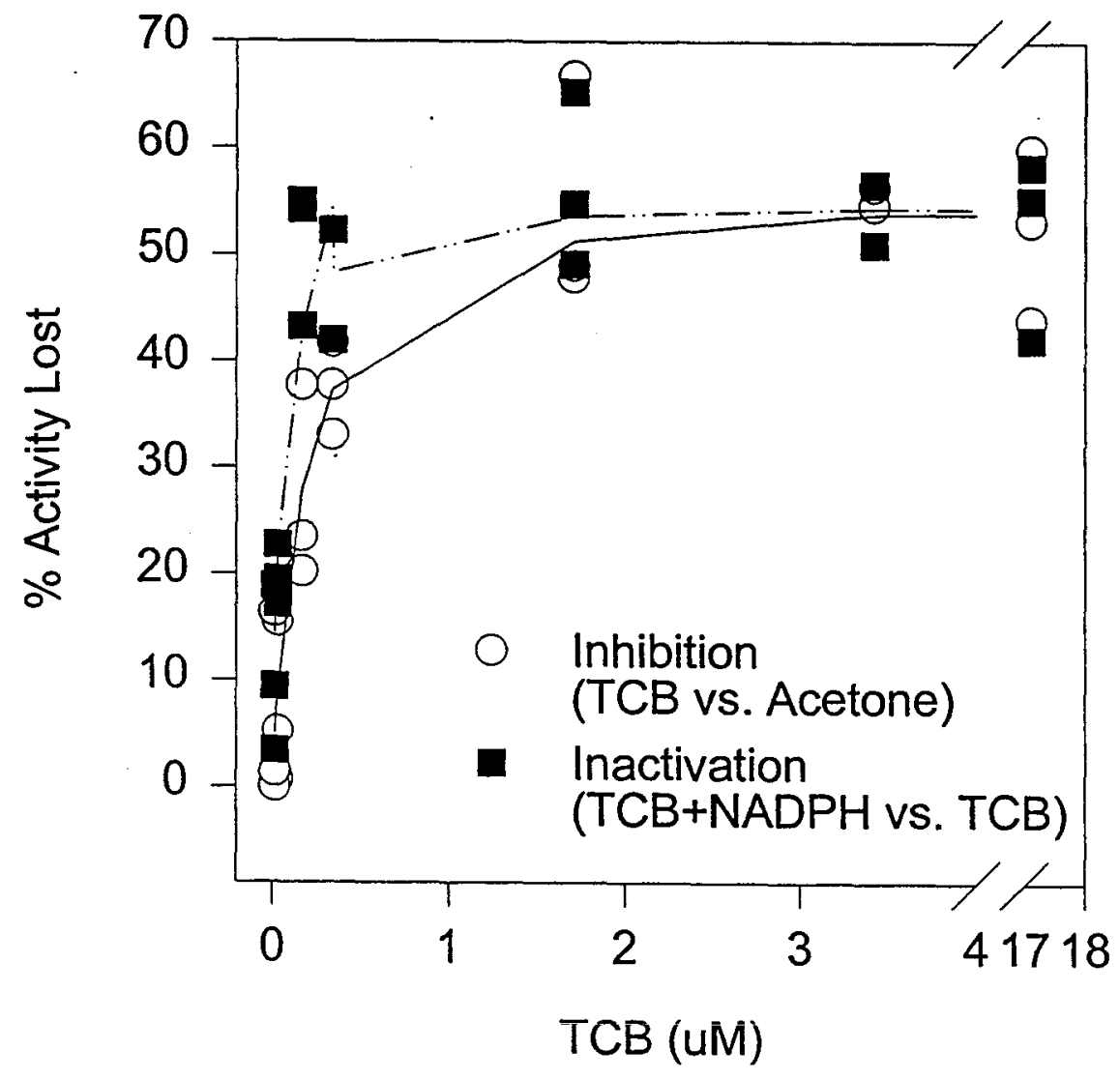

Figure 2. TCB concentration dependent inactivation of scup liver CYP1A. Incubation conditions and assay technique were as described in Figure 1, except that a range of TCB concentrations was used $(0.017-17 \mu \mathrm{M})$. Inhibition was calculated by comparing EROD activity at 10 minutes in control reaction mixtures to that in reaction mixtures containing TCB alone. Inactivation was calculated by comparing EROD activity at 30 minutes in reaction mixtures containing TCB alone to that in reaction mixtures containing TCB+NADPH. Results from 3 pools of microsomes were used to determine the curve fit. The IC50 was determined by a non-linear regression analysis of the activity loss vs. TCB concentration plot. The method of (Cha, 1975) was used to convert the $\mathrm{IC}_{50}$ to a $\mathrm{K}_{\mathrm{i}}(0.16$ $\mu \mathrm{M})$. TCB was considered a tight binding inhibitor because increasing concentrations of 7 ethoxyresorufin did not effectively displace the TCB (data not shown). 
The capacity to catalyze EROD was not restored by removal of TCB from microsomes incubated with TCB+NADPH. Microsomes incubated for one hour with TCB $+\mathrm{NADPH}$ had only $7 \pm 0 \%$ of the EROD capacity retained in microsomes incubated with acetone $\pm N A D P H ;$ following repeated washing and resedimenting microsomes to remove TCB, EROD rates were unchanged. However, at least 50\% of EROD activity could be restored by a similar removal of TCB from microsomes that had been incubated with TCB alone ( $37 \pm 4 \%$ vs. $68 \pm 4 \%$ of control activity before and after TCB removal, respectively).

In addition to the loss of EROD, scup liver microsomes incubated with $\mathrm{TCB}+\mathrm{NADPH}$ showed a loss of spectral $\mathrm{P} 450$. Incubation of microsomes for 30 minutes with TCB+NADPH resulted in the loss of approximately $50 \%$ of the spectral P450 signal (Table I). There was no loss of spectral P450 when microsomes were incubated with TCB alone (Table I). A slight, but not significant, loss of spectral P450 occurred when microsomes were incubated with NADPH alone. The TCB-stimulated loss of P450 was accompanied by a variable loss of heme and a variable appearance of cytochrome $\mathrm{P} 420$ (Table I). Thus, while the amount of P450 decreased consistently in the experiments, the proportion which was modified to $\mathrm{P} 420$ varied.

The above results suggest that TCB could cause the loss of CYP1A activity either by mechanism-based inactivation, i.e. inactivation by a metabolite of TCB, or by stimulation of oxidative inactivation. TCB is a substrate for scup CYP1A, but it is metabolized very slowly (White et al., 1997b). Scup hepatic microsomes used in these inactivation studies metabolized TCB at a rate of $0.34 \pm 0.08 \mathrm{pmol} / \mathrm{min} / \mathrm{mg}$. However, P450 content declined at $12 \pm 6 \mathrm{pmol} / \mathrm{min} / \mathrm{mg}$, calculated from the difference spectra, and CYP1A content declined at $8 \pm 3 \mathrm{pmol} / \mathrm{min} / \mathrm{mg}$, calculated from the loss of EROD (assuming that loss of EROD is equated with loss of CYP1A). Even though rat liver microsomes have been shown to activate TCB to a form which can bind to CYP1A1 (Shimada and Sawabe, 1983), the rate of TCB metabolism and hence possible covalent binding of TCB cannot account for the loss of P450.

In light of the extremely slow metabolism of TCB, we examined the possibility that catalytic uncoupling may be occurring. Microsomal oxidation of NADPH in the presence of acetone (carrier) was $13 \pm 5 \mathrm{nmol} / \mathrm{min} / \mathrm{mg}$ and increased in the presence of TCB, to $33 \pm$ $9 \mathrm{nmol} / \mathrm{min} / \mathrm{mg}$ (Table $\mathrm{V}$ ). When microsomes were incubated under anaerobic conditions, TCB-dependent inactivation of EROD did not occur. Thus, microsomes incubated anaerobically with TCB alone for 45 minutes had a capacity for EROD activity of 2544 
TABLE I

Loss of scup liver P450 stimulated by TCB and NADPH

\begin{tabular}{|c|c|c|c|c|c|}
\hline \multirow[b]{2}{*}{$\begin{array}{l}\text { Additions to } \\
\text { reaction } \\
\text { mixtures } \\
\end{array}$} & \multicolumn{2}{|c|}{$\mathrm{P} 450$} & \multirow{2}{*}{$\begin{array}{c}\mathrm{P} 420 \\
\mathrm{nmol} / \mathrm{mg} \\
\text { (Range) }\end{array}$} & \multicolumn{2}{|c|}{ Heme } \\
\hline & $\mathrm{nmol} / \mathrm{mg}$ & $\begin{array}{l}\text { \% Loss } \\
\text { (Range) }\end{array}$ & & $\mathrm{nmol} / \mathrm{mg}$ & $\begin{array}{l}\text { \% Loss } \\
\text { (Range) }\end{array}$ \\
\hline Acetone & $0.89 \pm 0.33$ & & ND & $1.44 \pm 0.52$ & \\
\hline NADPH & $0.73 \pm 0.35$ & $\begin{array}{c}22 \pm 9 \\
(17-47)\end{array}$ & $\begin{array}{l}0.04 \pm 0.07 \\
(0.00-0.19)\end{array}$ & $1.26 \pm 0.49$ & $\begin{array}{l}16 \pm 12 \\
(0-37)\end{array}$ \\
\hline TCB & $0.91 \pm 0.46$ & & $\mathrm{ND}$ & $1.34 \pm 0.46$ & \\
\hline $\mathrm{TCB}+\mathrm{NADPH}$ & $0.48 \pm 0.22 *$ & $\begin{array}{c}49 \pm 7 \\
(32-63)\end{array}$ & $\begin{array}{l}0.07 \pm 0.10 \\
(0.00-0.29)\end{array}$ & $1.05 \pm 0.40$ & $\begin{array}{l}28 \pm 16 \\
(1-48)\end{array}$ \\
\hline
\end{tabular}

To determine if there was a loss of $\mathrm{P} 450$ or heme, microsomes $(0.4 \mathrm{mg}$ protein/ml) were incubated in buffer ( $50 \mathrm{mM}$ TRIS, $0.1 \mathrm{mM}$ EDTA, $\mathrm{pH} 7.6)$ at $30^{\circ} \mathrm{C}$. The following chemicals were added in various combinations at the final concentrations indicated: acetone $(0.5 \%)$, TCB $(17 \mu \mathrm{M})$, and NADPH $(0.7 \mathrm{mM})$. Following a 30 minute incubation, total $\mathrm{P} 450$ concentration was determined by bubbling reaction mixtures with $\mathrm{CO}$ and obtaining the dithionite-difference spectrum. Heme was determined in reaction mixtures using the pyridine hemochrome assay. $\mathrm{P} 450$ determinations were made on 9 pools of microsomes and initial concentrations ranged from $0.53-1.40 \mathrm{nmol} / \mathrm{mg}$. Heme determinations were made on 6 pools of microsomes, and initial concentrations ranged from $0.60-2.04$ $\mathrm{nmol} / \mathrm{mg}$. Heme and P450 determinations were not made in the same experiments. Data are means \pm SD.

* - Significantly different from all other incubation conditions ( $\mathrm{p}<0.01$, Tukey-Kramer). ND - Not detectable. 
$\mathrm{pmol} / \mathrm{min} / \mathrm{mg}$, and aliquots of the same pool of microsomes incubated anaerobically with TCB plus NADPH had an EROD activity of $2829 \mathrm{pmol} / \mathrm{min} / \mathrm{mg}$. Enhanced electron transfer, oxygen dependence and exceedingly slow rates of substrate turnover are consistent with uncoupling of electron transport from substrate oxidation.

If inactivation is occurring because of uncoupling, then interruption of the electron flow to CYP1A should reduce the magnitude of inactivation. Cytochrome $c$ inhibits CYP by competing for electrons from CYP reductase (Estabrook et al., 1996). Addition of 10 $\mu \mathrm{M}$ cytochrome $\mathrm{c}$ to microsomal incubations with TCB+NADPH lessened the rate of inactivation (Figure 3). The rate of loss of EROD was $3.5 \pm 0.6 \mathrm{pmol} / \mathrm{min} / \mathrm{mg}$ in the presence of cytochrome $c$ as compared to $7.7 \mathrm{pmol} / \mathrm{min} / \mathrm{mg}$ in its absence.

A series of antioxidants, prooxidants and enzymes were tested for their influence on TCB-dependent EROD inactivation. Initially, several catalase inhibitors were tested. Azide $(0.1 \mathrm{mM})$ caused a 2 -fold increase in the rate of inactivation in the presence of TCB+NADPH by 10 minutes, and inactivation in the presence of TCB+NADPH was enhanced significantly by azide by 20 minutes (Figure $4 \mathrm{~A}$ ). There was no significant loss of EROD activity from microsomes incubated with NADPH and $0.1 \mathrm{mM}$ azide and without TCB. (There was a loss of activity at a higher concentration of azide $(1 \mathrm{mM})+\mathrm{NADPH}$; Figure 4). Two other catalase inhibitors, aminotriazole (ATA) and hydroxylamine (HA), at $0.1 \mathrm{mM}$, did not alter the rate of inactivation (Table II). Therefore, the enhanced inactivation due to azide does not appear to result from inhibition of catalase but rather occurs through some other mechanism.

As with addition of azide, addition of $\mathrm{H}_{2} \mathrm{O}_{2}$ increased the rate of inactivation by TCB+NADPH (Figure 4B). At 10 minutes, there was a 3-fold greater loss of EROD activity from microsomes when $\mathrm{H}_{2} \mathrm{O}_{2}$ was added with the TCB+NADPH, compared to the loss occurring without added $\mathrm{H}_{2} \mathrm{O}_{2}$. Little loss of activity occurred with $\mathrm{H}_{2} \mathrm{O}_{2}$ alone, or with $\mathrm{H}_{2} \mathrm{O}_{2}+\mathrm{NADPH}$. As expected, when catalase was added together with $\mathrm{H}_{2} \mathrm{O}_{2}$, it eliminated the increase in inactivation due to the exogenous $\mathrm{H}_{2} \mathrm{O}_{2}$ (Table III). However, adding catalase did not affect the inactivation caused by TCB+NADPH (Table III).

Attempts to scavenge ROS or to alter the iron concentration external to the active site had no effect on inactivation. Addition of SOD did not decrease the inactivation due to TCB+NADPH (Table IV). Similarly, neither the hydrophilic reactive oxygen scavenging compounds, ascorbate and mannitol, nor the lipophilic reactive oxygen scavenging compound, tocopherol, altered the inactivation stimulated by TCB (Table IV). Likewise, manipulation of the iron content in the reaction mixture did not influence inactivation (Table 


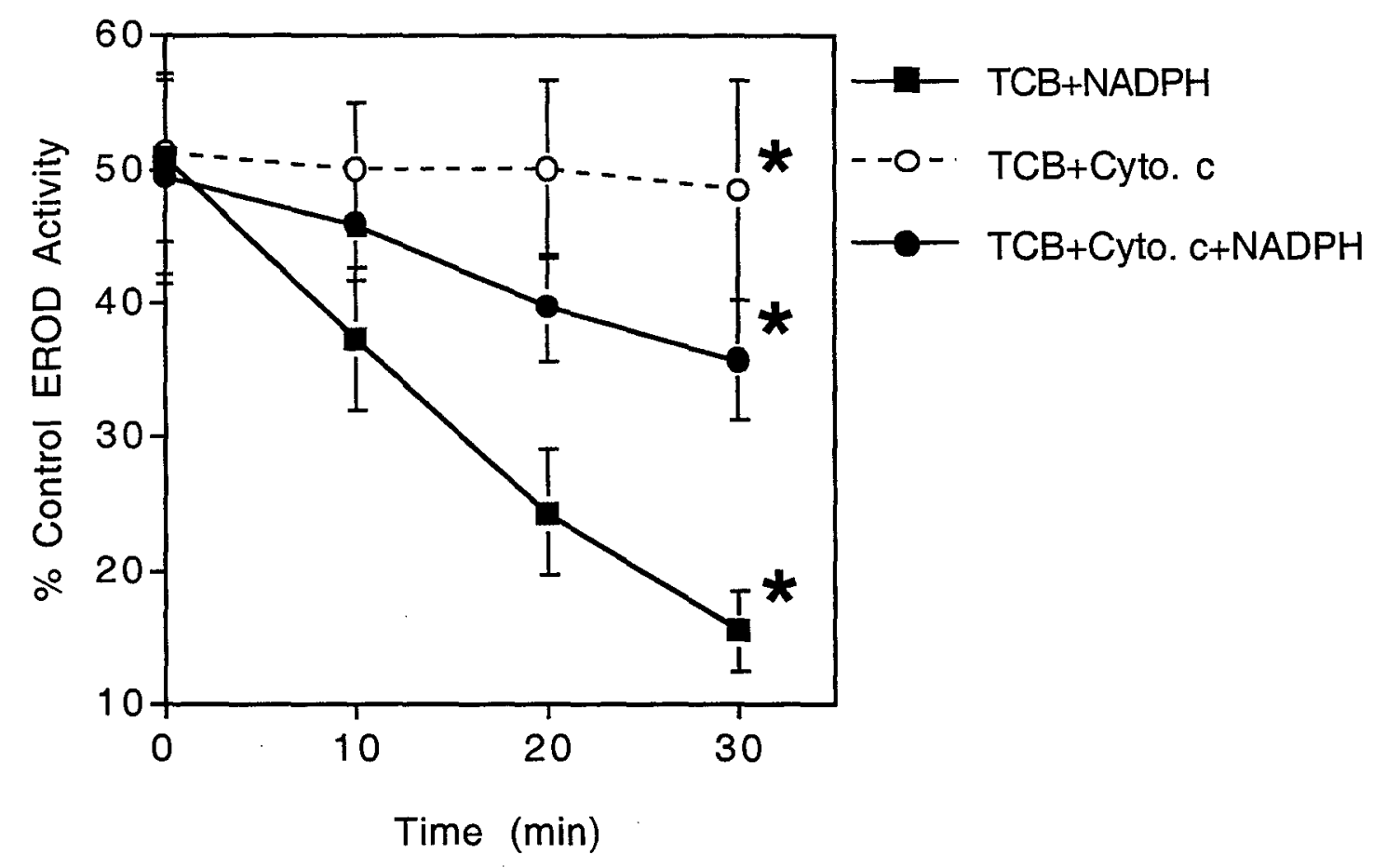

Figure 3. Effect of cytochrome $c$ on TCB-stimulated scup liver CYP1A inactivation. Incubation conditions and assay technique were as described in Figure 1, except for the addition of cytochrome $c(10 \mu \mathrm{M})$. Percent control EROD activity was calculated by comparing reaction mixtures containing $\mathrm{TCB}+\mathrm{NADPH}$ to control reaction mixtures, reaction mixtures containing $\mathrm{TCB}+\mathrm{cytochrome} c$ to those containing cytochrome $c$ and reaction mixtures containing $\mathrm{TCB}+\mathrm{cytoch}$ rome $c+\mathrm{NADPH}$ to those containing $\mathrm{TCB}+$ cytochrome $c$. Data are the means $\pm \mathrm{SD}$ from 5 pools of microsomes. *Statistically different from all other incubation conditions analyzed at 30 minutes $(p<0.01$, TukeyKramer). 

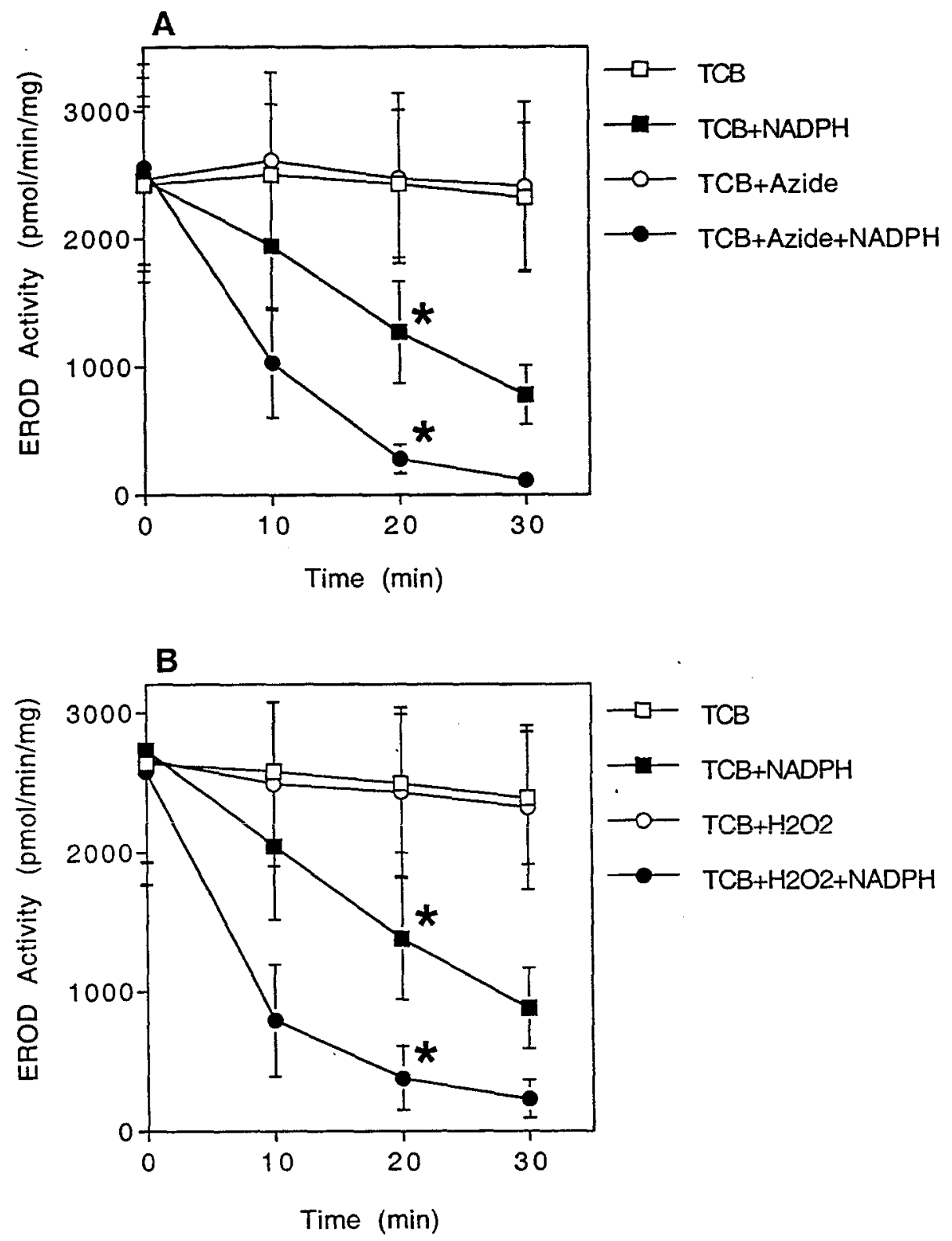

Figure 4. Effects of azide (A) and $\mathrm{H}_{2} \mathrm{O}_{2}$ (B) on TCB-stimulated scup liver CYP1A inactivation. Incubation conditions and assay technique were as described in Figure 1, except for the addition of azide $(0.1 \mathrm{mM})$ or $\mathrm{H}_{2} \mathrm{O}_{2}(100 \mathrm{mM})$. Addition of $1 \mathrm{mM}$ azide + NADPH resulted in a loss of activity over time; the EROD activity was $3158 \pm 1046$ $\mathrm{pmol} / \mathrm{min} / \mathrm{mg}$ at $10 \mathrm{minutes}$ and $1599 \pm 606 \mathrm{pmol} / \mathrm{min} / \mathrm{mg}$ at 30 minutes. Addition of 0.1 $\mathrm{mM}$ azide or $100 \mathrm{mM} \mathrm{H}_{2} \mathrm{O}_{2}$ to acetone or TCB reaction mixtures did not alter EROD activity. Data are the means $\pm S D$ from 5 pools of microsomes. *Statistically different from all other incubation conditions analyzed at 20 minutes ( $\mathrm{p}<0.01$, Tukey-Kramer). 
TABLE II

Effect of catalase inhibitors on TCB-stimulated CYP1A inactivation

\begin{tabular}{|c|c|c|c|}
\hline \multirow[t]{2}{*}{ Additions to reaction mixtures } & \multicolumn{2}{|c|}{$\begin{array}{l}\text { EROD Activity ( } \mathrm{pmol} / \mathrm{min} / \mathrm{mg} \text { ) } \\
\text { in aliquots taken at: }\end{array}$} & \multirow{2}{*}{ \% Loss of activity ${ }^{a}$} \\
\hline & 10 minutes & 30 minutes & \\
\hline \multicolumn{3}{|l|}{ Aminotriazole (ATA) ${ }^{b}$} & \multirow{5}{*}{52} \\
\hline TCB & $1705 \pm 831$ & $1626 \pm 659 *$ & \\
\hline $\mathrm{TCB}+\mathrm{NADPH}$ & $1456 \pm 616$ & $785 \pm 207$ & \\
\hline $0.1 \mathrm{mM} \mathrm{ATA}+\mathrm{NADPH}$ & $3932 \pm 1330$ & $3498 \pm 841^{*}$ & \\
\hline $0.1 \mathrm{mM} \mathrm{ATA}+\mathrm{TCB}$ & $1653 \pm 686$ & $1614 \pm 547^{*}$ & \\
\hline $0.1 \mathrm{mM}$ ATA+TCB+NADPH & $1001 \pm 546$ & $709 \pm 298$ & 56 \\
\hline \multicolumn{3}{|l|}{ Hydroxylamine $(\mathrm{HA})^{\mathrm{c}}$} & \multirow{5}{*}{66} \\
\hline TCB & $3283 \pm 257$ & $3118 \pm 164^{*}$ & \\
\hline $\mathrm{TCB}+\mathrm{NADPH}$ & $2482 \pm 483$ & $1072 \pm 157$ & \\
\hline $0.1 \mathrm{mM} H A+\mathrm{NADPH}$ & $7642 \pm 481$ & $6595 \pm 1107^{*}$ & \\
\hline $0.1 \mathrm{mM} \mathrm{HA}+\mathrm{TCB}$ & $3283 \pm 428$ & $3203 \pm 379 *$ & \\
\hline $0.1 \mathrm{mM} \mathrm{HA}+\mathrm{TCB}+\mathrm{NADPH}$ & $2766 \pm 274$ & $947 \pm 85$ & 70 \\
\hline
\end{tabular}

Microsomes ( $0.1 \mathrm{mg}$ protein $/ \mathrm{ml}$ ) were incubated in buffer ( $50 \mathrm{mM}$ TRIS, $0.1 \mathrm{mM}$ EDTA, $\mathrm{pH} 7.6)$ at $30^{\circ} \mathrm{C}$. The following chemicals were added in various combinations at the final concentrations indicated: acetone $(0.5 \%)$, ATA $(0.1 \mathrm{mM}), \mathrm{HA}(0.1 \mathrm{mM}), \mathrm{NADPH}(1.8$ $\mathrm{mM}), \mathrm{TCB}(1.7 \mu \mathrm{M})$. Aliquots were removed from the reaction mixtures at times 10 and 30 minutes and then were assayed fluorometrically for EROD over 5 minutes. ATA (1 $\mathrm{mM}$ ) in the presence of NADPH reduced EROD activity; the EROD activity was $2910 \pm$ $937 \mathrm{pmol} / \mathrm{min} / \mathrm{mg}$ at $10 \mathrm{~min}$ and $1753 \pm 896 \mathrm{pmol} / \mathrm{min} / \mathrm{mg}$ at 30 minutes.

a - \% loss of activity was calculated by comparing EROD activity in reaction mixtures containing TCB+NADPH to that in reaction mixtures containing TCB.

$\mathrm{b}$ - For all of the reaction mixtures described below, data are the means \pm SD from 5 pools of microsomes.

c - For all of the reaction mixtures described below, data are the means \pm SD from 3 determinations with one pool of microsomes.

* - Significantly different from TCB+NADPH ( $p<0.05$, Dunnett's). 


\section{TABLE III}

Effect of $\mathrm{H}_{2} \mathrm{O}_{2}$ on TCB-stimulated CYP1A inactivation

\begin{tabular}{|c|c|c|c|}
\hline \multirow[t]{2}{*}{ Additions to reaction mixtures } & \multicolumn{2}{|c|}{$\begin{array}{l}\text { EROD Activity ( } \mathrm{pmol} / \mathrm{min} / \mathrm{mg} \text { ) } \\
\text { in aliquots taken at: }\end{array}$} & \multirow{2}{*}{$\begin{array}{c}\% \text { Loss of activity } a \\
30 \text { minutes } \\
\end{array}$} \\
\hline & 10 minutes & 30 minutes & \\
\hline $\mathrm{TCB}$ & $2579 \pm 501$ & $2387 \pm 475^{*}$ & \\
\hline $\mathrm{TCB}+\mathrm{NADPH}$ & $2045 \pm 525$ & $879 \pm 290$ & 63 \\
\hline $\mathrm{TCB}+\mathrm{NADPH}+$ Catalase & $2072 \pm 549$ & $908 \pm 204$ & 62 \\
\hline $\mathrm{H}_{2} \mathrm{O}_{2}+\mathrm{TCB}+\mathrm{NADPH}$ & $795 \pm 400$ & $230 \pm 136 *$ & 90 \\
\hline $\mathrm{H}_{2} \mathrm{O}_{2}+\mathrm{TCB}+\mathrm{NADPH}+$ Catalase & $1887 \pm 593$ & $813 \pm 195$ & 66 \\
\hline
\end{tabular}

Incubation conditions and assay technique were as described in Figure 2, except for the additions of catalase ( 800 units) and $\mathrm{H}_{2} \mathrm{O}_{2}(1 \mathrm{mM})$. Data are the means \pm SD from 3 pools of microsomes.

a - \% loss of activity was calculated by comparing the EROD activity in reaction mixtures containing $\mathrm{TCB}+\mathrm{NADPH}$ to that in reaction mixtures containing TCB.

* - Significantly different from TCB+NADPH ( $\mathrm{p}<0.05$, Dunnett's). 


\section{TABLE IV}

Effects of antioxidants and iron concentration on TCB-stimulated inactivation of CYP1A

\begin{tabular}{|c|c|c|c|}
\hline \multirow[t]{2}{*}{ Additions to reaction mixtures } & \multirow[t]{2}{*}{ Property } & \multicolumn{2}{|c|}{$\begin{array}{l}\text { EROD Activity }{ }^{\text {a }} \text { Retained After } \\
\text { Incubation with: }\end{array}$} \\
\hline & & $\mathrm{TCB}$ & $\mathrm{TCB}+\mathrm{NADPH}^{b}$ \\
\hline None & & $2428 \pm 512$ & $912 \pm 293$ \\
\hline Superoxide Dismutase $(400 \mathrm{u})$ & Metabolizes superoxide & 2563 & 927 \\
\hline Ascorbate $(1 \mathrm{mM})$ & ROS scavenger & 2736 & 1101 \\
\hline Mannitol (1 mM) & ROS scavenger & 2627 & 854 \\
\hline Tocopherol (1 mM) & ROS scavenger & $2509 \pm 482$ & $1045 \pm 132$ \\
\hline Iron $(1 \mathrm{mM})$ & & 2347 & 789 \\
\hline DTPA $(1 \mathrm{mM})$ & Iron chelator & 3352 & 919 \\
\hline Deferoxamine (1 mM) & Iron chelator & 2143 & 554 \\
\hline
\end{tabular}

Incubation conditions and assay technique were as described in Figure 2, except for the additions listed. Data are either the average of two determinations or the means $\pm S D$ of at least 3 determinations.

a - EROD activity ( $\mathrm{pmol} / \mathrm{min} / \mathrm{mg}$ ) was measured following a 30 minute incubation.

b - Activity with TCB and NADPH reflects inactivation. 
IV). If iron external to the enzyme was catalyzing $\mathrm{OH} \bullet$ formation, and if such externally produced radicals were involved in inactivation, then chelation of external iron may reduce inactivation. However, addition of the iron chelators, deferoxamine or diethylenetriaminepenta-acetic acid (DTPA), did not reduce inactivation. Additions of chelated iron also had no effect on inactivation.

Stimulation of the formation of reactive oxygen species by TCB: The above results are indicative of oxidative inactivation and suggest that ROS are formed in the active center of scup CYP1A. This should be accompanied by enhanced release of ROS from microsomes. The production of $\mathrm{H}_{2} \mathrm{O}_{2}$ and $\mathrm{O}_{2}^{-\bullet}$ by liver microsomes was measured by several methods, but primarily by using the fluorescent probes $2^{\prime}, 7^{\prime}$ dichlorodihydrofluorescein (DCDFDA) and dihydroethidium (HE). DCDFDA is oxidized to $2^{\prime}, 7^{\prime}$-dichlorofluorescein (DCF) by $\mathrm{H}_{2} \mathrm{O}_{2}$, and $\mathrm{HE}$ is oxidized by $\mathrm{O}_{2}^{-\bullet}$ directly to ethidium. The stoichiometry of both reactions is 1:1 (Robinson et al., 1994).

Liver microsomes from both control and BP-treated scup oxidized DCDFDA and $\mathrm{HE}$ at very low rates in the presence of the probes alone. These rates were increased by addition of NADPH (Figure 5). Adding either acetone+NADPH or TCB+NADPH to control liver microsomes did not aiter DCDFDA and HE oxidation rates, compared to rates obtained with NADPH alone. Addition of acetone+NADPH to liver microsomes from BPtreated scup also did not alter significantly the DCDFDA and HE oxidation compared to that with NADPH. However, when TCB + NADPH were added to liver microsomes from BP-treated scup, there was a significant increase in DCDFDA and HE oxidation over that seen with NADPH alone (Figure 5). That the HE oxidation stimulated by TCB+NADPH was due to $\mathrm{O}_{2}^{-}$was confirmed by addition of SOD to reaction mixtures; SOD abolished fluorescence produced above the levels occurring with NADPH only.

The Nash and adrenochrome reactions supported conclusions that both $\mathrm{H}_{2} \mathrm{O}_{2}$ and $\mathrm{O}_{2}$ - were being produced by $\mathrm{BP}$-treated scup liver microsomes in the presence of TCB+NADPH. $\mathrm{H}_{2} \mathrm{O}_{2}$ formation quantified using the Nash reaction was $1 \pm 1 \mathrm{nmol}$ formaldehyde formed $/ \mathrm{min} / \mathrm{mg}$. $\mathrm{O}_{2}^{-}$- formation determined using the adrenochrome reaction was $19 \pm 5 \mathrm{pmol}$ adrenaline oxidized $/ \mathrm{min} / \mathrm{mg}$.

To evaluate further the possible involvement of CYP1A in production of ROS, microsomes pre-incubated under various conditions were examined for the capacity to oxidize HE (Figure 6). When microsomes were pre-incubated with acetone or acetone+NADPH for periods of 0-30 minutes, and then combined with NADPH and HE, those microsomes oxidized $\mathrm{HE}$ at a very low rate. When microsomes pre-incubated with 
Figure 5. ROS production in liver microsomes from control and BP-treated scup. (A) $\mathrm{H}_{2} \mathrm{O}_{2}$ production as assessed by the oxidation of DCDFDA to DCF. (B) $\mathrm{O}_{2}^{-\bullet}$ production as assessed by the oxidation of $\mathrm{HE}$ to ethidium. In a 48-well plate, approximately $0.1 \mathrm{mg}$ of microsomal protein was diluted with HBSS containing $5 \mu \mathrm{M} \mathrm{DCDFDA}$ and $7.5 \mu \mathrm{M} \mathrm{HE}$ (final concentrations). Some reaction mixtures contained 200 units SOD. Following a 15 minute incubation at $30^{\circ} \mathrm{C}, 1.7 \mathrm{nmol} \mathrm{TCB}$ in acetone or $5 \mu \mathrm{l}$ acetone was added. Reactions were initiated with NADPH $(1.7 \mathrm{mM})$. The rates of DCF and ethidium production were monitored fluorometrically over 5 minutes. Calculations were made using DCF and ethidium bromide as standards. Data are the means + SD from at least 3 pools of microsomes. *Statistically different from acetone+NADPH ( $p<0.05$, Dunnett's). 

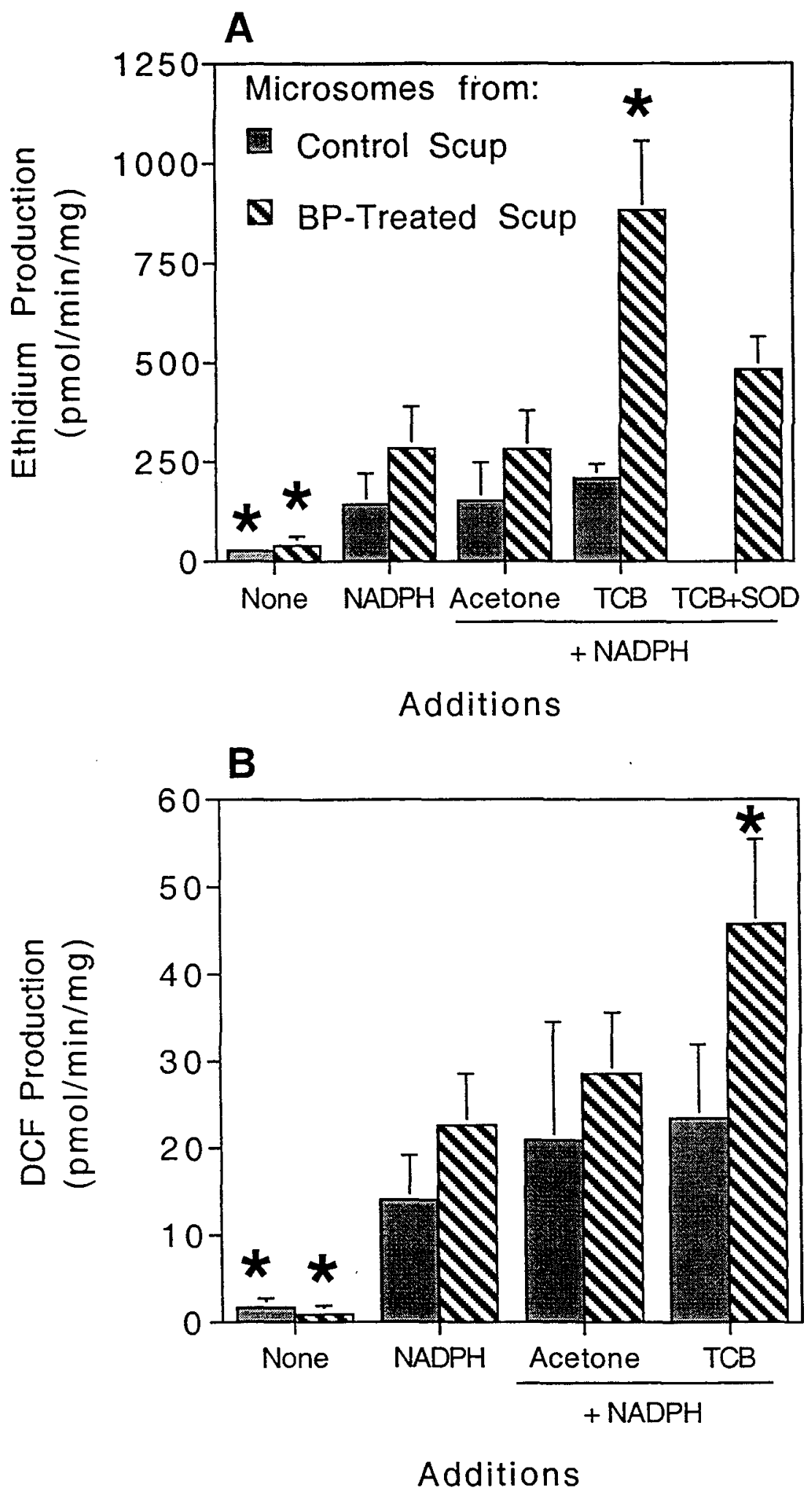


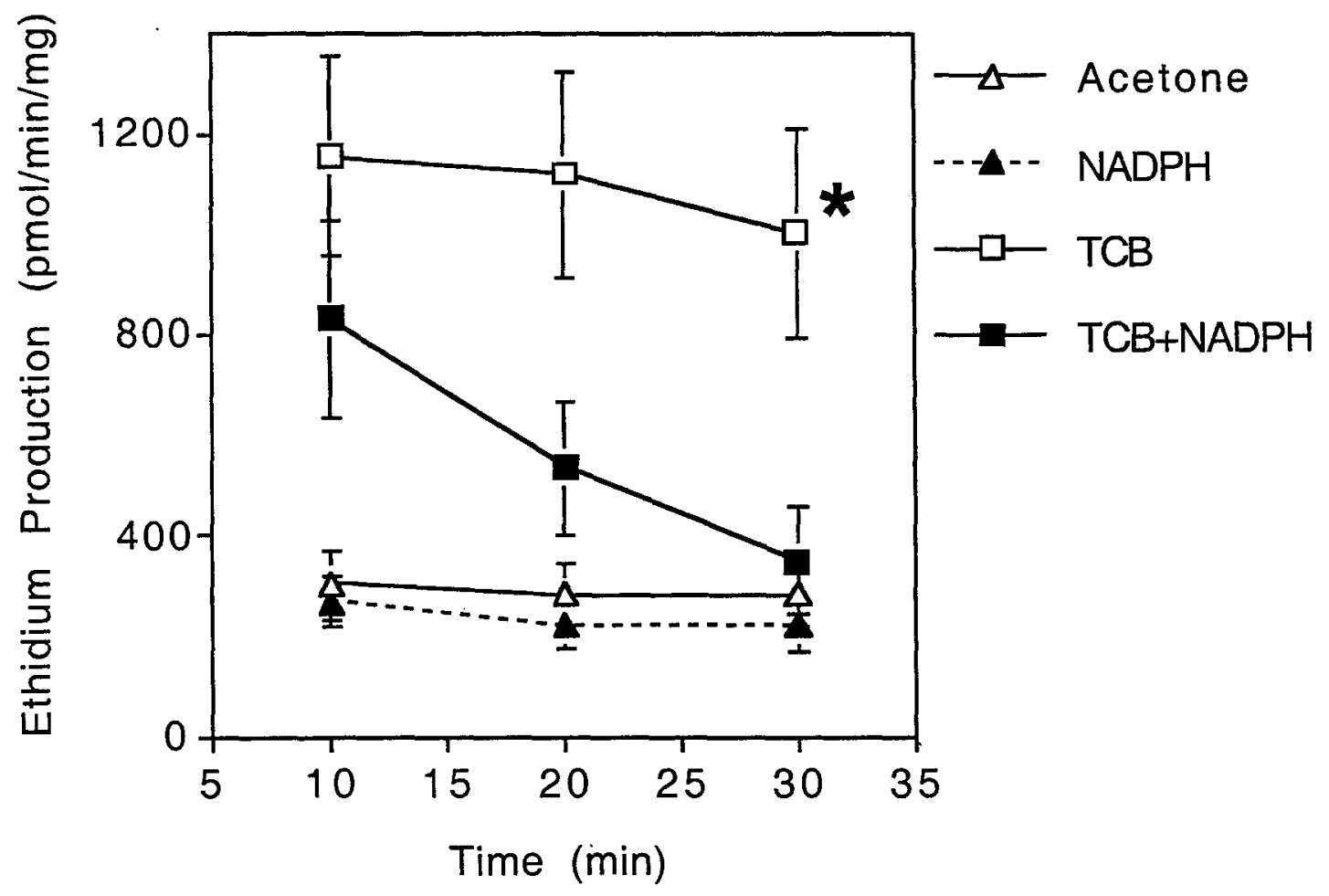

Figure 6. Effect of TCB and NADPH on the capacity of scup liver CYP1A to produce ROS. Microsomes were pre-incubated as described in Figure 1, except that reaction mixtures contained $0.4 \mathrm{mg}$ of microsomal protein and $17 \mathrm{nmol}$ TCB. Aliquots $(50 \mu \mathrm{l})$ were removed from each reaction mixture at 10,20 and 30 minutes, and each was combined with $100 \mu \mathrm{lHBSS}, \mathrm{HE}(15 \mu \mathrm{M})$, and NADPH $(1.4 \mathrm{mM})$ in a well of a 48-well plate. The rates of ethidium production were determined as in Figure 6. Data are the means \pm SD from 3 pools of microsomes. *Statistically different from all other incubation conditions analyzed at 30 minutes ( $\mathrm{p}<0.01$, Tukey-Kramer). 
TCB alone were combined with $\mathrm{HE}$ and NADPH, they oxidized $\mathrm{HE}$ at a high rate, regardless of the duration of the pre-incubation. Aliquots of microsomes pre-incubated with $\mathrm{TCB}+\mathrm{NADPH}$ initially had a high capacity for HE oxidation. However, those microsomes pre-incubated with $\mathrm{TCB}+\mathrm{NADPH}$ showed a time-dependent loss of the capacity to produce ROS that paralleled the loss of CYP1A (EROD) activity; by 30 minutes, the capacity to produce ROS decreased to levels seen with microsomes preincubated with acetone or NADPH.

TCB-stimulated CYP inactivation in rat liver microsomes: When microsomes from Aroclor-treated rats were incubated with $\mathrm{TCB}+\mathrm{NADPH}$ there was inactivation of CYP1A (EROD activity) (Table V). However, with rat liver microsomes, the loss of EROD activity due to inactivation was less than was seen with scup; at 30 minutes there was only a $15 \%$ inactivation of rat CYP1A, compared to the $63 \%$ inactivation in scup liver microsomes. Immunoblot analysis with antibodies to scup CYP1A and to mouse CYP1A2 showed that both CYP1A1 and CYP1A2 were present in rat liver microsomes (data not shown). However, methoxyresorufin O-demethylation (MROD), a preferred activity of CYP1A2 in rat liver microsomes, was not inactivated by $\mathrm{TCB}+\mathrm{NADPH}$, while scup liver microsomes experienced a $77 \pm 8 \%$ loss of MROD activity due to inactivation (Table V). As with scup liver microsomes, the TCB+NADPH dependent loss of EROD activity from rat liver microsomes was enhanced by the addition of azide (Table V).

The rate of TCB metabolism by rat liver microsomes was $50 \mathrm{pmol} / \mathrm{min} / \mathrm{mg}$. Although this rate is two orders of magnitude greater than the rate with scup liver microsomes (Table V), it still may be slow enough to be promote uncoupling. The rat liver microsomal NADPH oxidation rate in the presence of TCB was similar to that seen with scup liver microsomes and was greater than the rate of TCB turnover (Table V).

Formation of reactive oxygen species by rat liver microsomes: Patterns of ROS production similar to those with scup liver microsomes were seen also with rat liver microsomes. Liver microsomes alone from control or from Aroclor-treated rats oxidized DCDFDA and HE at low rates, and those rates increased in the presence of NADPH (Figure 7). With control rat liver microsomes, addition of acetone+NADPH or TCB+NADPH did not alter DCDFDA and HE oxidation rates, compared to that caused by NADPH alone. However, when liver microsomes from Aroclor-treated rats were incubated with $\mathrm{TCB}+\mathrm{NADPH}$, there was a significant increase in the rate of both DCDFDA and HE oxidation compared to that obtained with NADPH alone, or to the rate seen with control microsomes incubated under any condition (Figure 7). SOD only partly abolished 


\section{TABLE V}

Comparison of scup and rat liver microsomal enzyme activities and CYP1A inactivation

\begin{tabular}{lcc}
\multicolumn{1}{c}{ Assay } & $\begin{array}{c}\text { Scup Liver } \\
\text { Microsomes } \\
(\mathrm{n}=7)\end{array}$ & $\begin{array}{c}\text { Rat Liver } \\
\text { Microsomes } \\
(\mathrm{n}=3)\end{array}$ \\
\hline $\begin{array}{l}\text { Spectral P450 } \\
\text { (nmol/mg) }\end{array}$ & $0.75 \pm 0.23$ & $2.38 \pm 0.60$ \\
CYP1A & & \\
$\quad$ (nmol/mg) & $0.38 \pm 0.15$ & $0.26 \pm 0.28$ \\
NADPH Oxidation ${ }^{\mathrm{b}}$ & & $5 \pm 1$ \\
$\quad$ (nmol/min/mg) & $20 \pm 4$ & \\
Cytochrome $c$ Reductase Activity & & $263 \pm 55$ \\
$\quad$ (nmol/min/mg) & $125 \pm 39$ & $38.5 \pm 7.8$ \\
TCB Metabolism \\
$\quad$ (pmol/min/mg)
\end{tabular}

a - The immunoreactive bands were visualized using NBT/BCIP and quantified by video image analysis by comparison to scup standards of known concentration. Where appropriate, the CYP1A1 values for rat are relative, reported as scup CYP1A equivalents. b - Calculated by subtracting the rate of NADPH oxidation with the carrier present from the rate of oxidation with $\mathrm{TCB}$ present.

c - Assayed at 30 minutes. 

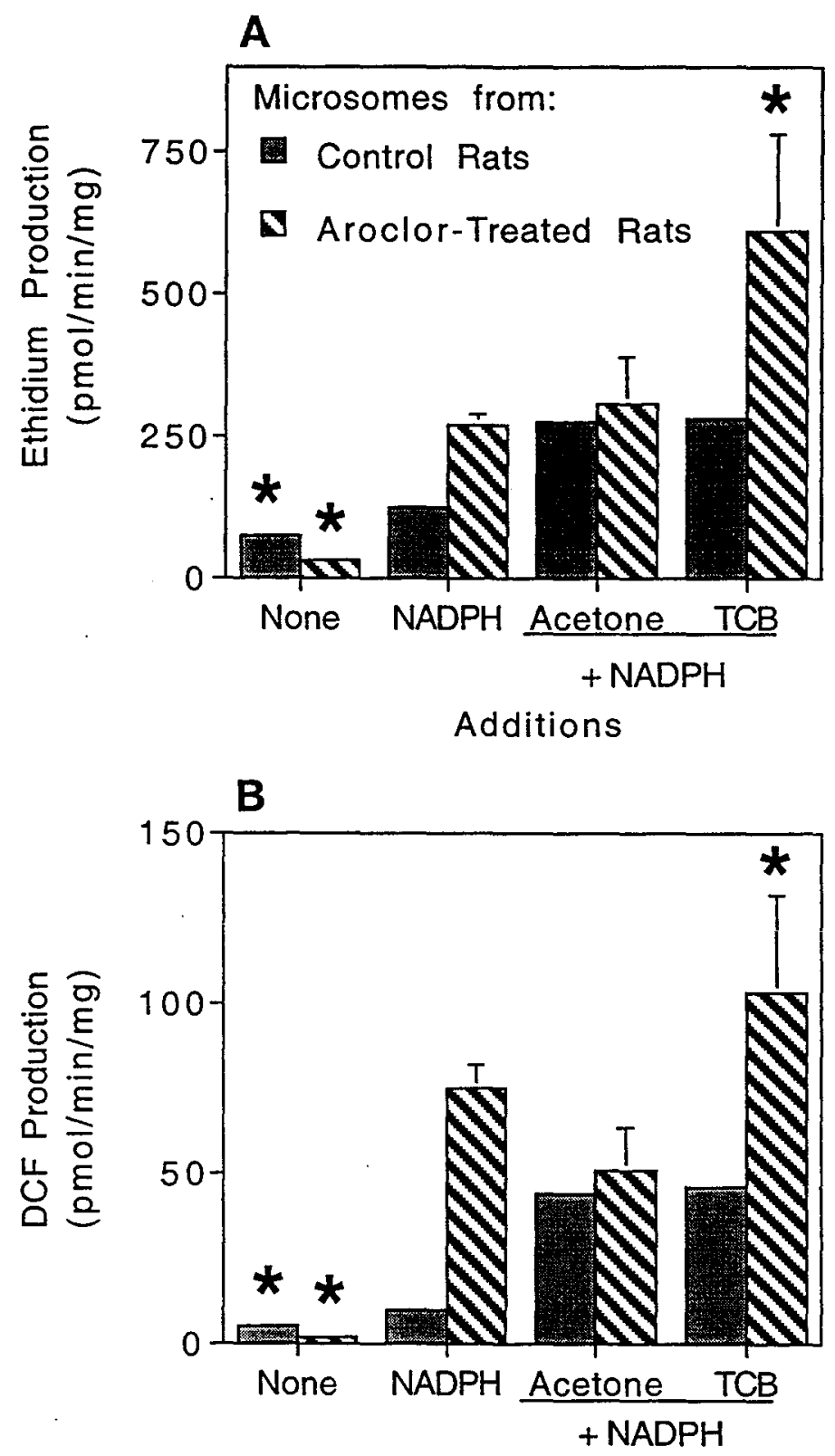

Additions

Figure 7. ROS production in liver microsomes from control and Aroclor treated rats. (A) $\mathrm{H}_{2} \mathrm{O}_{2}$ production as assessed by the oxidation of DCDFDA to DCF. (B) $\mathrm{O}_{2}^{-\bullet}$ production as assessed by the oxidation of $\mathrm{HE}$ to ethidium. Incubations were as described in Figure 6 using liver microsomes from untreated rats and rats treated with 62.5 to $500 \mathrm{mg} / \mathrm{kg}$ Aroclor 1254. Data are the means + SD from 3 pools of microsomes except that values from control rats were determined from 1 pool of microsomes. *Statistically different from acetone+NADPH ( $<<0.05$, Dunnett's). 

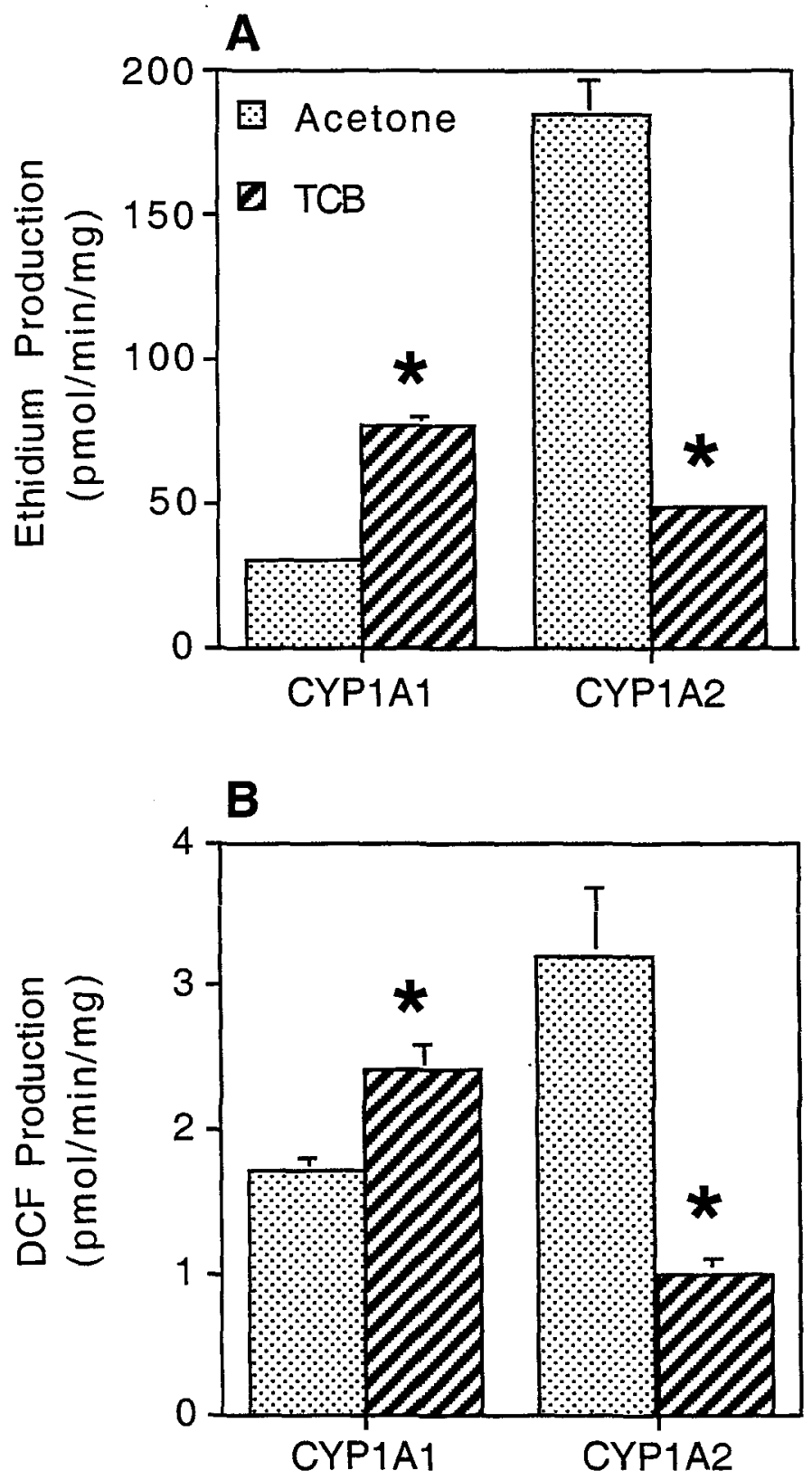

Figure 8. ROS production in microsomes from insect cells expressing human CYP1A1 and CYP1A2. (A) $\mathrm{H}_{2} \mathrm{O}_{2}$ production as assessed by the oxidation of DCDFDA to DCF. (B) $\mathrm{O}_{2}^{-\bullet}$ production as assessed by the oxidation of $\mathrm{HE}$ to ethidium. Incubations were as described in Figure 6. The P450 concentration and cytochrome $c$ reductase activity were the same in both the CYP1A1 and CYP1A2 microsomes, as indicated by the manufacturer's analyses. Data are the means $+\mathrm{SD}$ from three replicates. *Statistically different from acetone+NADPH ( $\mathrm{p}<0.05$, Dunnett's). 
$\mathrm{HE}$ oxidation, suggesting that radicals additional to $\mathrm{O}_{2}^{-\bullet}$ were contributing to the oxidation by rat liver microsomes (data not shown). Comparing microsomes from rats treated with a range of doses of Aroclor $1254(62.5-500 \mathrm{mg} / \mathrm{kg})$ showed that ROS production stimulated by TCB+NADPH was correlated with the CYP1A1 catalytic activity (EROD) of those microsomes $\left(\mathrm{r}^{2}=0.968, \mathrm{p}<0.001\right)$.

ROS production by human CYPIAs. Microsomes from baculovirus-infected insect cells expressing NADPH-CYP reductase and either human CYP1A1 or CYP1A2 were examined for their ability to produce ROS. The rates of DCDFDA and HE oxidation by microsomes containing either expressed CYP1A1 or CYP1A2, but with no additions, were low (data not shown). In the presence of NADPH alone, CYP1A2 microsomes oxidized DCDFDA and HE at substantial rates, 5-fold greater than the rates obtained with CYP1A1 microsomes under the same conditions (Figure 8). Addition of TCB+NADPH stimulated DCDFDA and HE oxidation by the CYP1A1 microsomes by 2 -fold, but decreased probe oxidation by the CYP1A2 microsomes (Figure 8). Rates of NADPH-CYP reductase activity were similar in microsomes containing CYP1A1 and CYP1A2, indicating that the differences in ROS production reflected differences in activity of the CYP1As.

\section{DISCUSSION}

3,3',4,4'-Tetrachlorobiphenyl is a competitive inhibitor of CYP1A (Gooch et al., 1989) and recently was found to inactivate CYP1A (White et al., 1997a). Suppression of hepatic CYP1A content by high doses of TCB was attributed to that inactivation (White et al., 1997a). We employed hepatic microsomes from a species (scup) that is highly susceptible to CYP1A inactivation as a model to investigate the mechanism. We determined that inactivation occurs through uncoupling, resulting in formation and attack of ROS within the CYP1A active site. TCB also stimulates release of ROS by liver microsomes of scup and rats induced for CYP1A. In rat, ROS release and EROD inactivation appeared to involve CYP1A1, not CYP1A2. The balance between inactivation and ROS release appears to differ between species, suggesting differences in CYP1A active site structure. TCB also stimulated ROS production by expressed human CYP1A1 but not CYP1A2. This is the first demonstration of a pHAH AhR agonist directly stimulating the release of ROS from CYP1A1.

CYP1A Inactivation: Several observations suggest that inactivation of scup CYP1A by TCB involves uncoupling. TCB binds tightly in the scup CYP1A active site, indicated by a low $\mathrm{K}_{\mathrm{m}}$ for TCB metabolism $\left(0.7 \mu \mathrm{M}\right.$ (White et al., 1997b)) and low $\mathrm{K}_{\mathrm{i}}$ for 
competitive inhibition of CYP1A $(<0.3 \mu \mathrm{M})$ (Gooch et al., 1989; M. E. Hahn, unpublished results). Yet, the rate of metabolism is exceedingly slow $(<1 \mathrm{pmol}$ TCB metabolized/min/nmol CYP1A). TCB stimulated microsomal NADPH oxidation, and the TCB-stimulated inactivation of CYP1A was both NADPH and oxygen dependent. We speculate that steric hindrance due to lateral chlorines lodges TCB in the substrate access channel, rendering it inaccessible to attack by the peroxy-ferryl complex of CYP and favoring release of reduced oxygen from the heme iron. Exogenous antioxidant enzymes, oxygen scavenging compounds, iron and iron chelators had no effect on CYP1A inactivation by TCB, indicating that the chemistry involved is initiated and constrained within the active site.

The identity of the chemical species causing CYP1A inactivation is unclear. Both $\mathrm{H}_{2} \mathrm{O}_{2}$ and $\mathrm{O}_{2}^{-}$were released by microsomes incubated with TCB+NADPH. SOD abolished $\mathrm{HE}$ oxidation, indicating that there was release of $\mathrm{O}_{2}^{-\bullet}$ following addition of one electron, as shown for other CYP (Kuthan et al., 1978). $\mathrm{H}_{2} \mathrm{O}_{2}$ could result either from dismutation of $\mathrm{O}_{2}^{-\bullet}$ or from direct formation after addition of a second electron. Notably, the reactivity of $\mathrm{H}_{2} \mathrm{O}_{2}$ or $\mathrm{O}_{2}^{-\bullet}$ is limited (Davies, 1987), with half-lives three orders of magnitude longer than that of $\mathrm{OH} \cdot(\mathrm{Yu}, 1994)$.

It is possible that $\mathrm{OH} \bullet$ is responsible for CYP1A inactivation. In the Fenton reaction, $\mathrm{H}_{2} \mathrm{O}_{2}$ reacts with $\mathrm{Fe}^{2+}$ to form $\mathrm{OH} \cdot$. With unmetabolized TCB lodged in the active site, heme iron may undergo cycles of oxidation and reduction to $\mathrm{Fe}^{2+}$. We suggest that pentacoordinate ferrous heme resulting from that reduction acts as a Fenton catalyst in the conversion of $\mathrm{H}_{2} \mathrm{O}_{2}$ to $\mathrm{OH} \bullet$ in the active site. The ability of heme iron to act as a Fenton catalyst has been questioned (Gutteridge, 1986). However, observations that $\mathrm{Cu}, \mathrm{Zn}-\mathrm{SOD}$ and Fe-SOD but not Mn-SOD are oxidatively inactivated suggests that Fenton chemistry might occur in an enzyme active site; manganese cannot act as a Fenton catalyst (Beyer and Fridovich, 1987). The auto-inactivation of lactoperoxidase was proposed to involve heme iron in the ferrous state acting as a Fenton catalyst (Jenzer et al., 1987). It has been suggested (Hodgson and Fridovich, 1975; Matheson and Travis, 1985) that "free" OH• (formed external to the active site) is not responsible for inactivation of SOD and myeloperoxidase, but rather that either a caged $\mathrm{OH} \bullet$ or a metal coordinated $\mathrm{OH} \bullet$ (in the active site) causes inactivation of these enzymes. In like fashion, oxidative inactivation of CYP1A could occur via production and attack of $\mathrm{OH} \bullet$ entirely within the active site.

Low concentrations of azide or $\mathrm{H}_{2} \mathrm{O}_{2}$ enhanced the TCB-dependent inactivation of CYP1A. Other catalase inhibitors, ATA or HA, did not affect the inactivation, indicating that 
the azide effect did not result from catalase inhibition. This implies that both azide and $\mathrm{H}_{2} \mathrm{O}_{2}$ can enter the active site even with TCB bound in the access channel, while slightly larger molecules (ATA or HA) can not. The release of $\mathrm{O}_{2} \bullet$ suggests latitude for passage of small molecules. As with $\mathrm{H}_{2} \mathrm{O}_{2}$, azide can interact with reduced iron to form highly reactive azidyl radical (Ortiz de Montellano et al., 1988); microsomes incubated with azide and NADPH can produce azidyl radicals (Reinke et al., 1994). Azide is thought to inactivate horseradish peroxidase via formation and addition of an azidyl radical to the heme (Ortiz de Montellano et al., 1988). CYP1A heme iron transiently reduced in the presence of TCB could catalyze conversion of both azide and $\mathrm{H}_{2} \mathrm{O}_{2}$ to radical species. The results with azide and $\mathrm{H}_{2} \mathrm{O}_{2}$ support the possibility that heme iron may be acting as a Fenton catalyst.

Microsomes incubated with TCB+NADPH consistently lost spectral P450 content, corresponding to the loss of CYP1A activity (EROD). However, the fate of that P450 appeared to vary. Cytochrome P420 was formed in some instances, indicating modification of the environment of an intact heme (Stern et al., 1973). However, the amount of P420 formed was always less than the amount of P450 lost. In most incubations heme was lost, but the extent of that loss also was highly variable. Lack of correspondence between P450 loss, heme loss and P420 formation implies that there may be multiple sites of attack during inactivation of CYP1A. Oxidative auto-inactivation in other enzymes can involve amino acid modification (Blech and Borders, 1983) and/or heme modification (Matheson and Travis, 1985; Beyer and Fridovich, 1987).

As far as we are aware, this is the first study to show that substrate-mediated inactivation of CYP1A can result from attack of ROS formed in situ. This differs from the inactivation of rat CYP1A1 by the alkylating agent 2-bromo-4'-nitroacetophenone (Parkinson et al., 1986). Alkylation destabilizes the oxy-cytochrome complex so that it decomposes before mono-oxygenation of a substrate can occur. Decomposition of the oxy-cytochrome complex results in ROS release, but unlike TCB-stimulated inactivation of CYP1A, alkylation does not result in oxidative modification of the protein or in a loss of spectrallydetectable P450.

Previously, inactivation of CYP2B was proposed to result from the production of $\mathrm{H}_{2} \mathrm{O}_{2}$ (Guengerich and Strickland, 1977; Karuzina and Archakov, 1994), but that inactivation, and hence the mechanism, differs from the inactivation of scup CYP1A. First, CYP2B inactivation occurred with excess NADPH alone and decreased when substrate was added (Guengerich and Strickland, 1977; Loosemore et al., 1980; Karuzina and Archakov, 1994). Inactivation of CYP1A required the presence of both NADPH and TCB. Second, 
CYP2B inactivation was attributed to $\mathrm{H}_{2} \mathrm{O}_{2}$ released from the enzyme. With CYP1A, oxygen is released as $\mathrm{O}_{2}^{-\bullet}$ and possibly as $\mathrm{H}_{2} \mathrm{O}_{2}$. Third, inactivation of CYP2B was exacerbated by catalase inhibitors, both azide and $\mathrm{HA}$, and was relieved by catalase and the radical scavengers ionol and mannitol (Guengerich and Strickland, 1977; Karuzina and Archakov, 1994). Similar attempts to modify ROS concentrations external to the active site had no influence on CYP1A inactivation. Fourth, inactivation of CYP2B was primarily due to effects on heme; spectral P450 content declined in parallel with heme, there was no P420 formation, and heme was covalently bound to the protein (Guengerich, 1978; Karuzina and Archakov, 1994). In contrast, heme loss and P420 formation both occurred, and were variable, during CYP1A inactivation by TCB.

CYP1As and Reactive Oxygen Production: The evidence here indicates that CYP1A is a source of ROS when microsomes are incubated with the AhR agonist TCB. Control scup liver microsomes formed ROS when incubated with NADPH, similar to results with control rat and human liver microsomes (Rashba-Step and Cederbaum, 1994; Reinke et al., 1994). The stimulation of ROS formation by TCB occurred only with liver microsomes from animals induced for CYP1A. Induced rat liver microsomes also formed ROS; these microsomes metabolized TCB at 100 times the rate seen in scup liver microsomes, yet that rate was only $50 \mathrm{pmol} / \mathrm{min} / \mathrm{mg}$, slow enough to suggest that TCB could uncouple rat CYP1A. As activity of scup CYP1A declined due to inactivation, ROS production declined in parallel, further supporting the role of CYP1A in the production of ROS.

A single CYP1A form has been identified in scup, and while it has properties of both CYP1A1 and CYP1A2, scup CYP1A is more like CYP1A1 (Morrison et al., 1995; Stegeman et al., 1996). Given the role of mammalian CYP1A1 in TCB metabolism (Ishida et al., 1991), we hypothesized that CYP1A1 might form ROS when bound with TCB. TCB stimulated ROS production only by rat liver microsomes having high levels of CYP1A. Both CYP1A1 and CYP1A2 were detectable by Western blot in the rat microsomes. However, rates of EROD (a preferred CYP1A1 activity) in native microsomes were correlated closely with the degree to which TCB stimulated ROS production by those microsomes. Moreover, EROD in rat liver microsomes was inactivated while MROD, a preferred CYP1A2 activity (Tsyrlov et al., 1993), was not inactivated by incubation with TCB+NADPH. The results with baculovirus-expressed human CYP1A1 and CYP1A2 also support the hypothesis that TCB-bound CYP1A1 is a source of ROS. TCB stimulated an increase in ROS production by expressed human CYP1A1, while it decreased ROS production by expressed human 
CYP1A2. Notably, when incubated with NADPH alone, CYP1A2 released much more ROS than did CYP1A1.

Others have suggested that rat CYP1A1 can form ROS when bound with pHAH. The pHAH-stimulated oxidation of bilirubin was proposed to result from its reaction with ROS produced during uncoupling of CYP1A1, although ROS were not directly measured (DeMatteis et al., 1991). Our findings that pHAH stimulate release of ROS by CYP1A1 may also help to explain observations of oxidative damage associated with induction of CYP1A1. Porcine endothelial cells treated with TCB showed increased CYP1A1, ROS production and lipid peroxidation (Toborek et al., 1995). In Hepa1c1c7 cells, TCDD treatment resulted in increased CYP1A1 activity and oxidative DNA damage (Park et al., 1996). Thus, CYP1A1 induced by $\mathrm{pHAH}$ may be a source of ROS, thereby contributing to oxidative damage in vivo.

In conclusion, the results here demonstrate that rat, human and scup CYP1As produce ROS in the presence of a slowly metabolized pHAH, apparently due to uncoupling. One result of ROS production is the inactivation of CYP1A via attack of ROS within the active site. We suggest that the attacking species is $\mathrm{OH}^{\bullet}$, formed via Fenton chemistry between $\mathrm{H}_{2} \mathrm{O}_{2}$ and the heme iron. The oxidation of CYP1A could target it for degradation (Davies, 1987), which could explain the decrease in CYP1A content seen in animals and cells in culture exposed to higher concentrations of pHAH (Sinclair et al., 1989; Stegeman et al., 1995; White et al., 1997a). Such an in vivo effect has not been described for oxidative inactivation of other CYP. The difference in susceptibility of scup and rat CYP1A to inactivation suggests that the active sites are conformationally different. Such differences may favor metabolism of TCB by rat CYP1A1 and retention of ROS by scup CYP1A. Modeling studies are underway to determine if TCB "fits" differently into CYP1A active sites from various species. ROS from CYP1A may modify proteins, lipids and nucleotides (Yu, 1994) as well as alter gene expression (Sen and Packer, 1996). The pHAH-stimulated formation and release of ROS from CYP1A may be a mechanism contributing to the toxicity of planar halogenated AhR agonists. 


\section{CHAPTER 4}

Structure-Activity Relationships in the Stimulation of Reactive Oxygen

Production and Cytochrome P450 1A Inactivation by Halogenated Aromatic Hydrocarbons 


\begin{abstract}
The relationship of chemical structure to the substrate-dependent inactivation of cytochrome P4501A (CYP1A) was investigated in the marine teleost scup (Stenotomus chrysops). Previously, we demonstrated that the binding of 3,3'4,4'-tetrachlorobiphenyl (IUPAC\# 77) to scup CYP1A elicited oxidative inactivation of the enzyme and also resulted in release of reactive oxygen species (ROS) (Chapter 3). Here, benzo[a]pyrene (BP), two ortho substituted chlorobiphenyls (CB), 2,2',5,5'-tetrachlorobiphenyl (IUPAC\# 52) and 2,3,3',4,4'-pentachlorobiphenyl (IUPAC\# 105) and two non-ortho substituted CBs, 3,3',4,4',5' pentachlorobiphenyl (IUPAC\# 126) and 3,3',4,4',5,5'-hexachlorobiphenyl (IUPAC\# 169) were examined for the ability to stimulate ROS generation and to inactivate CYP1A in scup liver microsomes containing high levels of CYP1A. Both CB 126 and 169 stimulated release of ROS from liver microsomes in the presence of $\mathrm{NADPH}$, while BP and the ortho-substituted CBs, 52 and 105, did not. Microsomal NADPH oxidation rates increased upon addition of BP, or CBs 105, 126 and 169. Microsomal ethoxyresorufin Odeethylation (EROD) was inhibited by BP and CBs 105,126 or $169 . \mathrm{K}_{\mathrm{i}}$ values for CBs 126 and 169 were similar (0.16 and $0.20 \mu \mathrm{M}$, respectively); however, that for CB 105 was greater $(0.60 \mu \mathrm{M})$. In addition to inhibition, there was a progressive loss of EROD in the presence of NADPH and CBs 105, 126 or 169, attributed to inactivation of CYP1A. Following a 30 minute incubation, the $\mathrm{K}_{\mathrm{mInactivation}}$ values were similar for $\mathrm{CBs} 77,126$ and 169 , and that for CB 105 was greater $(0.05,0.14,0.08$, and $0.37 \mu \mathrm{M}$, respectively). Similarly, the rate of inactivation stimulated by $\mathrm{CB} 105+\mathrm{NADPH}$ was $70 \%$ less than the rates seen with CBs 77,126 or 169 . CB 52 neither inhibited nor inactivated EROD. Inactivation of CYP1A stimulated by CBs 126 and 169 was accompanied by loss of spectral $\mathrm{P} 450$, enhanced by the addition of azide or $\mathrm{H}_{2} \mathrm{O}_{2}$ and decreased by addition of cytochrome $c$. Thus, CB 126 and 169 appear to oxidatively inactivate CYP1A, as has been shown for CB 77. The inactivation of CYP1A and the release of ROS were stimulated only by planar CBs that are aryl hydrocarbon receptor (AhR) agonists and possibly CYP1A substrates. The release of ROS resulting from planar CB binding to CYP1A represents a possible mechanism by which these AhR agonists exert their toxicity.
\end{abstract}




\section{INTRODUCTION}

Polychlorinated biphenyls are ubiquitous in the global environment, and exposure can result in hepatocellular carcinoma, immunotoxicity, wasting syndrome and reproductive, endocrine and developmental toxicity (as reviewed in (Safe, 1994)). Congeners that lack substitution at ortho sites (e.g. 3,3',4,4'-tetrachlorobiphenyl, IUPAC\# 77) can achieve a planar conformation similar to that of 2,3,7,8-tetrachlorodibenzo- $p$ dioxin (TCDD) (Safe et al., 1985). By comparing the TCDD equivalency factors (TEF) of chlorobiphenyl (CB) congeners, the coplanar congeners, including $C B 77,3,3^{\prime}, 4,4^{\prime}, 5$,pentachlorobiphenyl (IUPAC\# 126) and 3,3',4,4',5,5'-hexachlorobiphenyl (IUPAC\# 169), are most potent in eliciting toxic effects in fish (Janz and Metcalfe, 1991; Walker and Peterson, 1991; Newsted et al., 1995) and mammals (Safe, 1990; Tillitt et al., 1991). Even though other congeners are found more frequently or at greater concentrations in environmental samples, the coplanar CB congeners 77, 126 and 169 are most likely to contribute to adverse biological effects attributable to $\mathrm{pHAH}$ in environmental samples (McFarland and Clark, 1989).

Despite intensive study confirming the aryl hydrocarbon receptor-dependence of pHAH toxicity (Poland and Glover, 1980; Fernandez-Salguero et al., 1996), the mechanism(s) of toxicity remains unclear. Bioactivation has not been found to be a significant avenue to toxicity of pHAH. Metabolism of pHAH is slow, and the metabolites are not considered reactive (Yoshimura et al., 1987; Koga et al., 1990; Safe, 1992). Potential mechanisms of pHAH-mediated toxicity may include altered regulation of genes involved in growth and differentiation (Choi et al., 1991; Gaido et al., 1992; Hoffer et al., 1996; Wang et al., 1997), altered arachidonic acid metabolism (Rifkind et al., 1990; Schlezinger et al., 1998) and altered $\mathrm{Ca}^{2+}$ homeostasis (McConkey et al., 1988). In addition, stimulation of oxygen activation may contribute significantly to pHAH toxicity, considering that reactive oxygen species (ROS) can attack any member of the cellular machinery, including proteins (Davies, 1987; Stadtman and Berlett, 1991), lipids (Girotti, 1985) and nucleotides (Breen and Murphy, 1995).

A growing number of studies support the conclusion that TCDD and $\mathrm{CB}$ congeners induce oxidative stress and that this is dependent upon the aryl hydrocarbon receptor (AhR) (Faux et al., 1992; Alsharif et al., 1994; Park et al., 1996). Although the mechanism of ROS generation by AhR agonists also is not clear, evidence supports the hypothesis that induction of cytochrome P4501A (CYP1A) might be involved in ROS generation. CYP1A induction has been correlated with oxidative damage following $\mathrm{pHAH}$ exposure (Toborek 
et al., 1995; Park et al., 1996). Hepatic microsomal and mitochondrial fractions but not cytosolic fractions from TCDD-treated rats can stimulate oxidative DNA damage (Wahba et al., 1989). CB 77 stimulates the production of ROS by teleost and mammalian CYP1As (Chapter 3), and this supports the earlier suggestion that bilirubin oxidation is catalyzed by ROS produced during uncoupling of rat CYP1A1 by CB 77 (DeMatteis et al., 1991). Under the same conditions, CB 126 stimulates bilirubin oxidation as well (DeMatteis et al., 1991). Considering also that CB 126 is even more refractory to metabolism than CB 77 (Yoshimura et al., 1987; Koga et al., 1990), ROS production via uncoupling of CYP1A may be a common effect of pHAH.

Determining the structure-activity relationships for uncoupling should indicate whether CYP1A-generated ROS might be involved in AhR agonist toxicity. Our approach to determine uncoupling was to examine oxidative inactivation of CYP1A. We have demonstrated that CYP1A is oxidatively inactivated when CB 77 is present in the active site in the marine fish model scup (Stenotomus chrysops) and have hypothesized that inactivation occurs by the attack of $\mathrm{OH} \bullet$, leading to denaturation of the protein (Chapter 3). Evidence from earlier studies suggests that like uncoupling, oxidative inactivation of CYP1A by planar CB congeners including CBs 126 and 169 may be a general phenomenon (Rodman et al., 1989; Newsted et al., 1995; Lorenzen et al., 1997).

In this paper we examined the hypothesis that, like $\mathrm{CB} 77$, planar $\mathrm{CB}$ congeners in general stimulate the production of ROS through uncoupling of the CYP1A catalytic cycle and oxidative inactivation of the enzyme. We used scup CYP1A as our model because it has been shown to be extremely sensitive to inactivation by $\mathrm{CB} 77$ in vitro and to suppression in vivo (White et al., 1997a; Chapter 3). We investigated the effects of a rapidly metabolized substrate, benzo[a]pyrene (BP), and both ortho and non-ortho substituted CB congeners on scup liver CYP1A. ROS release and inactivation of CYP1A appear to be dependent upon chemical structure; only substrates of CYP1A that are slowly metabolized stimulated inactivation. While the physiological consequences of a loss of CYP1A are unknown, release of ROS may represent a mechanism of pHAH toxicity.

\section{MATERIALS AND METHODS}

Chemicals: Benzo[a]pyrene was purchased from Aldrich (Milwaukee, WI). 2',7'Dichlorodihydrofluorescein diacetate, 7-ethoxyresorufin, and dihydroethidium were purchased from Molecular Probes (Eugene, OR). 2,2',5,5'-Tetrachlorobiphenyl (IUPAC\# 52) was purchased from Pathfinder (St. Louis, MO). 3,3',4,4'-Tetrachlorobiphenyl 
(IUPAC\# 77), 2,3,3',4,4'-pentachlorobiphenyl (IUPAC\# 105), 3,3',4,4',5pentachlorobiphenyl (IUPAC\# 126) and 3,3',4,4',5,5'-hexachlorobiphenyl (IUPAC\# 169) were purchased from Ultra Scientific (North Kingstown, RI). All other reagents were purchased from Sigma (St. Louis, MO).

Animals: Scup (Stenotomus chrysops ) were caught by trapping in Vineyard Sound, MA in August of 1996. Fish were held in flow-through seawater tanks at $14^{\circ} \mathrm{C}$ and maintained on a diet of Purina Trout Chow. Experimental animals ranged in size from 182 to $305 \mathrm{~g}$. Control fish received no treatment. To induce CYP1A, fish were injected intra-peritoneally with a solution of benzo[a]pyrene $(10 \mathrm{mg} / \mathrm{kg})$ in corn oil. Three days following injection the fish were killed by severing the spinal cord. The livers were harvested, and microsomes were made immediately. Four microsome pools were prepared with livers from 3 fish per pool.

Microsome preparation: Microsomes were prepared from livers by differential centrifugation (Stegeman et al., 1979). Following the initial sedimentation, microsomes were washed by resuspending in $0.15 \mathrm{M} \mathrm{KCl}$ and sedimenting again. Pellets were resuspended in buffer (50 mM TRIS, $\mathrm{pH} 7.4,1 \mathrm{mM}$ dithiothrietol, $1 \mathrm{mM}$ EDTA, .20\% glycerol) and frozen in liquid $\mathrm{N}_{2}$ until use. Protein content was determined using the bicinchoninic acid method (Smith et al., 1985), with bovine serum albumin standards.

Western blotting for CYP1A quantification: Immunoblotting procedures were modified from those previously described (Kloepper-Sams et al., 1987). Microsomal proteins $(10 \mu \mathrm{g} / \mathrm{lane})$ were resolved on $8-16 \%$ SDS-PAGE gels and electrophoretically transferred to $0.05 \mu \mathrm{m}$ nitrocellulose membrane. The primary antibody was the mouse monoclonal antibody 1-12-3 (Park et al., 1986), raised against scup P450E (CYP1A; (Morrison et al., 1995)). The secondary antibody was alkaline phosphatase linked goat anti-mouse IgG (Biorad, Hercules, CA). The immunoreactive bands were visualized using nitro blue tetrazolium and 5-bromo-4-chloro-3-indoyl-phosphate and quantified by video image analysis (NIH Image 1.60b5) by comparison to scup standards of known concentration.

In vitro studies of CYP1A inactivation: The procedure was as described in Chapter 3 except for the following additions: $\mathrm{BP}(1.5 \mu \mathrm{M}), \mathrm{CB} 52(1.7 \mu \mathrm{M}), \mathrm{CB} 105(0.015-31$ $\mu \mathrm{M}), \mathrm{CB} 126(0.015-15 \mu \mathrm{M})$, and $\mathrm{CB} 169(0.014-14 \mu \mathrm{M})$. EROD loss resulting from inhibition was calculated by comparing EROD at 10 minutes in control and $\mathrm{CB}$ reaction mixtures. EROD loss resulting from inactivation was calculated by comparing EROD at 30 minutes in $\mathrm{CB}$ and $\mathrm{CB}+\mathrm{NADPH}$ reaction mixtures. Curve fitting was performed using 
Sigma Plot for Macintosh (SSPS Inc., Chicago, II). For inhibition, the IC50 values were determined directly from the plot of $\mathrm{CB}$ concentration and activity loss. The methods of (Cha, 1975) and (Cheng and Prusoff, 1973) were used to convert the IC50 to a $\mathrm{K}_{\mathrm{i}}$ with $0.22 \mu \mathrm{M}$ as the $\mathrm{K}_{\mathrm{m}}$ for 7-ethoxyresorufin metabolism (M. E. Hahn, unpublished results).

NADPH oxidation: NADPH oxidation was determined by monitoring the decrease in absorbance at $340 \mathrm{~nm}$ in reaction mixtures prepared as in the inactivation assay using 0.4 $\mathrm{mg}$ protein/ml and $15 \mu \mathrm{M} \mathrm{CB}$ (Imai, 1979).

Spectral P450 assay: Loss of spectral P450 was determined as described in Chapter 3 except for the following additions: CB 126 or $169(13-15 \mu \mathrm{M})$

Peroxide and superoxide formation: $\mathrm{H}_{2} \mathrm{O}_{2}$ and $\mathrm{O}_{2}^{-\bullet}$ formation were determined as described in Chapter 3 except for the following additions: $\mathrm{BP}$ and CBs 52, 105, 126, or 169 (1.5 nmol in acetone).

Statistics Statistics were calculated using Microsoft Excel (Microsoft, Inc., Redmond, WA) and SuperAnova for Macintosh (Abacus Concepts, Inc., Berkeley, CA). A two-tailed Student's t-test was used to analyze EROD and total P450 inactivation data ( $\mathrm{CB}$ vs. $\mathrm{CB}+\mathrm{NADPH}$ ). A one-factor ANOVA was used to analyze the inactivation experiments including additions and the ROS experiments. The Tukey-Kramer multiplecomparisons test was used in analyses of inactivation experiments. The Dunnett's test was used for the ROS experiments with the acetone+NADPH reaction mixture as the control.

\section{RESULTS}

ROS production stimulated by CYP1A substrates: $\mathrm{BP}$ and the $\mathrm{CB}$ congeners were tested for the ability to stimulate ROS production in scup liver microsomes. Production of ROS during incubation of liver microsomes from untreated scup with NADPH was unaffected by the addition of any $\mathrm{CB}$ congener (data not shown). As with $\mathrm{CB} 77$, incubation of liver microsomes from BP-treated scup with NADPH and the non-ortho $\mathrm{CBs}$ 126 and 169 significantly increased DCDFDA and HE oxidation (Figure 1). DCDFDA is oxidized to $\mathrm{DCF}$ by $\mathrm{H}_{2} \mathrm{O}_{2}$, and $\mathrm{HE}$ is oxidized to ethidium by $\mathrm{O}_{2}^{-\bullet}$. $\mathrm{BP}$ and the ortho $\mathrm{CBs}$ 52 and 105 , did not alter ROS production significantly from that obtained with acetone+NADPH.

Inactivation of scup liver CYP1A: CB- and NADPH- dependent inactivation of CYP1A was studied in liver microsomes from BP-treated scup using the in vitro assay employed previously (White et al., 1997a). In control reaction mixtures containing acetone $\pm N A D P H, E R O D$ remained constant over 30 minutes (data not shown). When 
microsomes were incubated with $\mathrm{CB}$ alone, EROD was decreased $20 \pm 10 \%$ with $\mathrm{CB} 105$, $70 \pm 6 \%$ with $\mathrm{CB} 126$ and $62 \pm 10 \%$ with $\mathrm{CB} 169$ as compared to control reaction mixtures (Figure 2), but this decrease remained constant through time (data not shown). At 30 minutes, reaction mixtures containing $\mathrm{CB} 105+\mathrm{NADPH}$ showed a $32 \pm 7 \%$ loss of EROD, containing $\mathrm{CB} 126+\mathrm{NADPH}$ showed a $70 \pm 7 \%$ loss of EROD and containing $\mathrm{CB}$ $169+\mathrm{NADPH}$ showed a $67 \pm 11 \%$ loss of EROD compared to those reaction mixtures containing $\mathrm{CB}$ alone (Figure 2). Confirming earlier results, reaction mixtures containing CB 77 showed a $50 \pm 6 \%$ decrease in EROD due to inhibition and $62 \pm 6 \%$ decrease in EROD due to inactivation when NADPH was added (Figure 2). The capacity to catalyze EROD was not altered by incubation of microsomes with either CB 52 alone or $\mathrm{CB}$ $52+\mathrm{NADPH}$ (Figure 2). When microsomes were incubated with BP alone, EROD decreased $93 \pm 6 \%$. due to inhibition. However, in contrast to results with the $C B$ congeners, EROD in reaction mixtures containing BP+NADPH increased 7-fold above that in reaction mixtures with BP alone, by 30 minutes (Figure 2).

To determine if loss of $\mathrm{P} 450$ protein co-occurred with loss of CYP1A catalytic activity, spectral P450 content was assessed in the reaction mixtures. Similar to EROD, no significant loss of total P450 occurred with either CB 126, CB 169 or NADPH alone (Figure 3a). Incubation of hepatic microsomes for 30 minutes with $C B 126$ or 169 $+\mathrm{NADPH}$ resulted in $52 \pm 8 \%$ and $47 \pm 9 \%$ losses of P450, respectively (Figure $3 \mathrm{~b}$ ). The loss of P450 was accompanied by a variable appearance of cytochrome P420, with amounts of $\mathrm{P} 420$ formed ranging from $0.14-0.20 \mathrm{nmol} / \mathrm{mg}$ for $\mathrm{CB} 126$, and $0.11-0.19$ $\mathrm{nmol} / \mathrm{mg}$ for $\mathrm{CB} 169$. In comparison, incubation of microsomes for 30 minutes with $\mathrm{CB}$ 77 and NADPH resulted in a $38 \pm 9 \%$ loss of P450 and formation of $0.15-0.26 \mathrm{nmol}$ P420/mg (Figure 3b).

Both inhibition and inactivation were CB concentration dependent (Figure 4). Variation of the 7-ethoxyresorufin concentration had little affect on the inhibition of EROD by the non-ortho $\mathrm{CB}$ congeners (data not shown), therefore the Cha calculation for the conversion of the IC50 to a $\mathrm{K}_{\mathrm{i}}$ may provide the closest approximation of the true $\mathrm{K}_{\mathrm{i}}$. CB 126 and $\mathrm{CB} 169$ had $\mathrm{K}_{\mathrm{i}}$ values similar to that for $\mathrm{CB} 77$ while that for $\mathrm{CB} 105$ was 3-fold greater (Table $\mathrm{I}$ ). The $\mathrm{K}_{\mathrm{m} \text { Inactivation values for } \mathrm{CBs}} 126$ and 169 were 2 to 3 -fold less than that for CB 105 (Table I). CBs 126 and 169 had greater efficacy in stimulating inactivation than did CB 105 (Table I). Using EROD and spectral P450 data 
Figure 1. Effect of $\mathrm{CB}$ congeners and BP on ROS production in scup liver microsomes. A) $\mathrm{O}_{2}^{-\bullet}$ production as assessed by oxidation of $\mathrm{HE}$ to ethidium. B) $\mathrm{H}_{2} \mathrm{O}_{2}$ production as assessed by oxidation of DCDFDA to DCF. In a 48-well plate, approximately $0.1 \mathrm{mg}$ of microsomal protein $(398 \pm 42 \mathrm{pmol}$ CYP1A/mg) was diluted to $160 \mu \mathrm{l}$ with HBSS containing $5 \mu \mathrm{M}$ DCDFDA and $7.5 \mu \mathrm{M} \mathrm{HE}$ (final concentrations). Following a 15 minute incubation at $30^{\circ} \mathrm{C}, 1.3-1.5 \mathrm{nmol} \mathrm{BP}$ or CBs $52,105,126$ or 169 in acetone or $5 \mu \mathrm{l}$ acetone was added. Reactions were initiated with NADPH $(1.7 \mathrm{mM})$. The rates of DCF and ethidium production were monitored fluorometrically over 5 minutes. Calculations were made using DCF and ethidium bromide as standards. Incubation of microsomes without NADPH resulted in very low levels of DCF or ethidium production. Data for $\mathrm{CB}$ 77 are from Chapter 3. Data are means \pm SD from at least 3 pools of microsomes. *Statistically different from acetone+NADPH ( $\mathrm{p}<0.01$, Dunnett's). 

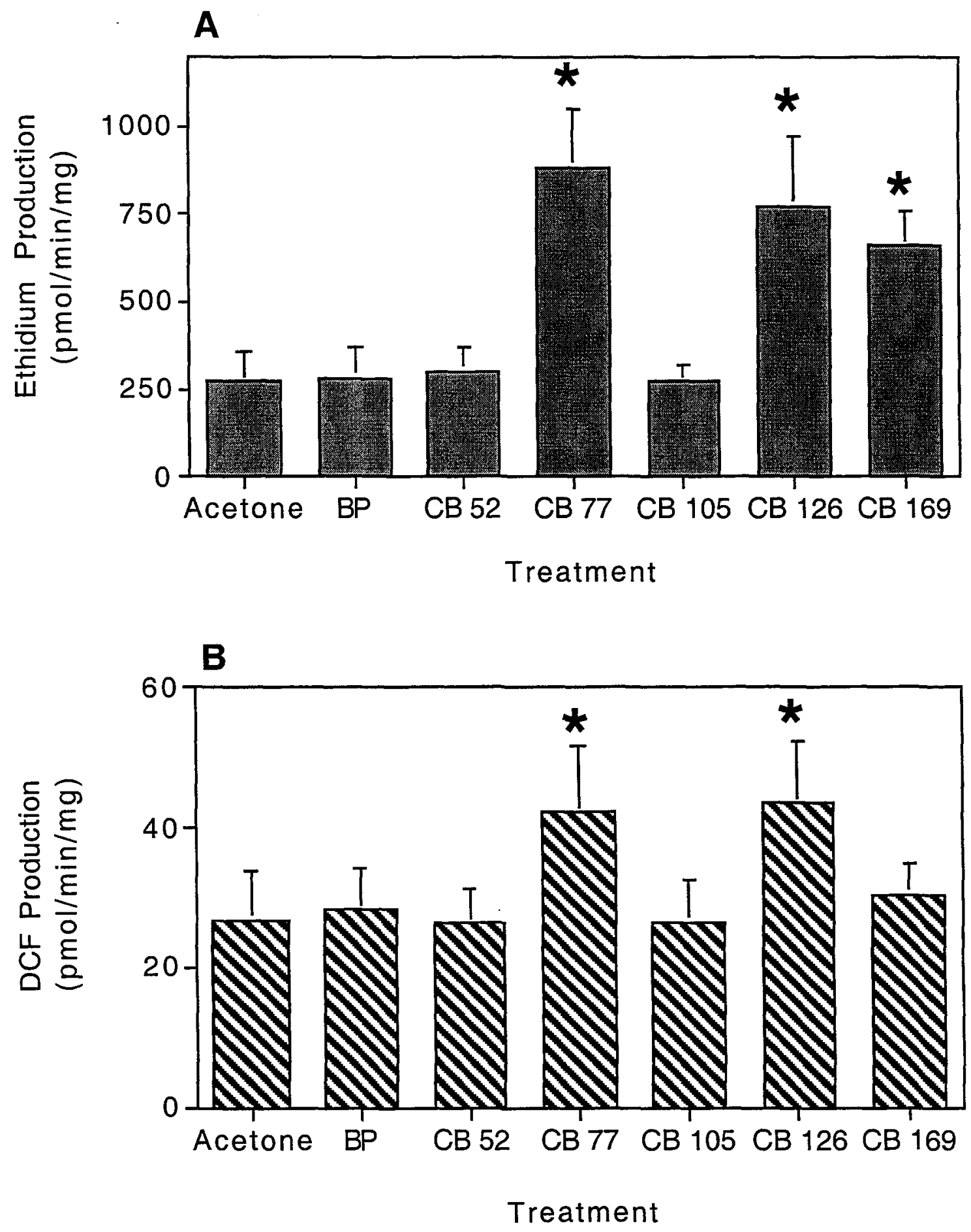


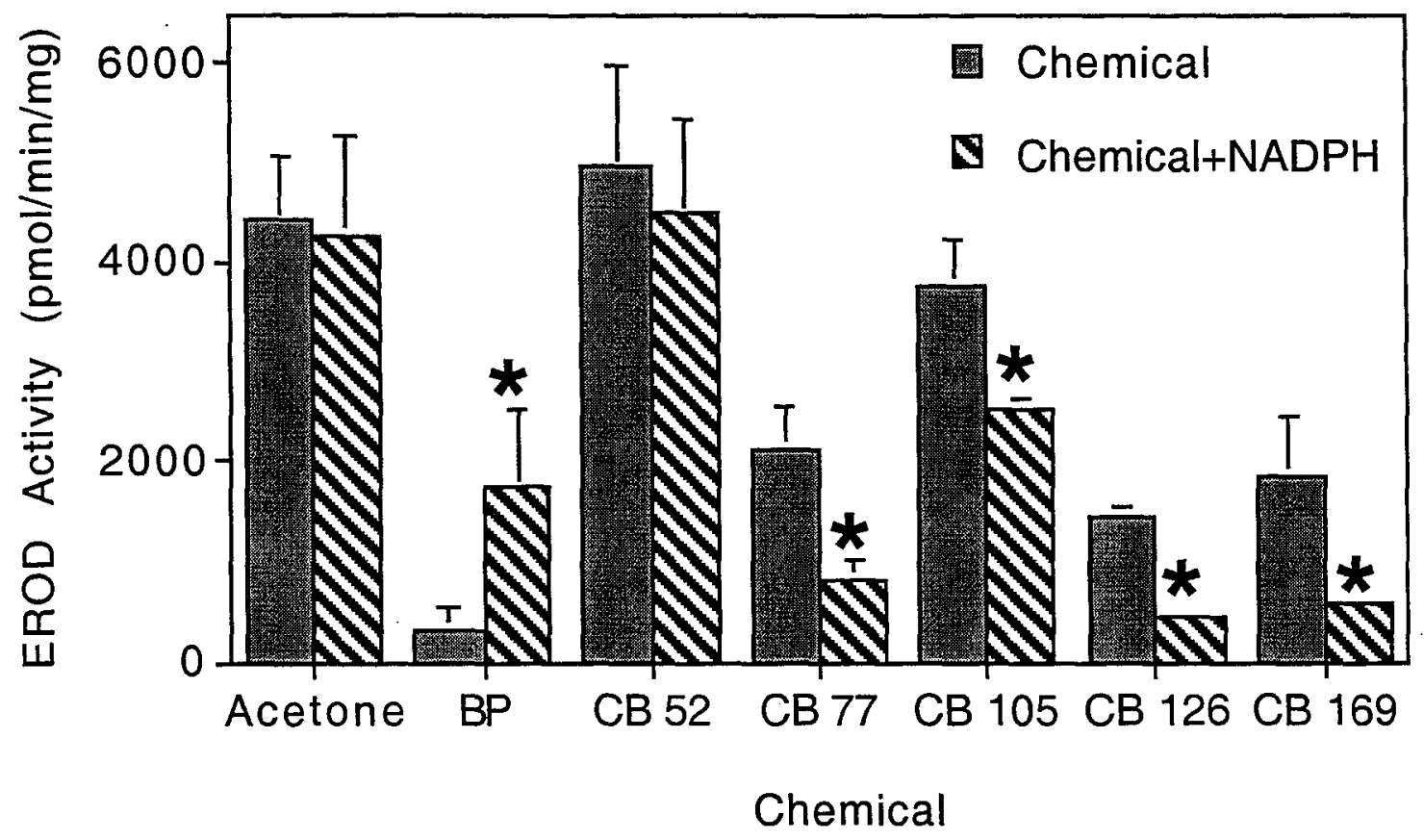

Figure 2. Inhibition and inactivation of scup liver CYP1A stimulated by BP and $\mathrm{CBs} 52$, $77,105,126$ and 169. Microsomes (0.1 mg protein $/ \mathrm{ml}$ with $398 \pm 42 \mathrm{pmol} \mathrm{CYP} 1 \mathrm{~A} / \mathrm{mg}$ ) were incubated in buffer ( $50 \mathrm{mM}$ TRIS, $0.1 \mathrm{mM}$ EDTA, $\mathrm{pH}$ 7.6) at a final volume of $1 \mathrm{ml}$ in glass test tubes at $30^{\circ} \mathrm{C}$. The following chemicals were added in various combinations at the final concentrations indicated: acetone $(5 \mu \mathrm{l})$, NADPH $(1.8 \mathrm{mM}), \mathrm{CB} 52,77,105,126$ or $169(1.3-1.7 \mu \mathrm{M})$. Aliquots were removed from reaction mixtures at times zero, 10, 20 and 30 minutes and assayed fluorometrically for EROD over 5 minutes. Data shown here are from the 30 minute time point. EROD was constant in microsomes incubated with acetone or NADPH. Following an initial loss of EROD upon addition of CBs 77, 105, 126 or 169, EROD remained constant. The rate of loss of EROD during incubation with NADPH and CBs 77, 105, 126 or 169 was constant over time for each congener. Data are means \pm SD from 3-4 pools of microsomes. *-Significantly different from $\mathrm{CB}(\mathrm{p}<0.005$, Student's t-test). 
independently, rates of inactivation were calculated (Table I). Rates of inactivation were determined from the decline in EROD by assuming that loss of EROD is equated with loss of CYP1A. Both methods rendered similar rates of inactivation. CBs 77, 126 and 169 stimulated loss of $\mathrm{P} 450$ at a similar rate. In comparison, the rate of inactivation with $\mathrm{CB}$ $105+\mathrm{NADPH}$ was at least $70 \%$ less than that seen with the coplanar congeners.

Previously, azide and $\mathrm{H}_{2} \mathrm{O}_{2}$ were shown to enhance $\mathrm{CB} 77$ stimulated inactivation of CYP1A (Chapter 3). Azide caused a 2-fold increase in the rate of inactivation in the presence of $\mathrm{CB} 126+\mathrm{NADPH}$ or $\mathrm{CB} 169+\mathrm{NADPH}$ at 10 minutes (Figure 5). Incubation of azide with $\mathrm{CB} 126+\mathrm{NADPH}$ resulted in statistically significant enhancement of inactivation at both 10 and 30 minutes. Similarly, $\mathrm{H}_{2} \mathrm{O}_{2}$ increased the loss activity due to inactivation stimulated by CBs 126 and 169 by 3-fold at 10 minutes (Figure 6). Incubation of $\mathrm{H}_{2} \mathrm{O}_{2}$ with $\mathrm{CB} 126+\mathrm{NADPH}$ resulted in statistically significant enhancement of inactivation at 10 and 30 minutes and with $\mathrm{CB} 169+\mathrm{NADPH}$ resulted in statistically significant enhancement of inactivation at 10 minutes.

Electron transfer was found to be an essential component in the inactivation of CYP1A mediated by $\mathrm{CB} 77$, therefore $\mathrm{BP}$ and the $\mathrm{CB}$ congeners were tested for the ability to stimulate NADPH oxidation. BP stimulated NADPH oxidation to the greatest extent, with CBs 105, 126 and 169 also causing significant increases (Table II). CB 52 did not significantly stimulate NADPH oxidation (Table II ).

Cytochrome $c$ inhibits CYP1A by competing for electrons from cytochrome P450 reductase (Estabrook et al., 1996), thereby reducing inactivation by preventing the reduction of molecular oxygen bound to the heme. When cytochrome $c(10 \mu \mathrm{M})$ was added to reaction mixtures containing CBs 126 or 169 and NADPH, the rate of inactivation decreased (Figure 7). The rate of loss of EROD was $7 \pm 4 \mathrm{pmol} / \mathrm{min} / \mathrm{mg}$ in the presence of $\mathrm{CB} 126+\mathrm{NADPH}+\mathrm{cyt}$ tochrome $c$ as compared to $12 \mathrm{pmol} / \mathrm{min} / \mathrm{mg}$ the absence of cytochrome $c$. The rate of loss of EROD was $4 \pm 2 \mathrm{pmol} / \mathrm{min} / \mathrm{mg}$ in the presence of CB $169+\mathrm{NADPH}+\mathrm{cytochrome} c$ as compared to $16 \mathrm{pmol} / \mathrm{min} / \mathrm{mg}$ the absence of cytochrome $c$. Electron transfer appears to be an essential component in the inactivation of CYP1A by CBs 126 and 169.

\section{DISCUSSION}

Microsomal CYP1A in the fish Stenotomus chrysops has been shown to be extremely susceptible to oxidative inactivation when CB 77 binds and uncouples the catalytic cycle of the enzyme (White et al., 1997a; Chapter 3). In addition, ROS are 
Figure 3. Loss of spectral P450 in the presence of CBs and NADPH. A) P450 spectra of scup liver microsomes following incubation with acetone, NADPH, CB 126 or CB $126+\mathrm{NADPH}$. B) Total spectral P450 content ( $\mathrm{nmol} / \mathrm{mg}$ ) of scup liver microsomes. To determine if there was a loss of $\mathrm{P} 450$, microsomes $(0.4 \mathrm{mg}$ protein $/ \mathrm{ml})$ were incubated in buffer (50 mM TRIS, $0.1 \mathrm{mM}$ EDTA, $\mathrm{pH} 7.6)$ at $30^{\circ} \mathrm{C}$. The following chemicals were added in various combinations at the final concentrations indicated: acetone $(0.5 \%), \mathrm{CB}$ 126 or $169(13-15 \mu \mathrm{M})$, and NADPH $(0.7 \mathrm{mM})$. Following a 30 minute incubation, total P450 concentration was determined by bubbling reaction mixtures with $\mathrm{CO}$ and obtaining the dithionite-difference spectra (Bonkovsky et al., 1984). Data are means \pm SD from 3 pools of microsomes. *-Significantly different from CB ( $\mathrm{p}<0.05$, Student's t-test). ** Significantly different from $C B(p<0.001$, Student's t-test). 

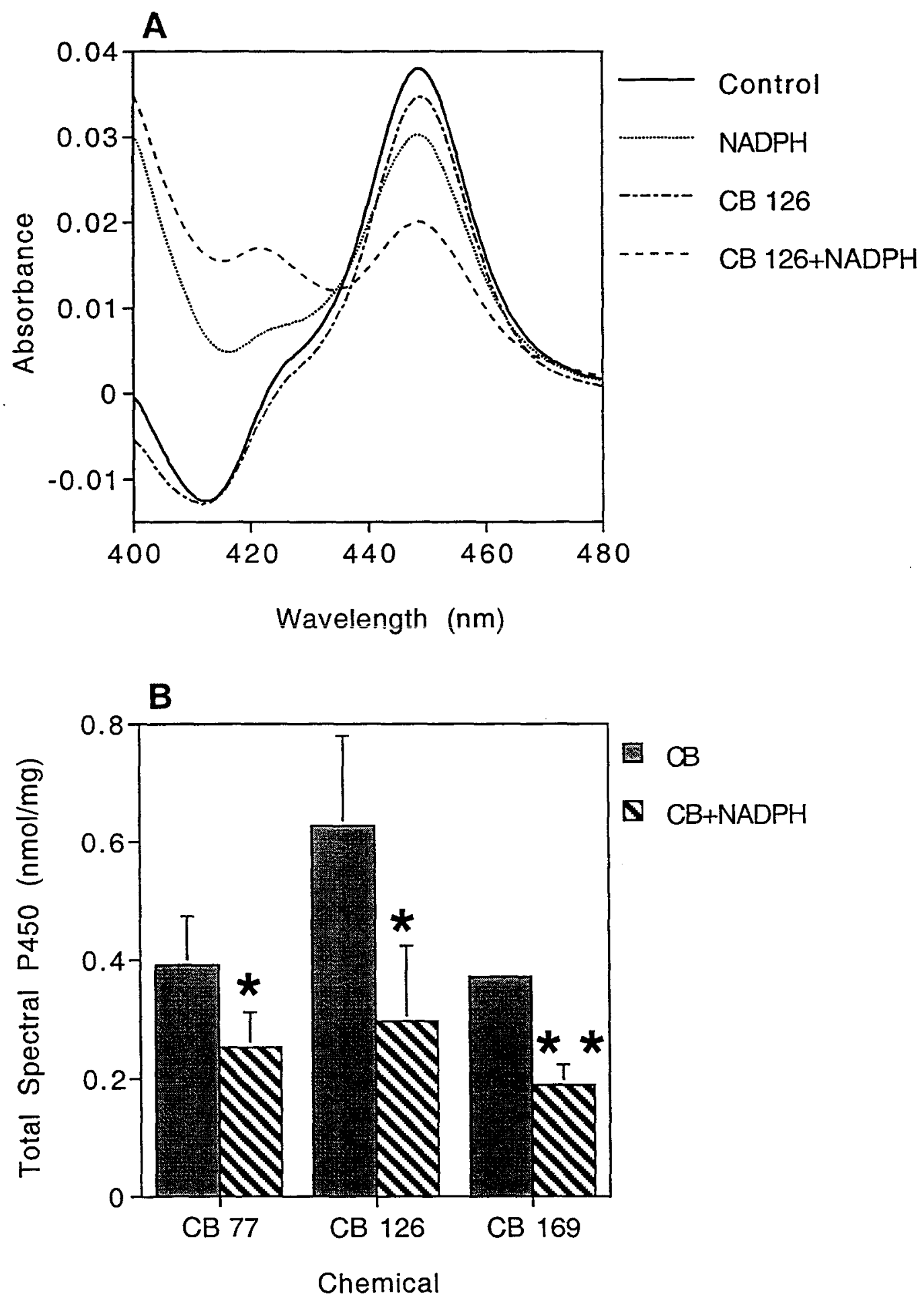
Figure 4. Concentration dependent inhibition and inactivation of CYP1A stimulated by $\mathrm{CBs} 105$ (A), 126 (B) and 169 (C). Incubation conditions and assay technique were as described in Figure 2, except that a range of $\mathrm{CB}$ concentrations was used (0.013-30 $\mu \mathrm{M})$. Open circles - EROD loss due to inhibition was calculated by comparing EROD at 10 minutes in control and $\mathrm{CB}$ reaction mixtures. Closed squares - EROD loss due to inactivation was calculated by comparing EROD at 30 minutes in $\mathrm{CB}$ and $\mathrm{CB}+\mathrm{NADPH}$ reaction mixtures. Results from 2-3 pools of microsomes were used in the non-linear regression analysis. 

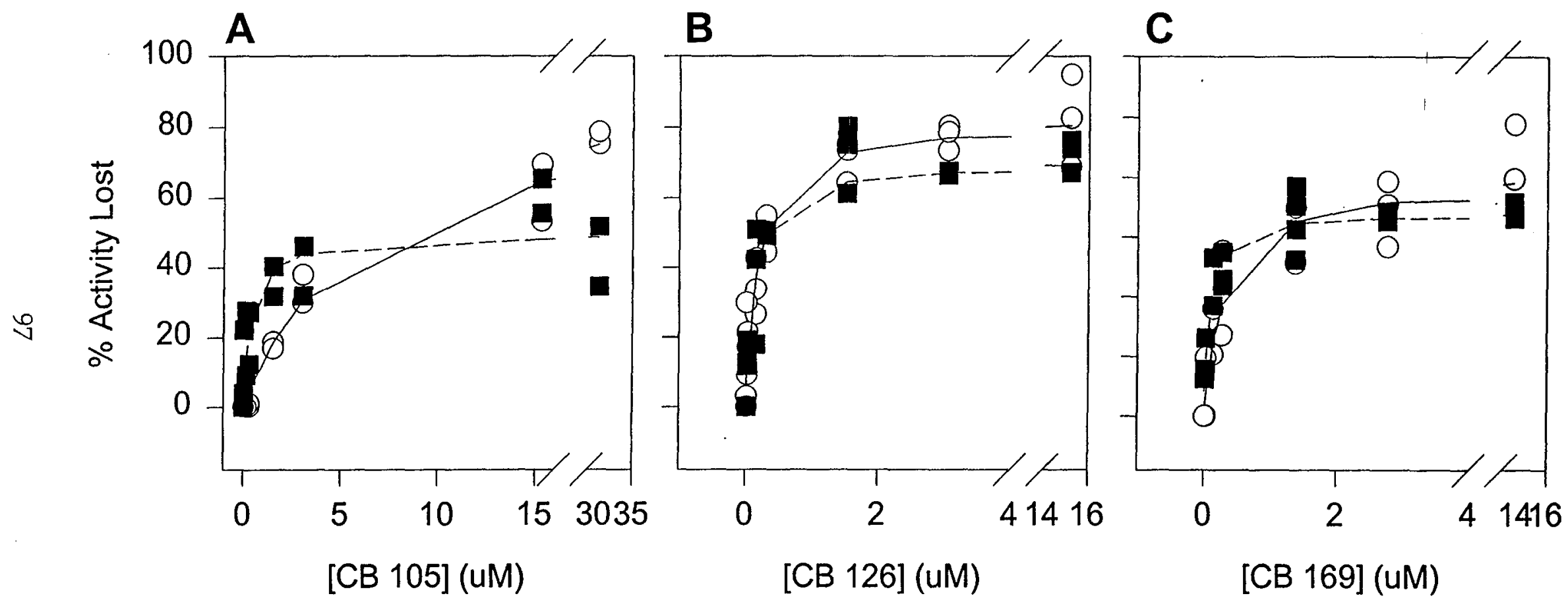


\section{TABLE I}

In vitro inhibition and inactivation of EROD by $\mathrm{CB}$ congeners in scup liver microsomes.

\begin{tabular}{|c|c|c|c|c|c|c|c|c|}
\hline \multirow[b]{2}{*}{$\mathrm{CB}$} & \multicolumn{4}{|c|}{ Inhibition } & \multicolumn{4}{|c|}{ Inactivation } \\
\hline & $\begin{array}{l}\mathrm{IC}_{50} \\
(\mu \mathrm{M})\end{array}$ & $\begin{array}{l}\mathrm{K}_{\mathrm{i}}^{\mathrm{a}} \\
(\mu \mathrm{M})\end{array}$ & $\begin{array}{l}\mathrm{K}_{\mathrm{i}}^{\mathrm{b}} \\
(\mu \mathrm{M})\end{array}$ & $\begin{array}{c}\text { Max. \% } \\
\text { Activity } \\
\text { Lost } \\
\end{array}$ & $\begin{array}{l}\mathrm{K}_{\mathrm{m}} \\
(\mu \mathrm{M})\end{array}$ & $\begin{array}{c}\text { Max. } \% \\
\text { Activity } \\
\text { Lost } \\
\end{array}$ & $\begin{array}{c}\text { Rate }^{\mathrm{c}} \\
\text { Calculated } \\
\text { from EROD }\end{array}$ & $\begin{array}{c}\text { Rate }^{\mathrm{c}} \\
\text { Calculated } \\
\text { from } \mathrm{P} 450 \\
\end{array}$ \\
\hline 77 & $0.18^{\mathrm{d}}$ & 0.02 & 0.16 & 60 & 0.05 & 55 & $8 \pm 3^{e}$ & $12 \pm 3$ \\
\hline 105 & 6.00 & 0.59 & & 80 & 0.37 & 50 & $3 \pm 2$ & $\mathrm{ND}$ \\
\hline 126 & 0.18 & 0.02 & 0.16 & 81 & 0.14 & 74 & $12 \pm 5$ & $11 \pm 1$ \\
\hline 169 & 0.22 & 0.02 & 0.20 & 72 & 0.08 & 68 & $16 \pm 5$ & $6 \pm 1$ \\
\hline
\end{tabular}

Inhibition and inactivation constants and maxima were calculated from data presented in Figure 4 . The $\mathrm{IC}_{50}, \mathrm{~K}_{\mathrm{mInactivation}}$ and maximum values were determined by a nonlinear regression analysis of the plot of $\mathrm{CB}$ concentration and activity loss (Figure 3 ).

a - The method of (Cheng and Prusoff, 1973) was used to convert the IC50 to a $\mathrm{K}_{\mathrm{i}}$ with $0.22 \mu \mathrm{M}$ as the $\mathrm{K}_{\mathrm{m}}$ for 7-ethoxyresorufin metabolism (M. E. Hahn, unpublished results).

b - For CBs 77, 126 and 169, the method of (Cha, 1975) was used to convert the IC50 to a $\mathrm{K}_{\mathrm{i}}$, considering the planar $\mathrm{CB}$ congeners as tight binding inhibitors.

c - Rates were calculated from the data in Figures 2 and 4 and are presented as pmol $\mathrm{P} 450 / \mathrm{min} / \mathrm{mg}$. The rate of inactivation was determined by equating the loss of EROD activity in a given set of microsomes over a 30 minute time period with the specific CYP1A content of those microsomes.

d - Data from Chapter 3.

e - Mean \pm SD from 3-4 pools of microsomes.

ND - Not determined. 

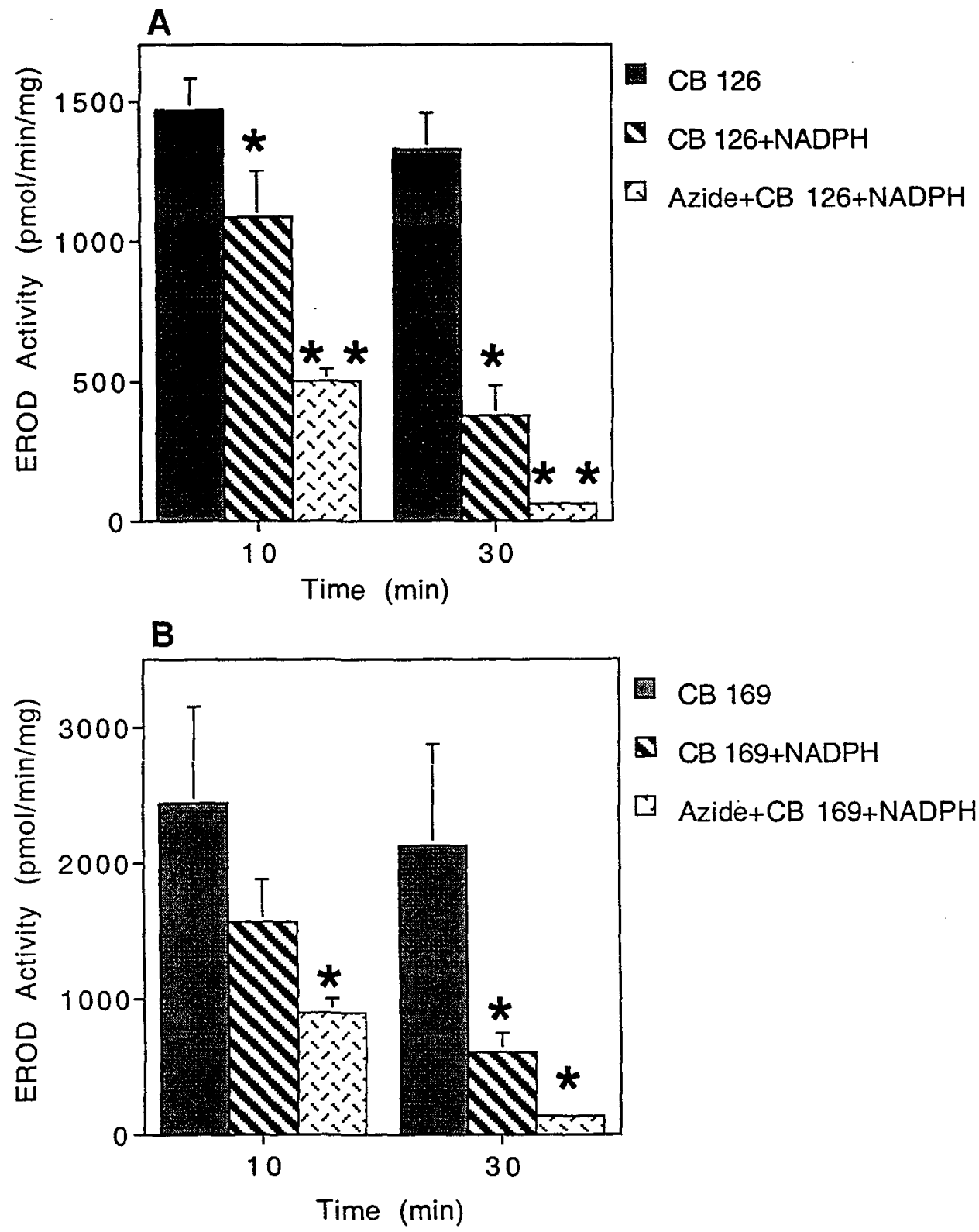

Figure 5. Effect of azide on CB-stimulated CYP1A inactivation in scup liver microsomes. A) CB 126. B) CB 169. Incubation conditions and assay technique were as described in Figure 2, except for the addition of azide $(0.1 \mathrm{mM})$. The azide concentration used was previously determined not to cause a loss of activity without the presence of both NADPH and $\mathrm{CB}$ (Chapter 3 ). Data are means \pm SD from 4 pools of microsomes. *Statistically different from $\mathrm{CB}\left(\mathrm{p}<0.05\right.$, Tukey-Kramer). ${ }^{* *}$ Statistically different from $\mathrm{CB}$ and $\mathrm{CB}+\mathrm{NADPH}(\mathrm{p}<0.05$, Tukey-Kramer). 


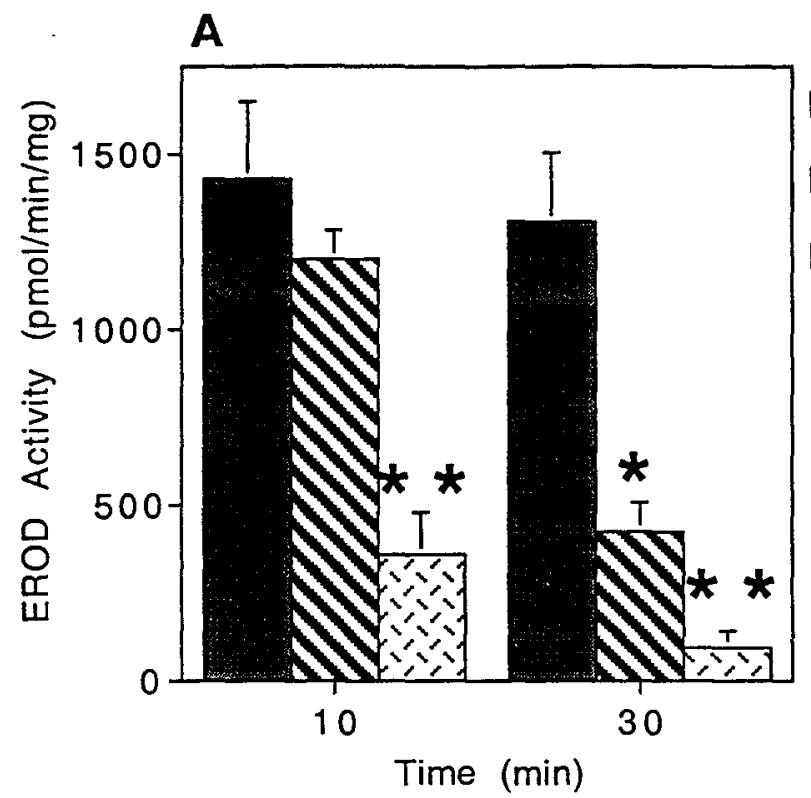

\author{
CB 126 \\ CB 126+NADPH \\ $\mathrm{H} 2 \mathrm{O} 2+\mathrm{CB} 126+\mathrm{NADPH}$
}

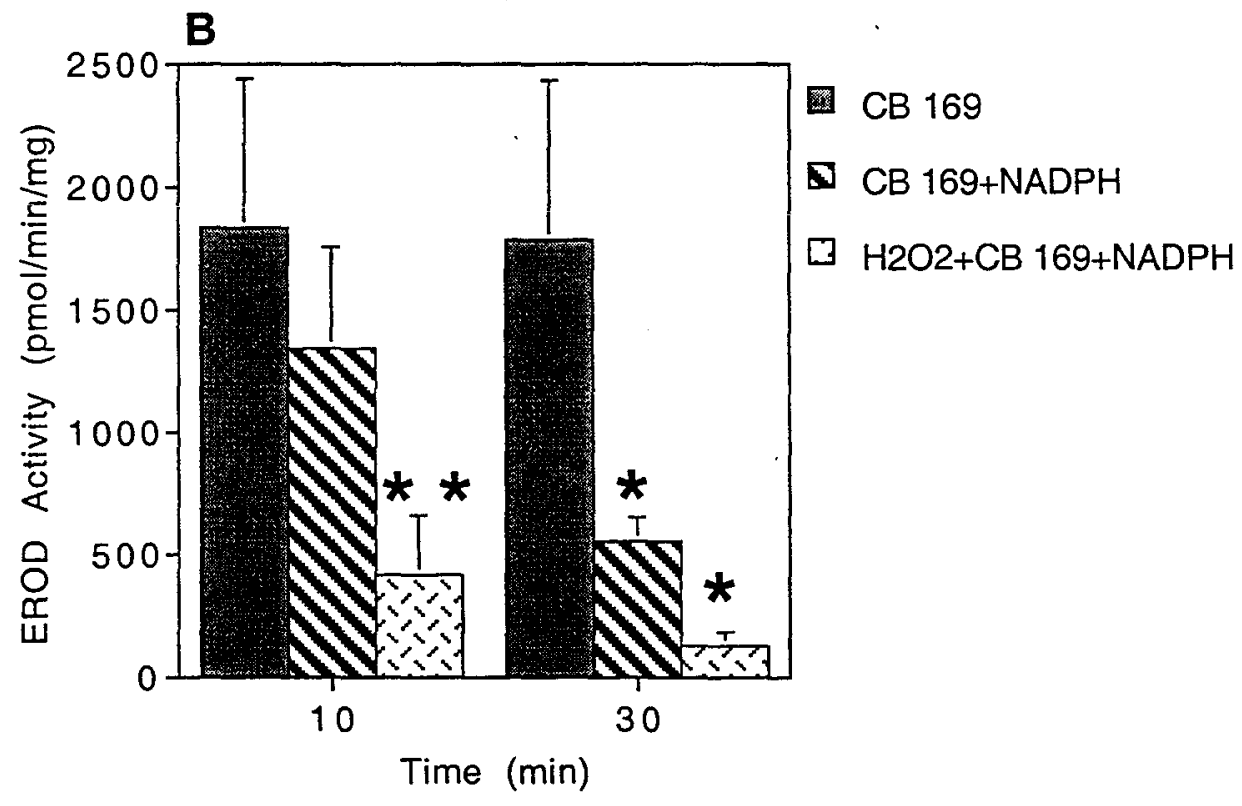

Figure 6. Effect of $\mathrm{H}_{2} \mathrm{O}_{2}$ on CB-stimulated CYP1A inactivation in scup liver microsomes. A) CB 126. B) CB 169. Incubation conditions and assay technique were as described in Figure 2, except for the addition $\mathrm{H}_{2} \mathrm{O}_{2}(100 \mathrm{mM})$. The $\mathrm{H}_{2} \mathrm{O}_{2}$ concentration used was previously determined not to cause a loss of activity without the presence of both NADPH and $\mathrm{CB}$ (Chapter 3 ). Data are means \pm SD from 4 pools of microsomes. *Statistically different from $\mathrm{CB}(\mathrm{p}<0.05$, Tukey-Kramer). **Statistically different from $\mathrm{CB}$ and $\mathrm{CB}+\mathrm{NADPH}(\mathrm{p}<0.05$, Tukey-Kramer $)$. 
TABLE II

NADPH oxidation in scup liver microsomes.

\begin{tabular}{cc}
\hline Additions & $\begin{array}{c}\text { NADPH Oxidation } \\
(\mathrm{nmol} / \mathrm{min} / \mathrm{mg})\end{array}$ \\
\hline NADPH & $13 \pm 1^{\mathrm{a}}$ \\
NADPH+ & \\
Acetone & $11 \pm 3$ \\
BP & $33 \pm 7^{*}$ \\
CB 52 & $14 \pm 4$ \\
CB 105 & $24 \pm 5^{*}$ \\
CB 126 & $28 \pm 2^{*}$ \\
CB 169 & $28 \pm 8^{*}$ \\
\hline
\end{tabular}

The rate of NADPH oxidation was determined by monitoring the decrease in absorbance at $340 \mathrm{~nm}$ (Imai, 1979) in incubations prepared as in the inactivation assay using $0.4 \mathrm{mg}$ protein $/ \mathrm{ml}$ and acetone $(0.5 \%)$ or $15 \mu \mathrm{M} \mathrm{CB}$ in acetone.

a - Mean \pm SD from at least 3 microsome pools.

* - Significantly different from acetone+NADPH ( $\mathrm{p}<0.01$, Dunnett's). 


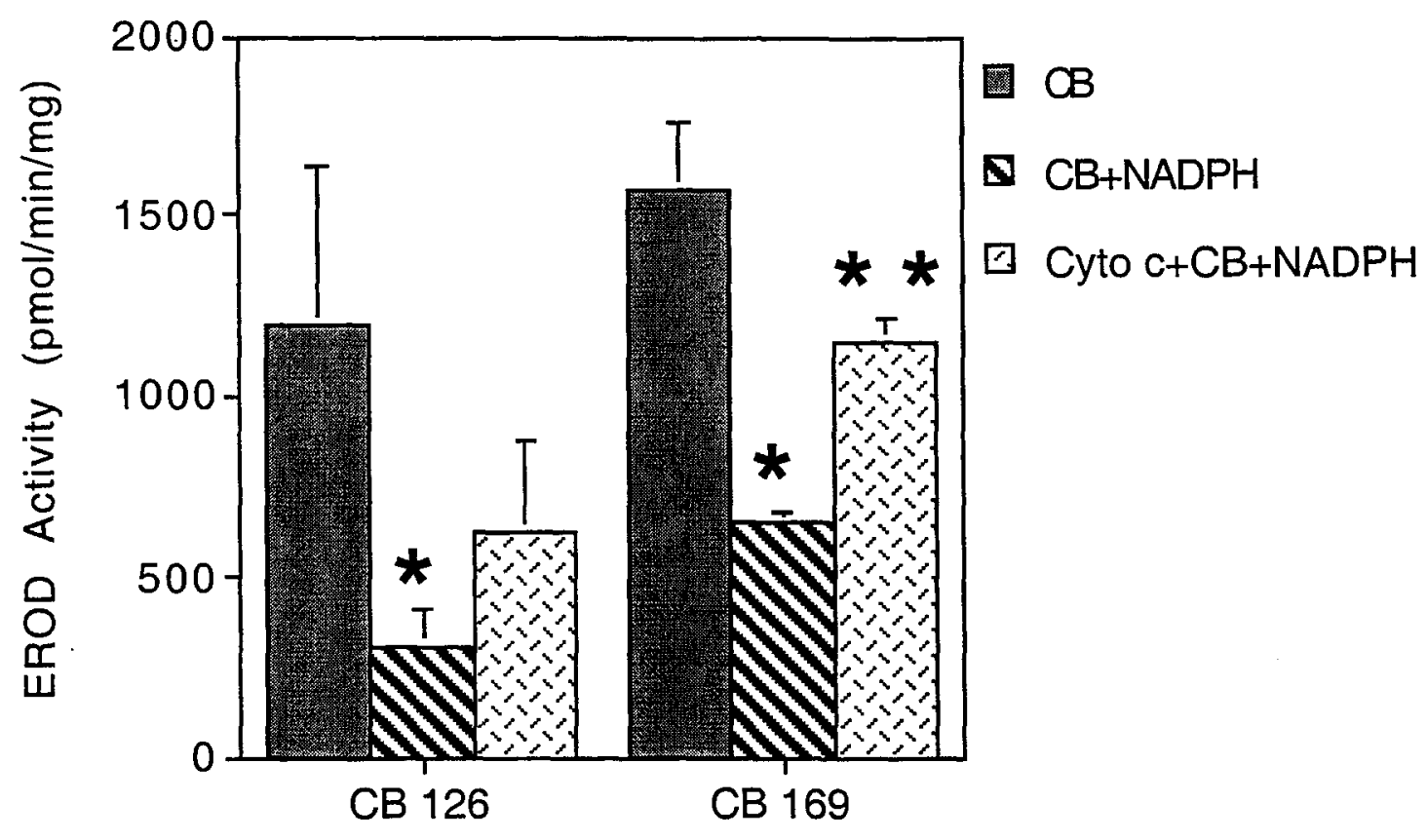

Chemical

Figure 7. Effect of cytochrome $c$ on CB-stimulated CYP1A inactivation in scup liver microsomes. Incubation conditions and assay technique were as described in Figure 2, except for the addition of cytochrome $c(10 \mu \mathrm{M})$. Data shown are from the 30 minute time point. Data are means \pm SD from 3-4 pools of microsomes. *Statistically different from $\mathrm{CB}\left(\mathrm{p}<0.01\right.$, Tukey-Kramer). ${ }^{* *}$ Statistically different from $\mathrm{CB}$ and $\mathrm{CB}+\mathrm{NADPH}$ ( $\mathrm{p}<0.01$, Tukey-Kramer). 
released during the interaction of CB 77 and CYP1A. Here we addressed the hypothesis that any pHAH that is an AhR agonist would bind to CYP1A with effects similar to CB 77 . As occurs with CB 77, the coplanar CBs 126 and 169 stimulated ROS formation by and inactivation of scup CYP1A. The mono-ortho CB 105 also stimulated CYP1A inactivation although to a lesser extent than the non-ortho $\mathrm{CBs}$ and did not stimulate ROS release. The di-ortho CB 52 and the rapidly metabolized CYP1A substrate, BP, stimulated neither ROS release nor CYP1A inactivation. This study lends support to the hypothesis that catalytic uncoupling by slowly metabolized substrates may also create an environment in the active site which is favorable to the formation and attack of ROS. Moreover, release of ROS promoted by $\mathrm{pHAH}$ could be a mechanism by which some AhR agonists/CYP1A substrates exert toxicity.

Inactivation of CYPIA Stimulated by CBs: We previously hypothesized that the inactivation of CYP1A mediated by CB 77 occurs through an oxidative mechanism (Chapter 3). We speculated that steric hindrance due to the chlorines may lodge the CB in the substrate access channel, rendering the molecule largely inaccessible to attack by the peroxy-ferryl complex of P450. As a result, reduced oxygen is released from the heme iron. The exact identity of the ROS causing CYP1A inactivation is unknown. Some studies have suggested that $\mathrm{O}_{2}^{-\bullet}$ can cause release of iron from heme (Gutteridge, 1986; Das et al., 1992); however, the data in our study suggested that $\mathrm{OH} \bullet$ is responsible. Fenton chemistry requires the presence of both $\mathrm{H}_{2} \mathrm{O}_{2}$ and a reduced iron. $\mathrm{H}_{2} \mathrm{O}_{2}$ is produced by scup CYP1A as a result of uncoupling during $\mathrm{CB}$ metabolism. If the $\mathrm{CB}$ remains in the active site stimulating electron flow and oxygen binding, activation and release, then presumably, the heme iron continues to cycle between $\mathrm{Fe}^{3+}$ and $\mathrm{Fe}^{2+}$. We suggested that penta-coordinate ferrous heme in the active site is able to act as a Fenton catalyst in the conversion of $\mathrm{H}_{2} \mathrm{O}_{2}$ to $\mathrm{OH} \cdot$. Oxidative inactivation in other enzymes can involve OH• attack on an amino acid or the heme (Matheson and Travis, 1985; Beyer and Fridovich, 1987; Jenzer et al., 1987).

Results from this study suggest that this oxidative inactivation can be stimulated by any $\mathrm{CB}$ that is a slowly metabolized substrate for CYP1A. 1) Stimulation of NADPH oxidation and inhibition of EROD by CBs 126 and 169 suggest that they interact with the CYP1A active site. 2) ROS production was stimulated by both CBs 126 and 169, but only in microsomes with induced levels of CYP1A. Thus the presence of CYP1A is required for the production of ROS. 3) Both CBs 126 and 169 stimulated loss of CYP1A catalytic activity and total P450. The rate of loss was greater with CBs 126 and 169 than 
had been seen previously with CB 77 (Chapter 3). Both CBs 126 and 169 are more refractory to metabolism than CB 77 (Safe, 1994), potentially increasing uncoupling. 4) The inactivation stimulated by CBs 126 and 169 was dependent upon electron flow. 5) As has been seen with $\mathrm{CB} 77$, the inactivation of CYP1A could be accelerated by the addition of azide and $\mathrm{H}_{2} \mathrm{O}_{2}$, both of which undergo Fenton chemistry to form highly reactive radicals (Ortiz de Montellano et al., 1988; Partridge et al., 1994). 6) CB 52, a di-ortho CB which is not a substrate for CYP1A, did not stimulate NADPH oxidation, inhibit EROD, inactivate CYP1A or stimulate ROS release. 7) BP, a rapidly metabolized substrate, stimulated NADPH oxidation and inhibited EROD but did not stimulate CYP1A inactivation or ROS release. These results are consistent with attack of internally produced activated oxygen being a generalized mechanism of inactivation stimulated by slowly metabolized CYP1A substrates.

On the other hand, the mono-ortho CB 105 inactivated CYP1A but did not stimulate ROS release. Mono-ortho $\mathrm{CBs,} \mathrm{including} \mathrm{CB} 105$, can assume an almost co-planar configuration and thus are able to interact with the AhR and induce EROD activity in mammals (Safe et al., 1985; McFarland and Clark, 1989). Even though CB 105 is ineffective at inducing CYP1A in several fish species (Gooch et al., 1989; Bernhoft et al., 1994; Newsted et al., 1995), it apparently can interact with scup CYP1A as was indicated by its ability to stimulate NADPH oxidation and to inhibit EROD activity. Another monoortho $\mathrm{CB}, 2,3,3^{\prime}, 4,4^{\prime}, 5$-hexachlorobiphenyl (IUPAC \#156), also inhibits EROD activity in scup liver microsomes (Gooch et al., 1989). However, CB 105 inhibited and inactivated CYP1A to a lesser extent than the coplanar CBs. Activation of oxygen may not be as rapid, as suggested by the lesser rate of CYP1A inactivation in the presence of $C B$ 105 , and thus no increase in ROS release was seen. Other studies have demonstrated that treatment with the mono-ortho CB 2,3,4,4'5-pentachlorobiphenyl (IUPAC \#118) increases oxidase activity in rat liver microsomes (Buchmann et al., 1991) and in porcine pulmonary endothelial cells (Toborek et al., 1995). Just as CB 105 is less effective at inhibiting and inactivating CYP1A than the coplanar congeners, it also is a less potent AhR agonist and has a lower TEF than the coplanar CB congeners (Safe et al., 1985; Safe, 1994).

CYP1A and Oxidative Stress: Exposure to $\mathrm{pHAH}$ can result in oxidative stress. Kestrels show increased lipid peroxidation following treatment with CB 126 (Hoffman et al., 1996), and rats respond to TCDD treatment with increased lipid peroxidation and oxidative DNA damage (Stohs, 1990; Stohs et al., 1990). Furthermore, pHAH-induced oxidative stress has been correlated with activation of the AhR (Faux et al., 1992; Alsharif 
et al., 1994; Park et al., 1996)., as well as induction of CYP1A (Otto and Moon, 1995; Toborek et al., 1995; Palace et al., 1996). In vitro experiments performed here with CBs 126 and 169 and earlier studies with CB 77 (Chapter 3) showed that coplanar CB congeners stimulate ROS production in liver microsomes from scup induced for CYP1A but not from liver microsomes from control fish. In addition, hepatic microsomal and mitochondrial fractions but not cytosolic fractions from TCDD-treated rats can increase the incidence of DNA single strand breaks (Wahba et al., 1989). Together, these results indicate that interaction of pHAH with CYP1A induced through the AhR could be the immediate source of ROS in vivo.

Whether CB congeners can stimulate ROS release from CYP other than CYP1A is not known. Several psuedosubstrates, including perfluoro- $n$-hexane and $1,1,1$ trichloroethane, and partial uncouplers, including hexobarbital, 5-alkyl-5-ethylbarbituates, and benzphetamine, stimulate the release of ROS by CYP2B (Estabrook et al., 1979; Jeffery and Mannering, 1982; Kuthan and Ullrich, 1982; Ekstrom and IngelmanSundberg, 1986; Takamo et al., 1988). CB congeners with di-ortho substitutions can induce the CYP2B subfamily (Safe et al., 1985), and 2,2',4,4',6,6'-hexachlorobiphenyl (IUPAC \#155) may uncouple microsomal CYP2B as it stimulates NADPH oxidation and oxygen consumption but is not metabolized (Hesse and Wolff, 1977). However, studies of porphyrinogen and bilirubin oxidation, attributed to ROS produced during catalytic uncoupling, show that 2,2',4,4'-tetrachlorobiphenyl (IUPAC \#47) only weakly induces this oxidation in vivo and in vitro (DeMatteis et al., 1988; DeMatteis et al., 1989). Whether non-coplanar CB congeners stimulate ROS production by CYP2B remains to be determined.

Considering that bioactivation of $\mathrm{pHAH}$ does not contribute significantly to their toxicity, the uncoupling of CYP1A and resultant release of ROS may be an important contributor to the toxicity of $\mathrm{pHAH}$. We have demonstrated that the coplanar $\mathrm{CB}$ congeners stimulate release of ROS from scup liver microsomes with induced levels of CYP1A. Further investigation with CBs 126 and 169 indicated that the mechanism of CYP1A protein and activity loss associated with incubation with these $\mathrm{CB}$ congeners was oxidative inactivation, as has been shown for $\mathrm{CB} 77$ (Chapter 3). Data here, together with results with $\mathrm{CB} 77$, show that the interaction of $\mathrm{pHAH}$ with scup liver CYP1A stimulates the production of ROS in vitro. Planar HAH stimulate oxidative stress (Faux et al., 1992; Alsharif et al., 1994; Smith et al., 1995; Park et al., 1996), suggesting that ROS may play a role in $\mathrm{AhR}$ agonist toxicity in vivo. CBs occur in the environment as complex mixtures; 
thus while single congeners may exist at very low concentrations, particularly coplanar $\mathrm{CBs}$, a combination of CBs may additively or synergistically induce CYP1A catalytic activity and toxicity (Bol et al., 1989; Janz and Metcalfe, 1991; Newsted et al., 1995; Zabel et al., 1995). Potentially, combinations of congeners could stimulate physiologically significant amounts of ROS during environmental exposure. We suggest that release of ROS may be a mechanism by which pHAHs promote toxicity. 


\section{CHAPTER 5}

Inactivation of Cytochrome P450 1A In Vivo by 3,3',4,4',5Pentachlorobiphenyl and its Potential Relationship to Oxidative Stress 


\begin{abstract}
In vertebrates, the planar halogenated aromatic hydrocarbon (pHAH) 3,3',4,4'tetrachlorobiphenyl both induces and inhibits cytochrome P450 1A (CYP1A). Moreover, multiple pHAHs, including 3,3',4,4'-tetrachlorobiphenyl (IUPAC \#77), 3,3',4,4',5pentachlorobiphenyl (PeCB) (IUPAC \#126) and 3,3',4,4',5,5'-hexachlorobiphenyl (IUPAC \#169), inactivate CYP1A and stimulate the production of reactive oxygen (ROS) in vitro. The ability of $\mathrm{PeCB}$ to stimulate CYP1A inactivation, ROS production and oxidative stress in vivo was examined in the marine teleost scup (Stenotomus chrysops). In liver, a low dose of PeCB $(0.01 \mathrm{mg} / \mathrm{kg})$ induced total P450, CYP1A protein and CYP1A catalytic activities (ethoxyresorufin O-deethylation and methoxyresorufin $\mathrm{O}-$ demethylation) over an 18 day period. A high dose of PeCB $(1 \mathrm{mg} / \mathrm{kg})$ only minimally induced hepatic total P450 and CYP1A protein, and CYP1A catalytic activities remained at control levels. In contrast, CYP1A mRNA expression was induced strongly by both doses (15- to 35-fold). That the inactivating effect was largely specific for CYP1A was suggested by the minimal effects on P450A (a CYP3A-like protein), P450B (a CYP2B-like protein) and cytochrome b5 content. Less inactivation of CYP1A occurred in heart, gill or kidney. ROS production (measured by the oxidation of dihydroethidium) was stimulated by $\mathrm{PeCB}$ in liver microsomes from the low dose fish, and the rate of PeCB-stimulated ROS production was correlated with EROD activity $\left(\mathrm{r}^{2}=0.641, \mathrm{p}<0.0005\right)$. Oxidative stress, as indicated by increases in catalase, glutathione peroxidase, glutathione reductase and superoxide dismutase activities, was simulated transiently by the low dose. PeCB appears to oxidatively inactivate scup liver CYP1A both in vitro and in vivo.
\end{abstract}




\section{INTRODUCTION}

Interaction of planar halogenated aromatic hydrocarbons (pHAH), as well as polynuclear aromatic hydrocarbons and natural products, with the aryl hydrocarbon receptor results in the increased expression of drug metabolizing enzymes (Hankinson, 1995). In particular, cytochrome P450 1A (CYP1A) is induced potently by such compounds in mammals (Parkinson et al., 1980; Parkinson et al., 1983) and fish (Melancon and Lech, 1983; Gooch et al., 1989; Miranda et al., 1990; Monosson and Stegeman, 1991). However, pHAH may regulate CYP1A at multiple levels. 3,3',4,4tetrachlorobiphenyl (TCB) is a substrate of CYP1A in fish (White et al., 1997b) and CYP1A1 in mammals (Ishida et al., 1991) and therefore can competitively inhibit CYP1A catalytic activity in vitro (Gooch et al., 1989). Loss of catalytic activity following treatment with high doses of coplanar chlorobiphenyl (CB) congeners occurs without the loss of protein in vivo (Melancon and Lech, 1983; Voorman and Aust, 1988; Miranda et al., 1990; Monosson and Stegeman, 1991; Lindstrom-Seppa et al., 1994) and in cultured cells (Sawyer and Safe, 1982; Rodman et al., 1989; Hahn et al., 1993; Kennedy et al., 1993; Lorenzen et al., 1997), suggesting that coplanar CB congeners could inhibit CYP1A in vivo. Last, TCB, at high doses, suppresses CYP1A protein induction in several species (Lambrecht et al., 1988; Sinclair et al., 1989; Newsted et al., 1995; Stegeman et al., 1995; White et al., 1997a).

Suppression of CYP1A protein induction at high doses of planar CB congeners has been hypothesized to result from oxidative inactivation. In vivo, suppression occurs posttranscriptionally. A low dose of TCB $(0.1 \mathrm{mg} / \mathrm{kg})$ induces hepatic CYP1A mRNA expression, protein and catalytic activity to nearly maximal levels in the marine fish model scup (Stenotomus chrysops); a high dose of TCB $(5 \mathrm{mg} / \mathrm{kg}$ ) strongly induces CYP1A mRNA expression but minimally induces CYP1A protein and activity (White et al., 1997a). Loss of CYP1A occurs during the incubation of scup liver microsomes with TCB+NADPH, as well (White et al., 1997a; Chapter 3). Attack of a metabolically activated product cannot account for the loss of CYP1A because metabolism of TCB by scup proceeds exceedingly slowly (White et al., 1997a; White et al., 1997b). Enhanced electron transfer, oxygen dependence and exceedingly slow rates of TCB turnover are

consistent with uncoupling of electron transport from substrate oxidation (Chapter 3). As a result, reactive oxygen species (ROS) may be released from the active site of CYP1A or may attack and inactivate the protein (Chapter 3). ROS attack may be involved in the decline in CYP1A seen in vivo. 
In vitro oxidative inactivation and ROS release are stimulated by several slowly metabolized pHAH that are CYP1A substrates, including 2,3,3',4,4'-pentachlorobiphenyl, 3,3',4,4',5-pentachlorobiphenyl (PeCB) and 3,3',4,4',5,5'-hexachlorobiphenyl (Chapter 4). Loss of protein induction but not CYP1A mRNA expression following treatment with high doses of multiple planar $\mathrm{CB}$ congeners suggests that inactivation may occur with pHAH generally in vivo, as well (Rodman et al., 1989; Newsted et al., 1995; Lorenzen et al., 1997). Recently, 2,3,7,8-tetrachlorodibenzo-p-dioxin (TCDD) also has been shown to cause suppression of CYP1A1, but not CYP1A2, in mice, in combination with an increase in 8-hydroxydeoxyguanosine content (Shertzer et al., 1998).

We hypothesized from the in vitro data that the coplanar $\mathrm{PeCB}$ would suppress CYP1A induction in scup liver and induce oxidative stress in vivo. Of the coplanar CB congeners, PeCB is the most potent in eliciting toxic effects in fish (Janz and Metcalfe, 1991; Walker and Peterson, 1991; Newsted et al., 1995) and mammals (Safe, 1990; Tillitt et al., 1991). If uncoupling and ROS production are involved in PeCB toxicity, that toxicity may be enhanced by the lack of PeCB metabolism (Yoshimura et al., 1987; Koga et al., 1990). Although low doses of PeCB $(0.01-0.1 \mathrm{mg} / \mathrm{kg})$ potently induced CYP1A mRNA, protein and activity in scup liver, a high dose $(1 \mathrm{mg} / \mathrm{kg})$ induced only CYP1A mRNA and suppressed induction of CYP1A protein and activity. As with TCB, this effect appeared to be largely specific to CYP1A. Interestingly, suppression of CYP1A induction was organ-dependent, with hepatic CYP1A being most susceptible to inactivation. PeCB transiently stimulated anti-oxidant enzyme activity in scup liver in vivo. Furthermore, the capacity for hepatic microsomes to produce ROS was correlated with CYP1A activity. The results are consistent with the hypothesis that ROS are involved in the in vivo suppression of scup liver CYP1A by coplanar CB congeners.

\section{MATERIALS AND METHODS}

Chemicals: 7-Ethoxyresorufin and dihydroethidium were purchased from Molecular Probes (Eugene, OR). 3,3',4,4',5-Pentachlorobiphenyl (IUPAC\# 126) was purchased from Ultra Scientific (North Kingstown, RI). All other reagents were purchased from Sigma (St. Louis, MO).

Animals: Scup (Stenotomus chrysops ) were caught by trapping in Vineyard Sound, MA in August, 1996, and experiments were conducted in August, 1997. Fish were held in flow-through seawater tanks at $14^{\circ} \mathrm{C}$ and maintained on a diet of Purina Trout Chow. Experimental animals (mixed sex) were gonadally undeveloped and ranged in size 
from 136 to $327 \mathrm{~g}$. Fish were injected intra-peritoneally with corn oil or solutions of $3,3^{\prime}, 4,4^{\prime}, 5$-pentachlorobiphenyl $(0.01,0.1$ or $1 \mathrm{mg} / \mathrm{ml}, 1 \mathrm{ml} / \mathrm{kg}$ body weight) in corn oil. For each dose group, three tanks contained six fish, and at each time point two fish from each tank were sampled. Fish were fed once weekly. Untreated fish were killed by severing the spinal cord on Day 0 . Injected fish were killed 3, 7, and 16 or 18 days following dosing. Body and liver weights were recorded and used to calculate the Hepatosomatic Index (HSI=the percent of total body weight represented by the liver). Sections of liver for RNA preparation were removed and frozen in liquid N2. Immediately following dissection of heart, gill, kidney and liver, microsomes and cytosols were prepared from sections of each (Stegeman et al., 1979). Microsomal pellets were resuspended in buffer (50 mM TRIS, pH 7.4, $1 \mathrm{mM}$ dithiothrietol, $1 \mathrm{mM}$ EDTA, 20\% glycerol) and frozen in liquid $\mathrm{N}_{2}$ until use. Protein content was determined using the bicinchoninic acid method (Smith et al., 1985), using bovine serum albumin as a standard.

Quantification of CYPIA mRNA: RNA was prepared using RNA-Stat (Tel-Test Inc., Friendswoods, TX) by following the manufacturer's instructions. RNA pellets were washed once in $4 \mathrm{M} \mathrm{LiCl}$ to remove glycogen, followed by two washes in $95 \%$ ethanol. Total RNA was quantified by its absorbance at $260 \mathrm{~nm}$ on a Shimadzu UV-2401PC spectrophotometer.

Total RNA samples ( $10 \mu \mathrm{g}$ each) were denatured in formamide/formaldehyde and separated on a $1 \%$ agarose $/ 2.2 \mathrm{M}$ formaldehyde gel, in $20 \mathrm{mM}$ MOPS running buffer. RNA was transferred to a positively charged membrane (Chomczynski, 1992). Equal loading was assessed from visualization of ethidium bromide staining of ribosomal RNA. The dried membrane was pre-hybridized for $2 \mathrm{hr}$ at $42^{\circ} \mathrm{C}$, in a buffer composed of $5 \mathrm{x}$ SSPE, $0.1 \%$ SDS, $2 x$ Denhardt's solution, $50 \%$ formamide and $100 \mu \mathrm{g} / \mathrm{ml}$ calf thymus DNA. ${ }^{32} \mathrm{P}$-Labeled probe (see below) was added to the pre-hybridization buffer, and the membrane was hybridized at $42^{\circ} \mathrm{C}$ for approximately $12 \mathrm{hrs}$. The membrane was washed two times at $42^{\circ} \mathrm{C}$ for 30 minutes with $2 x$ SSC, $0.1 \%$ SDS and exposed to Kodak XOMAT AR film. The relative amount of CYP1A mRNA was determined using densitometric analysis of a video image (NIH Image 1.60b5).

A cDNA probe containing $75 \%$ of the scup CYP1A coding region (Morrison et al., 1995 ) was used for quantification of CYP1A mRNA. The probe was radiolabeled with [ $\alpha-$ 32P]dCTP (Amersham, Arlington Heights, IL) using a Prime-a-Gene labeling kit (Promega, Madison, WI). 
Western blotting for CYP1A quantification: Immunoblotting procedures were modified from those previously described (Kloepper-Sams et al., 1987). For CYP1A determinations, liver microsomal protein was applied to nylon membrane using a slot manifold (Kloepper-Sams and Stegeman, 1994). For all other analyses microsomal proteins $(30-40 \mu \mathrm{g})$ were resolved on 6-18\% SDS-PAGE gels and electrophoretically transferred to nylon membrane. The primary antibodies were the mouse monoclonal antibody 1-12-3 (Park et al., 1986), against scup P450E (CYP1A; (Morrison et al., 1995)), the rabbit polyclonal antibody against scup P450B (a CYP2B-like protein) (Gray, 1988; Stegeman et al., 1990)) and the rabbit polyclonal antibody against scup P450A (a CYP3A-like protein) (Celander et al., 1996). The secondary antibodies were alkaline phosphatase linked goat anti-mouse IgG and goat anti-rabbit IgG (Schleicher and Schuell, Keene, NH). Bands were developed using enhanced chemiluminescence (Tropix, Bedford, MA) and quantified by video image analysis (NIH Image 1.60b5) by comparison to scup standards of known concentration..

Cytochromes b5 and P450 The content of hepatic microsomal P450 was determined from the dithionite-difference spectra of CO-treated microsomes (Bonkovsky et al., 1984), and cytochrome b5 content was determined from NADH difference spectra (Stegeman et al., 1979), as previously described.

Enzyme assays: Microsomal ethoxyresorufin (EROD) and methoxyresorufin (MROD) O-dealkylation activities were determined fluorometrically by the method of Hahn et al. (1993), using a Cytofluor 2300 (Millipore) multiwell plate reader. Microsomal NADPH-cytochrome P450 reductase activity was determined as previously described (Stegeman et al., 1982). The activities of catalase (Beutler, 1975), glutathione peroxidase (Sies et al., 1979), glutathione reductase (Sies et al., 1979), and superoxide dismutase (McCord and Fridovich, 1969) were determined in the cytosols.

Superoxide formation: $\mathrm{O}_{2}-$ formation was determined using the fluorescent dye, dihydroethidium (HE), as described in Chapter 3. Additions included acetone $(5 \mu \mathrm{l})$, PeCB (1.7 nmol in acetone) and NADPH (1.4 mM). ROS production stimulated by PCB 126 was calculated by subtracting the fluorescence in the well containing acetone to that in the well containing PeCB.

Statistics Statistics were calculated using SuperAnova for Macintosh (Abacus Concepts, Inc., Berkeley, CA). Nested, one-factor ANOVAs were used to analyze differences between treatment groups within sampling days. Tank was not found to be a significant factor. Because RNA and extrahepatic tissue samples were pooled per tank, 

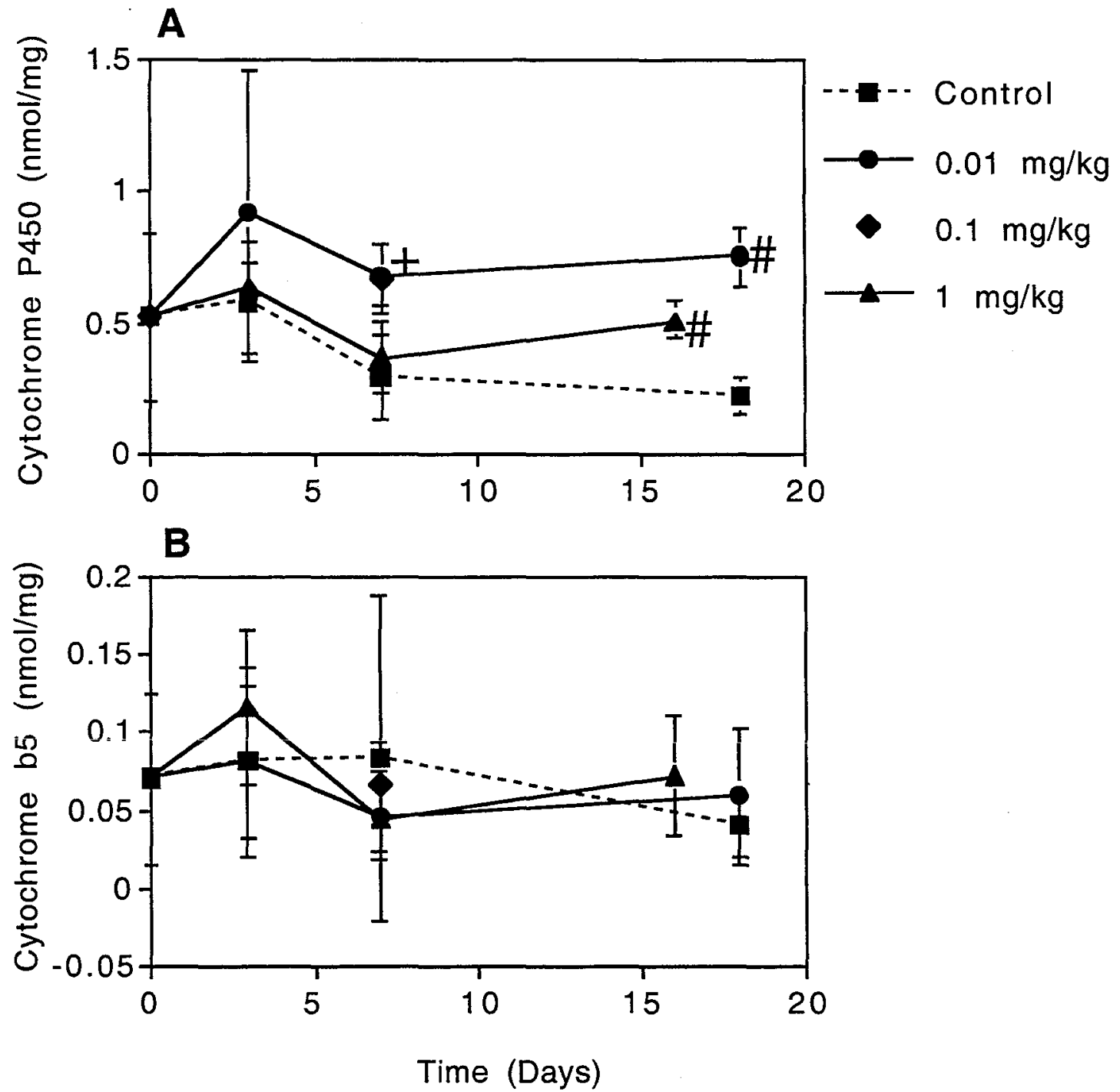

Figure 1. Effect of PeCB on hepatic microsomal cytochrome P450 (A) and cytochrome b5 (B) content. Cytochrome contents were determined spectrally. Data represent the means \pm $\mathrm{SD}$ of measurements on 6 fish per treatment group except for the $0.01 \mathrm{mg} / \mathrm{kg}$ dose on Day $18(\mathrm{n}=4)$ and the $1 \mathrm{mg} / \mathrm{kg}$ dose on Day $16(\mathrm{n}=3)$. + -Statistically different from control and $1 \mathrm{mg} / \mathrm{kg}$ dose $(\mathrm{p}<0.05)$. \#-Statistically different from control $(\mathrm{p}<0.05)$. The $0.1 \mathrm{mg} / \mathrm{kg}$ dose was significantly different from control and $1 \mathrm{mg} / \mathrm{kg}$ dose $(\mathrm{p}<0.05)$. 
Figure 2. Effect of PeCB on CYP1A mRNA expression in scup liver. A) Northern blot of CYP1A mRNA. Lanes 1-2. Control, Day 3. Lanes 3-4. $0.01 \mathrm{mg} \mathrm{PeCB} / \mathrm{kg}$, Day 3. Lanes 5-6. $1 \mathrm{mg} \mathrm{PeCB} / \mathrm{kg}$, Day 3. Lanes 7-8. $0.01 \mathrm{mg} \mathrm{PeCB} / \mathrm{kg}$, Day 7. Lanes 9-10. $0.1 \mathrm{mg} \mathrm{PeCB} / \mathrm{kg}$, Day 7. Lanes 11-12. $1 \mathrm{mg} \mathrm{PeCB} / \mathrm{kg}$, Day 7. Lanes 13-14. $0.01 \mathrm{mg}$ PeCB $/ \mathrm{kg}$, Day 18. Lanes $15-16.1 \mathrm{mg} \mathrm{PeCB} / \mathrm{kg}$, Day 16. B) Comparison of CYP1A $\mathrm{mRNA}$ in liver of scup treated with various doses of PeCB. For each time point, livers from fish in the same tank were pooled before RNA preparation. Total RNA (10 $\mu \mathrm{g} / \mathrm{lane})$ was separate on agarose gel, transferred to nylon membrane, probed with a 32P-labeled cDNA containing $75 \%$ of the scup CYP1A coding region, and densitometrically quantified. Data represent the means \pm SD of measurements on 3 pools per treatment group except for the $0.01 \mathrm{mg} / \mathrm{kg}$ dose on Day $18(\mathrm{n}=4)$ and the $1 \mathrm{mg} / \mathrm{kg}$ dose on Day $16(\mathrm{n}=3)$. ++. Statisically different from control and $1 \mathrm{mg} / \mathrm{kg}$ dose $(\mathrm{p}<0.01)$. \#-Statistically different from control $(\mathrm{p}<0.05)$. \#\#-Statistically different from control $(\mathrm{p}<0.01)$. The $0.1 \mathrm{mg} / \mathrm{kg}$ dose was significantly different from control and $1 \mathrm{mg} / \mathrm{kg}$ dose $(\mathrm{p}<0.01)$. 
A

$\begin{array}{llllllllllllllll}1 & 2 & 3 & 4 & 5 & 6 & 7 & 8 & 9 & 10 & 11 & 12 & 13 & 14 & 15 & 16\end{array}$
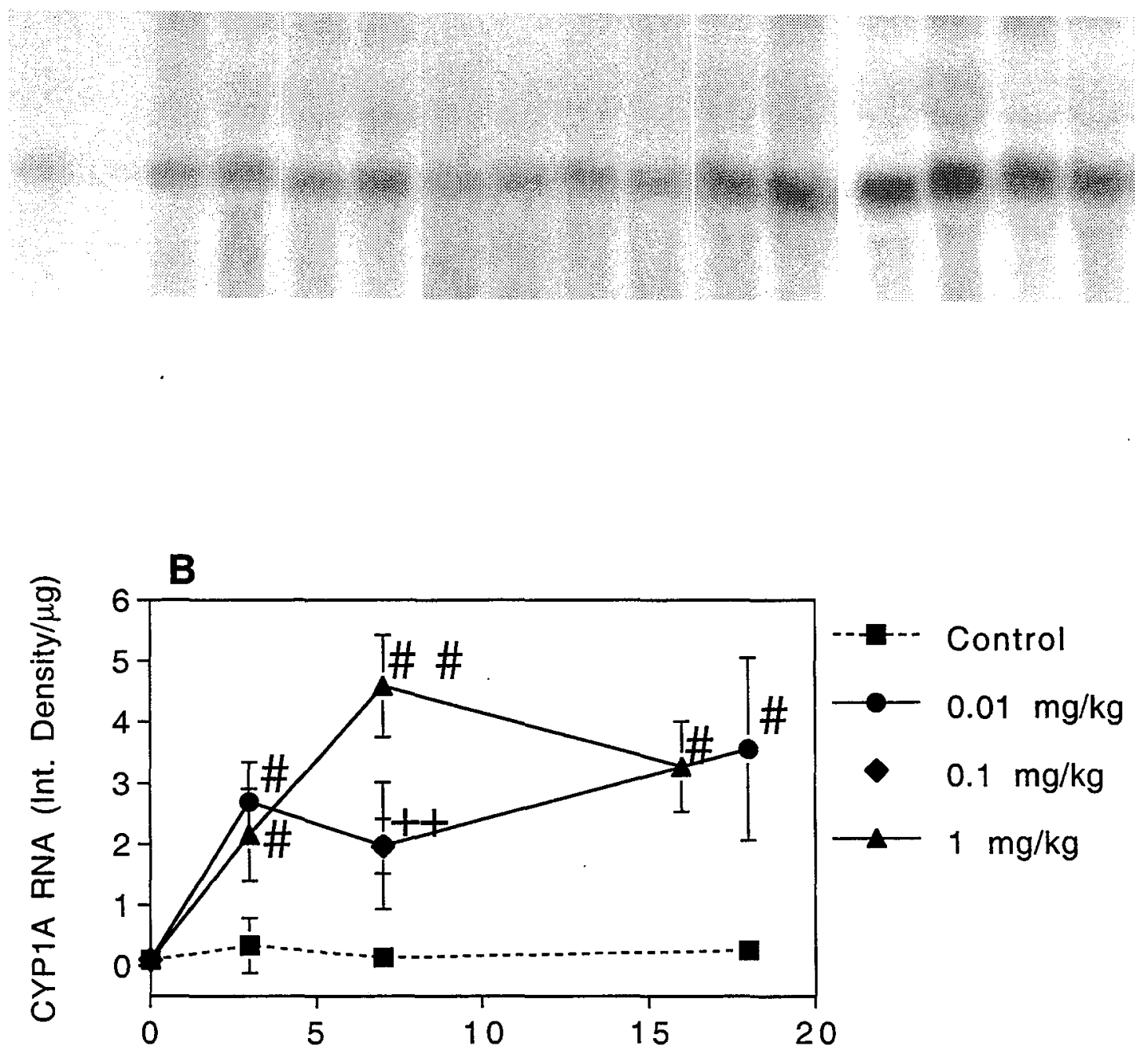
one-factor ANOVAs were to analyze assays using these samples. The Tukey-Kramer multiple-comparisons test was used to determine which doses were different. Due to deaths in the $1 \mathrm{mg} / \mathrm{kg}$ dose group, fish in this group were killed on Day 16 while those in the control and $0.01 \mathrm{mg} / \mathrm{kg}$ dose groups were killed on Day 18. Fish killed on days 16 and 18 were analyzed together.

\section{RESULTS}

Gross effects: No change in the Hepatosomatic Index occurred in any dose group over the experimental period (data not shown). However, while no deaths due to toxicity occurred in the first seven days post-injection, one of the five remaining fish in the $0.01 \mathrm{mg}$ $\mathrm{PeCB} / \mathrm{kg}$ dose group died between Days 7 and 18, and three of the six remaining fish in the $1 \mathrm{mg}$ PeCB/kg dose group died between Days 7 and 16.

Hepatic mono-oxygenase components: The content of total spectral P450 in hepatic microsomes from control fish decreased over time; however, the change was not statistically significant. Although the content of total P450 in hepatic microsomes from fished dosed with $0.01 \mathrm{mg} P \mathrm{PeB} / \mathrm{kg}$ peaked on Day 3, it was not significantly induced above controls until Day 7 and remained elevated on Day 18 (Figure 1A). The $0.1 \mathrm{mg}$ $\mathrm{PeCB} / \mathrm{kg}$ dose significantly induced total P450 by Day 7 , and the level of total P450 was similar to that induced by the $0.01 \mathrm{mg} \mathrm{PeCB} / \mathrm{kg}$ dose. The $1 \mathrm{mg} \mathrm{PeCB} / \mathrm{kg}$ dose did not significantly induce total P450 until Day 16. The maximal induction of total P450 by the $0.01 \mathrm{mg} \mathrm{PeCB} / \mathrm{kg}$ dose was 3-fold, while that by the $1 \mathrm{mg} \mathrm{PeCB} / \mathrm{kg}$ dose was 2 -fold. The specific content of b5 was not affected by any of the treatments (Figure 1B).

CYP1A expression, protein content and activity: Hepatic CYP1A mRNA expression was assessed using a cDNA probe containing $75 \%$ of the scup CYP1A coding region (Figure $2 \mathrm{~A}$ ). Ethidium bromide staining of ribosomal RNA was visualized on the

membrane to confirm equivalent loading of samples (data not shown). CYP1A mRNA expression was significantly elevated by Day 3 in both the 0.01 and $1 \mathrm{mg} \mathrm{PeCB} / \mathrm{kg}$ dose groups and remained elevated through Days 16-18 (Figure 2B). Maximal induction (15fold) by the $0.01 \mathrm{mg} \mathrm{PeCB} / \mathrm{kg}$ dose occurred 18 days post-injection, and maximal induction (35-fold) by the $1 \mathrm{mg} P \mathrm{PeB} / \mathrm{kg}$ dose occurred 7 days post-injection. The $0.1 \mathrm{mg}$ $\mathrm{PeCB} / \mathrm{kg}$ dose significantly induced CYP1A mRNA expression at Day 7 (Figure 2B).

Induction of CYP1A protein followed a similar pattern to that seen with total $\mathrm{P} 450$ content. Despite being in captivity for one year, the presence of measurable CYP1A in controls suggests that these fish were not depurated fully. A peak in CYP1A content 
occurred on Day 3 following the $0.01 \mathrm{mg}$ PeCB $/ \mathrm{kg}$ dose; however, CYP1A protein was significantly induced only on Days 7 and 18 (Figure $3 \mathrm{~A}$ ). The $0.1 \mathrm{mg} \mathrm{PeCB} / \mathrm{kg}$ dose significantly induced CYP1A protein at Day 7, and the content was similar to that induced by the $0.01 \mathrm{mg} \mathrm{PeCB} / \mathrm{kg}$ dose. The $1 \mathrm{mg} P e C B / \mathrm{kg}$ dose did not significantly induce CYP1A protein over that seen in controls until Day 16; however, the content of CYP1A was still significantly less than that seen in the $0.01 \mathrm{mg} \mathrm{PeCB} / \mathrm{kg}$ dose group (3-fold vs. 5fold, respectively).

EROD and MROD activity have been attributed to CYP1A1 and CYP1A2 in mammals (16). As of yet, a single CYP1A form has been identified in scup, and it is hypothesized to be a type ancestral to both mammalian CYP1A1 and CYP1A2 $(4,17)$. Scup CYP1A is thought to catalyze both EROD and MROD. EROD activity increased by Day 3 in the $0.01 \mathrm{mg} P \mathrm{PeCB} / \mathrm{kg}$ dose group but was not induced significantly above EROD in controls until Day 7 (Figure 3B). EROD activity reached maximal induction (4-fold) on Day 18 in the $0.01 \mathrm{mg} \mathrm{PeCB} / \mathrm{kg}$ dosed fish. The $0.1 \mathrm{mg} \mathrm{PeCB} / \mathrm{kg}$ dose significantly induced EROD activity (3-fold) at Day 7. EROD activity was not induced by the $1 \mathrm{mg}$ $\mathrm{PeCB} / \mathrm{kg}$ dose over the course of the experiment. Unlike EROD activity, MROD activity peaked at 6-fold induction in the $0.01 \mathrm{mg} P \mathrm{PeB} / \mathrm{kg}$ dosed fish on Day 3 and declined through Day 18 (Figure 3C). MROD activity was induced significantly at Day 7 by the 0.01 and $0.1 \mathrm{mg} \mathrm{PeCB} / \mathrm{kg}$ doses. MROD activity was not induced by the $1 \mathrm{mg} \mathrm{PeCB} / \mathrm{kg}$ dose over the course of the experiment.

Total P450 was correlated strongly with CYP1A throughout the experiment (Figure 4A). EROD activity also was correlated strongly with CYP1A content; however, on Day 3 the slope of the correlation decreased, i. e. the turnover number for EROD activity decreased (Figure 4B).

Other CYP proteins: Hepatic microsomes were immunoblotted with antibodies to two other major P450 forms expressed in scup liver: P450A, a possible CYP3A homologue (Celander et al., 1996) and P450B, a probable CYP2B homologue (Gray, 1988; Stegeman et al., 1990). The content of P450A was not affected by any of the treatments (Figure 5A). Little change in $\mathrm{P} 450 \mathrm{~B}$ content occurred with any treatment (Figure 5B). However, on Day 7 the $0.01 \mathrm{mg}$ PeCB/kg dose slightly induced P450B, and the $1 \mathrm{mg} \mathrm{PeCB} / \mathrm{kg}$ dose slightly suppressed $\mathrm{P} 450 \mathrm{~B}$ content. $\mathrm{P} 450 \mathrm{~B}$ content in the $0.01 \mathrm{mg}$ $\mathrm{PeCB} / \mathrm{kg}$ dose group was only significantly different from the $1 \mathrm{mg} \mathrm{PeCB} / \mathrm{kg}$ dose group on Day 7.

Oxidative stress: Several studies have suggested that CYP1A produces reactive 
Figure 3. Effect of PeCB on hepatic microsomal CYP1A content (A) and catalytic activity (EROD - B; MROD - C). Liver microsomal fractions $(0.2-4 \mu \mathrm{g} / \mathrm{slot})$ were applied to nylon membrane with a slot blot manifold, and immunoblotted with MAb 1-12-3 against scup CYP1A. CYP1A reactive bands were visualized using enhanced chemiluminescence and quantified by densitometric analysis. Enzyme activities were determined fluorometrically by the method of Hahn et al. (1993). Data represent the means \pm SD of measurements on 6 fish per treatment group except for the $0.01 \mathrm{mg} / \mathrm{kg}$ dose on Day $18(\mathrm{n}=4)$ and the $1 \mathrm{mg} / \mathrm{kg}$ dose on Day $16(\mathrm{n}=3)$. ${ }_{-}^{+}$-Statisically different from control and $1 \mathrm{mg} / \mathrm{kg}$ dose $(\mathrm{p}<0.05)$. ${ }_{++}^{+}$Statisically different from control and $1 \mathrm{mg} / \mathrm{kg}$ dose $(\mathrm{p}<0.01)$. \#\#-Statistically different from control $(\mathrm{p}<0.01)$. The $0.1 \mathrm{mg} / \mathrm{kg}$ dose was significantly different from control $(\mathrm{p}<0.05)$. 

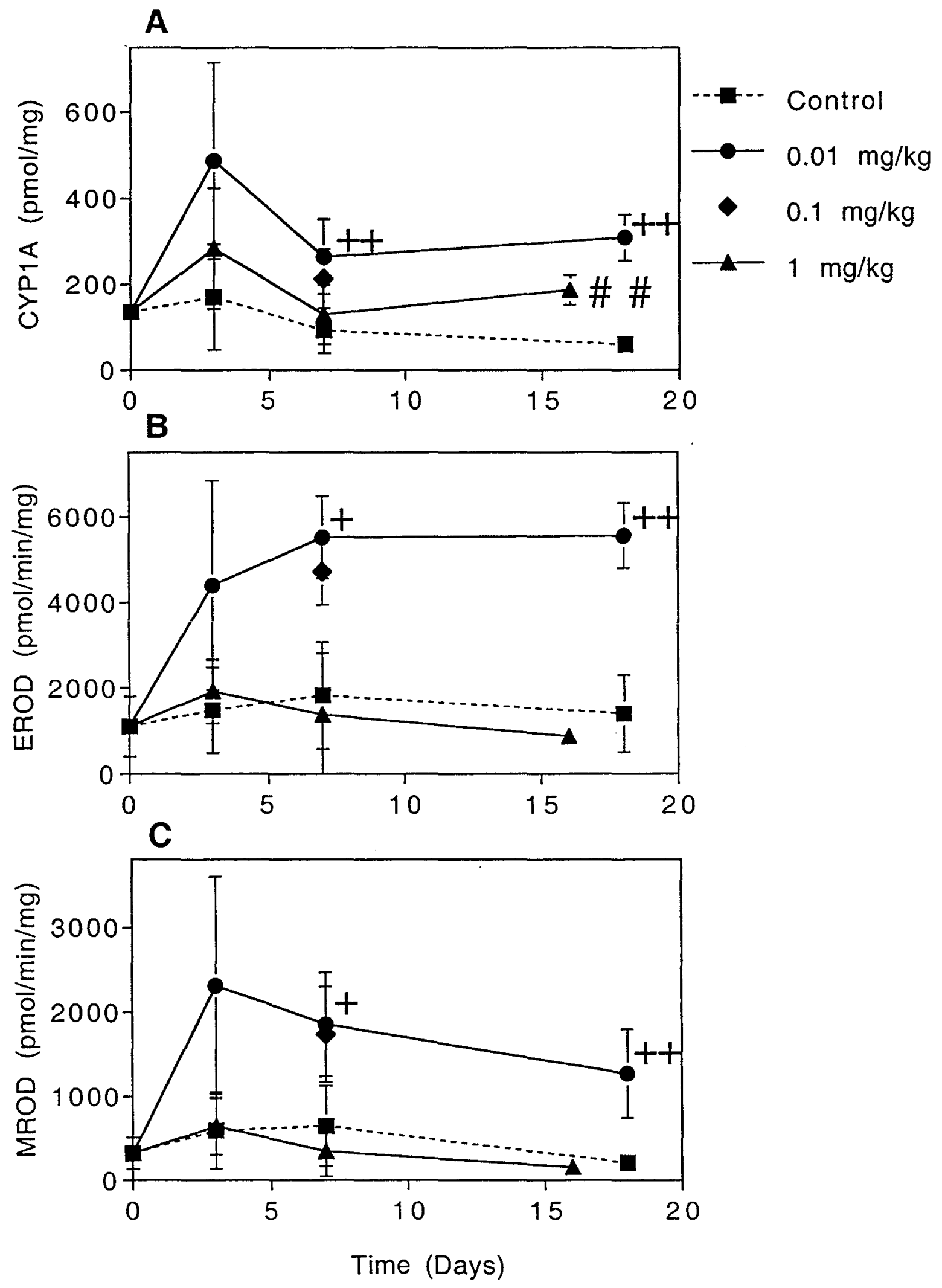

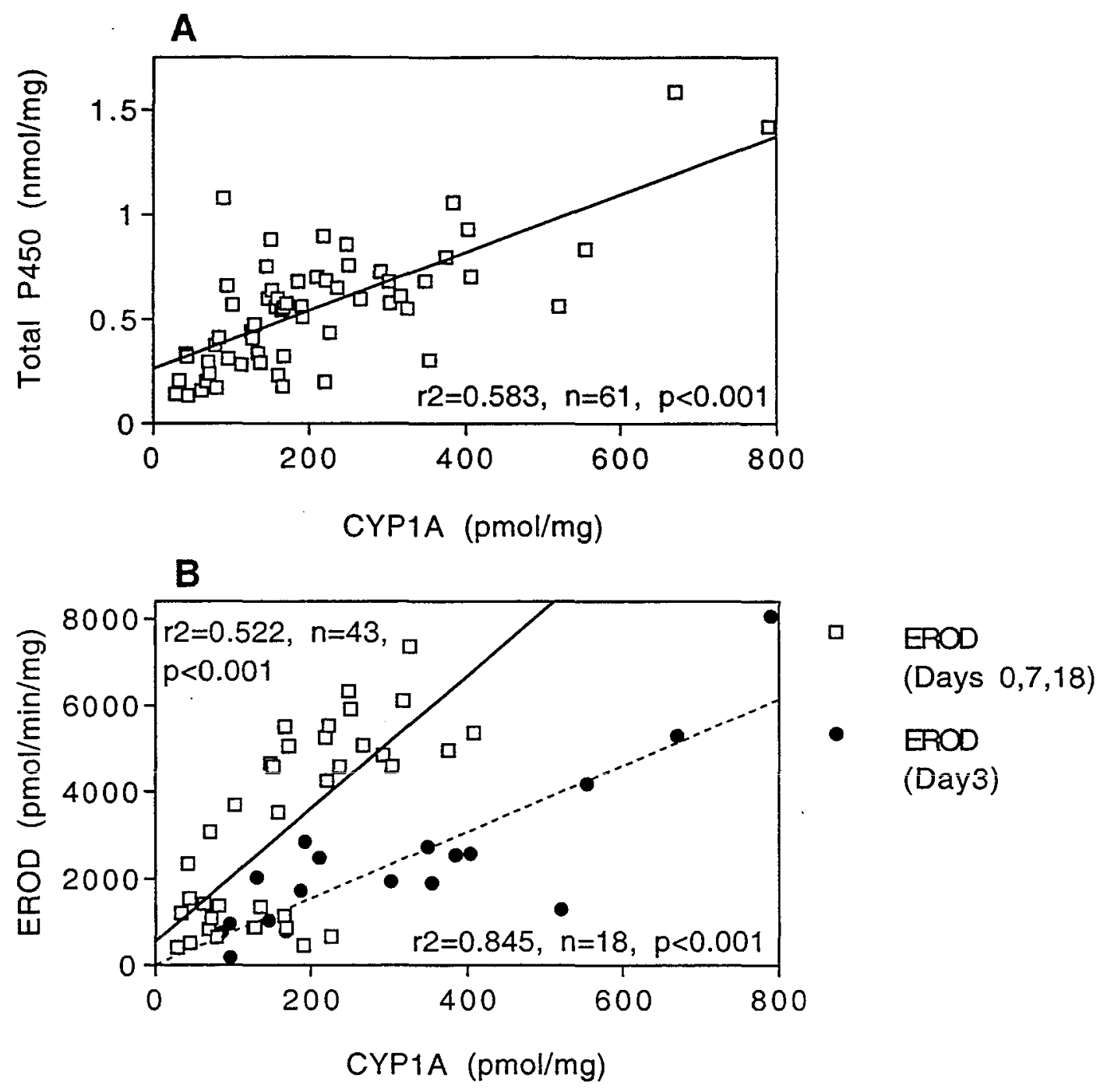

Figure 4. Correlation of CYP1A content with total P450 content and EROD activity. A) CYP1A versus total P450. B) CYP1A versus EROD. 


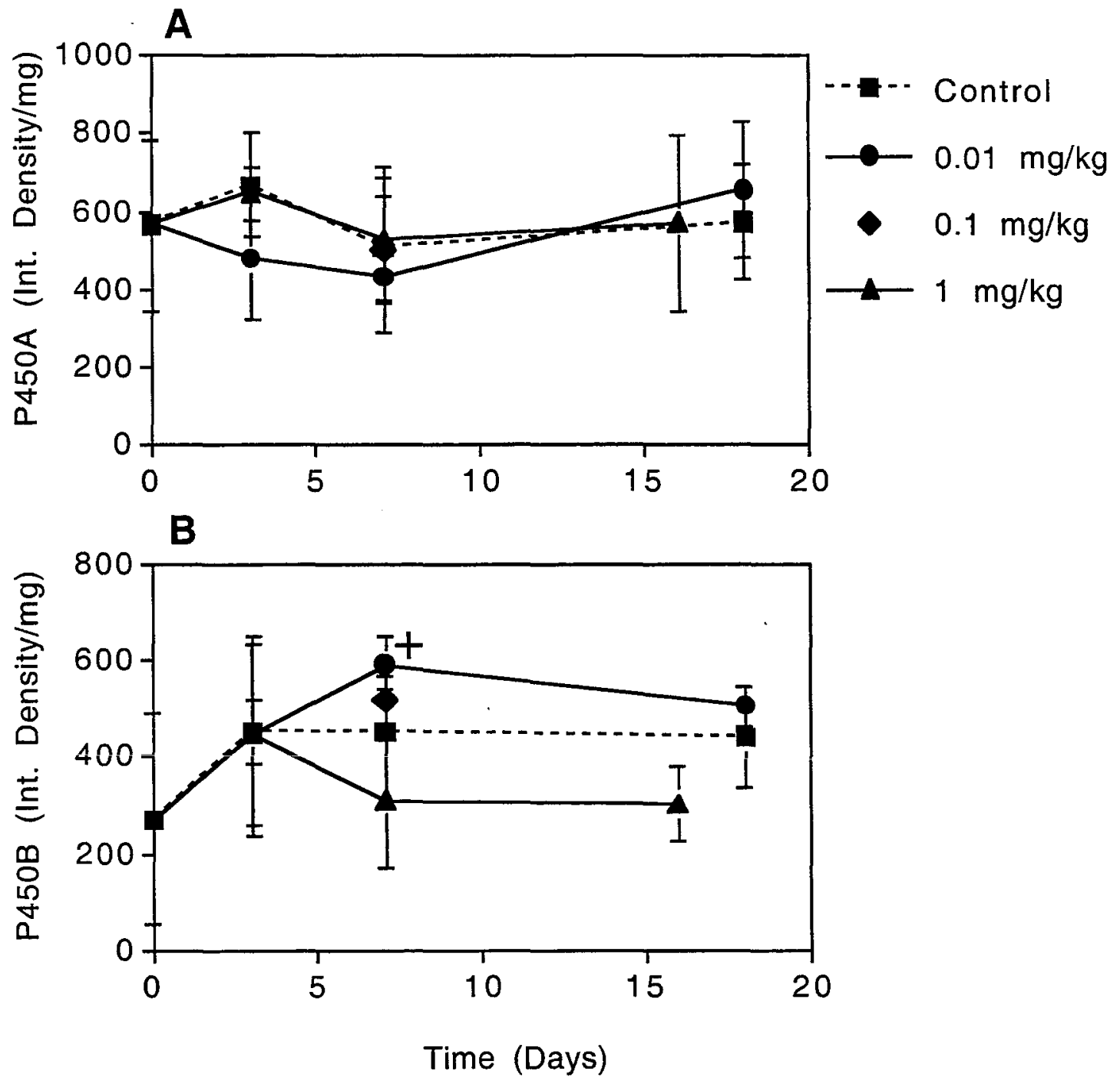

Figure 5. Effect of PeCB on hepatic microsomal P450A (A) and P450B (B). Liver microsomal fractions ( $30 \mu \mathrm{g} / \mathrm{lane}$ ) were electrophoresed, transferred to nylon membrane, and immunoblotted with polyclonal anti-scup P450A (a CYP3A-like protein) and polyclonal anti-scup P450B (a CYP2B-like protein). Reactive bands were visualized using enhanced chemiluminescence and quantified by densitometric analysis. Data represent the means \pm SD of measurements on 6 fish per treatment group except for the $0.01 \mathrm{mg} / \mathrm{kg}$ dose on Day $18(\mathrm{n}=4)$ and the $1 \mathrm{mg} / \mathrm{kg}$ dose on Day $16(\mathrm{n}=3)$. +-Statisically different from control and $1 \mathrm{mg} / \mathrm{kg}$ dose $(\mathrm{p}<0.05)$. 
oxygen species during its interaction with pHAHs (DeMatteis et al., 1991; Park et al., 1996; Chapters 3 and 4). The potential for hepatic microsomes to produce ROS was determined by incubating microsomes with PCB 126, NADPH and HE. HE is oxidized to the fluorescent product ethidium by superoxide (Robinson et al., 1994). HE oxidation was greatest in microsomes from fish treated with the $0.01 \mathrm{mg} \mathrm{PeCB} / \mathrm{kg}$ dose (Figure 6A). The potential to produce ROS was significantly elevated by Day 7 in the 0.01 and $0.1 \mathrm{mg}$ $\mathrm{PeCB} / \mathrm{kg}$ dose groups, and it remained elevated in the $0.01 \mathrm{mg} \mathrm{PeCB} / \mathrm{kg}$ dose group through Day 18. The $1 \mathrm{mg} \mathrm{PeCB} / \mathrm{kg}$ dose did not significantly affect the potential to produce ROS. The potential to produce ROS was highly correlated with EROD activity (Figure 6B).

In vivo oxidative stress was assessed by measuring the activities of several antioxidant enzymes. Similar patterns of induction were seen with all of the anti-oxidant enzymes measured, including catalase, glutathione peroxidase, glutathione reductase and superoxide dismutase (Figure 7). The activities of all of the enzymes were significantly induced by the $0.01 \mathrm{mg} \mathrm{PeCB} / \mathrm{kg}$ dose at Day 3 and then decreased through Day 18 . Glutathione peroxidase activity remained significantly elevated on Day 7. The 0.1 and 1 $\mathrm{mg} \mathrm{PeCB} / \mathrm{kg}$ doses did not significantly alter the activity of any of the anti-oxidant enzymes over the course of the experiment.

Extrahepatic organs: The patterns of CYP1A induction in microsomes from extrahepatic tissues differed from that seen liver microsomes. In heart, CYP1A content was significantly induced by the $0.01 \mathrm{mg} P \mathrm{PCB} / \mathrm{kg}$ dose by Day 7 and continued to increase over time (Figure $8 \mathrm{~A}$ ). The $1 \mathrm{mg} \mathrm{PeCB} / \mathrm{kg}$ dose strongly induced CYP1A content in the heart by Day 16 . In gill, only the 0.01 and $0.1 \mathrm{mg} \mathrm{PeCB} / \mathrm{kg}$ dose significantly induced CYP1A content over that in controls, despite an increase in CYP1A content in the $1 \mathrm{mg}$ $\mathrm{PeCB} / \mathrm{kg}$ dose group on Day 16 (Figure $8 \mathrm{~B}$ ). In the kidney, a significant increase in CYP1A content was seen in the $1 \mathrm{mg} \mathrm{PeCB} / \mathrm{kg}$ dose group by Day 3 (Figure 8C). By Day 7, all three dose groups had similar induction of renal CYP1A. The CYP1A content remained elevated in both the 0.01 and $1 \mathrm{mg} \mathrm{PeCB} / \mathrm{kg}$ dose groups through Days 16-18.

EROD induction had a slightly different pattern than that seen with CYP1A content in extra-hepatic organs. In heart, EROD activity was significantly induced by $0.01 \mathrm{mg}$ $\mathrm{PeCB} / \mathrm{kg}$, reaching a maximal level by Day 7 (9-fold induction) which was sustained to the end of the experiment (Figure 9A). The $0.1 \mathrm{mg} \mathrm{PeCB} / \mathrm{kg}$ dose did not induce EROD activity significantly in heart. EROD activity was strongly induced by the $1 \mathrm{mg} \mathrm{PeCB} / \mathrm{kg}$ dose at Day 16 (10-fold induction). In gill, the $0.01 \mathrm{mg} \mathrm{PeCB} / \mathrm{kg}$ dose significantly 

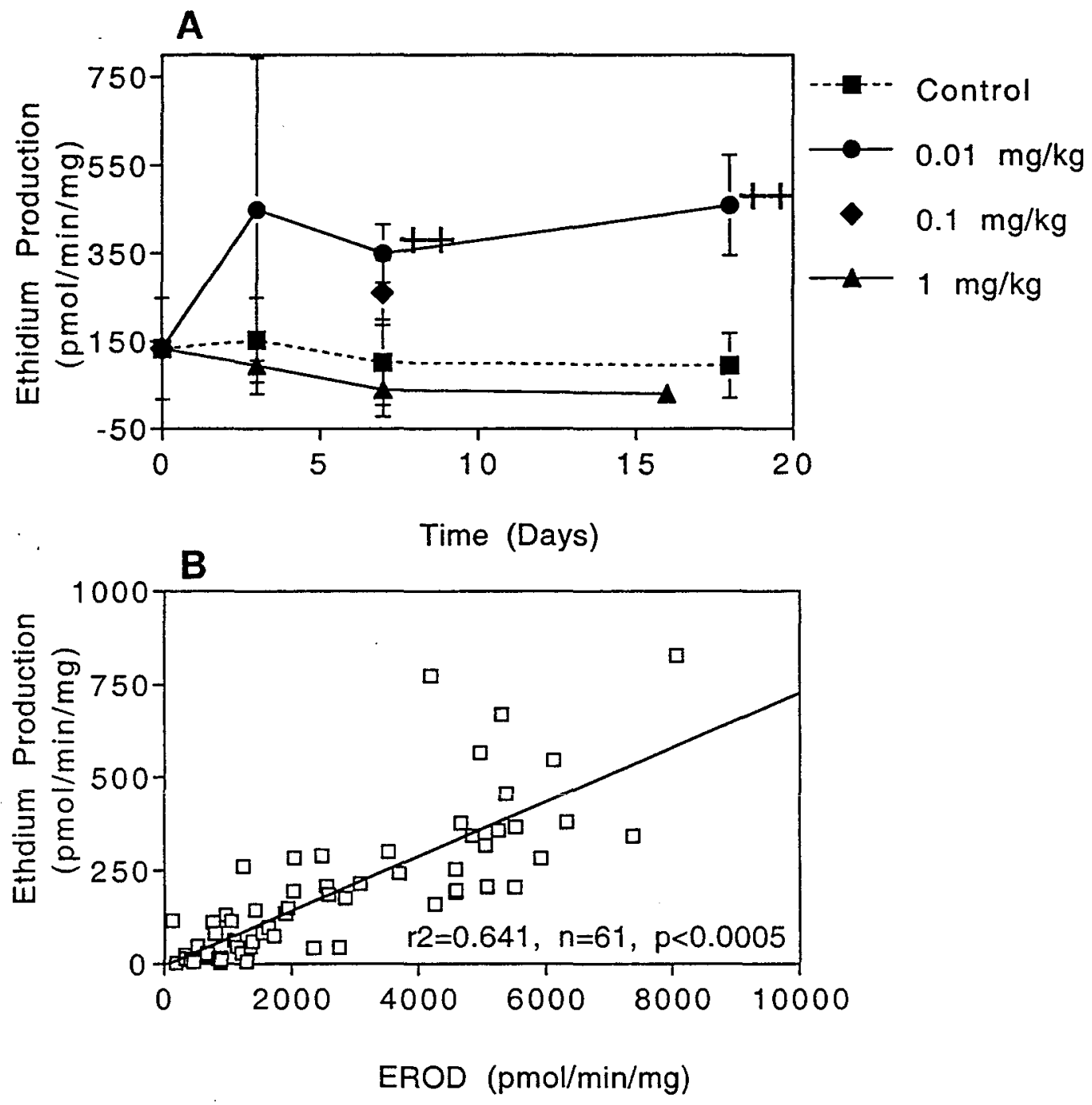

Figure 6. Effect of PeCB on the potential of hepatic microsomes to produce ROS (A) and correlation of ROS production with EROD activity (B). Microsomal protein $(0.1 \mathrm{mg})$ was diluted in HBSS containing $7.5 \mu \mathrm{M} \mathrm{HE}$ (final concentration). Following a 15 minute preincubation at $30^{\circ} \mathrm{C}$, either acetone $(5 \mu \mathrm{l})$ or $\mathrm{PeCB}(1.7 \mathrm{nmol}$ in acetone) was added. Reactions were initiated with NADPH $(1.4 \mathrm{mM})$, and fluorescence was monitored over 10 minutes. ROS production stimulated by PCB 126 was calculated by subtracting the fluorescence in the well containing acetone to that in the well containing PeCB. Data represent the means \pm SD of measurements on 6 fish per treatment group except for the $0.01 \mathrm{mg} / \mathrm{kg}$ dose on Day $18(\mathrm{n}=4)$ and the $1 \mathrm{mg} / \mathrm{kg}$ dose on Day $16(\mathrm{n}=3)$. ${ }^{++}$-Statisically different from control and $1 \mathrm{mg} / \mathrm{kg}$ dose $(\mathrm{p}<0.01)$. The $0.1 \mathrm{mg} / \mathrm{kg}$ dose was significantly different from control and $1 \mathrm{mg} / \mathrm{kg}$ dose $(\mathrm{p}<0.05)$. 
Figure 7. Effect of $\mathrm{PeCB}$ on hepatic cytosolic catalase activity (A), glutathione peroxidase activity (B), glutathione reductase activity (C), and superoxide dismutase activity (D). Enzyme activities were quantified spectrophotometrically. Data represent the means \pm SD of measurements on 6 fish per treatment group except for the $0.01 \mathrm{mg} / \mathrm{kg}$ dose on Day 18 $(\mathrm{n}=4)$ and the $1 \mathrm{mg} / \mathrm{kg}$ dose on Day $16(\mathrm{n}=3)$. +-Statisically different from control and 1 $\mathrm{mg} / \mathrm{kg}$ dose $(\mathrm{p}<0.05)$. ${ }^{++}$-Statisically different from control and $1 \mathrm{mg} / \mathrm{kg}$ dose $(\mathrm{p}<0.01)$. \#-Statistically different from control ( $\mathrm{p}<0.05$ ). 

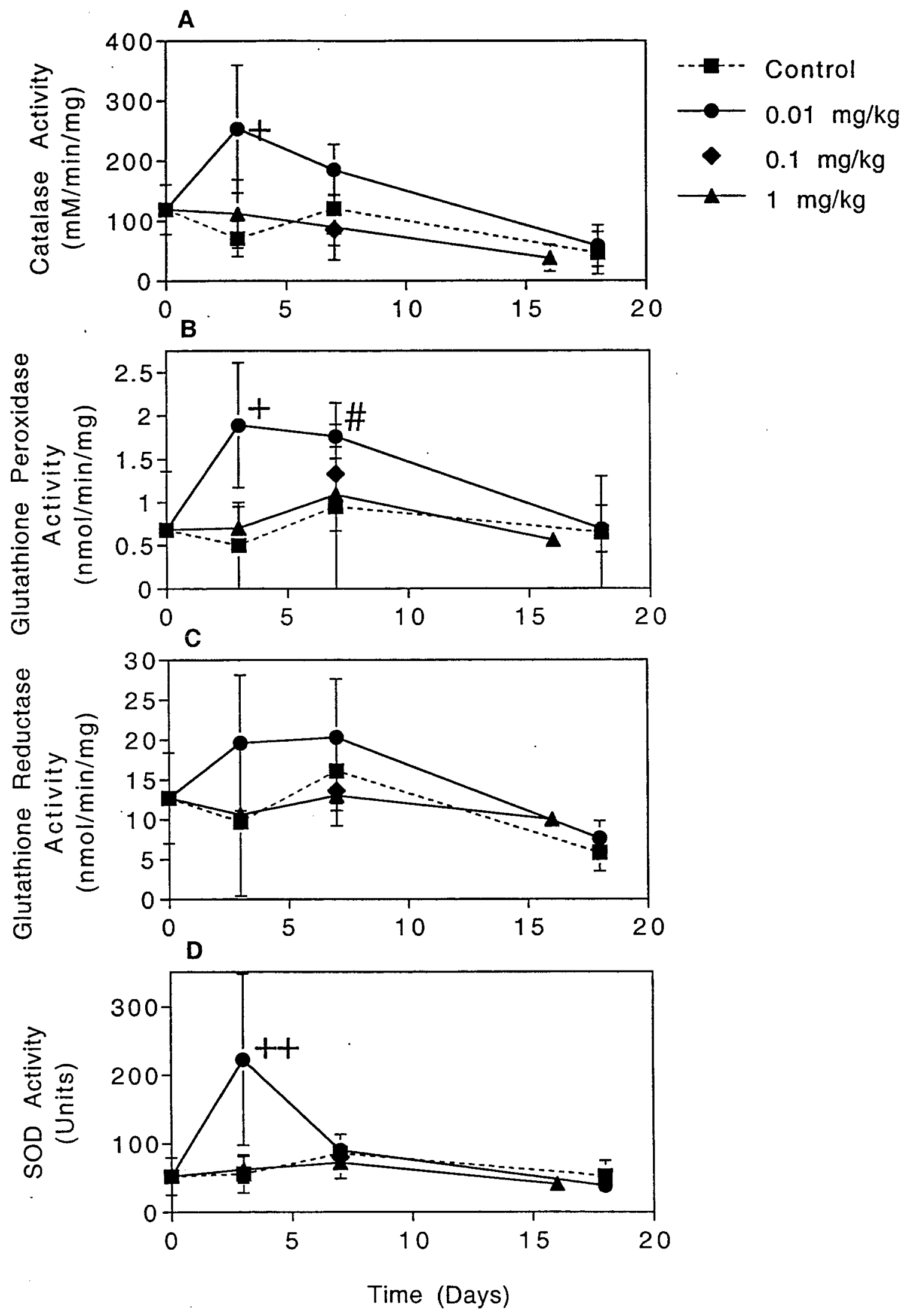
Figure 8. Effect of PeCB on extra-hepatic microsomal CYP1A content. A) Heart. B) Gill. C) Kidney. For each time point, organs from fish in the same tank were pooled before microsome preparation. Microsomal fractions (30 $\mathrm{g} / \mathrm{lane}$ ) were electrophoresed, transferred to nylon membrane, and immunoblotted with MAb 1-12-3 against scup CYP1A. CYP1A reactive bands were visualized using enhanced chemiluminescence and quantified by densitometric analysis. Data represent the means \pm SD of measurements on 3 pools per treatment group. +-Statisically different from control and $1 \mathrm{mg} / \mathrm{kg}$ dose $(\mathrm{p}<0.05)$. \#-Statistically different from control $(\mathrm{p}<0.05)$. \#\#-Statistically different from control $(\mathrm{p}<0.01)$. For gill and kidney, the $0.1 \mathrm{mg} / \mathrm{kg}$ dose was significantly different from control and $1 \mathrm{mg} / \mathrm{kg}$ dose $(\mathrm{p}<0.05)$. 

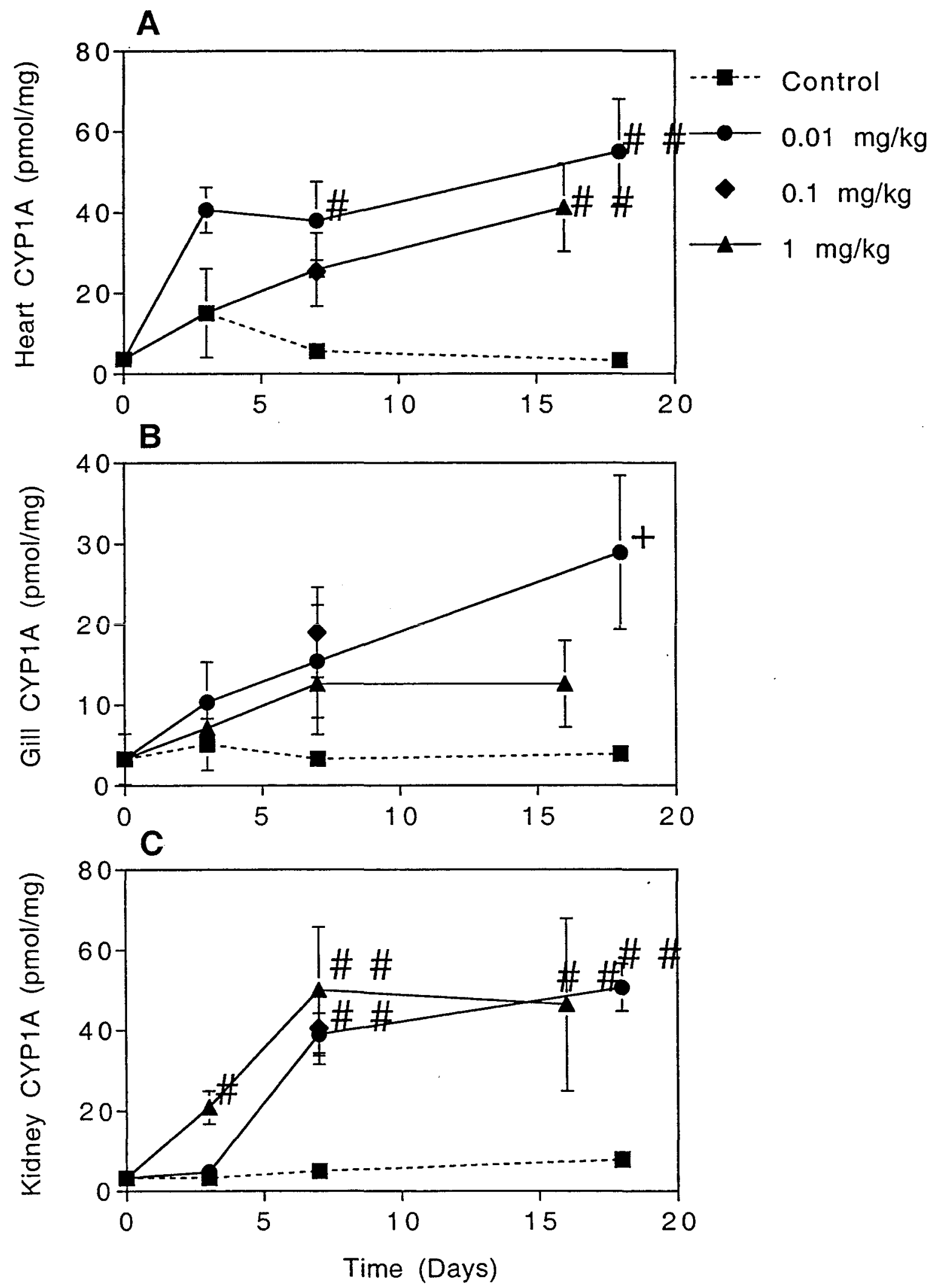
Figure 9. Effect of PeCB on extra-hepatic microsomal CYP1A catalytic activity (EROD). A) Heart. B) Gill. C) Kidney. For each time point, organs from fish in the same tank were pooled before microsome preparation. EROD activity was determined fluorometrically. Data represent the means \pm SD of measurements on 3 pools per treatment

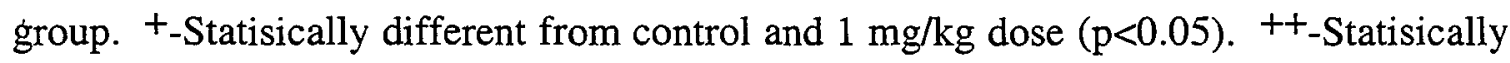
different from control and $1 \mathrm{mg} / \mathrm{kg}$ dose $(\mathrm{p}<0.01)$. \#-Statistically different from control $(\mathrm{p}<0.05)$. \#\#-Statistically different from control $(\mathrm{p}<0.01)$. For gill and kidney, the 0.1 $\mathrm{mg} / \mathrm{kg}$ dose was significantly different from control and $1 \mathrm{mg} / \mathrm{kg}$ dose $(\mathrm{p}<0.05)$. 

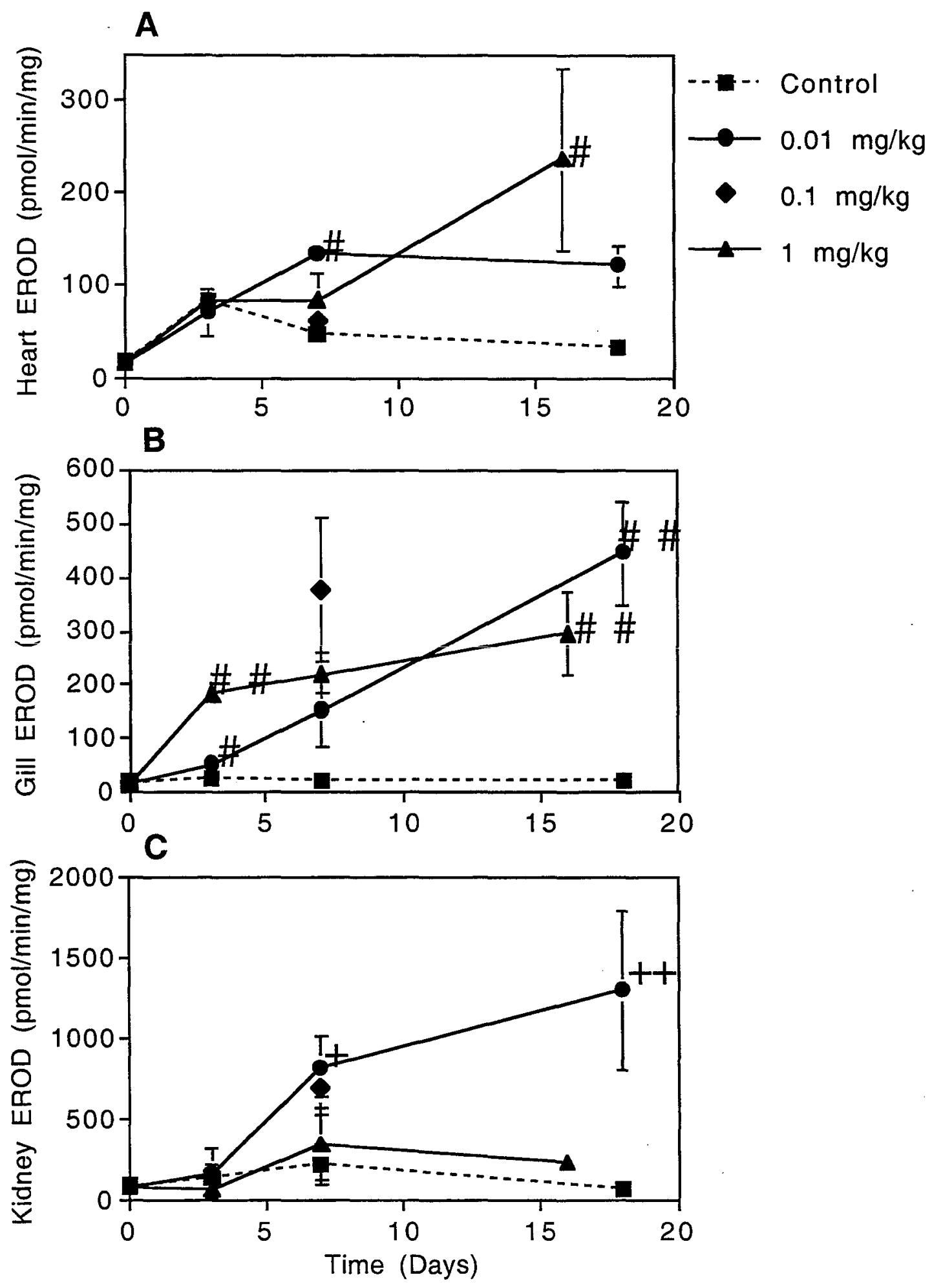
induced EROD activity by Day 7, and the activity continued to increase through Day 18 (14-fold maximal induction)(Figure 9B). At Day 7, EROD activity was greatest in the 0.1 $\mathrm{mg} \mathrm{PeCB} / \mathrm{kg}$ dose group (9-fold induction). The $1 \mathrm{mg} P e C B / \mathrm{kg}$ dose significantly increased EROD activity in gill by Day 3 with a slight increase in activity through Day 16. Unlike the other extrahepatic organs, while the $0.01 \mathrm{mg} \mathrm{PeCB} / \mathrm{kg}$ dose strongly induced renal EROD activity from Days 7-18, the EROD activity in the $1 \mathrm{mg} \mathrm{PeCB} / \mathrm{kg}$ dose group was suppressed throughout the entire experiment (Figure 9C). The $0.1 \mathrm{mg} \mathrm{PeCB} / \mathrm{kg}$ dose significantly induced renal EROD activity on Day 7.

\section{DISCUSSION}

Planar HAH can regulate CYP1A via induction, inhibition and inactivation. Coplanar CB congeners, including TCB, PeCB and 3,3',4,4',5,5-hexachlorobiphenyl are potent inducers of CYP1A (Parkinson et al., 1980; Melancon and Lech, 1983; Parkinson et al., 1983; Gooch et al., 1989; Miranda et al., 1990; Monosson and Stegeman, 1991; Palace et al., 1996). Presumably all coplanar CBs are competitive inhibitors of CYP1A, as has been shown for TCB (Gooch et al., 1989). In vitro studies also have shown that coplanar CB congeners oxidatively inactive CYP1A (White et al., 1997a; Chapters 3 and 4). PeCB potently induced CYP1A mRNA, protein and catalytic activity at low doses (0.01-0.1 $\mathrm{mg} / \mathrm{kg})$ and induced CYP1A mRNA at a high dose $(1 \mathrm{mg} / \mathrm{kg})$ but suppressed induction of CYP1A protein and catalytic activity at that high dose. Suppression of hepatic CYP1A content by high doses of TCB (White et al., 1997a) and PeCB may be attributed to the same oxidative inactivation seen in vitro. The organ specificity of CYP1A-suppression could result simply from a lesser concentration of $\mathrm{PeCB}$ or from a reduction in reductase activity in extra-hepatic organs (Stegeman et al., 1982). This study and others have demonstrated oxidative stress resulting from $\mathrm{pHAH}$ exposure, supporting the conclusion that CYP1A produces ROS in vivo and that ROS are the in vivo mechanism of CYP1A inactivation.

Comparison of Induction and Suppression of CYPIA by PeCB and TCB: PeCB was a more potent inducer of CYP1A than TCB, with maximal induction being reached at a dose of $0.01 \mathrm{mg} \mathrm{PeCB} / \mathrm{kg}$, as compared to a dose of $0.1 \mathrm{mg} \mathrm{TCB} / \mathrm{kg}$ (White et al., 1997a). The same relationship has been seen in rainbow trout (Newsted et al., 1995) and mammals (Safe et al., 1985). At a dose of $0.1 \mathrm{mg} / \mathrm{kg} \mathrm{PeCB}$, CYP1A induction was similar to that with $0.01 \mathrm{mg} \mathrm{PeCB} / \mathrm{kg}$, although there may have been slight inactivation at this dose. In absolute values, the low dose of PeCB induced CYP1A protein and activity with similar 
efficacy as TCB (White et al., 1997a). The fold induction of CYP1A protein and activity by PeCB was lower than that seen with TCB; however, this is only a result of the fact that the fish used in the current experiment were not depurated as long as those in the TCB experiment.

In vitro studies have suggested that oxidative inactivation of scup CYP1A occurs not only with TCB, but also with PeCB, 2,3,3',4,4'-pentachlorobiphenyl, and $3,3^{\prime}, 4,4^{\prime}, 5,5^{\prime}$-hexachlorobiphenyl (Chapter 4). In this study, we have demonstrated that inactivation of CYP1A by PeCB apparently occurs in vivo. Comparison of nominal doses of TCB and PeCB suggests that a similar dose $(\approx 1 \mathrm{mg} / \mathrm{kg})$ is required for PeCB and TCB

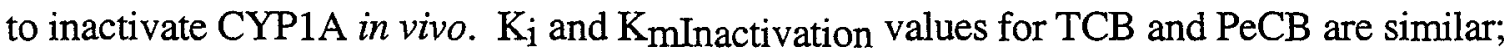
however the rate of inactivation of EROD activity was greater with PeCB than with TCB (Chapter 4). The loss of suppression by TCB at Day 16 probably resulted from the significant decrease in the hepatic TCB concentration (White et al., 1997a). Suppression of CYP1A was maintained by the high dose of PeCB despite the dose being 5-fold lower than that used previously with TCB; this may result from PeCB being eliminated more slowly than TCB (Yoshimura et al., 1987; Koga et al., 1990). Residue analysis of the livers of these fish are required to confirm this hypothesis.

High doses of both TCB and PeCB caused complete suppression of EROD but induced CYP1A protein moderately. Loss of catalytic activity following treatment with high doses of coplanar CB congeners without the loss of protein occurs in vivo (Melancon and Lech, 1983; Voorman and Aust, 1988; Miranda et al., 1990; Monosson and Stegeman, 1991; Lindstrom-Seppa et al., 1994) and in cultured cells (Sawyer and Safe, 1982; Rodman et al., 1989; Hahn et al., 1993; Kennedy et al., 1993; Hahn and Chandran, 1996; Lorenzen et al., 1997). This suggests that inhibition may contribute partially to the loss of EROD activity (Gooch et al., 1989). However, in in vitro assays, despite the total loss of EROD activity and substantial loss of spectral P450 during incubation with TCB and NADPH, there is no loss of immunodetectable CYP1A (White et al., 1997a). Thus, the inactivated protein may retain the epitope recognized by the antibody, and degradation of the protein may occur more slowly than inactivation. A similar lag between loss of catalytic activity and loss of protein is seen during the mechanism-based inactivation of CYP1A1 by analogues of 3,5-diethoxycarbonyl-1.4-dihydro-2,4,6-trimethylpyridine (Riddick et al., 1990).

As with the regulation of CYP1A by TCB, the effects of PeCB appear to be largely specific for CYP1A. Heme production was not suppressed generally, as the cytochrome 
b5 content remained constant for all treatments over the course of the experiment. Significant, sustained protein induction following the low dose $\mathrm{PeCB}$ treatment and significant suppression of protein induction following the high dose of $\mathrm{PeCB}$ only occurred with CYP1A and not with P450A or P450B.

The data also may suggest that another CYP was induced transiently. While the relationship between total P450 and CYP1A remained constant throughout the experiment, the turnover number for EROD activity decreased on Day 3. Peaks in total P450, CYP1A content and MROD activity, but not EROD activity occurred on Day 3. PeCB induces both CYP1A1 and CYP1A2 in mammals (Safe et al., 1985). Therefore, one explanation for this anomaly may be that a P450 that is recognized by MAb 1-12-3 and catalyzes MROD activity was induced on Day 3. However, to date, MAb 1-12-3 has been thought to recognize only one protein (Park et al., 1986), and scup have been thought to have only one CYP1A (Morrison et al., 1995). Multiple CYP1A genes have been isolated from trout treated with 3-methylcholanthrene (Berndtson and Chen, 1994), and potentially a second CYP1A exists in scup. Further, experiments are required to address this issue.

CYPIA and Oxidative Stress In Vivo: Induction of specific P450 isoforms has been correlated with increased oxidase activity in microsomes. Ethanol treatment in rats results in induction of CYP2E1, oxidase activity and lipid peroxidation (Ekstrom and Ingelman-Sundberg, 1989). Some studies indicate that there is an increase in microsomal oxidase activity following treatment with CYP2B inducers; however, results have been variable (Auclair et al., 1978; Urquhart and Elder, 1987; Buchmann et al., 1991; Sakai et al., 1992). Liver microsomes from mice treated with hexachlorobenzene or 3methylcholanthrene (MC) and rats treated with TCB or MC produce elevated amounts of ROS (Urquhart and Elder, 1987; Buchmann et al., 1991). However, the results with rats also have been contradicted (Sakai et al., 1992). In the experiments performed here, there was no increase in oxidase activity without the presence of additional PeCB. Very low doses of PeCB were originally administered, therefore much of it may have been removed during microsome preparation. Thus, the variable results seen previously with CYP1A may be related to the original dose and the removal of the compound during microsome preparation.

A growing body of studies support the conclusion that the pHAH, TCDD, induces oxidative stress in vivo. Treatment of female rats with TCDD results in a $600 \%$ increase in single strand breaks in DNA and a 500\% increase in lipid peroxidation in the liver (Stohs et al., 1990). Peritoneal lavage cells (PLC) from TCDD treated rats exhibit increased $\mathrm{O}_{2}{ }^{-\bullet}$ 
production and single strand DNA breaks (Alsharif et al., 1994). TCDD-stimulated toxicity (Poland and Glover, 1980) and oxidative stress both appear to be AhR dependent In PLC from AhR-responsive mice a 25-fold lower dose of TCDD is required to stimulate $\mathrm{O}_{2} \bullet$ production than that required in non-responder mice (Alsharif et al., 1994). TCDD exposure induces both CYP1A activity and oxidative DNA damage in Hepalc1c7 cells, but induces neither in AhR defective c4 cells (Park et al., 1996). Potentially, $\mathrm{H}_{2} \mathrm{O}_{2}, \mathrm{O}_{2} \cdot \bullet$ and $\mathrm{OH} \bullet$ all are involved in TCDD-induced oxidative damage (Stohs et al., 1986).

Treatment with CB mixtures, as well as specific congeners, also promotes oxidative stress. Aroclor 1254 treatment stimulates hepatic lipid peroxidation in chickens, rats and guinea pigs (Combs and Scott, 1975; Kato et al., 1981; Dogra et al., 1988). Kestrels show increased lipid peroxidation following treatment with PeCB (Hoffman et al., 1996). This study and others have demonstrated increases in both CYP1A content and antioxidant enzyme activity following exposure to TCB and PeCB in fish (Otto and Moon, 1995; Palace et al., 1996). Further, iron potentiates 8-hydroxydeoxyguanosine formation, hepatocarcinogenesis and uroporphyria in AhR responsive mice (C57BL but not DBA/2) exposed to Aroclor 1254 (Faux et al., 1992; Smith et al., 1995). Considering that iron can act as a Fenton catalyst converting ROS produced in cells to $\mathrm{OH} \cdot$ which can attack cellular components, this data suggests that ROS are associated with that toxicity.

Despite that facts that $\mathrm{pHAH}$-stimulated oxidative stress is apparently AhR dependent (Faux et al., 1992; Smith et al., 1995) and that only microsomes with induced levels of CYP1A produce ROS (Chapter 3), there may be in vivo sources of ROS other than CYP1A. Potential sources of ROS can be narrowed by the fact that hepatic microsomal and mitochondrial fractions but not cytosolic fractions from TCDD-treated rats can increase the incidence of DNA single strand breaks (Wahba et al., 1989). First, pHAH may stimulate xanthine oxidase, peroxisome proliferation or mitochondrial multiplication (Stohs, 1990). Polychlorinated biphenyls with 3 or fewer chlorine substitutions can be metabolized to redox-cycling quinones (Oakley et al., 1996). Neutrophils can be activated by PCBs, but only by ortho-substituted PCBs (Ganey et al., 1993). Finally, NADPHcytochrome P450 reductase can be induced by pHAH (Manjunath and Dufresne, 1988) and is a known source of ROS (Morehouse et al., 1984). While CYP1A is implicated as the source of ROS in in vitro studies, alterations in mitochondrial activities or reductase activity may contribute to the oxidative stress stimulated by more highly chlorinated pHAHs in vivo. 
The toxicity of coplanar PCBs is correlated with the AhR and CYP1A induction; however, metabolic activation of these congeners is not significant. The production of ROS during the interaction of coplanar congeners with CYP1A may explain in part the role of CYP1A in the toxicity of pHAHs. One consequence of that ROS production may be self-inactivation of CYP1A, as has been shown with several coplanar congeners in vitro and with TCB and PeCB in vivo in the fish model scup. The consequences of a loss of CYP1A are unknown, but studies have shown a regulatory relationship between CYP1A and the AhR which may be perturbed by the loss of CYP1A (Chang and Puga, 1998). The multiplying studies which demonstrate oxidative stress following exposure to $\mathrm{pHAHs}$ supports the in vitro evidence of ROS production by CYP1A. 


\section{CHAPTER 6}

Characterization of the Reactive Oxygen Sensitive Transcription Factor, Nuclear Factor- $\mathrm{KB}$ in the Marine Fish Scup (Stenotomus chrysops) and Examination of its Activation by Aryl Hydrocarbon Receptor Agonists 


\section{ABSTRACT}

Members of the Rel family of proteins have been identified in Drosophila, Xenopus, birds and mammals, and evidence suggests that xenobiotic compounds may alter the activation of nuclear factor- $\mathrm{KB}(\mathrm{NF}-\mathrm{KB})$. Here we demonstrate that apparent members of the Rel protein family also exist in liver, kidney and heart of the marine fish scup (Stenotomus chrysops). Using the electrophoretic mobility shift assay, binding of an NF$\mathrm{KB}$ consensus sequence was evident, but highly variable, in vehicle-treated fish. The activation of NF- $\mathrm{kB}$ in vehicle-treated fish appeared to decrease over time. Two xenobiotic compounds, benzo[a]pyrene (BP) and 3,3',4,4',5-pentachlorobiphenyl (PeCB), were tested for the ability to activate NF-kB-DNA binding in scup liver. A $10 \mathrm{mg} \mathrm{BP} / \mathrm{kg}$ dose had no effect on NF-KB-DNA binding either at 3 or 6 days following treatment. Two experiments with $\mathrm{PeCB}$ gave conflicting results. The first experiment showed a 6-8-fold increase in activation 16-18 days following treatment with $\mathrm{PeCB}(0.01-1 \mathrm{mg} / \mathrm{kg})$; however, the second experiment showed no significant activation 14 days following treatment. The results appeared to be confounded both by the apparent injection effect and by high variability. Nuclear proteins from scup kidney and heart also specifically bound the NF$\kappa B$ consensus sequence, but with no dose specific pattern. The specificity and identity of the shifted band was confirmed. Scup liver nuclear extracts did not bind to the consensus binding sequences of another redox sensitive transcription factor AP-1 or a ubiquitous mammalian transcription factor Oct1. The binding was specifically competed by oligonucleotides containing various sequences of NF- $\mathrm{KB}$ binding regions; however, an oligonucleotide containing the aryl hydrocarbon receptor dioxin response element did not inhibit the band-shift. A DNA-protein crosslinking technique demonstrated that 3 proteins bound the NF- $\mathrm{KB}$ consensus sequence in scup liver, kidney and heart, 2 of which potentially correspond to the mouse p50 and RelA (p65) proteins as well as a smaller protein of approximately $30 \mathrm{kD}$. Antibodies to mammalian p50 primarily immunoprecipitated the apparent $50 \mathrm{kD}$ protein in scup liver, kidney and heart. The data indicate that the Rel family of proteins is present in fish and represented by at least a p50 homologue. Activation of NF- $\mathrm{kB}$ by aryl hydrocarbon receptor agonists remains a question, however. 


\section{INTRODUCTION}

$\mathrm{NF}-\mathrm{KB}$ is a multisubunit transcription factor that can rapidly activate genes encoding cytokines, cell surface receptors, cell adhesion molecules and acute phase proteins (Baeuerle, 1991). NF- $\mathrm{KB}$ subunits are members of the Rel homology family of proteins. The Rel homology domain is a 300-amino acid region which contains a DNAbinding region, a dimerization domain, a nuclear translocation signal and a region of interaction with proteins of the IKB family (Miyamoto and Verma, 1995; Verma et al., 1995). In mammals, the Rel family is represented by RelA, RelB, cRel, NF-kB 1 (p52/p100) and NF-kB2 (p50/p105) (see (Huguet et al., 1997)). The Rel family is represented by dorsal, dif and relish in Drosophila (Steward, 1987; Ip et al., 1993; Dushay et al., 1996). Homologs of NF-kB1, RelA, RelB and cRel have been sequenced from Xenopus (Kao and Hopwood, 1991; Suzuki et al., 1995; Tannahill and Wardle, 1995;

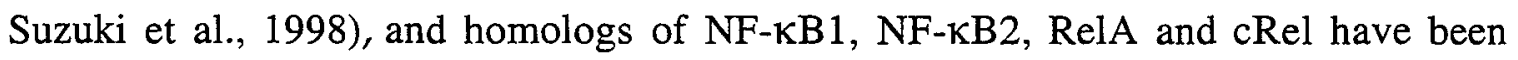
sequenced from birds (Wilhelmsen et al., 1984; Capobianco et al., 1990; Capobianco et al., 1992; Ikeda et al., 1993; Sif and Gilmore, 1993). RelA, RelB and cRel are synthesized "ready-to-use" and contain a transactivating domain, while p50 and p52 are proteolytically matured and do not contain a transactivating domain. Multiple homo- and heterodimers may by formed, the classic NF- $\mathrm{KB}$ dimer being p50/RelA. Different $\kappa B$ binding sites in gene promoters have different affinities for dimers, and thus the identity of the subunits in the dimer confer specificity to gene activation (Miyamoto and Verma, 1995; Muller et al., 1996).

Usually, NF-KB dimers are sequestered in the cytoplasm by an inhibitor, IKB. Upon stimulation by cytokines, mitogens, viral infection, $U V$ irradiation or reactive oxygen species (ROS), the inhibitor is phosphorylated, ubiquinated and digested by a proteosome, allowing NF- $\mathrm{KB}$ to translocate to the nucleus and bind DNA (Baldwin, 1996). In many cases, ROS are used as second messengers to initiate degradation of $\mathrm{IKB}$, as antioxidants block NF- $\mathrm{kB}$ activation by potent activators such as tumor necrosis factor- $\alpha$, interlukin-1, phorbol 12-myristate 13-acetate, lipopolysaccharide and okadaic acid (Schreck et al., 1991).

Recent studies have shown that xenobiotic compounds also may activate NF- $\mathrm{KB}$ binding. 2,3,7,8-Tetrachlorodibenzo-p-dioxin (TCDD) transiently stimulates NF-kB binding in rat thymocytes (Olnes et al., 1994), and TCDD-mediated activation of expression of a chloramphenicol acetyltransferase (cat) reporter gene linked to the promoter sequence of the human immunodeficiency virus type 1 (HIV-1) requires NF- $\mathrm{KB}$ activation 
(Yao et al., 1995). Two polynuclear aromatic hydrocarbons, 7,12-dimethylbenz[a]anthracene (DMBA) and benzo[a]pyrene (BP), transiently stimulate NF- $\mathrm{kB}$ binding in murine hepatoma cells (Shneider et al., submitted) and murine stromal cells (K. K. Mann, unpublished results). A more sustained activation of NF- $\mathrm{KB}$ binding is seen following treatment of HepG2 cells with quinones, including menadione and tert-butylhydroquinone (Pinkus et al., 1996; Chen and Cederbaum, 1997). In vivo, phenobarbital, ciprofibrate and carbon tetrachloride all have been shown to activate NF- $\mathrm{KB}$ binding in rat liver (Gruebele et al., 1996; Li et al., 1996; Li et al., 1996). ROS have been suggested to be a second messenger in the activation of NF-KB by xenobiotic compounds.

Aryl hydrocarbon receptor (AhR) mediated pathways may be contributing to the activation of NF- $\kappa B$. DMBA- and BP-mediated NF- $\mathrm{kB}$ activation have been shown to be AhR dependent (Shneider et al., submitted). The AhR regulates the expression of drug metabolizing enzymes, including cytochromes P450 1As (CYP1A), and genes involved in cell growth control (Hankinson, 1995). Studies have produced conflicting results as to whether AhR-mediated NF-KB activation is dependent upon CYP1A (Yao et al., 1995; Shneider et al., submitted). AhR agonists may activate NF-KB through CYP1A by stimulating its production of ROS. CYP1A might contribute to the production of ROS by forming redox cycling metabolites or by abortive reduction. In this study we investigated the effects of two AhR agonists on NF- $\mathrm{KB}$ activation in the marine fish scup (Stenotomus chrysops). BP is metabolized to 3 redox cycling quinones in mammals and fish (Lorentzen and Ts'o, 1977; Stegeman, 1981; Klotz et al., 1983), and the coplanar polychlorinated biphenyl 3,3',4,4',5-pentachlorobiphenyl (PeCB) stimulates ROS production by uncoupling the CYP1A catalytic cycle (Chapter 4).

Here we demonstrate for the first time that members of the Rel family of proteins are present in a teleost. An NF- $\mathrm{kB}$ consensus sequence bound at least 3 proteins in scup liver, kidney and heart, two of which potentially correspond with mammalian p50 and RelA. An antibody to mammalian p50 immunoprecipitated the $\approx 50 \mathrm{kD}$ binding protein in all 3 organs. An NF- $\kappa B$ consensus sequence was bound by nuclear proteins from untreated scup. BP did not increase the activation of NF- $\mathrm{kB}$, and PeCB activated NF- $\mathrm{kB}$ in only 1 of 2 experiments. While, we have confirmed the presence of the Rel family of proteins in a teleost, their regulation by AhR agonists is still a question. 


\section{MATERIALS AND METHODS}

Chemicals: 3,3',4,4',5-Pentachlorobiphenyl (IUPAC\# 126) was purchased from Ultra Scientific (North Kingstown, RI). Poly [dI-dC], pNd6 and 5-bromo-2'deoxyuridine were purchased from Boehringer Mannheim (Indianapolis, IN). [ $\gamma-32 \mathrm{P}] \mathrm{ATP}$ and $[\alpha-$ 32P]CTP were purchased from Amersham (Arlington Heights, $I L$ ). All other chemical reagents were purchased from Sigma (St. Louis, MO).

Animals: Scup (Stenotomus chrysops ) were caught by trapping in Vineyard Sound, MA in August, 1996 and the experiment conducted in August, 1997 or were caught in August, 1995 and the experiment conducted in June, 1998. Fish were held in flowthrough seawater tanks at $14^{\circ} \mathrm{C}$ and maintained on a diet of Purina Trout Chow. Treatment of fish in the August, 1997 experiment was described in Chapter 5. For the June, 1998 experiments, fish (mixed sex) were gonadally undeveloped. For the BP experiment, fish ranged in size from 90 to $252 \mathrm{~g}$. Fish were injected intra-peritoneally $(1 \mathrm{ml} / \mathrm{kg}$ body weight) with corn oil or a solution of BP $(10 \mathrm{mg} / \mathrm{ml})$ in corn oil. For each dose group, 3 tanks contained 3 fish each. At day 3 following injection one fish from each tank was sampled, at a day 6 the remaining fish were sampled. For the PeCB experiment, fish ranged in size from 39 to $107 \mathrm{~g}$. Fish were injected intra-peritoneally $(1 \mathrm{ml} / \mathrm{kg}$ body weight) with corn oil or solutions of $\mathrm{PeCB}(0.01$ or $1 \mathrm{mg} / \mathrm{ml})$ in corn oil. For each dose group, fish were split between 3 tanks. The control tanks contained 2 fish/tank. The low dose tanks contained 3 fish/tank. The high dose tanks contained 4 fish/tank. Fish were fed Purina Trout Chow once weekly and were sampled 14 days following treatment. Two of the high dose fish died prior to the completion of the experiment. Immediately following dissection, sections of liver, heart and kidney were frozen in liquid N2. Microsomes were prepared from portions of liver immediately following dissection.

Microsome preparation and analysis of CYP1A: Microsomes were prepared by differential centrifugation (Stegeman et al., 1979). Pellets were resuspended in buffer (50 $\mathrm{mM}$ TRIS, pH 7.4, $1 \mathrm{mM}$ dithiothrietol, $1 \mathrm{mM}$ EDTA, 20\% glycerol) and frozen in liquid $\mathrm{N}_{2}$ until use. Protein content was determined using the bicinchoninic acid method (Smith et al., 1985), with bovine serum albumin standards. Microsomal ethoxyresorufin Odeethylation (EROD) was determined fluorometrically (Hahn et al., 1993), using a Cytofluor 2300 (Millipore) multiwell plate reader. Immunoblotting procedures were modified from those previously described (Kloepper-Sams et al., 1987). Microsomal proteins (0.5-15 $\mu \mathrm{g} / \mathrm{lane})$ were resolved on 6-18\% SDS-PAGE gels and electrophoretically transferred to $0.05 \mu \mathrm{m}$ nitrocellulose membrane. The primary antibody was the mouse 
monoclonal antibody 1-12-3 (Park et al., 1986). The secondary antibody was a horseradish peroxidase-linked sheep anti-mouse IgG (Amersham). The immunoreactive bands were visualized using enhanced chemiluminescence (Amersham) and quantified by video image analysis (NIH Image $1.60 \mathrm{b5}$ ) by comparison to scup standards of known concentration.

Nuclear extract preparation: Crude nuclear extracts were prepared from tissues by the method of Deryckere and Gannon (1994). All manipulations were carried out at $4^{\circ} \mathrm{C}$. Tissues (100-300 mg) were ground in liquid $\mathrm{N}_{2}$ and added to a $15 \mathrm{ml}$ centrifuge tube with $5 \mathrm{ml}$ of isolation buffer (10 mM HEPES pH 7.9, $10 \mathrm{mM} \mathrm{KCl}, 0.1 \mathrm{mM}$ EDTA, $0.1 \mathrm{mM}$ EGTA, $1 \mathrm{mM}$ dithiothrietol (DTT), $0.5 \mathrm{mM}$ phenylmethylsulfonyl fluoride (PMSF)) that contained $0.6 \%$ IGEPAL. The ground tissues were homogenized with five strokes of pestle $\mathrm{B}$ in a Dounce homogenizer. Homogenates were spun at $500 \mathrm{~g}$ in a Sorval centrifuge for 30 seconds to remove unbroken tissue. The supernatant was transferred to another $15 \mathrm{ml}$ centrifuge tube, incubated for 5 minutes on ice and centrifuged for 5 minutes at $3000 \mathrm{~g}$. The supernatant was removed and the nuclear pellet transferred to a micro centrifuge tube. The pellet was resuspended in 50-100 $\mu$ l of extraction buffer $(20 \mathrm{mM}$ HEPES pH 7.9, $400 \mathrm{mM} \mathrm{NaCl}, 1.2 \mathrm{mM} \mathrm{MgCl} 2,0.2 \mathrm{mM}$ EDTA, $0.5 \mathrm{mM}$ DTT, $0.5 \mathrm{mM}$ PMSF and $5 \mu \mathrm{g} / \mathrm{ml}$ of each protease inhibitor (leupeptin, aprotinin, and pepstatin)) and incubated for 20 minutes. The supernatant was cleared by centrifuging at maximum speed in a microcentrifuge for 5 minutes. Protein content was determined using the bicinchoninic acid method (Smith et al., 1985), using bovine serum albumin as a standard. Supernatants were collected and stored at $-80^{\circ} \mathrm{C}$.

Gel-shift analysis of $N F-\kappa B$ activation: For analysis of NF- $\kappa \mathrm{B}$ activation, the double-stranded oligonucleotide 5'-AGTTGAGGGGACTTTCCCAGGC-3' (Promega, Madison, WI)) was used. The DNA probe was end-labeled using T4 polynucleotide kinase (Promega) and [ $\gamma-32$ P]ATP and was purified using a Centrispin-20 column (Princeton Separations, Adelphia, NJ). The electrophoretic mobility shift assay (EMSA) was performed as follows: the ${ }^{32}$ P-labeled DNA $(\sim 0.5 \mathrm{ng}, 50,000 \mathrm{cpm})$ and $2 \mu \mathrm{g}$ of nuclear extract were combined with buffer (Final concentrations: $10 \mathrm{mM}$ TRIS-HCl $\mathrm{pH}$ 7.5, $1 \mathrm{mM}$ EDTA, $40 \mathrm{mM} \mathrm{KCl}, 0.5 \mathrm{mM} \mathrm{MgCl} 2,1 \mathrm{mM} \mathrm{DTT}, 10 \%$ glycerol) and poly dI$\mathrm{dC}(1 \mu \mathrm{g})$ in a final volume of $20 \mu \mathrm{l}$. The mixture was incubated at room temperature for 30 minutes. Polyacrylamide gels $(6 \%)$ were pre-run at $80 \mathrm{~V}$ for 1 hour. Mixtures were electrophoresed at $80 \mathrm{~V}$ for 1.5 hours in $0.25 \mathrm{x}$ TBE (Final concentrations: $22 \mathrm{mM}$ TRISbase pH 8, $22 \mathrm{mM}$ boric acid, 0.4 mM EDTA). The gels were dried and exposed to film 
(Kodak X-OMAT AR). Shifted bands were quantified by video image analysis. EMSAs also were performed with ${ }^{32} \mathrm{P}$-labeled probes containing the AP-1 (Santa Cruz Biotechnology, Santa Cruz, CA) or Oct1 (Promega) consensus binding sequences. Specificity of shifted bands was determined by including 50-100x cold specific (NF-KB consensus sequences) and non-specific (AhR DRE 5'-GATCCGGCTCCGGCTCTTCTCACGCAACTCCGAGCTCAAAAA-3') oligonucleotides.

Identification of specific subunits: To identify specific NF- $\kappa B / R e l$ subunits, DNAprotein crosslinking studies were used (Ballard et al., 1989; Ballard et al., 1990). The photoreactive 32P-labeled oligonucleotide was prepared as follows. The oligonucleotide (5'-CAACGGCAGGGGAATTCCCCTCTCCTT-3') was annealed with the primer (5'AAGGAGAGGG-3') and filled in using the large fragment of DNA polymerase (Promega). The labeling mixture contained annealed oligonucleotide probe (5 pmol), $[\alpha-$ 32P]CTP $(50 \mu \mathrm{Ci})$, Klenow ( 2 units), BSA ( $2 \mathrm{mg}$ ) and buffer (Final concentrations: 20 mM HEPES 6.6, $2 \mathrm{mM} \mathrm{MgCl} 2,0.2 \mathrm{mM}$ DTT, $100 \mu \mathrm{M}$ each dATP, dGTP, dTTP, 100 $\mu \mathrm{M} 5^{\prime}$ bromo-2'deoxyuridine). The labeling reaction was performed at $16^{\circ} \mathrm{C}$ for 4 hours, chased with $0.4 \mathrm{mM}$ cold dCTP at room temperature for 30 minutes and purified using a Centrispin-20 column. The binding reaction was performed as follows: $5-20 \mu \mathrm{g}$ of nuclear extract were combined with buffer (Final concentrations: $20 \mathrm{mM}$ HEPES pH 7.9, 1 mM DTT, $1 \mathrm{mM}$ EDTA, 5\% glycerol), poly dI-dC $(1 \mu \mathrm{g})$, BSA $(5 \mu \mathrm{g})$, pdN6 $(1 \mu \mathrm{g})$ in a final volume of $20 \mu \mathrm{l}$. The mixture was incubated at room temperature for 5 minutes. The 32P-labeled DNA ( $2.5-5 \mathrm{ng}, 200,000-500,000 \mathrm{cpm})$ was added, and the mixture was incubated for 15 minutes at room temperature. The mixture was then incubated for 15 minutes under UV. At this point, some samples were boiled with sample treatment buffer and frozen at $-20^{\circ} \mathrm{C}$. Or, reaction mixtures were immunoprecipitated with antibodies to specific NF-kB/Rel subunits (Santa Cruz Biotechnology). To immunoprecipitate, a reaction mixture was combined with $180 \mu \mathrm{l}$ of RIPA buffer (10 mM TRIS pH 7.5, 150 $\mathrm{mM} \mathrm{NaCl}, 1 \mathrm{mM}$ EDTA, $1 \%$ Triton $\mathrm{x}-100,0.1 \% \mathrm{SDS}$ ) to which $0.5 \mathrm{mM}$ PMSF and 5 $\mu \mathrm{g} / \mathrm{ml}$ of each protease inhibitor (leupeptin, pepstatin, and sodium orthovanadate) were added). An antibody was added and the mixture incubated on ice for 1 hour. Protein Asepharose $\left(25 \mu \mathrm{l}\right.$ of a $50 \%$ slurry) was added and the mixture rotated for 1 hour at $4^{\circ} \mathrm{C}$. The mixture was quickly spun to remove the supernatant. The pellet was washed twice in RIPA containing $0.5 \mathrm{mM}$ PMSF. Sample treatment buffer was added to the mixture, and it was boiled for 5 minutes. All samples then were loaded on a 10\% SDS polyacrylamide gel and electrophoresed at 10-14 mAmps. The portion of the gel containing free probe was 
removed. The gel was fixed in $\mathrm{MeOH}(5 \%) / a c e t i c$ acid (5\%) for 30 minutes, dried and exposed to film.

Statistics: Statistics were calculated using Microsoft Excel (Microsoft, Inc., Redmond, WA) and SuperAnova for Macintosh (Abacus Concepts, Inc., Berkeley, CA). The Student's t-test was used to determine differences from control values in the BP experiment. Nested, one-factor ANOVAs with the Tukey-Kramer multiple comparisons test were used to analyze differences between treatment groups within sampling days for the $\mathrm{PeCB}$ experiments.

\section{RESULTS}

Fish treated with two AhR agonists, $\mathrm{BP}$ and $\mathrm{PeCB}$, were examined for activation of the AhR and of NF- $\mathrm{kB}-\mathrm{DNA}$ binding. BP strongly induced CYP1A protein and catalytic activity 3 and 6 days post-treatment (Figure 1). Binding of an NF- $\mathrm{KB}$ consensus sequence was determined with an EMSA. Hepatic nuclear proteins from both control and BP-treated scup bound an NF- $\kappa B$ consensus sequence (Figure 2). NF- $\kappa B$ activation decreased in the controls over time: however, no change in NF- $\mathrm{KB}$ activation occurred following $\mathrm{BP}$ treatment. CYP1A protein and catalytic activity were strongly induced by a low dose $(0.01$ $\mathrm{mg} / \mathrm{kg}$ ) of PeCB; while they were suppressed by treatment with a high dose of $\mathrm{PeCB}$ (Chapter 5, Figure 3). Like was seen in the BP experiment, hepatic nuclear proteins from both control and PeCB-treated scup bound an NF- $\mathrm{KB}$ consensus sequence (Figure 4). NF$\mathrm{KB}$ activation decreased over time in the controls. In the initial experiment, there was no significant increase in activation of NF-KB until days 16-18 at which time there was a 6fold increase in activation with the low dose and an 8-fold increase with the high dose. In the second experiment, a slight increase in activation occurred with the low dose at day 14; however, the variability was very large (Figure 4).

In order to confirm further that a Rel family protein was responsible for the bandshift of the NF- $\mathrm{KB}$ binding oligonucleotide, competition, crosslinking and immunoprecipitation studies were performed. First, liver nuclear extracts from control or treated fish did not bind to the consensus binding sequences of AP-1, another redox sensitive transcription factor (Meyer et al., 1994), or Oct1, a ubiquitous mammalian transcription factor (Pfisterer et al., 1994) (Figure 5). When a 50-100 fold excess of unlabeled oligonucleotides containing various sequences of NF- $\mathrm{KB}$ binding regions, the band-shift was eliminated (Figure 6). However, a 50-100 fold excess of unlabeled oligonucleotide containing the aryl hydrocarbon receptor dioxin response element (DRE) 


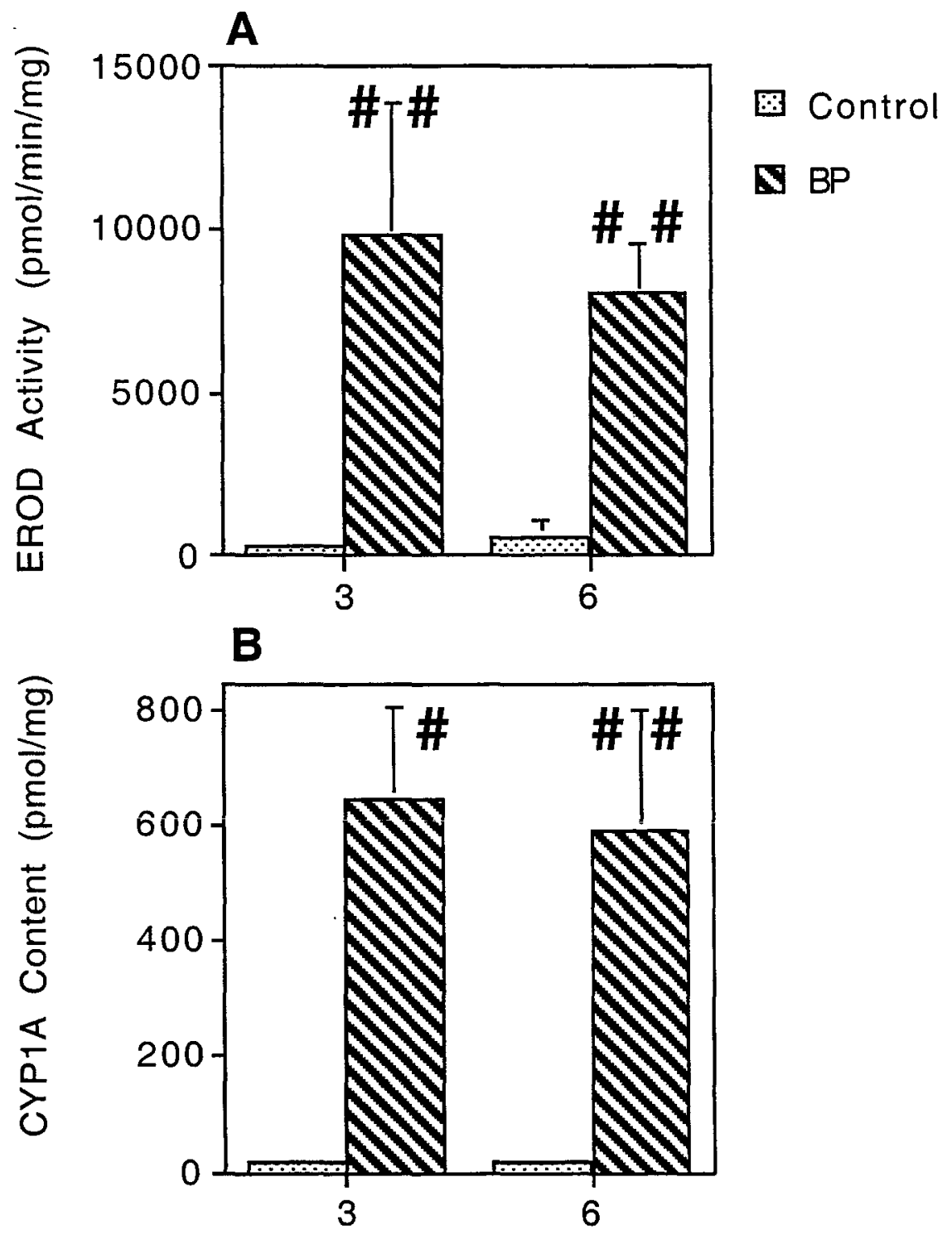

Time (Days)

Figure 1. Effect of BP on scup hepatic microsomal CYP1A content (A) and catalytic activity (EROD - B). Scup were injected IP with com oil or $10 \mathrm{mg} \mathrm{BP} / \mathrm{kg}$ and killed 3 or 6 days post-injection. Liver microsomal fractions (0.5-15 $\mu \mathrm{g} / \mathrm{lane})$ were electrophoresed, transferred to nitrocellulose, immunoblotted with MAb 1-12-3 against scup CYP1A, visualized using enhanced chemiluminescence and quantified by densitometric analysis. EROD was determined fluorometrically. Data represent the means \pm SD of measurements on 3 to 6 fish per treatment group. \#-Statisically different from control $(\mathrm{p}<0.05$, Student's $\mathrm{t}$-test). \#\#-Statistically different from control ( $\mathrm{p}<0.01$, Student's t-test). 
Figure 2. Binding of an NF- $\mathrm{KB}$ consensus sequence to liver nuclear proteins from control and BP-treated scup. Scup were injected IP with corn oil or $10 \mathrm{mg} \mathrm{BP} / \mathrm{kg}$ and killed 3 or 6 days post-injection. Nuclear extracts were prepared from livers from fish killed on Day 3 (A) and Day 6 (B) and analyzed by electrophoretic mobility shift assay for 32 P-labeled NF$\mathrm{KB}$ oligonucleotide binding. $\mathrm{C}$ ) Band intensity was quantified using video image analysis. *-Significantly different from day 3 ( $p<0.03$, Student's $t$-test). 
A

Con $\mathrm{BP}$
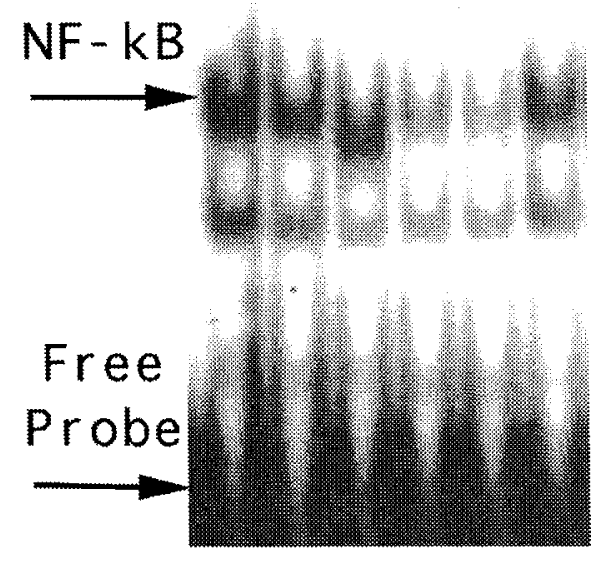

B
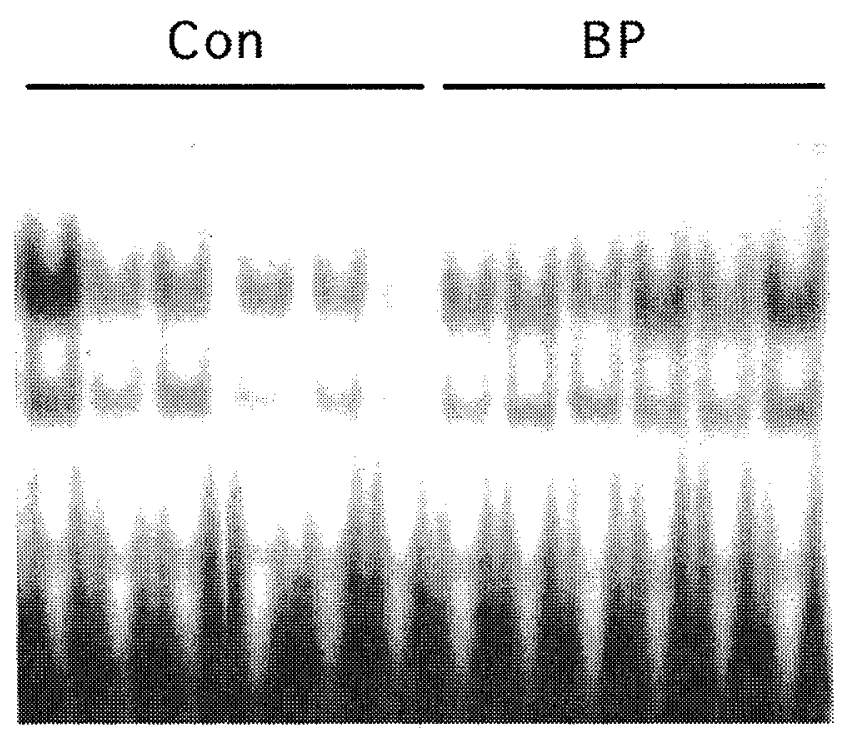

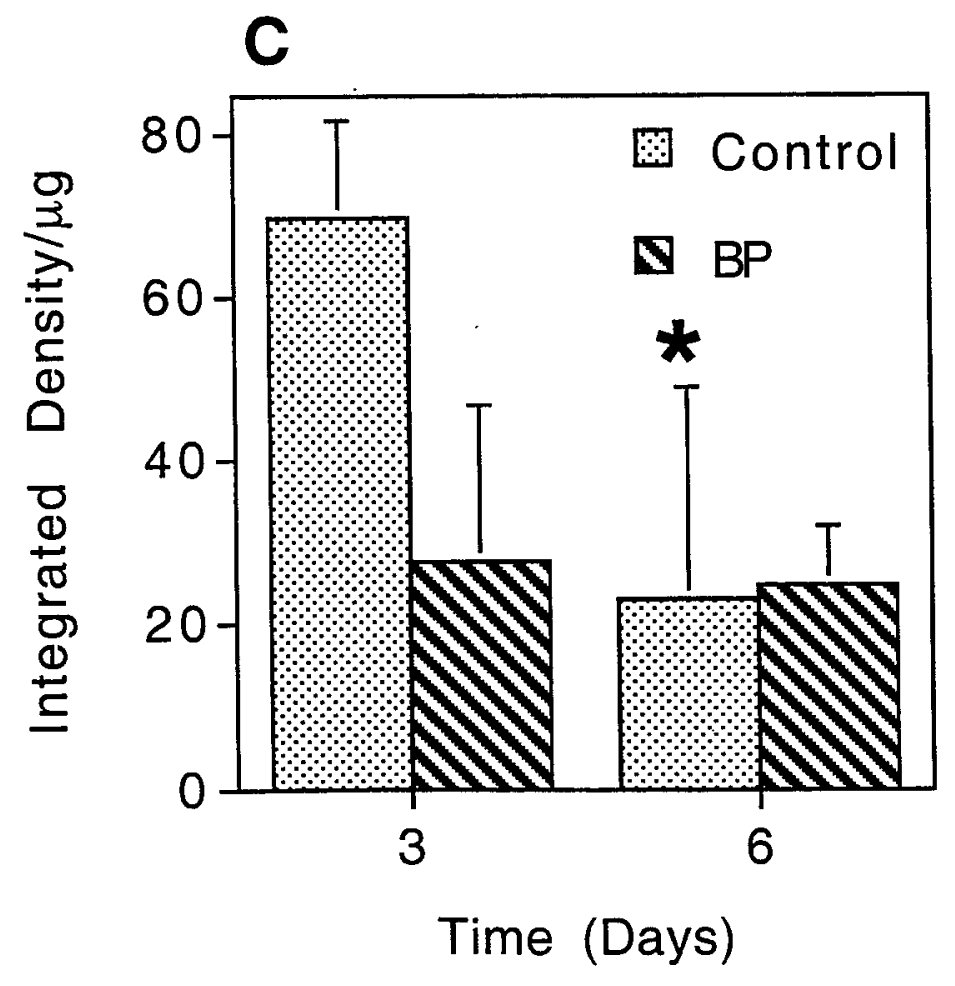



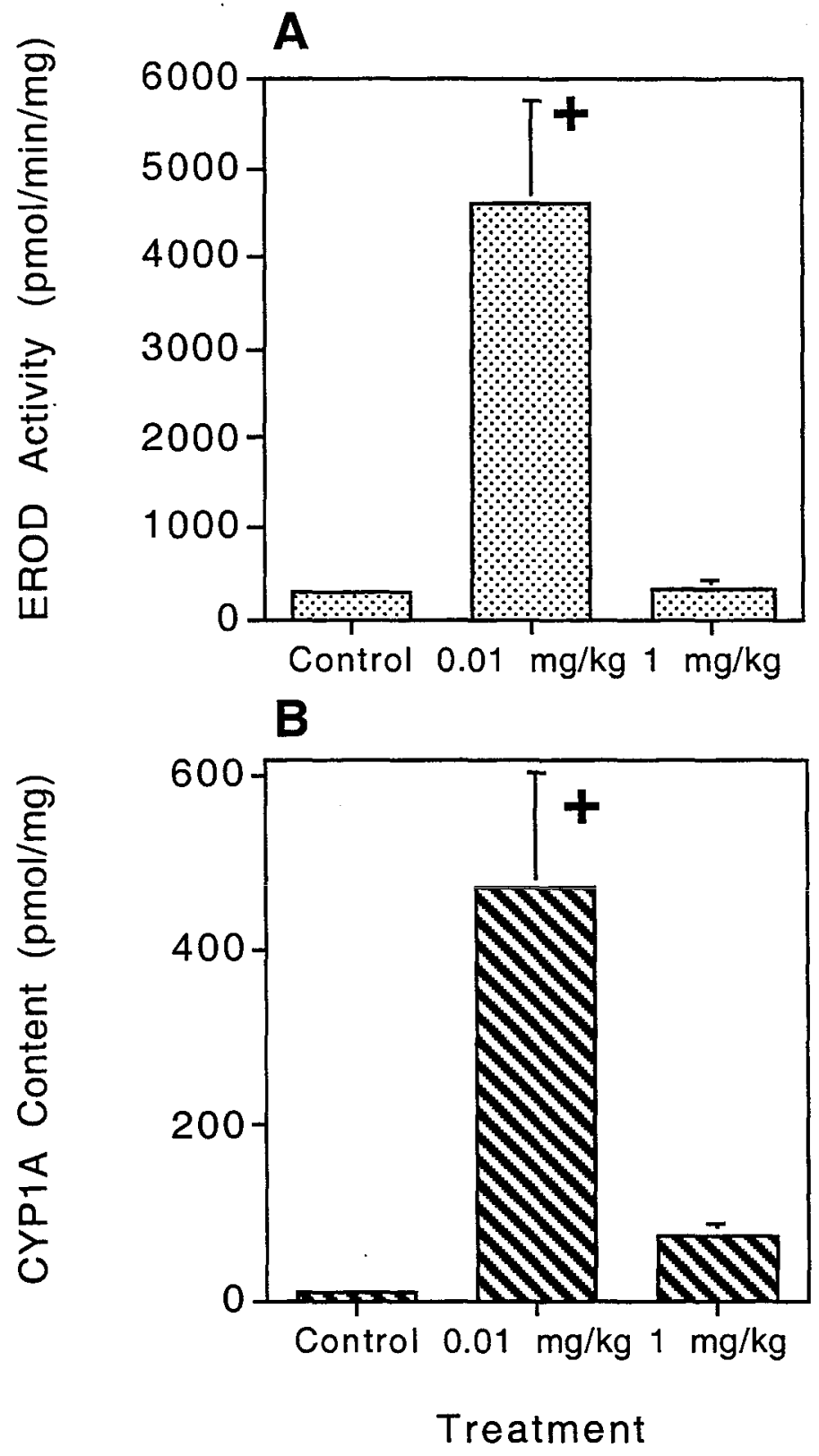

Figure 3. Effect of $\mathrm{PeCB}$ on hepatic microsomal CYP1A content (A) and catalytic activity (EROD - B). Scup were injected IP with corn oil, $0.01 \mathrm{mg} \mathrm{PeCB} / \mathrm{kg}$ or $1 \mathrm{mg} P$ PeCB/kg and killed 14 days post-injection. CYP1A content and activity in liver microsomes were determined as described in Figure 1. Data represent the means $\pm \mathrm{SD}$ of measurements on 6-10 fish per treatment group. ${ }^{+}$- Significantly different from control and $1 \mathrm{mg} / \mathrm{kg}$ dose groups ( $\mathrm{p}<0.01$, Tukey-Kramer). 


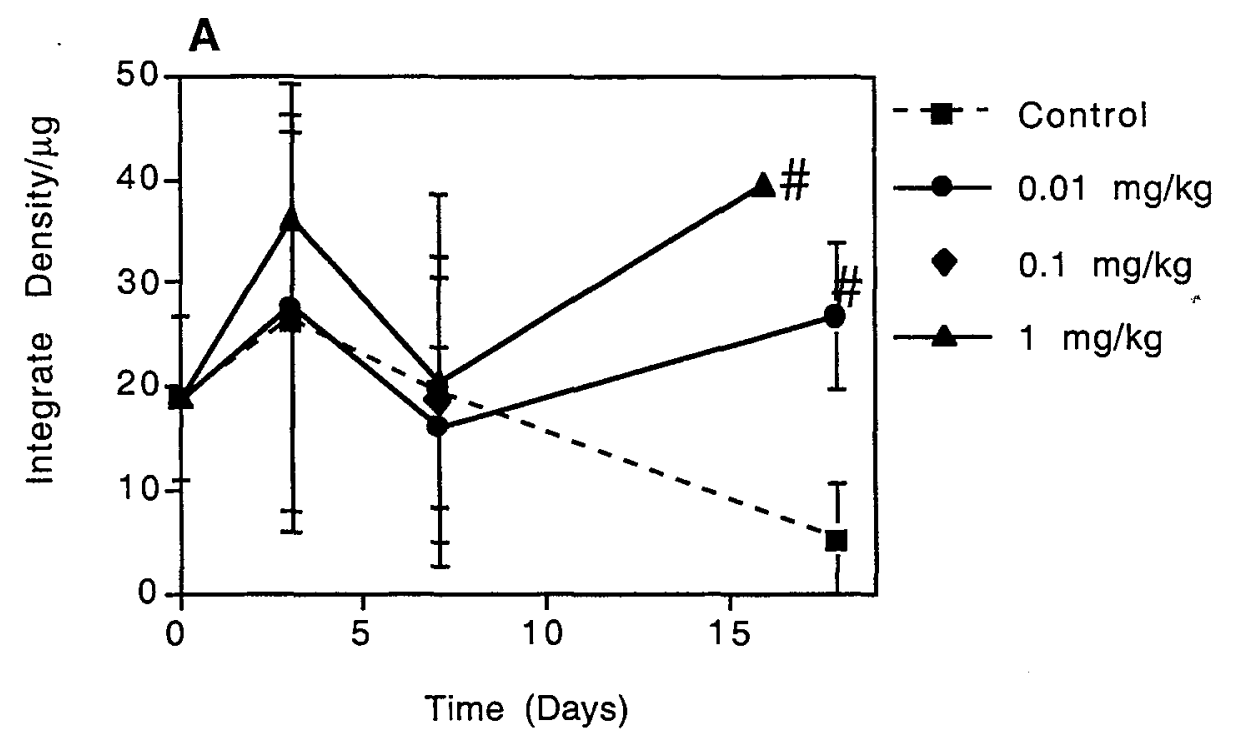

B

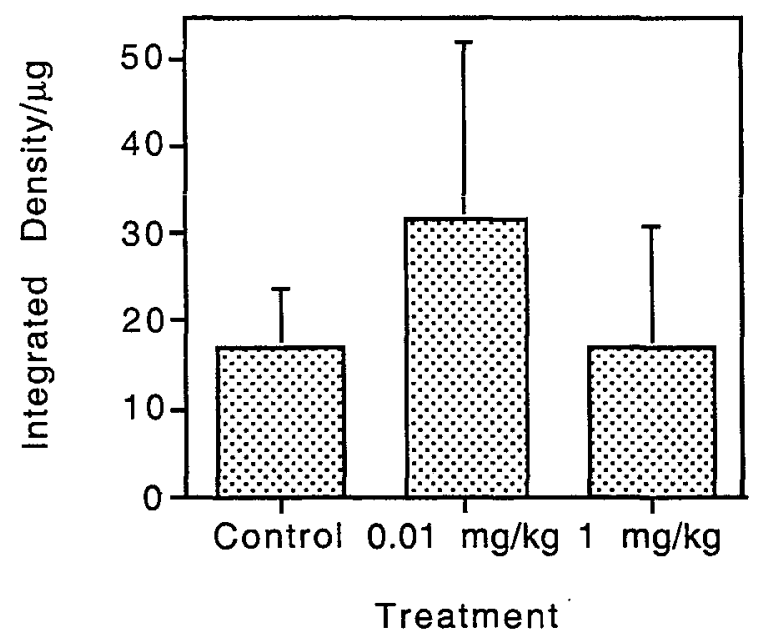

Figure 4. Quantification of NF-kB activation in liver of control and PeCB-treated scup. Nuclear extracts were prepared from livers and analyzed by electrophoretic mobility shift assay for ${ }^{32} \mathrm{P}$-labeled NF-KB oligonucleotide binding. Band intensity was quantified using video image analysis. A - Experiment 1 . Scup were injected IP with corn oil, 0.01 $\mathrm{mg} P \mathrm{PeB} / \mathrm{kg}, 0.1 \mathrm{mg} \mathrm{PeCB} / \mathrm{kg}$ or $1 \mathrm{mg} \mathrm{PeCB} / \mathrm{kg}$ and killed $3,7,16$, or 18 days postinjection. Data represent the means $\pm \mathrm{SD}$ of measurements on 6 fish per treatment group except for the $0.01 \mathrm{mg} / \mathrm{kg}$ dose on Day $18(\mathrm{n}=4)$ and the $1 \mathrm{mg} / \mathrm{kg}$ dose on Day $16(\mathrm{n}=3)$. \#-Statisically different from control $(\mathrm{p}<0.01)$. B - Experiment 2 . Scup were injected IP with corn oil, $0.01 \mathrm{mg} \mathrm{PeCB} / \mathrm{kg}$ or $1 \mathrm{mg} \mathrm{PeCB} / \mathrm{kg}$ and killed 14 days post-injection. Data represent the means $+\mathrm{SD}$ of measurements on 6-10 fish per treatment group. 


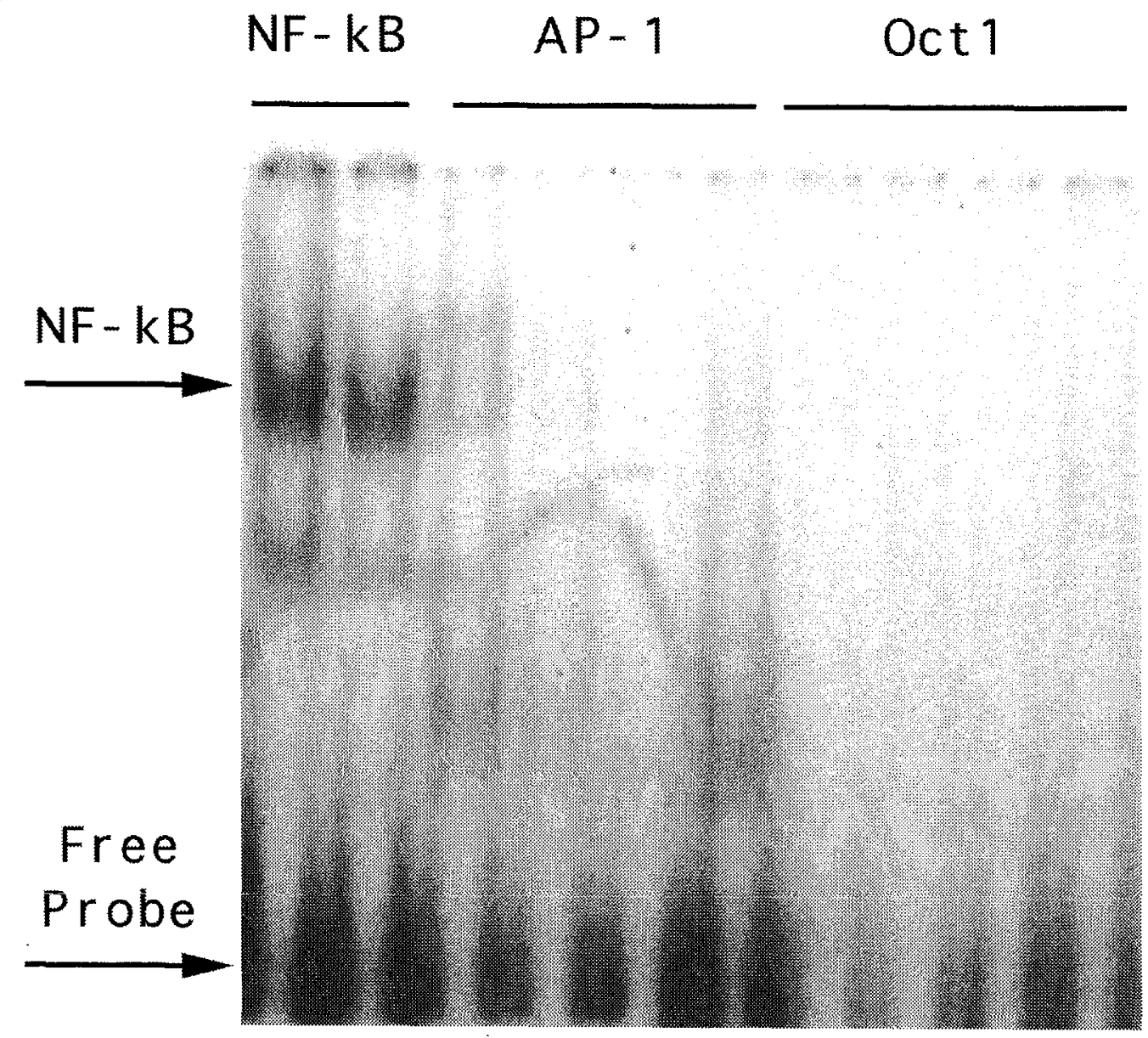

Figure 5. Nuclear proteins from scup liver bound an NF- $\mathrm{BB}$ consensus sequence but not AP-1 or Octl consensus sequences. Nuclear extracts were prepared from fish 3 days post-injection of $10 \mathrm{mg} \mathrm{BP} / \mathrm{kg}$ and analyzed by electrophoretic mobility shift assay for $32 \mathrm{P}$ labeled NF-KB, AP-1 or Oct1 oligonucleotide binding. 
did not inhibit the band-shift (Figure 6). The NF-KB consensus binding sequence was bound by hepatic nuclear proteins corresponding to mouse p50 and RelA (p65) and a smaller protein of approximately $30 \mathrm{kD}$ (Figure 7). The middle band could be immunoprecipitated with an antibody to mammalian p50 (Figure 7), but none of the bands was recognized by antibodies to mammalian p52, RelA, cRel or RelB (data not shown).

Nuclear proteins from scup kidney and heart also specifically bound the NF- $\mathrm{KB}$ consensus sequence, but with no dose specific pattern (Figure 8). Similar to liver, 3 nuclear proteins from scup heart and kidney bound the NF- $\mathrm{kB}$ consensus sequence (Figure

9 ). One of these proteins $(\approx 50 \mathrm{kD})$ was recognized by an antibody to mammalian $\mathrm{p} 50$ (Figure 9).

\section{DISCUSSION}

The Rel family of proteins has been identified and characterized in Drosophila, Xenopus, birds and mammals. ROS are responsible for the activation of nuclear translocation and DNA binding of NF- $\mathrm{KB}$, a transcription factor comprised of dimers of members of the Rel protein family. Previous work has shown that a number of xenobiotic compounds activate NF- $\mathrm{KB}$ and that this activation may occur through the stimulation of ROS production (Olnes et al., 1994; Gruebele et al., 1996; Li et al., 1996; Li et al., 1996; Pinkus et al., 1996; Chen and Cederbaum, 1997; Shneider et al., submitted). Here we have demonstrated the presence of the Rel protein family in a teleost, scup. Attempts to activate NF- $\mathrm{KB}$ DNA binding by treatment with AhR agonists gave conflicting results, however. While, we have confirmed the presence of the Rel family of proteins in a teleost, the regulation of NF- $\mathrm{KB}$ activation by AhR agonists is still a question.

A large gap exists in the knowledge of the evolution of Rel family proteins. While these proteins have been characterized in Drosophila (Steward, 1987; Ip et al., 1993; Dushay et al., 1996), the next higher animal in which they have been identified is an amphibian (Kao and Hopwood, 1991; Suzuki et al., 1995; Tannahill and Wardle, 1995; Suzuki et al., 1998). Considering the important function of Rel family proteins during development and in the immune system (Steward, 1987; Ip et al., 1993; Baeuerle and Henkel, 1994; Tannahill and Wardle, 1995), these proteins presumably should occur in teleosts, as well. Here we provide biochemical evidence for the presence of multiple Rel family proteins in the teleost scup. 1) An oligonucleotide containing an NF- $\mathrm{kB}$ consensus binding sequence forms a band shift in EMSAs with nuclear proteins from multiple scup 
Figure 6. Specific competition of binding of an NF-KB consensus sequence to scup liver nuclear proteins. Nuclear extracts were prepared from fish 3 days post-injection of $10 \mathrm{mg}$ $\mathrm{BP} / \mathrm{kg}$ and analyzed by electrophoretic mobility shift assay for ${ }^{32} \mathrm{P}-\mathrm{labeled} \mathrm{NF}-\mathrm{KB}$ oligonucleotide binding. The specificity of NF- $\mathrm{kB}$ binding activity was tested by the addition of 50-100-fold molar excess of unlabeled NF- KB binding oligonucleotide or the aryl hydrocarbon receptor dioxin response element (DRE). Lanes 4,6,8,10- 50-fold excess. Lanes 2,3,5,7,9-100-fold excess. 
Competitor
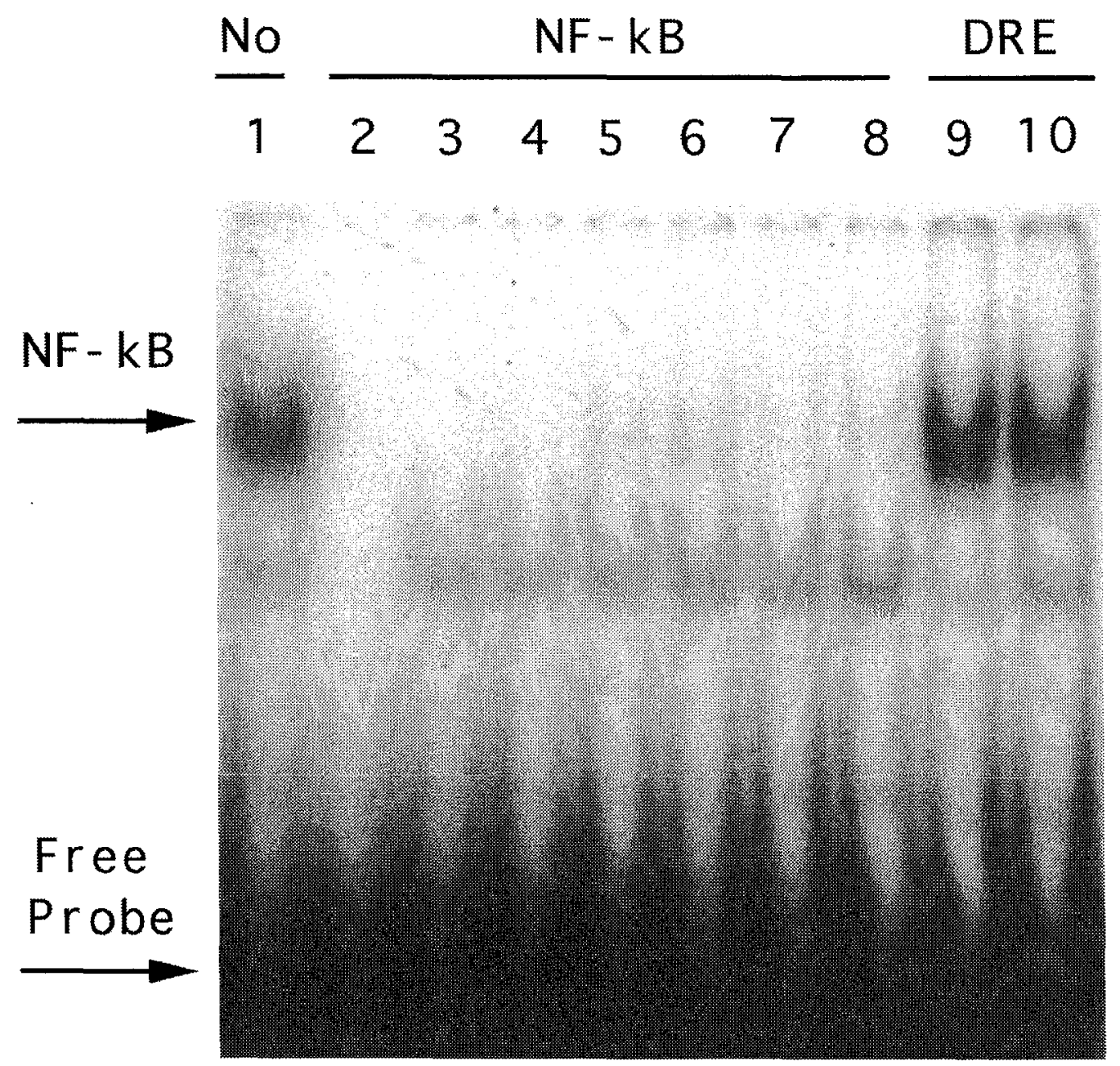

Competitors:

Lane 2.

Lanes 3-4.

Lanes 5-6.

Lanes 7-8.

Lanes 9-10.
5'-AGT TGA GGG GAC TIT CCC AGG C-3' 5'-CGG CAG GGG AAT TCC CCT CTC C-3' 5'-CGG CAG GGC AAT TCC CCT CTC C-3' 5'-CCG CTG GGG ACT TTC CAG GC-3' 5'-GAT CCG CTC CGG CTC TTC TCA CGC 


\section{Mouse Scup}

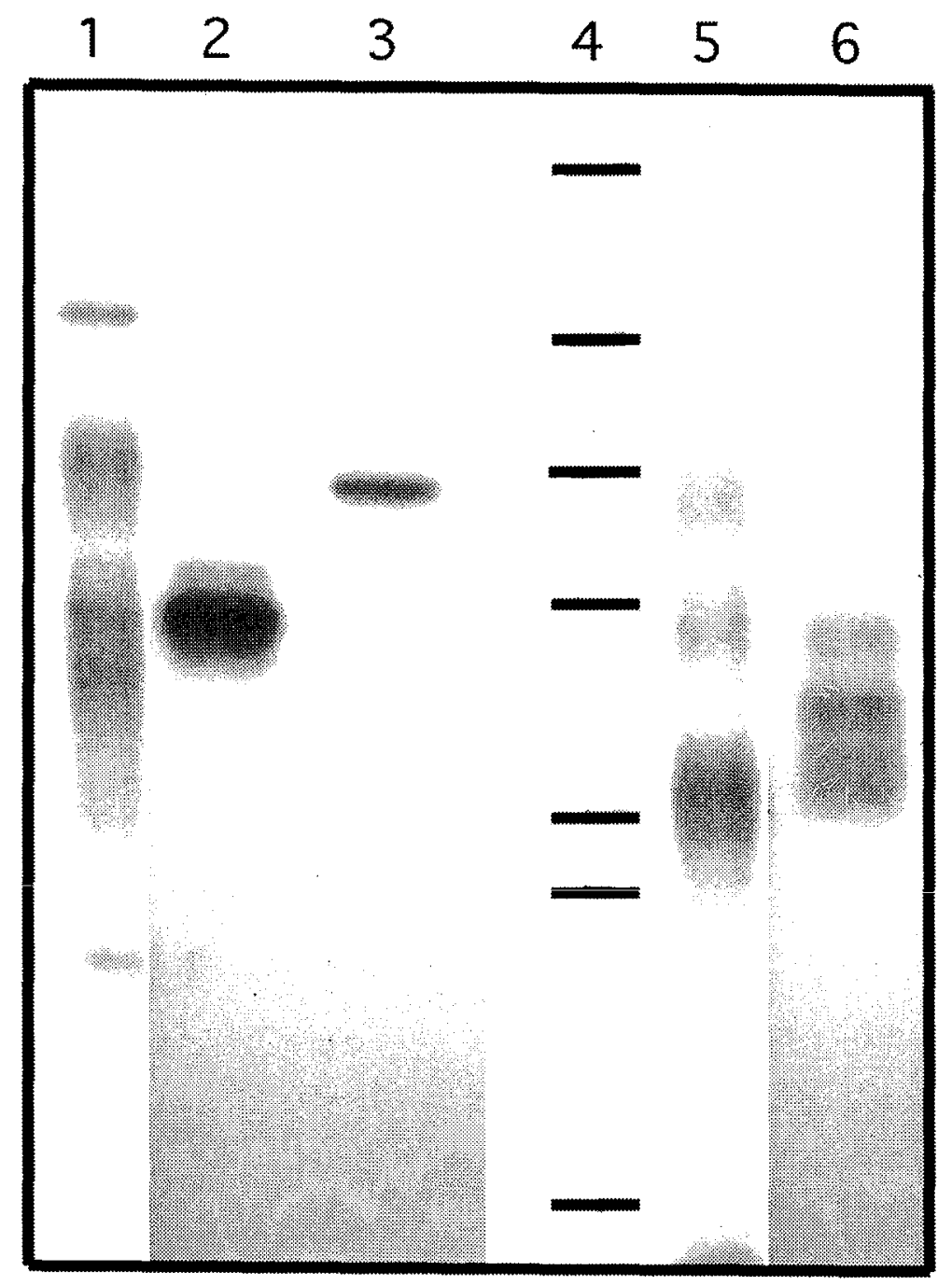

Figure 7. Binding of an NF- $\mathrm{kB}$ consensus sequence to at least 3 scup liver nuclear proteins. Nuclear extracts were prepared from fish 3 days post-injection of $10 \mathrm{mg} \mathrm{BP} / \mathrm{kg}$ or nuclear extracts from preB lymphocyte (BU-11) cells were incubated with a 5-bromo-2'deoxyuridine-substituted ${ }^{32} \mathrm{P}$-labeled NF- $\mathrm{kB}$ oligonucleotide probe and crosslinked by UV irradiation. The resultant labeled DNA-protein complexes also were immunoprecipitated with antibodies to specific NF-KB subunits. All were resolved on a $10 \%$ polyacrylamide gel. Results shown are different exposures of the same gel. Lanes $1 \& 5$. No immunoprecipitation. Lane $2 \& 6$. Immunoprecipitation with p50 antibody. Lane 3. Immunoprecipitation with RelA antibody. Lane 4. Molecular weight standards corresponding to $250,98,64,50,36,30$ and $16 \mathrm{kD}$. 


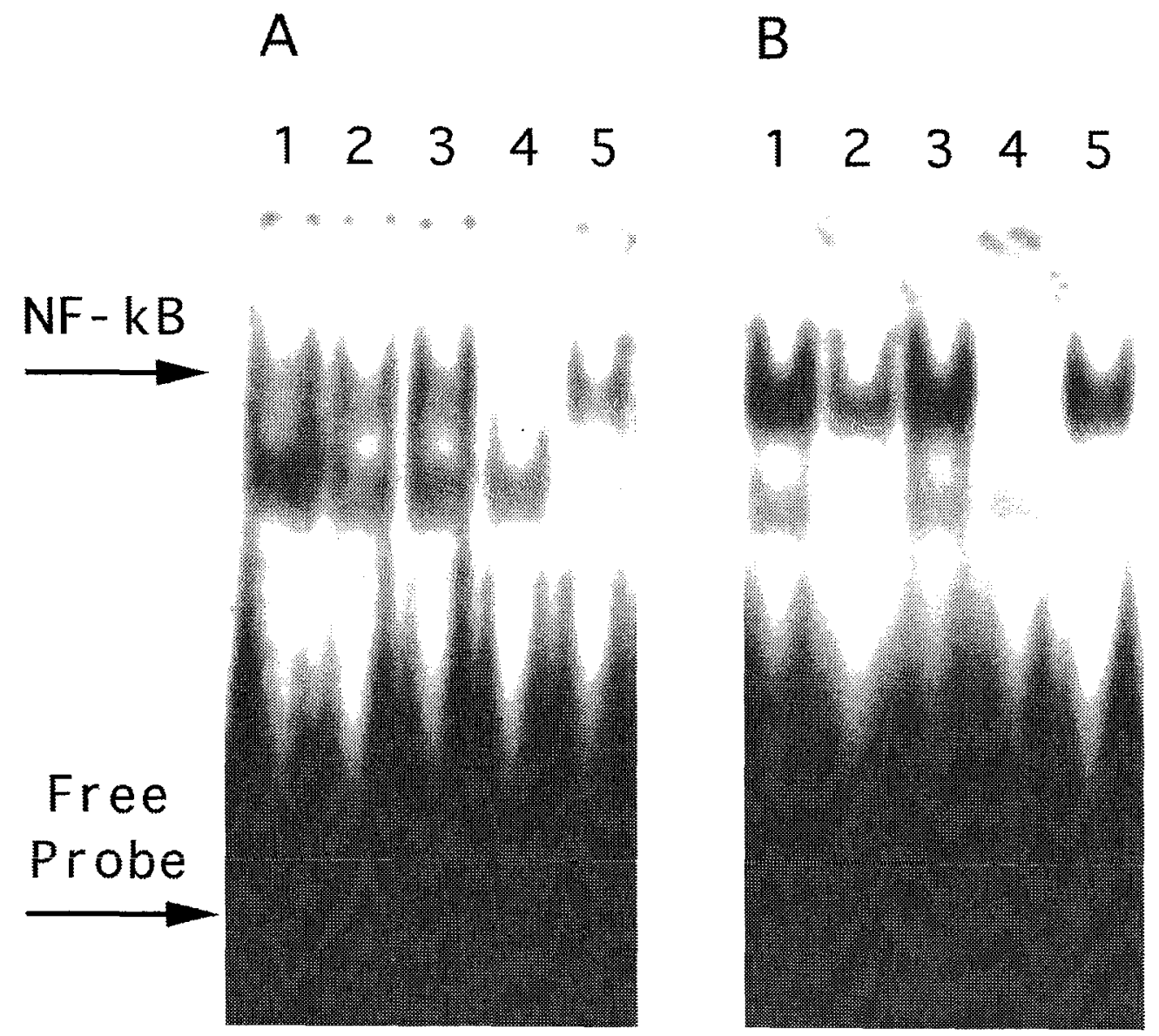

Figure 8. Specific binding of an NF- $\mathrm{kB}$ consensus sequence to scup kidney (A) and heart (B) nuclear proteins. Nuclear extracts were prepared from kidney or heart from scup 3 days post-injection of $10 \mathrm{mg} \mathrm{BP} / \mathrm{kg}$ and analyzed by electrophoretic mobility shift assay for 32P-labeled NF- $\mathrm{KB}$ oligonucleotide binding. The specificity of NF- $\mathrm{kB}$ binding activity was tested by the addition of 100 -fold molar excess of unlabeled NF- $\kappa B$ binding oligonucleotide or the aryl hydrocarbon receptor DRE. Lanes 1-3. No competitor. Lane 4. 100-fold excess specific competitor. Lane 5. 100-fold excess of non-specific competitor. 


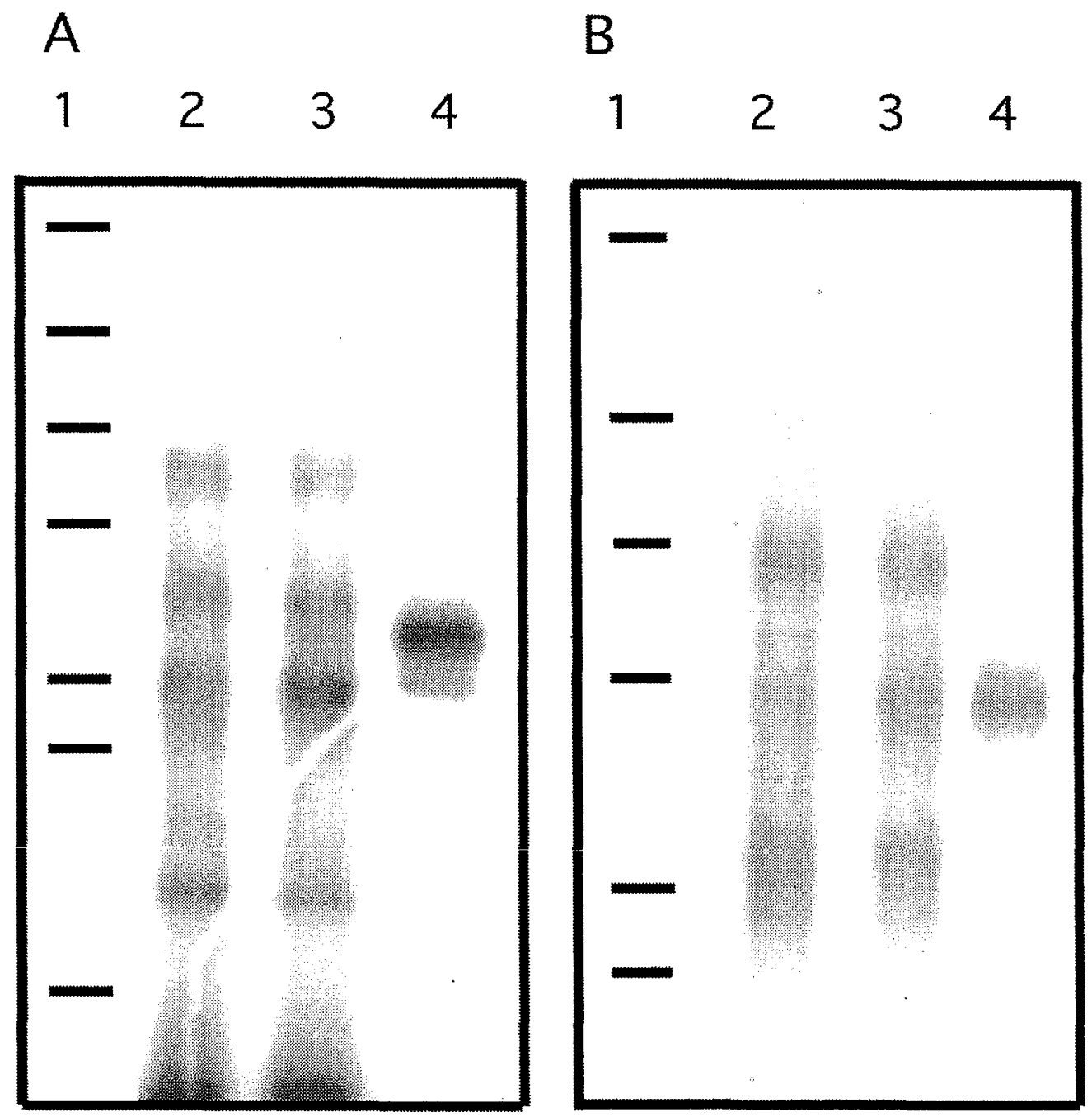

Figure 9. Binding of an NF- $\mathrm{KB}$ consensus sequence to at least 3 scup kidney (A) and heart (B) nuclear proteins. Nuclear extracts from kidney and heart from scup 3 days postinjection of $10 \mathrm{mg} \mathrm{BP} / \mathrm{kg}$ were incubated with a 5-bromo-2'-deoxyuridine-substituted 32Plabeled NF- $\mathrm{KB}$ oligonucleotide probe and crosslinked by UV irradiation. The resultant labeled DNA-protein complexes also were immunoprecipitated with antibodies to specific NF- $\mathrm{KB}$ subunits. All were resolved on a $10 \%$ polyacrylamide gel. Results shown are different exposures of the same gel. Lane 1 . Molecular weight standards corresponding to 250, 98, 64, 50, 36, 30 and 16 kD. Lanes 2-3. No immunoprecipitation. Lane 4. Immunoprecipitation with p50 antibody. 
organs. 2) The oligonucleotide binding could be specifically competed. 3). Protein/DNA crosslinking studies demonstrated 2 proteins which appeared to correspond with murine $\mathrm{p} 50$ and RelA. 4). The $\approx 50 \mathrm{kD}$ binding protein in multiple organs was recognized by an antibody to mammalian p50. The NF-kB1 and NF- $\mathrm{kB} 2$ genes have been found to evolve at the slowest rate of the Rel proteins (Huguet et al., 1997), thus the p50 antibody was most likely to recognize the teleost protein. Alignment analyses suggest that all Rel/NF- $\mathrm{kB}$ and IKB proteins truly belong to a superfamily of genes whose precursor contained both a Rel homology domain and an ankyrin repeat area (Huguet et al., 1997). Therefore, it is not surprising that these proteins would be present in fish as they are present in insects. Furthermore, an NF- $\mathrm{KB}$ binding site has been identified in the promoter of mitogenactivated protein kinase kinase 1 of carp (Leu et al., 1996).

A number of xenobiotic compounds have been shown to activate NF-kB-DNA binding. Redox cycling quinones activate NF- $\mathrm{kB}$ in HepG2 cells, apparently as a protective mechanism (Pinkus et al., 1996; Chen and Cederbaum, 1997). Phenobarbital and ciprofibrate have been shown to activate NF-KB-DNA binding in rat liver ( $\mathrm{Li}$ et al., 1996; Li et al., 1996). Phenobarbital induces CYP2B1/2B2, which was suggested to produce ROS as a metabolic by-product. Ciprofibrate, a peroxisome proliferator, induces enzymes in the peroxisomal $\beta$-oxidation pathway which also produce ROS as a byproduct. However, phenobarbital and ciprofibrate apparently activate different Rel proteins, suggesting that they activate NF-KB through different pathways ( $\mathrm{Li}$ et al., 1996; Li et al., 1996).

AhR agonists also have been shown to activate NF- $\mathrm{kB}$. DMBA- and BP-mediated NF- $\kappa B$ activation have been shown to be AhR dependent, but CYP1Al independent (Shneider et al., submitted). Activation of NF- $\mathrm{KB}$ by BP and DMBA occurs within an hour of treatment, a time too short for CYP1A induction, and activation occurs in Hepa cells with a functional AhR but deficient in CYP1A (Shneider et al., submitted). The effect of an antioxidant was not examined. In contrast, TCDD-mediated activation of expression of a cat reporter containing an NF- $\mathrm{kB}$ binding sequence occurred 24 hours post-treatment, could be blocked by anti-oxidants and required a functional CYP1A1 (Yao et al., 1995). It was hypothesized that the IgK light chain enhancer and the HIV-1 long terminal repeat are regulated differentially by NF- $\mathrm{KB}$, though the NF- $\kappa \mathrm{B}$ subunits involved in each case have not been identified (Yao et al., 1995; Shneider et al., submitted). It also is possible that there is a direct interaction between the AhR and RelA. RelA can be coimmunoprecipitated with AhR in cytosol or nuclear fractions of TCDD-treated COS cells that are cotransfected 
with AhR and RelA, and TCDD down-regulates NF- $\mathrm{KB}$ mediated gene expression in these cells (Tian et al., 1998).

Both $\mathrm{BP}$ and $\mathrm{PeCB}$ are $\mathrm{AhR}$ agonists and are capable of stimulating $\mathrm{ROS}$ production. BP is metabolized to 3 redox cycling quinones in scup (Klotz et al., 1983), and the coplanar polychlorinated biphenyl PeCB stimulates ROS production by uncoupling the CYP1A catalytic cycle (Chapter 4). Liver should be an appropriate site to analyze NF$\kappa B$ activation, as NF- $\mathrm{KB}$ is an important mediator of hepatocyte proliferation. NF- $\mathrm{KB}$ is rapidly activated following partial hepatectomy (Cressman et al., 1994), and livers of RelA knockout mice undergo massive apoptosis early in gestation (Beg et al., 1995). However, treatment of scup with BP and TCDD did not cause a consistent effect on hepatic NF- $\mathrm{KB}$ activation. Undeniably, the results were confounded by the fact that injection alone appeared to activate NF-kB. Why this occurred is unknown. One can only speculate that the stress of injection stimulated one of the many activators of NF- $\mathrm{KB}$. It does not appear that $\mathrm{AhR}$ agonists activate NF- $\kappa B$ simply by activating the AhR. If this were the case then both $\mathrm{BP}$ and $\mathrm{PeCB}$ would have activated $\mathrm{NF}-\mathrm{KB}$. Although, activation was not analyzed at very early time points, as the results in cell culture suggest is necessary to observe this phenomenon. The suppression of injection-induced NF- $\mathrm{BB}$ activation by BP at Day 3 , is reminiscent of the results seen with COS cells (Tian et al., 1998), although this suppression was not seen with PeCB treatment. In at least one of the experiments with PeCB there appeared to be activation of NF- $\mathrm{kB}$ at late time points. This is unlike results with other xenobiotics which cause activation within 3-6 days of treatment ( $\mathrm{Li}$ and Furness, 1991; Li et al., 1996; Li et al., 1996). The delay might have been caused by the type of ROS that were being produced. During CYP1A uncoupling in vitro, CBs appear to stimulate $\mathrm{O}_{2}^{-\bullet}$ production to a greater extent than $\mathrm{H}_{2} \mathrm{O}_{2}$ production (Chapter 3 ). Studies have suggested that $\mathrm{O}_{2}^{-\bullet}$ is only indirectly involved in a NF- $\mathrm{kB}$ activation, as a source of $\mathrm{H}_{2} \mathrm{O}_{2}$ (Schmidt et al., 1995). In the end, these experiments have raised more questions than they have answered.

$N F-\kappa B$ could play an important role in the defense against the effects of xenobiotics. First, the AhR regulates genes involved in the antioxidant response. AhR agonists can induce glutathione S-transferase Ya and NADPH:quinone oxidoreductase via the AhR as well as via an antioxidant response element (Rushmore et al., 1991; Hankinson, 1995). Proteins that are involved in the antioxidant response are also induced following NF- $\mathrm{KB}$ activation, suggesting that NF- $\mathrm{KB}$ may regulate their expression. These proteins include Mn-SOD (Pang et al., 1992), NADPH-oxidoreductase (Yao and 
O'Dwyer, 1995), inducible nitric oxide (Xie et al., 1994), and ferritin $\mathrm{H}$ (Kwak et al., 1995). NF- $\mathrm{kB}$ activation was suggested to be the mechanism by which HepG2 cells are protected from oxidative stress-induced cytotoxicity (Chen and Cederbaum, 1997). Second, an NF-kB consensus binding sequences has been identified in the promoter of the P-glycoprotein gene (Zhou and Kuo, 1997). P-glycoprotein can be induced by TCDD (Schuetz et al., 1995), and xenobiotics may be removed from cells via the P-glycoprotein transporter (Yeh et al., 1992). Therefore, it is important to continue to investigate the apparently complicated relationship between the AhR and NF- $\mathrm{KB}$ and the contribution of $\mathrm{NF}-\mathrm{KB}$ to the defense against xenobiotic induced effects. 


\section{CHAPTER 7}

Tissue Distribution of and Induction of Cytochrome P4501A by Model Aryl Hydrocarbon Receptor (AhR) Agonists in the American Eel and Investigation of the Effect of Endothelial CYP1A on AhR Agonist Pharmacokinetics 


\section{ABSTRACT}

We investigated both the dose-dependent response of hepatic cytochrome P4501A (CYP1A) in relation to inducer distribution and the in vivo dose-dependent response of endothelial CYP1A in a fish model, American eel (Anguilla rostrata). First, injection studies were used to determine the distribution of different doses of two radiolabeled model aryl hydrocarbon receptor (AhR) agonists, benzo[a]pyrene (BP), a polynuclear aromatic hydrocarbon, and 3,3',4,4'-tetrachlorobiphenyl (TCB), a planar halogenated aromatic hydrocarbon. Concentrations of BP and TCB were greatest in bile, liver, gut and kidney and were dose-dependent in bile, gill, gut, liver, muscle and rete mirabile. Second, increasing doses of B-naphthoflavone (BNF) $(0.1,1,5,10$, and $100 \mathrm{mg} / \mathrm{kg})$, BP $(0.1,1$ and $10 \mathrm{mg} / \mathrm{kg})$, and TCB $(0.1,1,10$ and $20 \mathrm{mg} / \mathrm{kg})$ all produced dose-dependent induction of CYP1A content and catalytic activity. Using the liver microsomal EROD data, BP, BNF and TCB all had ED50s of approximately $5 \mathrm{mg} / \mathrm{kg}$. However, BNF and BP had greater efficacy than TCB in eliciting hepatic CYP1A induction. Hepatic inducer concentration and CYP1A levels were correlated significantly. Third, previous studies have shown that endothelium is a major site of induction of CYP1A in vertebrates and have suggested that CYP1A induction in peripheral vasculature may be related to inducer dose (Drug Metab. Dispo. 19, 113-123 (1991)). Biochemical analysis of microsomes from heart and rete mirabile, organs in which CYP1A induction occurs predominantly in endothelial cells, showed an increase in CYP1A content and EROD activity following treatment with BP, BNF or TCB. CYP1A content and activity also were elevated in heart and rete mirabile in eels from a notably polluted site. Immunohistochemical (IHC) analysis with MAb 1-12-3 revealed increasing induction of CYP1A in the endothelium of the heart, gill, kidney and rete mirabile with increasing dose of $\mathrm{BNF}, \mathrm{BP}$ and $\mathrm{TCB}$. In the rete mirabile, greater doses of inducers were associated with increasing penetration of induction. In addition, a transition from endothelial to epithelial staining occurred in the gill, heart and kidney at high doses of BNF. We conclude not only that the penetration of endothelial cell CYP1A expression in the vessels of the rete mirabile reflects greater concentrations of inducer reaching the distal circulation, but also that endothelial CYP1A induction may limit the local distribution of inducers. The results are consistent with the hypothesis that endothelial CYP1A may participate in removal of AhR agonist/CYP1A substrates from the circulation. 


\section{INTRODUCTION}

Endothelial cells make up the lining of all blood and lymphatic vessels. The functions of endothelium are diverse, including providing a physical lining, maintaining blood vessel tone, controlling microvascular permeability, regulating platelet clumping, clotting and lymphocyte traffic, repairing damaged blood vessels and initiating angiogenesis (Pearson, 1991). Thus endothelium may be a site that is particularly sensitive to xenobiotic toxicity. For instance, activation of promutagens in endothelium may play a role in atherosclerosis (Juchau et al., 1976). Edema is a symptom of a syndrome common among developing fish, birds and mammals exposed to planar halogenated aromatic hydrocarbons (pHAH) (Peterson et al., 1993). Finally, both polynuclear aromatic hydrocarbons (PAH) and pHAH have been shown to alter endogenous arachidonic acid (AA) metabolism (Schlezinger et al., 1998); these metabolites can affect a number of endothelial cell functions (Schwartzman et al., 1987; Ohnishi et al., 1992; Harder et al., 1995; Campbell et al., 1996).

$\mathrm{PAH}$ and $\mathrm{pHAH}$ induce the expression of a number of genes, including cytochrome P4501A (CYP1A), through their interaction with the aryl hydrocarbon receptor (AhR) (Hankinson, 1995). The toxicity of PAH and pHAH may be mediated in part by their interaction with CYP1A. Liver is the major site of CYP1A induction (Goldstein and Linko, 1984); however, CYP1A can be induced in a variety of organs and cells types (Goldstein and Linko, 1984; Smolowitz et al., 1991). Human umbilical vein endothelial cells express CYP1A1 mRNA at a low constitutive level and at an increased level following polychlorinated biphenyl (PCB) or $\beta$-naphthoflavone (BNF) exposure (Farin et al., 1994). 3-Methylcholanthrene (MC) induces CYP1A protein in rat and rabbit aorta (Thirman et al., 1994; Stegeman et al., 1995), and TCDD induces an endothelial CYP, presumably CYP1A, in rabbit kidney and lung (Dees et al., 1982).

Strong induction of CYP1A has been seen in the endothelium of fish exposed to AhR agonists. Initially observed in the heart of scup (Stegeman et al., 1989), induction of CYP1A has been seen in endothelium in the liver, heart, gill, kidney, gut, gonad, spleen, red muscle and brain of fish exposed to BNF, 3,3',4,4'-tetrachlorobiphenyl (TCB), and 2,3,7,8-tetrachlorodibenzofuran (TCDF) (Miller et al., 1989; Stegeman et al., 1989; Smolowitz et al., 1991). By calculation, CYP1A could account for as much as $25 \%$ of the endothelial microsomal protein in the heart of BNF-treated fish (Stegeman et al., 1982; Stegeman et al., 1989). In scup dosed with the potent CYP1A agonist TCDF given at 3 $\mu \mathrm{g} / \mathrm{kg}$ and TCB, as less potent inducer, given at $1 \mathrm{mg} / \mathrm{kg}$, similar CYP1A induction occurs 
in liver and sites proximal to large vessels. However, in scup dosed with TCB, CYP1A induction also was seen in distal regions of the fish (Smolowitz et al., 1991). It was hypothesized that induction of endothelial CYP1A could influence the local concentration of inducer, both limiting the amount that could penetrate to the underlying tissue and the spread of the inducer to distal areas of the organism (Stegeman et al., 1995).

The extent to which endothelial CYP1A is catalytically active is not clear. In rabbit lung, CYP1A was ultrastructurally localized to endothelial cells, but cytochrome P450 reductase (CPR) was not detected (Overby et al., 1992). However, studies of porcine aorta endothelial cells (PAEC) confirm the presence of CPR in both catalytic and immunoblot assays (Stegeman et al., 1995). Bovine aorta endothelial cells and cardiac microsomes from scup produce metabolites of BP indicative of CYP1A metabolism (Baird et al., 1980; Stegeman et al., 1982). Mouse heart and kidney also have a BNF-inducible, metabolically active P450 in the endothelium (Brittebo, 1994). However, the catalytic activity of endothelial CYP1A is lower than that of equivalent amounts of hepatic CYP1A (e.g. (Stegeman et al., 1982)). The full significance of endothelial CYP1A remains a question because despite its low catalytic activity, its induction correlates with the toxicity of TCDD to embryos (Guiney et al., 1997).

In this study we investigated both induction of CYP1A in liver in relation to inducer distribution and induction of endothelial CYP1A in relation to its effect on AhR agonist pharmacokinetics. American eels (Anguilla rostrata) were exposed to model AhR agonists/CYP1A substrates. We demonstrated that liver CYP1A responds to BP, BNF and TCB in a dose-dependent fashion and that this induction correlates with hepatic inducer concentration. Eels may be particularly useful for the study of in vivo induction of endothelial CYP1A because they have a rete mirabile, a counter-current vascular structure, composed entirely of capillaries, which increases the partial pressure of oxygen to aid its secretion into the swim bladder (Krogh, 1959). We show that endothelial CYP1A is inducible in a number of organs and is metabolically active, albeit at low levels. We addressed the hypothesis that substrates might remain "bound" to endothelial CYP1A, limiting their distribution; CYP1A2 already is recognized as a binding protein in mammalian liver (Diliberto, 1997). In the rete mirabile, penetration of endothelial CYP1A induction increased with increasing dose of AhR agonists, corresponding with an increase in inducer concentration. In addition, a transition from endothelial to epithelial staining occurred in the gill, heart and kidney at high doses of BNF. Endothelial CYP1A may both 
enhance and ameliorate the toxicity of AhR agonists by holding them in a sensitive cell type but also by slowing their spread to underlying tissues and distal areas.

\section{MATERIALS AND METHODS}

Chemicals: Benzo[a]pyrene and $\beta$-naphthoflavone were purchased from Aldrich (Milwaukee, WI). Benzo[a]pyrene $\left({ }^{3} \mathrm{H}, 55 \mathrm{Ci} / \mathrm{mmol}\right)$ was purchased from Amersham (Arlington Heights, IL). Soluble was purchased from Dupont/NEN (Boston, MA). 7Ethoxyresorufin was purchased from Molecular Probes (Eugene, OR). 3,3',4,4'Tetrachlorobiphenyl (IUPAC\# 77), and 3,3',4,4'-tetrachlorobiphenyl-Ring-UL-14C (52.1 $\mathrm{mCi} / \mathrm{mmol}$ ) were purchased from Pathfinder (St. Louis, MO). MS 222 was the generous gift of Dr. Adria Elskus, but can be purchased from Sigma (St. Louis, MO). All other reagents were purchased from Sigma.

Animals used in experimental exposures: One hundred and twelve American eels, Anguilla rostrata, were purchased from Marine Resources at the Marine Biological Laboratory, Woods Hole, MA. All of the eels were females. For the first experiment the eels were kept at $20^{\circ} \mathrm{C}$. For all other experiments, the eels were kept for at least 3 days at $10^{\circ} \mathrm{C}$ in flow-through tanks until treated.

Animals from environmental collections: Eels were collected from three sites near Woods Hole, MA. Traps baited with horseshoe crab meat were used to collect the eels. Eighteen eels were collected from New Bedford Harbor, MA at the Aerovox site. Eight eels were collected from Marion Harbor, MA. Eleven eels were collected from Vineyard Sound, MA. Eels were killed and dissected immediately upon return to the lab as described below.

Treatment for chemical distribution: The eels were anesthetized in a solution of MS $222(6 \mathrm{~g} / 4 \mathrm{~L}$ sea water) and injected intra-peritoneally (IP) with corn oil or varying concentrations of ${ }^{3} \mathrm{H}-\mathrm{BP}$ ( 1 and $10 \mathrm{mg} / \mathrm{kg}$ ) and ${ }^{14} \mathrm{C}-\mathrm{TCB}(1$ and $10 \mathrm{mg} / \mathrm{kg}$ ) in corn oil. Eight days following injection, each eels was anesthetized in a solution of MS 222, and the spinal cord severed. Portions of freshly dissected organs (0.1-0.25 g each of liver, heart, gill, spleen, gut, kidney and muscle or 0.03-0.13 g of rete mirabile) were removed, weighed, rinsed with water, blotted and placed in $20 \mathrm{ml}$ scintillation vials. Bile was collected via syringe, and blood was collected from the caudal vein via syringe. Both were placed in $20 \mathrm{ml}$ scintillation vials.

Chemical distribution analysis: Soluble $(1 \mathrm{ml})$ was added to organs in the scintillation vials. The organs were minced with scissors and placed in a $50^{\circ} \mathrm{C}$ oven until 
dissolved (12-48 hours). A mixture of ethanol:Soluble (1:2) was added to the blood, and the vials were warmed to $50^{\circ} \mathrm{C}$ for 1 hour. $\mathrm{H}_{2} \mathrm{O}_{2}(30 \%, 0.75 \mathrm{ml})$ was added to all vials except those containing gut and muscle. All samples containing Soluble were acidified with $200 \mu \mathrm{l}$ of $6 \mathrm{~N} \mathrm{HCL}$. Scintiverse $(15 \mathrm{ml})$ was added to the vials and the samples were allowed to quench overnight before counting them on a Beckman LS5000TD scintillation counter. To calculate the concentration of BP and TCB in each organ, the radioactivity in control organs was subtracted from that in organs from treated eels. The remaining radioactivity was converted into $\mu \mathrm{g}$.

Treatment for dose response The eels were anesthetized in a solution of MS 222 and injected IP with corn oil or varying amounts of $\beta$-naphthoflavone (BNF) $(0.1,1,5$, 10 , and $100 \mathrm{mg} / \mathrm{kg}$ ), benzo[a]pyrene (BP) $(0.1,1$ and $10 \mathrm{mg} / \mathrm{kg})$, or $3,3^{\prime}, 4,4^{\prime}-$ tetrachlorobiphenyl (TCB) $(0.1,1$, and $10 \mathrm{mg} / \mathrm{kg})$ in corn oil. Each dose group consisted of at least 3 eels. Eels were kept in flow-through tanks at $20^{\circ} \mathrm{C}$ for experiment 1 and at $10^{\circ} \mathrm{C}$ for experiments $2-7$. They were not fed. Eels were killed on day 5 (Expt. 1) or day 8 (Expts. 2-7). Eels were killed as described above. Portions of heart, gill, kidney, rete mirabile and liver were preserved in $10 \%$ neutral buffered formalin. Liver, heart and rete mirabile also were collected for microsome preparation.

Microsome preparation and assays: Freshly dissected livers were immediately homogenized in cold homogenization buffer $(0.15 \mathrm{M} \mathrm{KCl}, 0.05 \mathrm{M}$ TRIS, $\mathrm{pH} 7.2)$. Hearts and rete mirabile were frozen in liquid $\mathrm{N}_{2}$ before homogenization. Microsomes were prepared as previously described (Stegeman et al., 1979). Protein content was determined using the bicinchoninic acid method (Smith et al., 1985), using bovine serum albumin standards. Microsomal ethoxyresorufin O-deethylase (EROD) activity was determined fluorometrically by the method of Hahn et al. (1993) using a Cytofluor 2300 (Millipore) multiwell plate reader. NADPH-cytochrome $\mathrm{P} 450$ reductase activity in rete microsomes was determined as previously described (Stegeman et al., 1982), using a Shimadzu 210 difference spectrophotometer. Microsomal P-450 content was determined using dithionitedifference spectra of CO-treated samples (Bonkovsky et al., 1984). Cytochrome b5 was determined using NADH difference spectra as previously described (Stegeman et al., 1979).

Western blotting for CYP1A quantification Immunoblotting procedures were modified from those previously described (Kloepper-Sams et al., 1987). Microsomal proteins (10-80 $\mu \mathrm{g} /$ lane) were resolved on 12\% SDS-PAGE gels and electrophoretically transferred to nylon or nitrocellulose $(1 \mu \mathrm{m})$ membrane. The primary antibody was the 
mouse monoclonal antibody 1-12-3 (Park et al., 1986), raised against scup P450E (CYP1A; (Morrison et al., 1995)). The secondary antibody was alkaline phosphatase linked goat anti-mouse IgG (Biorad, Hercules, CA). The immunoreactive proteins on nitrocellulose membrane were visualized using nitro blue tetrazolium and 5-bromo-4chloro-3-indoyl-phosphate (NBT/BCIP). The immunoreactive proteins on nylon membranes were visualized using enhanced chemiluminescence (Tropix, Bedford, MA). CYP1A content was quantified by densitometric analysis of video images (NIH Image, 1.60b5). The CYP1A values are relative, reported as scup CYP1A equivalents.

Immunohistochemical analysis: Preserved organs (liver, heart, kidney, gill and rete mirabile) were embedded in paraffin by Pathology Services, Inc., Cambridge, MA or by the Laboratory of Aquatic Animal Medicine and Pathology at the Marine Biological Laboratory, Woods Hole, MA. Tissue sections were cut to a thickness of $5 \mu \mathrm{m}$ and mounted on Fisher Superfrost Plus slides. Prior to staining, the sections were deparaffinated and hydrated in $1 \%$ PBS/BSA. While being hydrated the sections were incubated in $3 \% \mathrm{H}_{2} \mathrm{O}_{2}$ in water to block the activity of endogenous peroxidases. The hydrated sections were stained using an indirect peroxidase stain (Universal Immunoperoxidase Staining Kit (Murine), Signet Lab, Dedham, MA). The antibodies used were the monoclonal antibody MAb 1-12-3 and a peroxidase labeled goat anti-mouse secondary antibody. The staining procedure used was as described by Smolowitz et al. (1991). Staining of CYP1A was scored for intensity of staining ( $0=$ no stain, $1=$ mild stain, $2=$ moderate stain, $3=$ strong stain, $4=$ very strong stain) and for occurrence of staining $(0=$ no cells, $1=$ rare cells , $2=$ some cells, $3=$ many cells, $4=$ all cells staining). The stain index was computed by multiplying the intensity and occurrence scores for a scale from 0 16.

Statistics: Statistics were calculated using Microsoft Excel (Microsoft, Inc., Redmond, WA) and SuperAnova for Macintosh (Abacus Concepts, Inc., Berkeley, CA). A Student's t-test was used to test differences between the dose groups in the chemical distribution experiments. A one-factor ANOVA in combination with the Tukey-Kramer or Dunnett's multiple-comparisons tests was used to analyze all other data.

\section{RESULTS}

Chemical distribution analysis: First, the patterns of distribution of BP and TCB following IP injection into eels were examined (Figure 1) so that the distribution of the inducers might be compared with induction of CYP1A. Two doses ( 1 and $10 \mathrm{mg} / \mathrm{kg}$ ) of 
Figure 1. Distributions of ${ }^{3} \mathrm{H}-\mathrm{BP}$ and ${ }^{14} \mathrm{C}-\mathrm{TCB}$ in eels injected IP. A) $1 \mathrm{mg} / \mathrm{kg}$ dose B) $10 \mathrm{mg} / \mathrm{kg}$ dose C) Bile. Eels were injected IP with BP or TCB at the doses indicated and killed 8 days post-injection. Portions of freshly dissected organs were removed, weighed, rinsed with water, blotted and digested with Soluble. The organs were minced with scissors and placed in a $50^{\circ} \mathrm{C}$ oven until dissolved. Bile was collected via syringe. Blood was collected from the caudal vein via syringe and then added to ethanol:Soluble (1:2). $\mathrm{H}_{2} \mathrm{O}_{2}$ was added to all vials except those containing gut and muscle. All samples containing Soluble were acidified with HCL. Scintiverse was added to the vials, and the samples were allowed to quench overnight before counting. Data are means \pm SD of 3-6 individuals. a- Significantly greater than $1 \mathrm{mg} / \mathrm{kg}$ dose $(\mathrm{p}<0.05$, Student's $\mathrm{t}$-test $) \quad b$ Significantly greater than blood ( $\mathrm{p}<0.05$, Dunnett's). 
$1 \mathrm{mg} / \mathrm{kg} \mathrm{TCB} 10 \mathrm{mg} / \mathrm{kg} \mathrm{TCB}$ \ $1 \mathrm{mg} / \mathrm{kg} \mathrm{BP} \quad 10 \mathrm{mg} / \mathrm{kg} \mathrm{BP}$

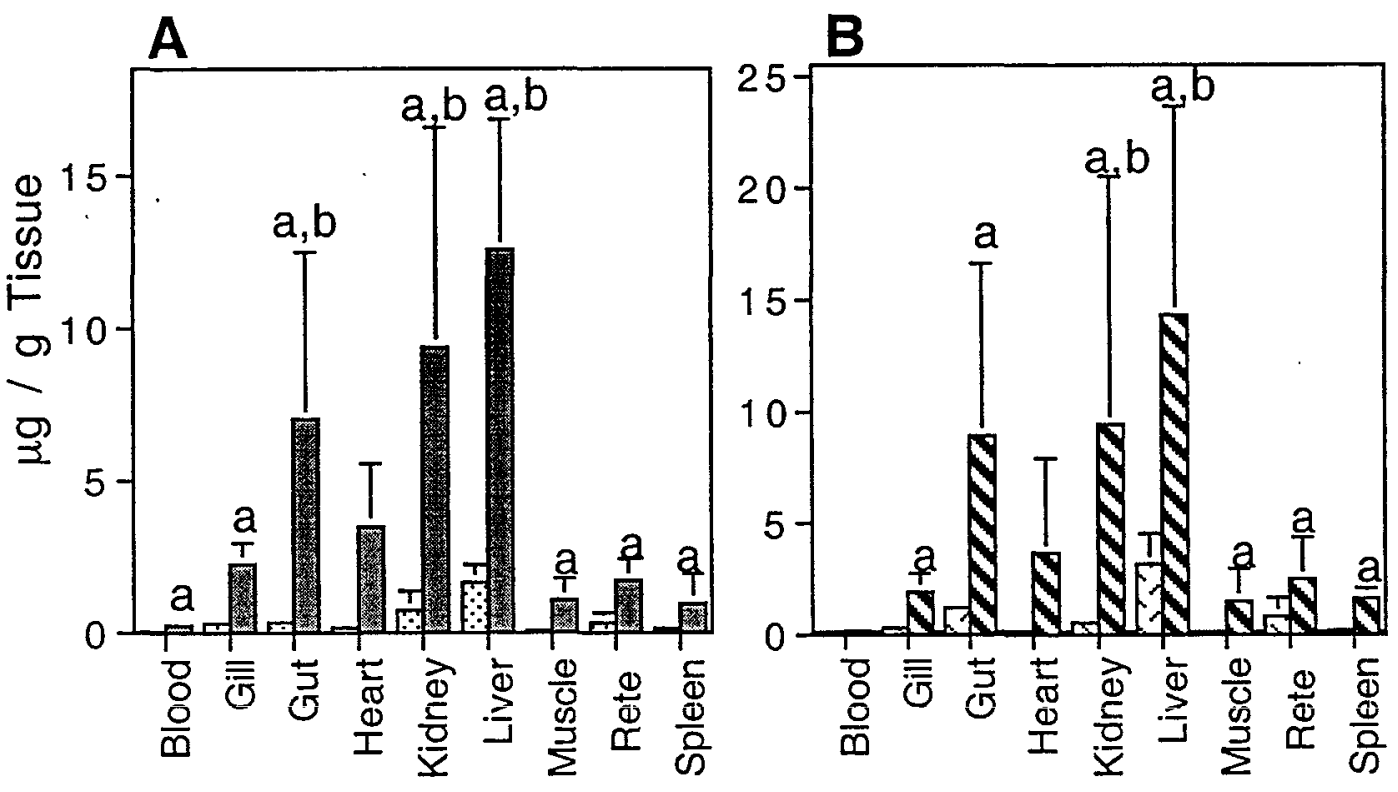

Tissue

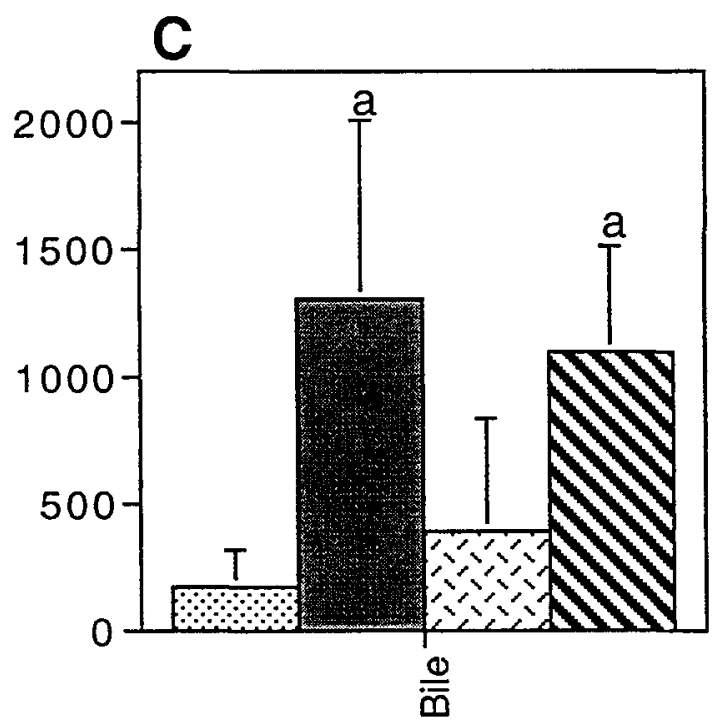


BP and TCB were tested, and tissues were sampled eight days after treatment. Concentrations of BP and TCB were found to be dose-dependent in gill, gut, liver, muscle and rete mirabile. In all cases bile contained the highest concentration of $\mathrm{BP}$ and TCB, and the concentrations of both chemicals were similar. Of the organs, liver contained the greatest concentration of BP and TCB. The other excretory organs, gut and kidney, also had comparatively high concentrations of $\mathrm{BP}$ and $\mathrm{TCB}$. The chemical concentrations in the gill, heart, and rete mirabile were higher than that seen in blood, though variability in the results prevented the differences from being significant.

\section{Liver}

Experimental exposure: We assessed CYP1A induction in liver to determine the responsiveness of CYP1A in eels to induction by model AhR agonists. MAb 1-12-3 reacted with one band in eel liver microsomes (Figure 2). Control eels had low basal levels of total P450 content, CYP1A content and ethoxyresorufin O-deethylase (EROD) activity (Table I, Figure 3).

Treatment with BNF, BP and TCB resulted in minimal effects on total P450 and b5 content (Table I). Significant increases in total P450 occurred only at the $10 \mathrm{mg} / \mathrm{kg}$ dose of $\mathrm{BNF}$ and BP.

Induction of CYP1A protein and activity in liver microsomes varied with inducer (BNF, BP or TCB) and dose (Figure 3). CYP1A content was induced significantly by doses greater than $1 \mathrm{mg} \mathrm{BNF} / \mathrm{kg}$, and CYP1A content in the 10 and $100 \mathrm{mg} B N F / \mathrm{kg}$ groups was significantly greater than in all other groups. Doses greater than $5 \mathrm{mg} \mathrm{BNF} / \mathrm{kg}$ resulted in EROD activities significantly greater than in control eels. EROD activity in the $100 \mathrm{mg} \mathrm{BNF} / \mathrm{kg}$ group was significantly different from that in all other groups. Both the 1 and $10 \mathrm{mg} \mathrm{BP} / \mathrm{kg}$ doses elicited significant CYP1A protein induction The $10 \mathrm{mg}$ BP/kg group had significantly greater CYP1A protein and activity than all other doses. Doses greater than $5 \mathrm{mg}$ TCB $/ \mathrm{kg}$ resulted in significant increases in CYP1A content and EROD activity compared to the control group. However, the $20 \mathrm{mg} \mathrm{TCB} / \mathrm{kg}$ dose did not significantly induce CYP1A content or EROD activity above that in eels receiving $10 \mathrm{mg}$ TCB/kg. Treatment with TCB resulted in a lesser induction of CYP1A protein and activity than was seen with BNF and BP (Table II), at comparable doses.

The results as described above refer to nominal or administered dose. Induction of CYP1A content and catalytic activity was assessed in livers of eels used in the chemical distribution studies to relate responses to tissue dose. For both BP and TCB, CYP1A 


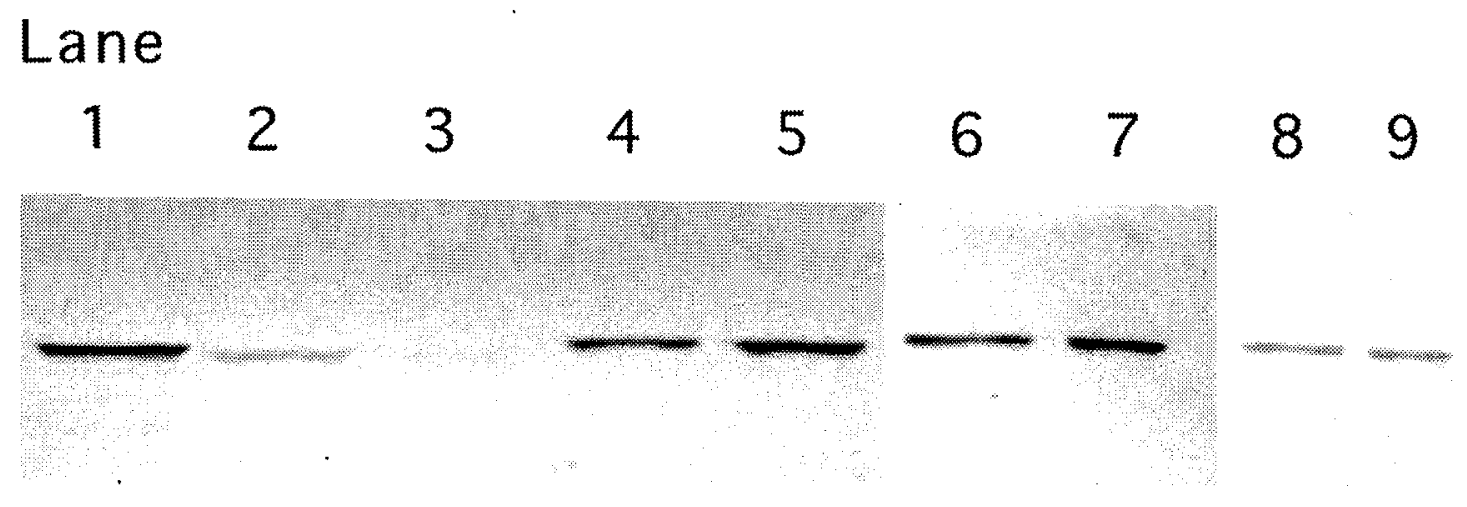

Figure 2. CYP1A protein expression in liver microsomes from eels treated with BNF, BP and TCB. Eels were injected IP with BNF, BP or TCB at the doses indicated and killed 8 days post-injection. Liver microsomal fractions were electrophoresed, transferred to nitrocellulose, immunoblotted with MAb 1-12-3 against scup CYP1A and visualized using NBT-BCIP. Lane 1: Scup CYP1A. Lanes 2-3: Control $(80 \mu \mathrm{g})$. Lanes 4-5: BNFtreated $(5 \& 10 \mu \mathrm{g})$ Lanes 6-7: TCB-treated $(5 \& 10 \mu \mathrm{g})$. Lanes 8-9: BP-treated $(10 \mu \mathrm{g})$. 


\section{TABLE I}

Total spectral P450 and cytochrome b5 content in eels treated with BNF, BP and TCB

\begin{tabular}{ccccc}
\hline Treatment & $\begin{array}{c}\text { Dose } \\
(\mathrm{mg} / \mathrm{kg})\end{array}$ & $\mathrm{n}$ & $\begin{array}{c}\mathrm{b} 5 \\
(\mathrm{nmol} / \mathrm{mg})\end{array}$ & $\begin{array}{c}\text { Total P450 } \\
(\mathrm{nmol} / \mathrm{mg})\end{array}$ \\
\hline Corn Oil & Control & 24 & $0.07 \pm 0.03$ & $0.28 \pm 0.08$ \\
\cline { 2 - 5 } TCB & 0.1 & 6 & $0.09 \pm 0.03$ & $0.34 \pm 0.10$ \\
& 1 & 8 & $0.05 \pm 0.01$ & $0.32 \pm 0.03$ \\
& 5 & 3 & $0.12 \pm 0.03$ & $0.43 \pm 0.11$ \\
& 10 & 18 & $0.08 \pm 0.03$ & $0.34 \pm 0.15$ \\
& 20 & 3 & $0.11 \pm 0.02$ & $0.38 \pm 0.101$ \\
\hline BNF & 0.1 & 3 & $0.08 \pm 0.05$ & $0.31 \pm 0.06$ \\
& 1 & 3 & $0.10 \pm 0.02$ & $0.30 \pm 0.03$ \\
& 5 & 3 & $0.10 \pm 0.03$ & $0.24 \pm 0.04$ \\
& 10 & 9 & $0.13 \pm 0.04$ & $0.42 \pm 0.15^{*}$ \\
BP & 100 & 3 & $0.18 \pm 0.03$ & $0.42 \pm 0.09$ \\
& 0.1 & 4 & $0.07 \pm 0.02$ & $0.22 \pm 0.04$ \\
& 1 & 13 & $0.08 \pm 0.02$ & $0.31 \pm 0.07$ \\
& 10 & 12 & $0.11 \pm 0.03$ & $0.38 \pm 0.08^{*}$ \\
\hline
\end{tabular}

Eel liver microsomal cytochrome P450 and b5 contents were determined spectrally as described in Methods. Values are means $\pm \mathrm{SD}$.

* - Significantly different from control ( $\mathrm{p}<0.05$, Tukey-Kramer). 

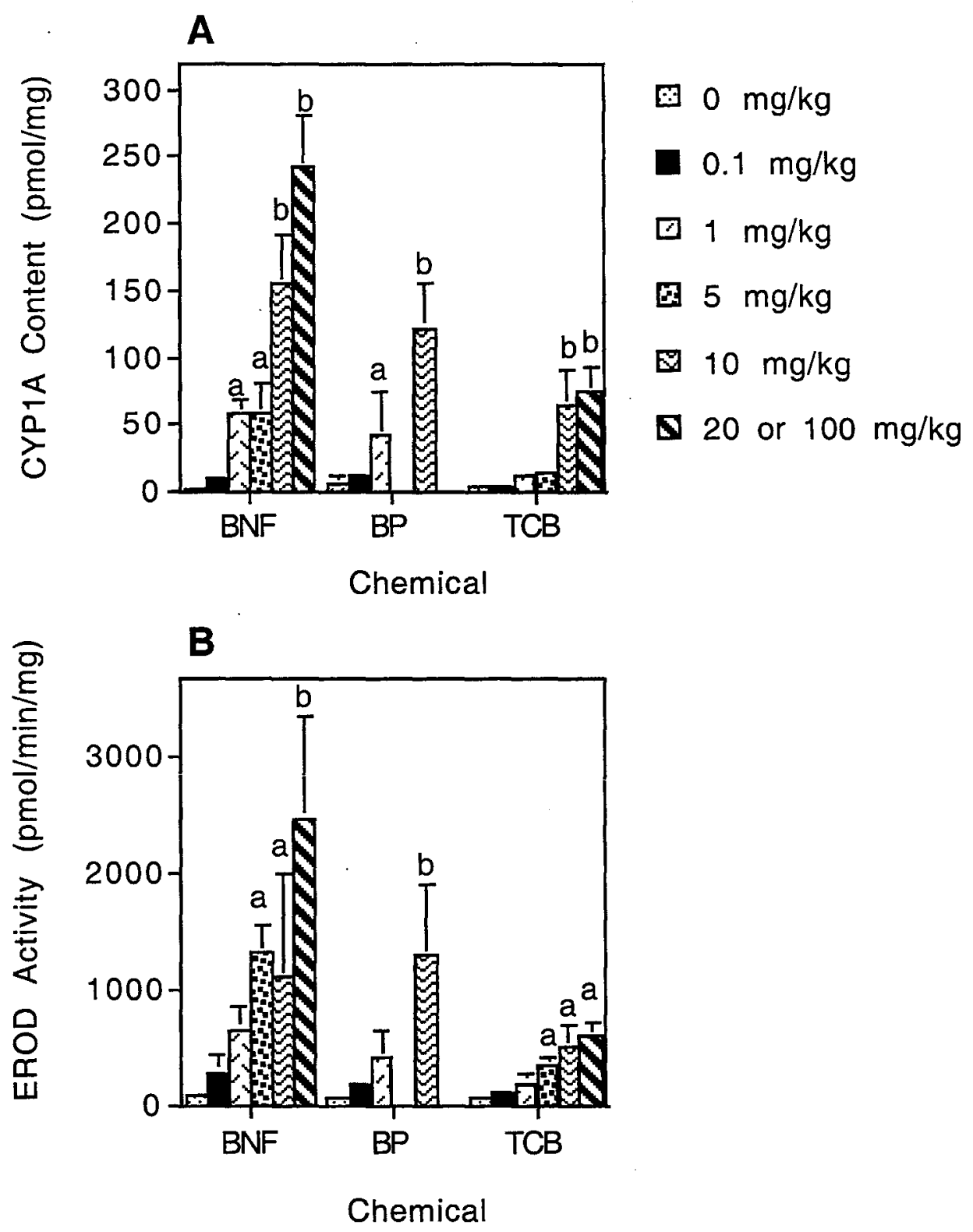

Figure 3. Quantification of liver CYP1A protein and activity in eels treated with BNF, BP and TCB. A) EROD activity. B) CYP1A content. Eels were injected IP with BNF, BP or TCB at the doses indicated and killed 8 days post-injection. Microsomal EROD activity was determined fluorometrically Immunoblot analysis was performed as described in Figure 2, and quantified by densitometric analysis. a- Significantly different from control $(\mathrm{p}<0.05$, Tukey-Kramer). b-Significantly different from all doses $(\mathrm{p}<0.05$, TukeyKramer). 


\section{TABLE II}

Comparison of the efficacy of BNF, BP and TCB in inducing CYP1A in eel liver

\begin{tabular}{cccc}
\hline Treatment & $\begin{array}{c}\text { Dose } \\
(\mathrm{mg} / \mathrm{kg})\end{array}$ & $\begin{array}{c}\text { CYP1A } \\
(\mathrm{pmol} / \mathrm{mg})\end{array}$ & $\begin{array}{c}\text { EROD Activity } \\
(\mathrm{pmol} / \mathrm{min} / \mathrm{mg})\end{array}$ \\
\hline Corn Oil & Control & $2 \pm 3$ & $81 \pm 47$ \\
\cline { 2 - 4 } BNF & 1 & $58 \pm 12^{*}$ & $661 \pm 194^{* *}$ \\
BP & & $43 \pm 32^{*}$ & $422 \pm 234^{*}$ \\
TCB & & $12 \pm 4$ & $193 \pm 70$ \\
BNF & 10 & $156 \pm 37^{* *}$ & $1115 \pm 901^{*}$ \\
BP & & $122 \pm 34^{* *}$ & $1312 \pm 600^{* *}$ \\
TCB & & $65 \pm 27$ & $502 \pm 191$ \\
\hline
\end{tabular}

Eel liver microsomal CYP1A content and EROD activity were determined as described in Methods. Values are means $\pm \mathrm{SD}$.

* - Significantly different from TCB $(\mathrm{p}<0.05)$.

** - Significantly different from TCB $(\mathrm{p}<0.01)$. 
content and activity were correlated strongly with the inducer concentrations in the liver (Figure 4).

Environmental exposure: Three sites were chosen for sampling of eels exposed to AhR agonists in the environment. PCB, dioxin and PAH concentrations in sediment were $2100,8,170 \mathrm{ug} / \mathrm{g}$ dry weight in New Bedford Harbor, MA (Pruell et al., 1990). This led to concentrations of PCBs as high as $1400 \mu \mathrm{g} / \mathrm{g}$ dry weight in $F$. heteroclitus and $700 \mu \mathrm{g} / \mathrm{g}$ dry weight (i.e. approximately $70 \mathrm{mg} / \mathrm{kg}$ wet weight) in A. rostrata (Lake et al., 1995). Marion Harbor, MA is an enclosed body of water with substantial boat traffic. Vineyard Sound is an open body of water where eels used in the experimental exposures were caught. Total P450 and b5 contents as well as CYP1A protein and EROD activity were significantly greater in liver of eels from New Bedford Harbor $(\mathrm{NBH})$ than in those from Marion Harbor or Vineyard Sound (Table III).

\section{Endothelium}

Biochemical analysis: Heart and rete mirabile microsomes were biochemically analyzed to examine the induction of CYP1A in endothelial cells. Endothelium represents as much as $8-9 \%$ of the mass of the teleost heart (Stegeman et al., 1989), and the rete mirabile is composed almost solely of endothelial cells (Krogh, 1959). In heart, CYP1A protein and activity increased with increasing doses of BP and TCB (Table IV). As in liver, similar CYP1A induction occurred with BNF and BP, while TCB treatment resulted in a lesser CYP1A induction. Not only was CYP1A protein detectable in rete mirabile (Figure 5), but EROD and CPR activity also were measurable (Table IV). Furthermore, in eels collected from variously polluted sites, endothelial CYP1A content and activity was elevated significantly in eels collected from NBH (Table V).

Immunohistochemical analysis: Immunohistochemical analyses were performed in order to determine the dose-dependence of endothelial CYP1A induction in a variety of organs. Across experiments, control eels which received corn oil had at most mild staining of CYP1A in gill pillar cells, heart endothelial cells, and kidney endothelial cells (Figure 6). No staining was observed in gill epithelium of control eels.

CYP1A was induced in endothelium in heart, kidney and gill by treatment with $\mathrm{BNF}, \mathrm{BP}$ or TCB, although the pattern of induction varied with the inducer (Figure 6). Both BP and TCB induced dose-dependent increases in endothelial staining in gill, heart,

and kidney. Doses greater than $10 \mathrm{mg} / \mathrm{kg}$ of $\mathrm{BP}$ or TCB resulted in significant CYP1A induction compared to that in controls. At $20 \mathrm{mg}$ TCB $/ \mathrm{kg}$, CYP1A immunostaining also was significantly greater than that in eels receiving $0.1 \mathrm{mg} \mathrm{TCB} / \mathrm{kg}$. CYP1A 


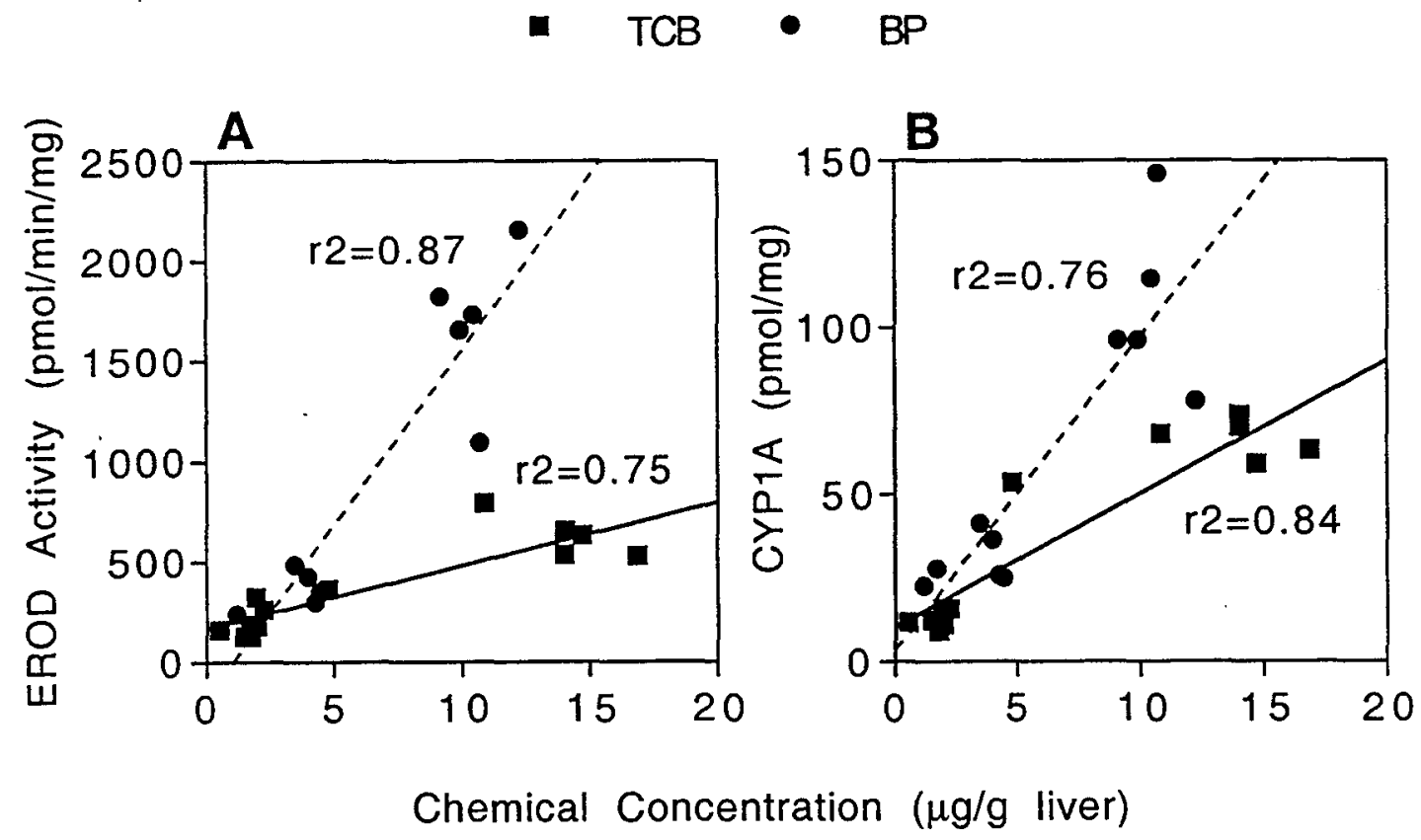

Figure 4. Correlation of $\mathrm{BP}$ and $\mathrm{TCB}$ concentration in eel liver with CYP1A induction. A) Inducer concentration vs. EROD activity B) Inducer concentration vs. CYP1A content. Inducer concentrations were determined as described in Figure 1. EROD activity and CYP1A content were determined as described in Figure 3. All of the relationships shown are correlated significantly $(\mathrm{p}<0.001)$. 


\section{TABLE III}

Characterization of CYP1A protein and activity in liver microsomes from eels collected from differentially polluted sites

\begin{tabular}{ccccc}
\hline Site & $\begin{array}{c}\text { EROD Activity } \\
(\mathrm{pmol} / \mathrm{min} / \mathrm{mg})\end{array}$ & $\begin{array}{c}\text { CYP1A } \\
(\mathrm{pmol} / \mathrm{mg})\end{array}$ & $\begin{array}{c}\text { Total P450 } \\
(\mathrm{nmol} / \mathrm{mg})\end{array}$ & $\begin{array}{c}\mathrm{b5} \\
(\mathrm{nmol} / \mathrm{mg})\end{array}$ \\
\hline New Bedford $(\mathrm{n}=16)$ & $321 \pm 119^{* *}$ & $190 \pm 92^{* *}$ & $0.55 \pm 0.10^{*}$ & $0.36 \pm 0.11^{* *}$ \\
Marion Harbor $(\mathrm{n}=8)$ & $116 \pm 28$ & $13 \pm 3$ & $0.35 \pm 0.08$ & $0.14 \pm 0.03$ \\
Vineyard Sound $(\mathrm{n}=10)$ & $77 \pm 32$ & $1 \pm 1$ & $0.41 \pm 0.07$ & $0.14 \pm 0.12$ \\
\hline
\end{tabular}

Eel liver microsomes from eels collected in New Bedford Harbor, Marion Harbor and Vineyard Sound were characterized for their cytochrome P450, b5 and CYP1A contents, and CYP1A catalytic activity (EROD) as described under Methods. Values are means \pm SD.

* - Significantly different from all other sites ( $\mathrm{p}<0.05$, Tukey-Kramer).

** - Significantly different from all other sites ( $p<0.01$, Tukey-Kramer). 


\section{TABLE IV}

Quantification of CYP1A content and activity in eel heart and rete mirabile following treatment with model AhR agonists

\begin{tabular}{ccccccc}
\hline & \multicolumn{3}{c}{ Heart } & & \multicolumn{3}{c}{ Rete mirabile } \\
\cline { 2 - 3 } \cline { 6 - 7 } Treatment & CYP1A $^{\mathrm{a}}$ & EROD & & CYP1A & EROD & Reductase \\
& & Activity & & & Activity & Activity \\
\cline { 2 - 3 } Control & ND & $2 \pm 2$ & & ND & 0.1 & 8.9 \\
BP 0.1 mg/kg & ND & $4 \pm 2$ & & 0.2 & 0.2 & 18.0 \\
BP $1 \mathrm{mg} / \mathrm{kg}$ & $23 \pm 23$ & $4 \pm 2$ & & 1.4 & 0.5 & 11.3 \\
BP $10 \mathrm{mg} / \mathrm{kg}$ & $255 \pm 143$ & $13 \pm 12$ & & 5.8 & 0.9 & 14.5 \\
BNF $10 \mathrm{mg} / \mathrm{kg}$ & $49 \pm 49$ & $9 \pm 6$ & & 3.9 & 0.9 & 5.6 \\
TCB $10 \mathrm{mg} / \mathrm{kg}$ & $22 \pm 14$ & $3 \pm 3$ & & 0.7 & 0.4 & 33.8 \\
\hline
\end{tabular}

Eels were injected IP with BNF, BP or TCB at the doses indicated and killed 8 days postinjection. Eel heart and rete mirabile were characterized for their CYP1A content and catalytic activity (EROD) as described under Methods. For heart, values are means $\pm \mathrm{SD}$ from 3-6 pools of 2-3 individual organs. For rete mirabile, each value is from a pool of 23 individual organs.

a - Integrated density/mg microsomal protein.

b - Pmol resorufin formed/min/mg microsomal protein.

$c$ - Integrated density measured in $80 \mu \mathrm{g}$ of post-mitochondrial supernatant protein.

d - Pmol resorufin formed/min/mg post-mitochondrial supernatant protein.

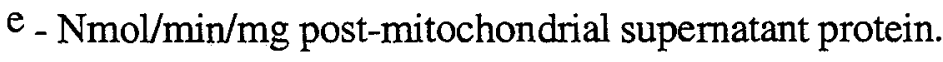

ND - Not detectable. 


\section{Lane}
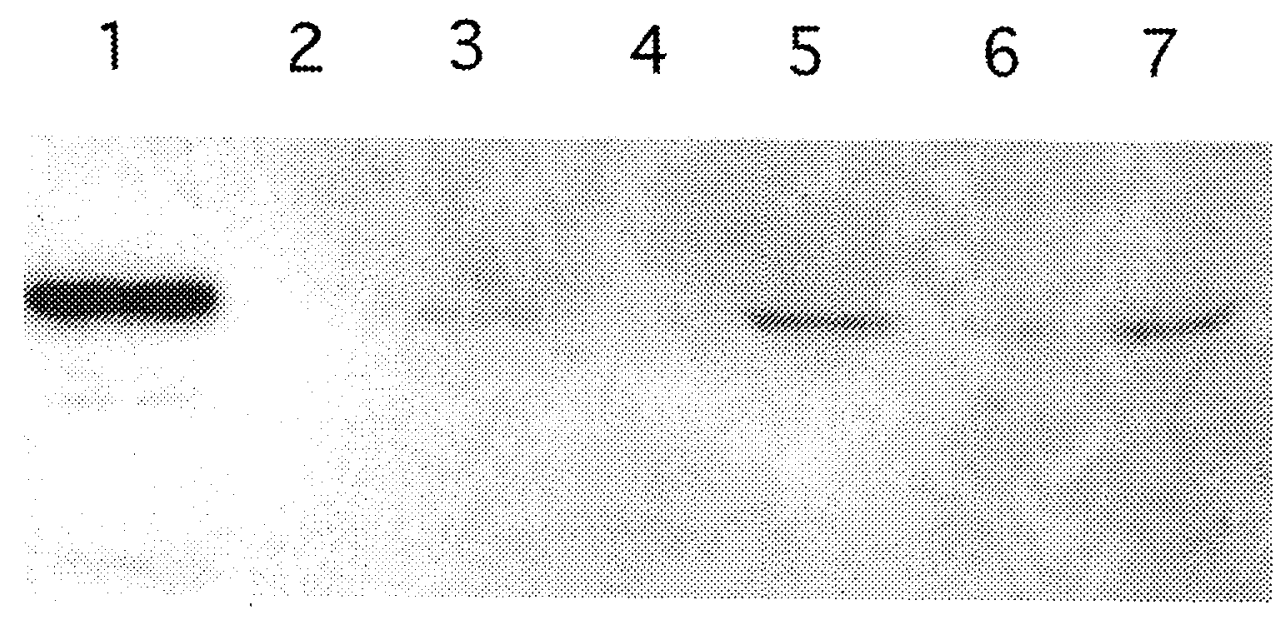

Figure 5. Immunodetection of CYP1A in rete mirabile microsomes from eels treated with $\mathrm{BNF}, \mathrm{BP}$ and TCB. Eels were injected IP with BNF, BP or TCB at the doses indicated and killed 8 days post-injection. Immunoblot analysis was performed as described in Figure 2, with the exceptions of being transferred to nylon and visualized using enhanced chemiluminescence. Lane 1: Scup CYP1A standard. Lane 2: Control. Lane 3: $1 \mathrm{mg}$ BP/kg. Lane 4: $0.01 \mathrm{mg} \mathrm{BP} / \mathrm{kg}$. Lane 5: $10 \mathrm{mg} \mathrm{BP} / \mathrm{kg}$. Lane 6: $10 \mathrm{mg} \mathrm{TCB} / \mathrm{kg}$. Lane 7: $10 \mathrm{mg} \mathrm{BNF} / \mathrm{kg}$. 


\section{TABLE V}

Characterization of CYP1A protein and activity in heart and rete mirabile microsomes from eels collected from differentially polluted sites

\begin{tabular}{ccccc}
\hline Site & Organ & $\begin{array}{r}\text { EROD Activity } \\
(\mathrm{pmol} / \mathrm{min} / \mathrm{mg})\end{array}$ & $\begin{array}{c}\text { CYP1A } \\
(\mathrm{pmol} / \mathrm{mg})\end{array}$ & $\begin{array}{c}\text { Endothelial CYP1A } \\
\text { (Stain Index) }\end{array}$ \\
\hline New Bedford & Heart & $\begin{array}{c}5.8 \pm 2.8^{*} \\
\mathrm{n}=11\end{array}$ & $\begin{array}{c}4.5 \pm 1.7 \\
<.001^{\mathrm{a}}\end{array}$ & $\begin{array}{c}10.1 \pm 3.5^{*} \\
\mathrm{nd}\end{array}$ \\
\cline { 2 - 5 } Rarion Harbor & Heart & $1.0 \pm 0.4$ & $<.001$ & $1.3 \pm 1.8$ \\
$\mathrm{n}=5$ & Rete & $0.2 \pm 0.1$ & $<.001$ & $\mathrm{nd}$ \\
\cline { 2 - 5 } Vineyard Sound & Heart & $0.6 \pm 0.5$ & $<.001$ & $0.2 \pm 0.4$ \\
$\mathrm{n}=8$ & Rete & $0.3 \pm 0.1$ & $<.001$ & $\mathrm{nd}$ \\
\hline
\end{tabular}

Eel heart and rete mirabile microsomes from eels collected in New Bedford Harbor, Marion Harbor and Vineyard Sound were characterized for their CYP1A content and CYP1A catalytic activity (EROD) as described under Methods. Values are means \pm SD.

* - Significantly different from all other sites ( $p<0.01$, Tukey-Kramer).

a - Bands corresponding to CYP1A were visible in two samples, but were unquantifiable. nd - Not determined 
immunostaining in BNF treated eels peaked at intermediate doses, which differed from that resulting from BP or TCB treatment where staining increased to the highest dose. Endothelial staining peaked at $1 \mathrm{mg} \mathrm{BNF} / \mathrm{kg}$ in gill pillar cells and $5 \mathrm{mg} \mathrm{BNF} / \mathrm{kg}$ in ventricular and kidney endothelial cells.

Gill epithelial cells also were inducible for CYP1A; however, the response was dependent upon the inducer (Figure 6). In BP and TCB-treated eels, gill epithelial staining remained mild, even at the highest doses. While gill endothelial staining in eels treated with doses greater than $5 \mathrm{mg} \mathrm{BNF} / \mathrm{kg}$ decreased, the gill epithelial staining was induced and continued to increase significantly with increasing dose.

CYP1A immunostaining in the rete mirabile: Immunohistochemical analysis of CYP1A showed a dose-dependent induction in the endothelial cells of the rete mirabile (Figure 7). All control and dosed fish showed significant positive staining in the pre-rete arteries; however, the extent of penetration of staining into the rete itself differed with inducer and dose. Rete from control fish had mild to strong staining in endothelial cells of the pre-rete arteries only. BNF was most effective at inducing CYP1A in the endothelium of the rete (Table VI). There was a dose-dependent increase in the CYP1A stain index in the pre-rete arteries, with maximal staining reached by the $1 \mathrm{mg} \mathrm{BNF/kg}$ dose. Similarly, the intensity of CYP1A staining in the heart-pole endothelium was dose-dependent. Doses greater than $1 \mathrm{mg} \mathrm{BNF} / \mathrm{kg}$ resulted in penetration of CYP1A staining into the mid-rete region, and doses greater than $5 \mathrm{mg} \mathrm{BNF} / \mathrm{kg}$ resulted in extension of penetration of endothelial CYP1A staining into the vessels of the bladder pole. In BP-treated eels, the CYP1A stain index in the pre-rete arteries was dose-dependent. Doses greater than $0.1 \mathrm{mg}$ $\mathrm{BP} / \mathrm{kg}$ resulted in CYP1A staining in heart-pole endothelium, and the intensity of staining increased with dose. A dose of $10 \mathrm{mg} \mathrm{BP} / \mathrm{kg}$ resulted in CYP1A induction in the mid-rete. While the CYP1A stain index in TCB-treated eels was dose-dependent, maximal staining (i.e. a score of 16) was not reached in these eels. Doses greater than $1 \mathrm{mg} / \mathrm{kg}$ TCB resulted in CYP1A staining in the heart-pole endothelium, and the intensity increased with dose. TCB did not induce CYP1A staining in the mid-rete. With all of the inducers as the dose increased, the proportion of eels with staining of retial CYP1A increased, evident most clearly in the heart pole.

\section{DISCUSSION}

Previous studies have suggested that eels may be useful in biomonitoring of aquatic pollution (van der Oost et al., 1996). However, the direct response of CYP1A in eels 
Figure 6. Immunohistochemical analysis of CYP1A protein in endothelium of eels treated with BNF, BP and TCB. A) BNF-treated eels $(n=3-10)$. B) BP-treated eels $(n=4-8)$. C) TCB-treated eels $(n=3-15)$. Eels were injected IP with BNF, BP or TCB at the doses indicated and killed 8 days post-injection. Tissues were dissected, embedded, sectioned and immunohistochemically analyzed for CYP1A as described under Methods. Staining of CYP1A was scored for intensity of staining ( $0=$ no stain, $1=$ mild stain, $2=$ moderate stain, $3=$ strong stain, $4=$ very strong stain) and for occurrence of staining ( $0=$ no cells, $1=$ rare cells, $2=$ =some cells, $3=$ many cells, $4=$ all cells staining). The stain index was computed by multiplying the intensity and occurrence scores for a scale from $0-16$. *-Significantly different from control. a-Significantly different from control and $0.1 \mathrm{mg} / \mathrm{kg}$. b_ Significantly different from control, 0.1 and $1 \mathrm{mg} / \mathrm{kg}$. C-Significantly different from 1 $\mathrm{mg} / \mathrm{kg}$. d-Significantly different from $5 \mathrm{mg} / \mathrm{kg}$. Significance was determined as $\mathrm{p}<0.05$ (Tukey-Kramer). 

( Control
國 $0.1 \mathrm{mg} / \mathrm{kg}$
$1 \mathrm{mg} / \mathrm{kg}$
国 $5 \mathrm{mg} / \mathrm{kg}$
目 $10 \mathrm{mg} / \mathrm{kg}$
区 20 or $100 \mathrm{mg} / \mathrm{kg}$
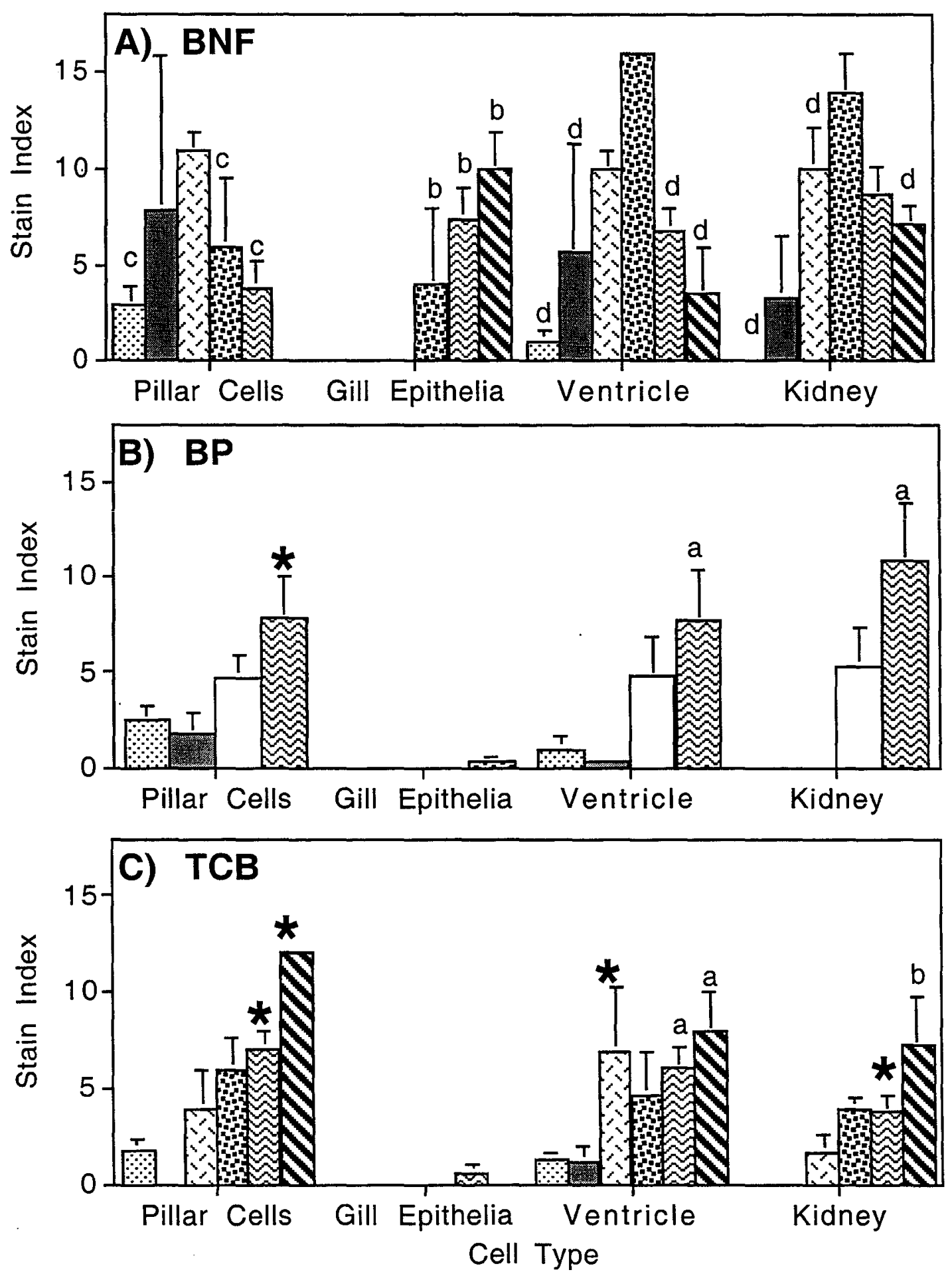
Figure 7. CYP1A immunostained sections of rete mirabile from eels treated with BNF. Eels were injected IP with $\mathrm{BNF}$ at the doses indicated and killed 8 days post-injection. A) Control (heart pole). B) $0.1 \mathrm{mg} / \mathrm{kg}$ (heart pole). C) $1 \mathrm{mg} / \mathrm{kg}$ (heart pole). D) $5 \mathrm{mg} / \mathrm{kg}$ (heart pole). E) $5 \mathrm{mg} / \mathrm{kg}$ (bladder pole). The immunostaining procedure used is as described by Smolowitz et al. (1991). 


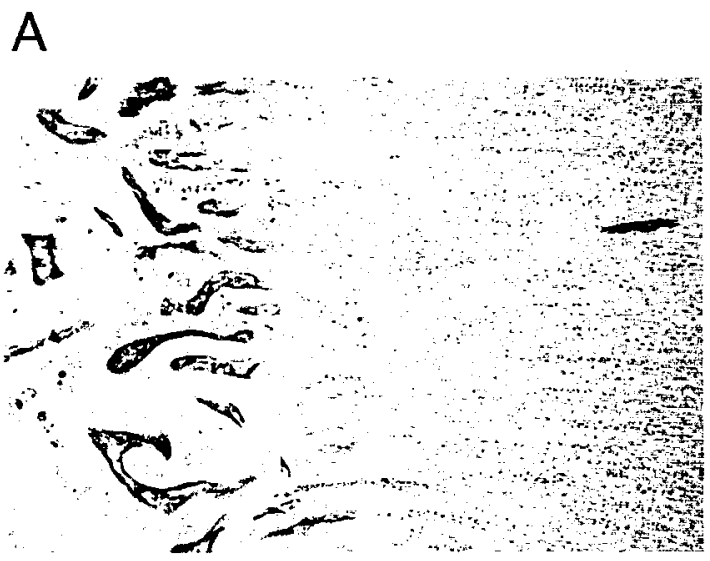

B

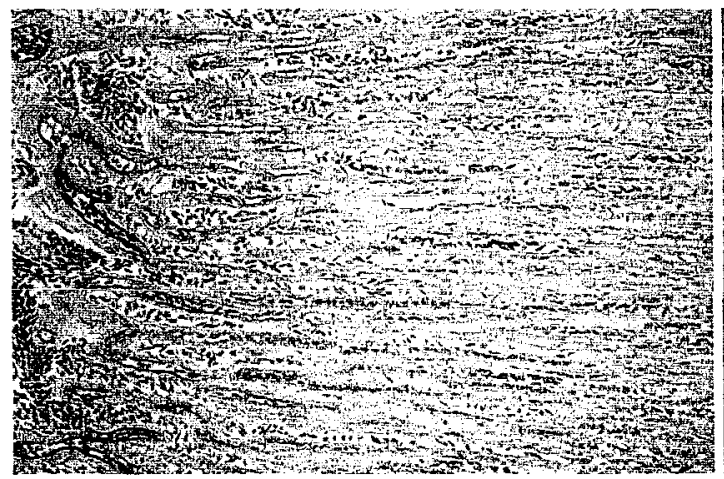

C

D

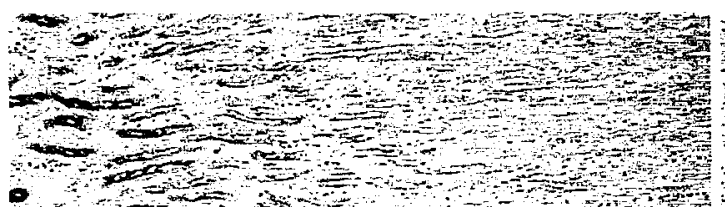

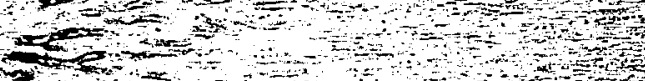

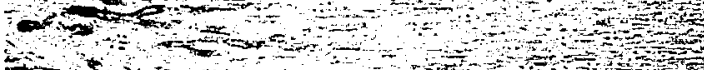

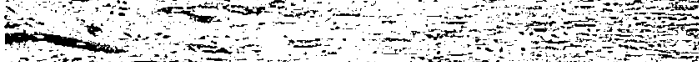

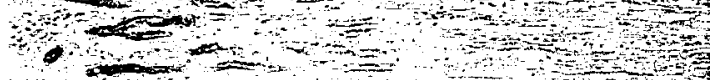

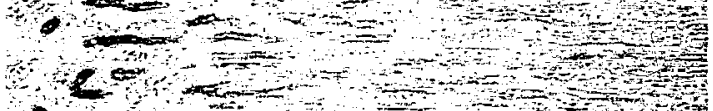
H. E

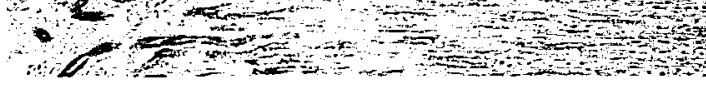
$\frac{3}{3}$ 
TABLE VI

Immunohistochemical analysis of CYP1A induction following treatment with BNF, BP and TCB in the rete mirabile of eels

\begin{tabular}{|c|c|c|c|c|c|c|c|}
\hline \multirow[b]{2}{*}{ Chemical } & \multirow[b]{2}{*}{$\begin{array}{c}\text { Dose } \\
(\mathrm{mg} / \mathrm{kg})\end{array}$} & \multicolumn{2}{|c|}{$\begin{array}{c}\text { Pre-rete } \\
\text { Endothelium } \\
\end{array}$} & \multicolumn{2}{|c|}{$\begin{array}{c}\text { Heart Pole } \\
\text { Endothelium }\end{array}$} & \multirow{2}{*}{$\begin{array}{c}\begin{array}{c}\text { Mid-rete } \\
\text { Endothelium }\end{array} \\
+ \text { t/total }\end{array}$} & \multirow{2}{*}{$\begin{array}{c}\begin{array}{c}\text { Bladder Pole } \\
\text { Endothelium }\end{array} \\
+/ \text { total }\end{array}$} \\
\hline & & $\begin{array}{l}\text { Stain } \\
\text { Index }\end{array}$ & $+/$ total $*$ & Intensity & $+/$ total & & \\
\hline \multirow[t]{6}{*}{ BNF } & 0 & $10 \pm 4$ & $3 / 3$ & 0 & $0 / 3$ & $0 / 3$ & $0 / 3$ \\
\hline & 0.1 & $13 \pm 2$ & $3 / 3$ & $1 \pm 1$ & $1 / 3$ & $0 / 3$ & $0 / 3$ \\
\hline & 1 & $16 \pm 0$ & $3 / 3$ & $3 \pm 1$ & $2 / 3$ & $1 / 3$ & $0 / 3$ \\
\hline & 5 & $16 \pm 0$ & $3 / 3$ & $4 \pm 1$ & $3 / 3$ & $3 / 3$ & $2 / 3$ \\
\hline & 10 & $16 \pm 0$ & 9/9 & $3 \pm 0$ & $9 / 9$ & $1 / 9$ & $1 / 9$ \\
\hline & 100 & $16 \pm 0$ & $3 / 3$ & $3 \pm 0$ & $3 / 3$ & $3 / 3$ & $2 / 3$ \\
\hline \multirow[t]{4}{*}{ BP } & 0 & $10 \pm 6$ & $7 / 12$ & $0 \pm 0$ & $4 / 12$ & $0 / 12$ & $0 / 12$ \\
\hline & 0.1 & $10 \pm 2$ & $4 / 4$ & $1 \pm 1$ & $3 / 4$ & $0 / 4$ & $0 / 4$ \\
\hline & 1 & $15 \pm 2$ & $6 / 7$ & $1 \pm 1$ & $6 / 7$ & $0 / 7$ & $0 / 7$ \\
\hline & 10 & $16 \pm 0$ & $6 / 6$ & $2 \pm 1$ & $6 / 6$ & $2 / 6$ & $1 / 6$ \\
\hline \multirow[t]{5}{*}{$\mathrm{TCB}$} & 0 & $10 \pm 4$ & $5 / 5$ & $0 \pm 0$ & $0 / 5$ & $0 / 5$ & $0 / 5$ \\
\hline & 0.1 & $6 \pm 3$ & $3 / 3$ & 0 & $0 / 3$ & $0 / 3$ & $0 / 3$ \\
\hline & 1 & $14 \pm 3$ & $3 / 3$ & $2 \pm 0$ & $3 / 3$ & $0 / 3$ & $0 / 3$ \\
\hline & 10 & $15 \pm 3$ & $12 / 12$ & $1 \pm 1$ & $12 / 12$ & $0 / 12$ & $0 / 12$ \\
\hline & 20 & $11 \pm 7$ & $3 / 3$ & $2 \pm 0$ & $3 / 3$ & $0 / 3$ & $0 / 3$ \\
\hline
\end{tabular}

Eels were injected IP with BNF, BP or TCB at the doses indicated and killed 8 days postinjection. Rete mirabile were dissected, embedded, sectioned and immunohistochemically analyzed for CYP1A as described under Methods. Staining of CYP1A was scored for intensity of staining ( $0=$ no stain, $1=$ mild stain, $2=$ moderate stain, $3=$ strong stain, $4=$ very strong stain) and for occurrence of staining ( $0=$ no cells, $1=$ rare cells , $2=$ some cells, $3=$ many cells, $4=$ all cells staining). The stain index in computed by multiplying the intensity and occurrence scores for a scale from 0-16.

* - Number of rete with positive staining over the total number analyzed. 
following treatment of AhR agonists has not been addressed. CYP1A in liver was significantly induced by both halogenated and non-halogenated AhR agonists. Furthermore, CYP1A induction in liver was correlated strongly with agonist concentration, whether PAH (BP) or pHAH (TCB). In comparison with other species, eels are moderately sensitive to CYPlA induction by AhR agonists.

CYP1A induction in endothelium could have multiple consequences. Previous studies have suggested that endothelial CYP1A induction may alter the pharmacokinetics of AhR agonists/CYP1A substrates (Smolowitz et al., 1991), affect vascular function (Pinto et al., 1986; Pinto et al., 1987), and stimulate toxicity (Guiney et al., 1997). In this study we evaluated the possible relationship between CYP1A induction in endothelium and the pharmacokinetics of AhR agonists. CYP1A in endothelium responded in a dose-dependent manner to treatment with AhR agonists and was highly inducible in heart, gill and kidney. The rete mirabile was examined for CYP1A induction because it is an organ that is composed almost solely of endothelial cells and may be a unique site in which to investigate the response of endothelial CYP1A to AhR agonists in vivo. Induction of CYP1A in rete mirabile could be observed in both immunohistochemical and biochemical assays. The patterns of induction in this vascular bed are consistent with the extent of penetration of inducer being limited at lower doses possibly by induction of CYP1A. The results also confirm that capillary endothelial CYP1A is metabolically active.

\section{Liver}

Tissue Distribution of BP and TCB: Previously, studies determined that the tissue distribution of highly lipophilic compounds, including pHAHs, is species specific. Cod injected with 2,3,3',4,4'-pentachlorobiphenyl or 2,3,7,8-tetrachlorodibenzo-p-dioxin have much greater concentrations of these chemicals in the liver than similarly treated rainbow trout (Bernhoft et al., 1994; Hektoen et al., 1994). This difference has been attributed to the fact that the main lipid store in cod is the liver, while in rainbow trout there are peritoneal and subcutaneous lipid stores. In the present study, eels tended to have low concentrations of both TCB and BP in the liver, though the liver did have greater concentrations of both $\mathrm{BP}$ and TCB than any other organ examined. The low concentrations of BP and TCB may be related to abundant peritoneal fat in these animals (personal observation), which could limit the amount distributed to other organs. The similarity in the concentrations of BP and TCB in most organs suggests that the pharmacokinetics of these chemicals are similar in eels. 
Induction and Suppression of Eel Liver CYP1A: BP and BNF are model nonhalogenated AhR agonists, and TCB is a model halogenated AhR agonist. CYP1A can be induced in a variety of fish by these AhR agonists (Gooch and Matsumura, 1983; Melancon and Lech, 1983; Beyer et al., 1997; White et al., 1997a). In eels, an ED50 for EROD activity of approximately $5 \mathrm{mg} / \mathrm{kg}$ for BNF, BP and TCB can be estimated from the dose-response curves. Furthermore, both EROD activity and CYP1A content were highly correlated with concentrations of BP and TCB in the liver. In comparison, the ED50 for administered doses of TCB has been estimated at $0.03 \mathrm{mg} / \mathrm{kg}$ in chicken embryo (Poland and Glover, 1977), 0.1 to $0.7 \mathrm{mg} / \mathrm{kg}$ in rainbow trout (Oncorhynchus mykiss) (Janz and Metcalfe, 1991; Newsted et al., 1995), $5.8 \mathrm{mg} / \mathrm{kg}$ in C57BL/6J mice (Poland and Glover, 1977), and $150 \mathrm{mg} / \mathrm{kg}$ in Wistar rats (Leece et al., 1985). In comparison to other species, eels are moderately sensitive to CYP1A induction by model AhR agonists.

BNF and BP had greater efficacy in inducing CYP1A than TCB. The induction of hepatic microsomal CYP1A content and catalytic activity was 2 to 3-fold greater in eels dosed with BNF or BP than in those dosed with TCB, compared at a $10 \mathrm{mg} / \mathrm{kg}$ dose. While TCB induced CYP1A in liver, a dose of $20 \mathrm{mg} / \mathrm{kg}$ did not produce a greater level of induction than did a $10 \mathrm{mg} / \mathrm{kg}$ dose. Increasing doses of $\overline{B N F}$ or $\overline{B P}$ resulted in increased induction of CYP1A in hepatic microsomes, with no decline in induction at administered doses that far exceeded doses of TCB. The reason for this greater efficacy is not known but might result from differences in pharmacokinetic distribution; however, the distribution studies demonstrate that the concentrations of BP and TCB were similar in all organs but spleen. The plateau in induction of CYP1A activity following treatment with high doses of TCB also may result from inhibition of CYP1A, as TCB is a competitive inhibitor of EROD activity (Gooch et al., 1989). However, there is a plateau in induction of both protein and activity at the $20 \mathrm{mg} / \mathrm{kg}$ dose, suggesting that catalytic inhibition is not the only contributing factor.

While TCB and other planar PCBs generally induce CYP1A, the rate of CYP1A activity and the content of CYP1A protein decline sharply following in vivo exposure to high doses of TCB, 3,3',4,4',5-pentachlorobiphenyl and 3,3',4,4',5,5'hexachlorobiphenyl in several species (Gooch et al., 1989; Sinclair et al., 1989; Newsted et al., 1995; Stegeman et al., 1995). In the fish model, scup (Stenotomus chrysops), the decline was shown to be largely specific for CYP1A, resulting from a loss of CYP1A protein following transcription (White et al., 1997a). The mechanism was determined to be 
oxidative inactivation (Chapter 3). Inactivation of CYP1A during the metabolism of TCB may explain in part the lack of increase in induction at the highest dose (See Appendix A).

Use of Eels as Biomonitoring Species: A previous study demonstrated the use of feral eels (Anguilla anguilla) in biomonitoring aquatic pollution (van der Oost et al., 1996). CYP1A content and activity were the most sensitive to environmental xenobiotics (van der Oost et al., 1996) and were correlated with tissue levels of PCBs and organochlorine pesticides (van der Oost et al., 1995). Although the relationship between AhR agonist concentration and CYP1A induction is species dependent (Bernhoft et al., 1994; Hektoen et al., 1994), in this study both BP and TCB concentrations were correlated with hepatic CYP1A induction. In addition, eels collected from NBH, an EPA Superfund site, had significantly elevated CYP1A levels compared to eels collected from other sites in the area. These results suggest that the eel is a good candidate for use as a biomonitoring species.

\section{Endothelium}

CYP1A Induction in Endothelium: In most extra-hepatic organs, CYP1A can be strongly induced in endothelium by AhR agonists (Smolowitz et al., 1991). In eels, the immunohistochemical CYP1A signal was as strong in endothelial cells as in hepatocytes. In other species it has been estimated that CYP1A could account for as much as $25 \%$ of the endothelial cell microsomal protein in heart (Stegeman et al., 1982; Stegeman et al., 1989). In this study, we observed a dose-dependent increase in endothelial CYP1A induction following treatment of BNF, BP and TCB.

Investigation of endothelial CYP1A induction in vivo is complicated by two factors. Most organs have multiple cell types which are inducible for CYP1A, and endothelial cells represent a very small proportion of the mass of most organs. Fish heart has been used as a model for CYP1A induction in endothelial cells. Although endothelium represents as much as $8-9 \%$ of the mass of the teleost heart (Stegeman et al., 1989), that proportion is less than in the rete mirabile, an organ composed almost solely of endothelial cells (Krogh, 1959). Thus, we deduced that the rete may be a unique site in which to study induction of CYP1A in endothelial cells in vivo. Both experimental and environmental exposure to AhR agonists resulted in induction of CYP1A in rete endothelial cells, detectable both immunohistochemically and biochemically. Both CYP1A catalytic activity and reductase activity were quantifiable in the rete, supporting conclusions that endothelial CYP1A is catalytically active (Overby et al., 1992; Brittebo, 1994; Stegeman et al., 1995). We have demonstrated that endothelial cells exposed to CYP1A inducers in vivo responded with increasing CYP1A content and activity. 
Although immunohistochemical studies have suggested that CYP1A may be as highly induced in endothelium as in hepatocytes, the catalytic activity of endothelial CYP1A is very low in comparison to that in liver. As has been found for PAEC (Stegeman et al., 1995), EROD rates in endothelial cells from induced eels are lower than that in liver of uninduced eels. In comparison, the maximum EROD rate quantified in eel rete mirabile was $3 \mathrm{pmol} / \mathrm{min} / \mathrm{mg}$ microsomal protein and in PAEC was $25 \mathrm{pmol} / \mathrm{min} / \mathrm{mg}$ total protein (Stegeman et al., 1995). The low activity may result from a deficiency of CPR in endothelial cells (Stegeman et al., 1982; Overby et al., 1992; Stegeman et al., 1995). Augmentation with rat reductase increased the CYP1A catalytic rate in PAEC, suggesting that there is not enough reductase to fully support the catalytic capacity of endothelial CYP1A (Stegeman et al., 1995).

Significance of Endothelial CYP1A Induction: The limited catalytic capacity of endothelial CYP1A raises the question of what significance CYP1A induction in endothelium might have. Endothelium is thought to act as a protective barrier, and induction of a metabolically inefficient CYP1A might contribute to the barrier function by holding substrates in the active site rather than metabolizing them. CYP1A2 strongly binds TCDD (Poland et al., 1989; Poland et al., 1989) and was shown to be responsible for the sequestration of TCDD in rat liver (Diliberto, 1997). Binding of TCB to CYP1A also may be inferred from inhibition studies using scup hepatic microsomes in which a $\mathrm{K}_{\mathrm{i}}$ of 18-22 $\mathrm{nM}$ at low protein concentrations (Hahn and Stegeman, 1994) and a $\mathrm{K}_{\mathrm{i}}$ of $0.2-0.3 \mu \mathrm{M}$ at high protein concentrations (Gooch et al., 1989; Chapter 3) were measured.

Slowly metabolized substrates might be effectively "bound" to endothelial CYP1A, resulting in sequestration in the endothelium that could limit the amount of inducer that can penetrate to underlying tissues or distal regions (Stegeman et al., 1995). Results from this study support the hypothesis that endothelial CYP1A might influence the pharmacokinetics of AhR agonists. First, concentrations of BP and TCB in the rete mirabile were dosedependent and were greater than in the blood. Second, as the agonist dose increased, penetration of CYP1A immunostaining into the rete increased. Third, CYP1A staining was never seen in efferent rete vessels. The correlation of AhR agonist concentration with endothelial CYP1A induction suggests that the AhR agonist is responsible for the endothelial CYP1A induction. However, concentration of AhR agonists from the blood and lack of efferent CYP1A induction suggest that endothelial CYP1A can effectively remove the agonists from the circulation. In humans, placental endothelium taken from smokers has elevated aryl hydrocarbon hydroxylase (AHH) activity, however the umbilical 
vein does not (Manchester et al., 1984). This suggests that the placental endothelium may remove inducers from the blood, and as CYP1A2 induction in extra-hepatic tissues is limited (Goldstein and Linko, 1984), the elevated AHH activity may indicate that CYP1A1 is responsible for that removal. In addition to controlling distal distribution of AhR agonists, endothelial CYP1A may influence passage of $A h R$ agonists to underlying tissues as seen in the transition of CYP1A immunostaining from within the endothelial cells to staining in cells underlying the endothelium high doses of BNF. Endothelial CYP1A may limit the spread of AhR agonists following low dose exposures.

Despite the relatively low catalytic activity of endothelial CYP1A, its induction has been correlated with overt toxicity. Guiney et al. (1997) found that the strongest CYP1A induction occurs in the vascular endothelium of lake trout embryos exposed to TCDD, and that this induction correlated with the toxic effects, culminating in mortality. Two potential routes to this toxicity may be alteration in arachidonic acid (AA) metabolism and production of reactive oxygen species (ROS). First, AA metabolites produced by P450s influence vascular function by altering endothelial cell permeability (Ohnishi et al., 1992), vascular tone (Harder et al., 1995), and cellular ion flux (Schwartzman et al., 1987; Campbell et al., 1996), and stimulating angiogenesis (Harder et al., 1995). BNF and MC treatment of canine coronary and rabbit pulmonary arteries leads to dose-dependent increases in AA induced endothelium-dependent relaxations (Pinto et al., 1986; Pinto et al., 1987), which can be reversed in the presence of general P450 inhibitors (Pinto et al., 1986) and 7ethoxyresorufin (Fulton et al., 1992; Fulton et al., 1995). Second, CYP1A binding of slowly metabolized substrates and resulting release of ROS during catalytic uncoupling (Chapters 3 and 4) in endothelium could be a mechanism of toxicity. Piperonyl butoxide, a general CYP inhibitor, and $\mathrm{N}$-acetylcysteine, an antioxidant, can protect against TCDDinduced mortality in fish embryos (Cantrell et al., 1996). Furthermore, porcine pulmonary endothelial cells respond to TCB treatment with increased CYP1A1 content and activity, as well as ROS production and lipid peroxidation (Toborek et al., 1995).

We have demonstrated that American eels respond to both PAHs and a pHAH with induction of hepatic and endothelial CYP1A. Liver CYP1A can be induced significantly by multiple model AhR agonists, and in comparison with other species, eels are moderately sensitive to CYP1A induction. That CYP1A induction is correlated strongly with inducer concentration supports the conclusion that eels can be a useful biomonitor. Endothelial CYP1A in eels is highly inducible and can respond to AhR agonists in a dose-dependent manner. Further, induction of CYP1A in endothelium appears to be strong in eels collected 
from a notably polluted site. Our results support the hypothesis that endothelial CYP1A can potentially sequester AhR agonists thereby modifying their pharmacokinetics. The results of this study suggest that the rete mirabile can be used a model for the study of CYP1A expression in endothelial cells in vivo and its role in the toxicity of AhR agonists. 
CHAPTER 8

Summary and Conclusions 


\section{Arachidonic Acid Metabolism}

The goal of these studies was to investigate cytochrome P450-related changes in a process that is important to the function of endothelial cells. Only one previous preliminary study had addressed CYP-mediated AA metabolism in fish (Zacharewski et al., 1996). Scup liver microsomes produced all possible types of P450-derived AA metabolites: EETs, DHETs, mid-chain HETEs and $\omega$-terminal HETEs. While liver microsomes from females and males produced identical metabolite profiles, gravid females had much lower rates of total AA metabolism. In fish, several CYP, including CYP1A, CYP2B, CYP2K and CYP3A, have been shown to be hormonally regulated (Pajor et al., 1990; Gray et al., 1991; Buhler et al., 1994), suggesting that these CYP might contribute to basal hepatic AA metabolism. Antibodies against scup CYP1A and a scup CYP2B-like protein inhibited liver microsomal AA metabolism, also suggesting that multiple CYP contribute to hepatic AA metabolism. These studies provide the first evidence of EETs and DHETs as endogenous constituents in teleost liver. Treatment of scup with the CYP1A inducer BP increased both liver microsomal AA metabolism and endogenous hepatic EET content, with a shift in EET regio- and enantioselectivity. While TCDD treatment did not significantly affect liver microsomal AA metabolism, it did increase endogenous EET content and alter EET regioselectivity. Kidney, gill and heart microsomes all metabolized AA, at rates 10 to 30 -fold less than with liver. BP treatment did not alter total EET content in heart and kidney; however there was a shift in favor of 14,15-EET. The predominant CYPs in mammalian kidney are the CYP2Cs (Capdevila et al., 1992), and CYP2N2 is highly expressed in heart of some fish (Oleksiak et al., 1998b). Therefore, CYP1A induction may not significantly alter the CYP compliment in these organs. However, other studies have shown that CYP1A-mediated AA metabolites can alter vasoactivity in blood vessels, as will be discussed below. Thus, scup liver and extrahepatic organs metabolize AA via multiple CYP forms to eicosanoids in vitro and in vivo. While AhR agonists alter metabolism of AA in early diverging vertebrates expressing both CYP1A and AhR, the magnitude of effects may depend upon the type of inducer.

Induction of CYP1A was correlated with changes in the regio- and stereochemistry of endogenous EETs, suggesting that CYP1A-mediated metabolism of AA is regio- and enantiospecific. Expressed CYP2P and CYP2N from $F$. heteroclitus also metabolize AA in a regio- and stereospecific fashion (Oleksiak et al., 1998a; Oleksiak et al., 1998b). Metabolism of AA by expressed or purified scup CYP1A is required to confirm the actual metabolites produced by this CYP. 
Marine fish contain less AA and greater amounts of n-3 fatty acids (e.g. eicosapentaenoic acid) than do mammals or freshwater fish, presumably due to differences in diet and in ability to elongate fatty acids (Weber, 1990). In comparison to mammals, amounts of endogenous AA metabolites and rates of microsomal AA metabolism were low in scup. Fish oils are rich in eicosapentaenoic (EPA) and docosahexaenoic acids; thus these fatty acids may be more readily available for metabolism in fish. Rat hepatic microsomes metabolize n-3 fatty acids to products with regiochemistry similar to P450derived AA metabolites (VanRollins et al., 1984; VanRollins et al., 1988; VanRollins, 1990). EPA has been implicated in regulation of tight junction permeability, gene expression and nitric oxide production (Achard et al., 1997; Okuda et al., 1997; Jiang et al., 1998). Even though EPA metabolites appear to be less biologically active than their AA-counterparts, they appear to contribute significantly to the maintenance of the cardiovascular system in mammals (Weber, 1990). Investigation of the metabolism of EPA by fish and the role of CYP-derived AA and EPA metabolites in cardiovascular, renal and hepatic function in fish is required.

This is the first study to demonstrate alteration of endogenous AA metabolites following treatment with a CYP inducer. Rifkind et al (1990) have raised the issue as to whether TCDD-induced changes in AA metabolism exacerbate or ameliorate the toxicity of TCDD. Rifkind et al (1994) argue that the effects of the AA metabolites produced by CYP1As are compatible with the syndrome of TCDD toxicity (i.e. alterations in hormonal regulation, fluid homeostasis, cell growth, and intermediary metabolism and increased intracellular $\mathrm{Ca}^{2+}$ ). However, it is also pointed out that some CYP-derived AA metabolites could protect against TCDD toxicity through anti-mitogenic and edema-inhibition pathways (Rifkind et al., 1990). Now that there is evidence for alterations in AA metabolism by AhR agonists in vivo, an examination of how predominant CYP1A-derived metabolites might contribute to pHAH toxicity is necessary.

\section{PHAH-Simulated-CYP1A Inactivation}

Previous studies in fish, birds and mammals have demonstrated induction, inhibition and suppression of CYP1A by TCB. Here we defined the mechanism of CBstimulated CYP1A inactivation. In vitro inactivation of scup CYP1A activity by TCB was time-dependent, NADPH-dependent, oxygen-dependent and irreversible. TCB increased microsomal NADPH oxidation rates, and CYP1A inactivation was lessened by adding

cytochrome $c$. CYP1A inactivation was accompanied by loss of spectral P450 and variable 
loss of heme and/or appearance of P420. Rates of TCB metabolism were too slow to support the rate of inactivation. Non-heme iron chelators, anti-oxidant enzymes, and ROS scavengers had no influence on inactivation. Adding $\mathrm{H}_{2} \mathrm{O}_{2}$ enhanced TCB-dependent inactivation, but only the enhancement was reversed by catalase. Inactivation was accelerated by azide but not by hydroxylamine or aminotriazole, suggesting that the azide effect is not dependent upon catalase. TCB also inactivated rat liver microsomal CYP1A; although the rate of inactivation was slower than that seen with scup CYP1A. The results indicate that TCB uncouples the catalytic cycle of CYP1A, ostensibly CYP1A1, resulting in formation of ROS within the active site. Furthermore, we hypothesized that the attacking species is $\mathrm{OH} \cdot$, formed by the interaction of the reduced heme iron with $\mathrm{H}_{2} \mathrm{O}_{2}$. The inactivation of CYP1A was stimulated by CBs that are AhR agonists and possibly CYP1A substrates, i.e. $\mathrm{CBs} 126$ and 169. The mono-ortho $\mathrm{CB} 105$ was less effective at stimulating inactivation of CYP1A. The non-ortho CB 52 and the rapidly metabolized CYP1A substrate BP did not stimulate inactivation. Inactivation of CYP1A was speciesspecific and was correlated with the rate of TCB metabolism. Based on in vitro data, we hypothesized that $\mathrm{CB} 126$ would suppress $\mathrm{CYP} 1 \mathrm{~A}$ induction in vivo. $\mathrm{CB} 126$ potently induced CYP1A mRNA, protein and catalytic activity at low doses $(0.01-0.1 \mathrm{mg} / \mathrm{kg})$ and induced CYP1A mRNA at a high dose $(1 \mathrm{mg} / \mathrm{kg})$ but suppressed induction of CYP1A protein and catalytic activity at that high dose. The suppression of CYP1A induction was organ-dependent, with hepatic CYP1A being most susceptible to inactivation.

Species differences in TCB metabolism and CYP1A inactivation suggest differences in the topology of the substrate access channel or the active site of homologous CYP1As. Such differences may favor metabolism of TCB by rat CYP1A1 and retention of ROS by scup CYP1A. Structural differences between scup CYP1A and rat CYP1A1 have been suggested by results from antibody studies. Only 1 of 9 antibodies raised against scup CYP1A recognize rat CYP1A1, and 2 of 10 antibodies raised against rat CYP1A1 recognize scup CYP1A (Klotz et al., 1986). In addition, even though polyclonal antibodies raised against scup CYP1A inhibit EROD activity in teleost microsomes, they do not inhibit EROD activity in BNF-treated rat liver microsomes (Stegeman et al., 1985). Modeling studies are planned to determine if TCB "fits" differently into CYP1A active sites from various species. Aligned amino acid sequences show both similarities and differences in residues in the vicinity of the CYP1A active site and considered involved in substrate binding (Figure 1) (Lewis and Lake, 1996). Only a small change in molecular size allows the binding and metabolism of BP but prevents the binding of benzo[e]pyrene (Lewis et 
al., 1994). This sieve effect has been attributed two phenylalanine residues (Phe 201 and Phe 243, using P450 cam nomenclature) that have a coplanar orientation (Lewis et al., 1994); this may be a site important to determining differences between the scup and rat proteins.

The consequences of suppression of CYP1A are unknown at this time. Studies of a CYP1A-deficient animal model are required, but this tool has not been developed as of yet. However, studies are beginning to recognize the regulation of AhR activation by CYP1A1 in a mammalian system. Studies in Hepa-1 cells have shown that the c37 mutant, which lacks CYP1A1 activity, has a constitutively activated AhR (Chang and Puga, 1998). Similarly, inhibition of CYP1A1 activity by ANF in the wild-type Hepa-1 also results in activation of the AhR. Chang and Puga (Chang and Puga, 1998) have hypothesized that an endogenous CYP1A substrate is responsible for the constitutive activation of the AhR. Metabolism of the substrate converts it to an inactive product; therefore, if CYP1A is not present or is inhibited the substrate will remain active resulting in the constitutive activation of the AhR. The endogenous ligands of the AhR have been suggested to be eicosanoids, compounds which also can be metabolized by CYP1A (Capdevila et al., 1990; Nebert, 1994). Thus, it is possible that the suppression of CYP1A resulting from inactivation mediated by coplanar PCBs may alter the homeostasis of the AhR. Considering that the AhR now is recognized to participate in control of cell cycle progression (Ma and Whitlock, 1996; Weiss et al., 1996), perturbation of AhR homeostasis may have physiologically important consequences.

\section{PHAH-Stimulated ROS Production}

Adding TCB to scup or rat liver microsomes containing CYP1A, but not control microsomes, stimulated formation of ROS; formation rates correlated with native CYP1A content. Use of multiple techniques confirmed that both $\mathrm{O}_{2}^{-\bullet}$ and $\mathrm{H}_{2} \mathrm{O}_{2}$ were produced by scup CYP1A. Expressed human CYP1As differed in their production of ROS. In the presence of NADPH alone, CYP1A2 microsomes oxidized DCDFDA and HE at rates 5fold greater than the rates obtained with CYP1A1 microsomes. Considering that CYP1A2 has been shown to be reduced in the absence of substrate (Guengerich and Johnson, 1997), this result is not surprising. However, another recent study reported that NADPH-

stimulated ROS production by human CYP1A1 was greater than that by CYP1A2 (Puntarulo and Cederbaum, 1998). Addition of TCB+NADPH stimulated ROS production by the human CYP1A1 microsomes, but decreased ROS production by the CYP1A2 
Figure 1. An alignment between CYP1A sequences demonstrating similarities and differences between amino acids in the vicinity of the CYP1A active site. A, B, C involved in hydrogen bonding. $\mathrm{D}$-Involved in limiting the size of the substrate binding site. $\mathrm{E}$ - Involved in $\pi$ - $\pi$ stacking with aromatic rings on substrates. F - Involved in hydrogen bonding by CYP1A1. G - Involved in hydrogen bonding by CYP1A2. H Possibly involved in discrimination of CYP1A1 and CYP1A2 substrates. I - Possibly involved in $\pi-\pi$ stacking with substrates and limiting the size of the substrate binding site. $\mathrm{J}$ - Possibly involved in substrate binding interactions or in limiting the size of the binding site. $\mathrm{K}$ - Involved in $\pi-\pi$ stacking with aromatic rings on substrates. Designations of active site amino acids are from (Lewis and Lake, 1996). Sequences were retrieved by GenBank accession numbers K03191 (human CYP1A1), Y00071 (mouse CYP1A1), K02246 (rat CYP1A1), U14162 (scup CYP1A), M21310 (trout CYP1A1), and X99453 (chicken CYP1A4). 


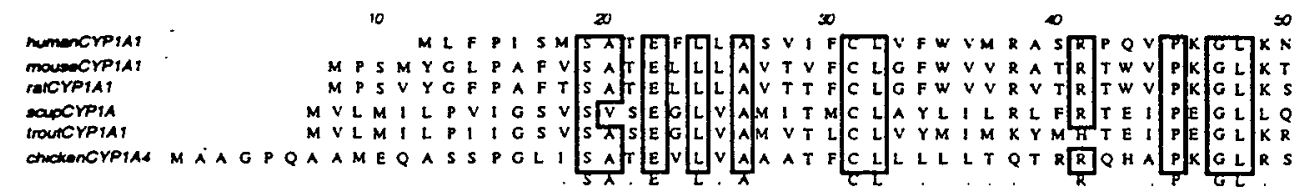

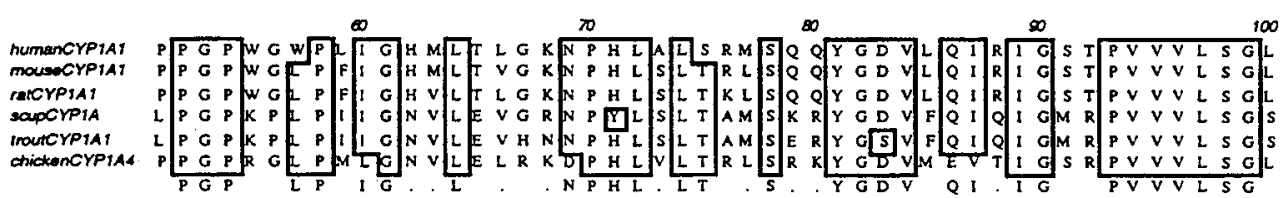

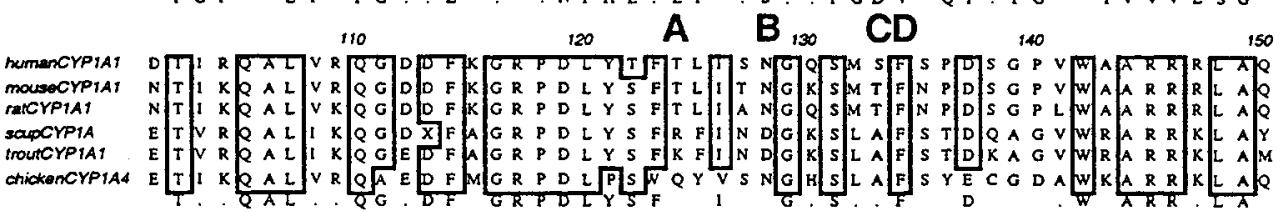
$100 \quad 170 \quad 180 \quad 190 \quad 200$

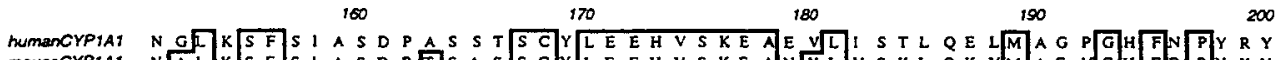
mousecrPIAT N A

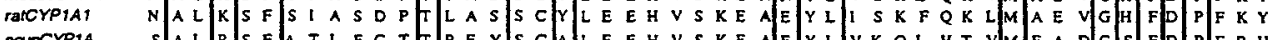

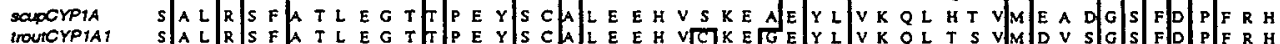

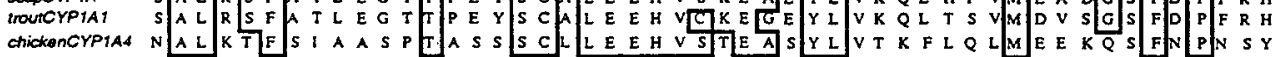
chickancrPIAA $N$ AL K T S F.

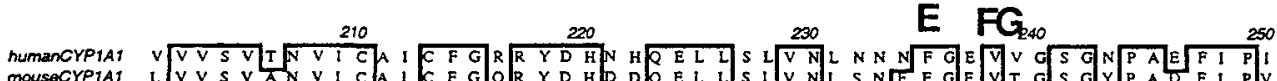
mousoCYPTAS L VV V S V V A N V I C C A

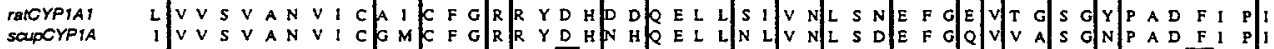

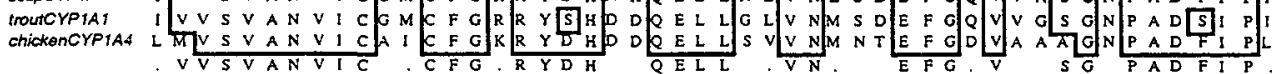

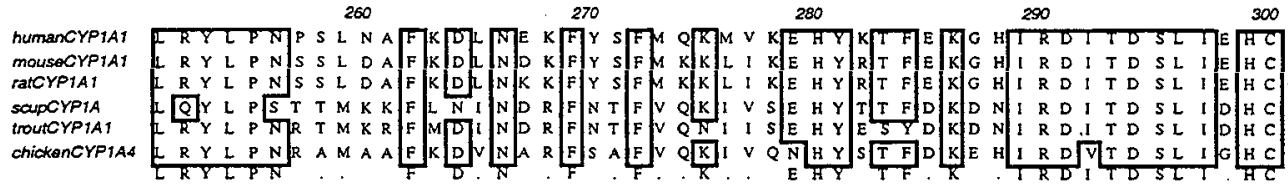
350

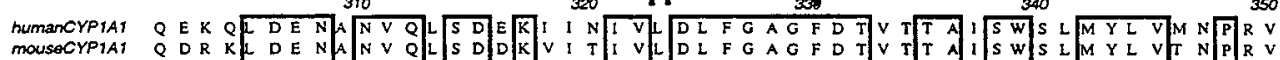

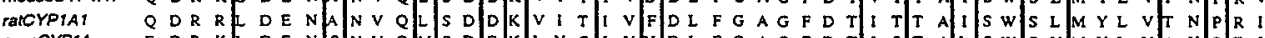
SCUPCYPIA C D D R K E D D E

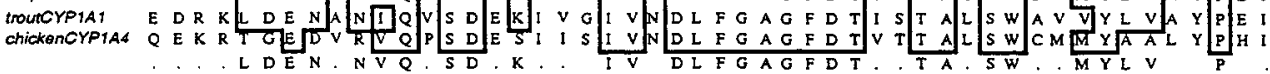

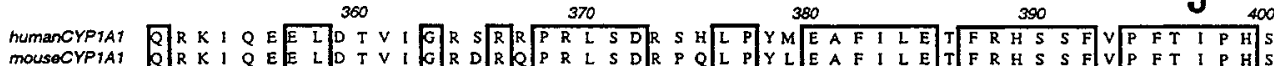
humanCYP1AT
mouseCYPIA1 Q humanCYP1AT
mouseCYP1A1 J 400

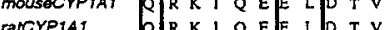

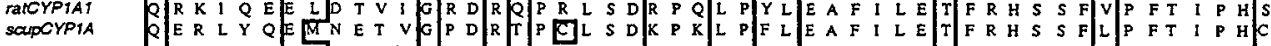

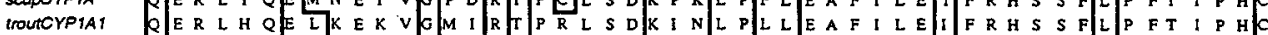

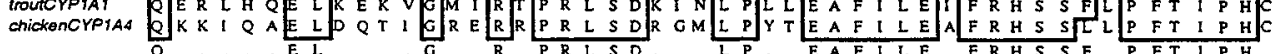

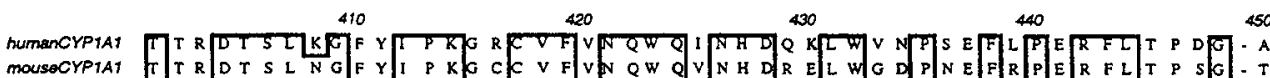

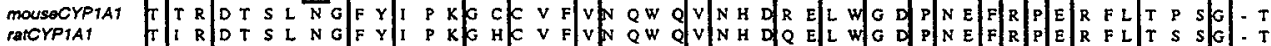

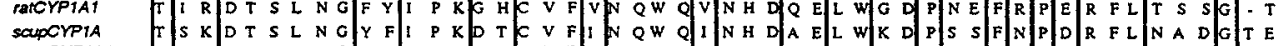

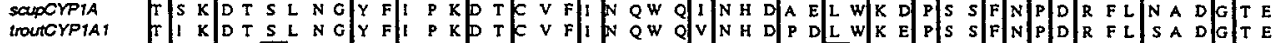

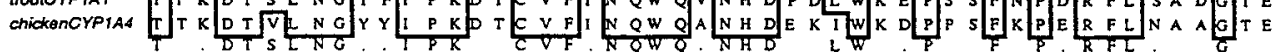

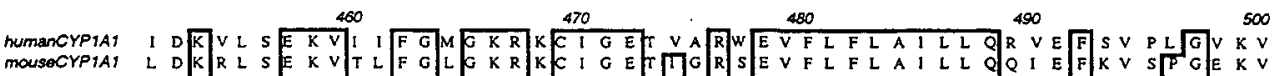

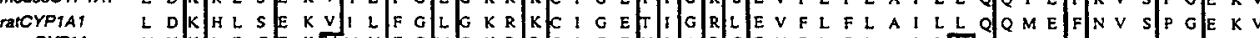
saupCVP1A V V N K L E OE

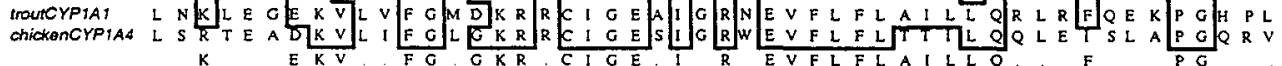

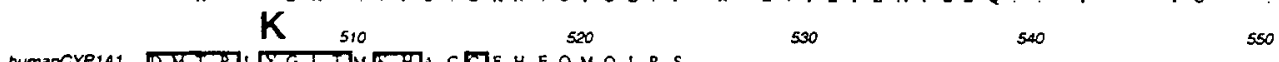
mouseCYPIA, D M T P TT Y G L T L L K H A R E E E H F Q V Q M R S S G PQH L Q A

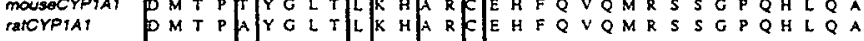

scapCrP1A

chickenCYP1AA 
microsomes. Therefore, the data suggest that $\mathrm{pHAH}$-stimulated ROS production is a result of the interaction with CYP1A1 in mammals. ROS formed by uncoupling of CYP1A could attack any member of the cellular machinery, including proteins (Davies, 1987; Stadtman and Berlett, 1991), lipids (Girotti, 1985) and nucleotides (Breen and Murphy, 1995). CBs have been shown to stimulate oxidative stress in this study as well as others (Stohs et al., 1990; Buchmann et al., 1991; Toborek et al., 1995; Park et al., 1996), and ROS production was shown to be both AhR-dependent (Faux et al., 1992; Alsharif et al., 1994; Park et al., 1996) and limited to microsomal and mitochondrial sources (Wahba et al., 1989). Uncoupling of CYP1A fits the criteria for the source of pHAH-stimulated ROS production.

Beyond inactivating CYP1A protein, oxygen and ROS may be important regulators of CYP1A. Oxidative stress has been shown to downregulate CYPs. While BNF substantially induced CYP1A1 and CYP1A2 mRNA expression in hepatocytes isolated from rats, co-treatment with $\mathrm{H}_{2} \mathrm{O}_{2}$ reduced transcription rates by $50 \%$ and $70 \%$, respectively (Barker et al., 1994). Oxidizing conditions decrease DNA binding of purified AhR (Ireland et al., 1995). Unlike other redox-sensitive transcriptions factors, the AhR does not contain conserved cysteines in its basic regions; however both the AhR and ARNT contain conserved cys-arg motifs in the PAS domain. In contrast, hyperoxia has been found to induce CYP1A expression in both mice (Gonder et al., 1985) and sheep (Hazinski et al., 1995). On the other hand, hypoxia also may influence CYP1A induction. Activated hypoxia inducible factor- $1 \alpha$ out competes dioxin-activated $A h R$ for binding of ARNT, resulting in reduced AhR-DNA binding (Gradin et al., 1996). A greater understanding of the regulation of the AhR and CYP1A by oxygen is required.

\section{$N F-\kappa B$ in a Teleost}

The goal of these studies was develop an assay with which we could analyze the physiological effect of the production of ROS during the uncoupling of CYP1A by pHAH. Even though analysis of antioxidant enzymes and oxidative damage are difficult to interpret, I initially attempted to measure an oxidative DNA adduct 8-hydroxydeoxyguanosine. This was abandoned due to the difficult nature of isolating DNA from scup. I turned to looking for a redox sensitive transcription factor whose activation I could use as a sensitive indicator of oxidative stress. First, this required finding a probe that would recognize such a protein in fish and then confirming its specificity. Thus, I have demonstrated for the first time that members of the Rel family of proteins are present in a 
teleost. An NF- $\mathrm{KB}$ consensus sequence bound at least 3 proteins in scup liver, kidney and heart, two of which potentially correspond with mammalian p50 and RelA. An antibody to mammalian p50 immunoprecipitated the $\approx 50 \mathrm{kD}$ binding protein in all 3 organs. In EMSAs the band-shifts were specifically competed by NF- $\mathrm{kB}$ binding oligonucleotides and not by the AhR DRE. Second, I attempted to use activation of NF-kB/DNA binding as an indicator of oxidative stress following treatment with two AhR agonists. An NF-kB consensus sequence was bound by nuclear proteins from untreated scup. BP did not increase the activation of NF- $\mathrm{kB}$, and PeCB activated NF- $\mathrm{kB}$ in only 1 of 2 experiments. While, we have confirmed the presence of the Rel family of proteins in a teleost, interpretation of the effects of AhR agonists on NF- $\mathrm{kB}$ activation is difficult. This is not necessarily surprising considering the conflicting results seen in cell culture (Yao et al., 1995; Tian et al., 1998; Shneider et al., submitted). Sequencing of members of the Rel family of proteins from scup is occurring as I write. This will confirm further the biochemical results which show that this family of proteins is present in a teleost. The identification, the distributions, the regulation and the functions of Rel family proteins in teleosts, as well as determining the relationship of teleost Rel proteins to mammalian, avian and amphibian Rel proteins, all remain questions for another thesis. Use of primary cell culture or the Hepa-expressed scup CYP1A system may reduce the confounding effects seen in vivo.

\section{CYP1A in Endothelium}

Endothelial cells may be a particularly sensitive target for PAHs and pHAHs. We have shown that CYP1A can be strongly induced in this cell type by several model AhR agonists. Induction of endothelial CYP1A is dose-dependent in multiple organs, and both cardiac endothelial CYP1A in microvascular endothelial CYP1A were metabolically active. In the rete mirabile, greater doses of inducers were associated with increasing penetration of induction. In addition, a transition from endothelial to epithelial staining occurred in the gill, heart and kidney at high doses of BNF. We conclude that the penetration of endothelial cell CYP1A expression in the vessels of the rete mirabile reflects greater concentrations of inducer reaching the distal circulation. The results are consistent with the hypothesis that endothelial cell CYP1A may participate in removal of AhR agonist/CYP1A substrates from the circulation.

We have shown that AA metabolism is altered by AhR agonists, and others have shown that P450-derived AA metabolites can affect endothelial cell function. Even though 
endothelial cells represent up to 8-9\% of the mass of the teleost heart (Stegeman et al., 1989), changes in CYP1A status may not have changed the CYP compliment of the heart as a whole, and thus we saw little change in AA metabolism following BP treatment. However, considering that CYP1A can represent up to $25 \%$ of endothelial microsomal protein (Stegeman et al., 1982) and the ability of CYP1A-induction to alter AA metabolism in an CYP1A-rich organ (i.e. liver), it is likely that changes in CYP1A-content in endothelial cells may have a profound effect on AA metabolism. For instance, BNF and MC treatment of canine coronary and rabbit pulmonary arteries leads to dose-dependent increases in AA induced endothelium-dependent relaxations (Pinto et al., 1986; Pinto et al., 1987). Studies on AA metabolism in cultured endothelial cells treated with AhR agonists would be required to answer this question definitively.

ROS play an important role in the normal physiology of endothelial cells, as well as participate in endothelial cell pathology. Endothelial cells produce nitric oxide (NO) as a paracrine factor which stimulates relaxation in vascular smooth muscle cells, and ROS are second messengers in shear flow induced gene expression (Chien et al., 1998; Hsieh et al., 1998). Endothelial cells also commonly encounter ROS produced by activated neutrophils (Baboir, 1978). However, ROS also have been implicated in atherosclerosis. Peroxidation of low density lipoproteins has been suggested to attract adhering monocytes (Halliwell, 1993), and ROS induce the transcription of vascular cell adhesion molecule-1 whose promoter contains an NF-KB consensus binding sequence (Weber et al., 1994; Alexander, 1995). Treatment of endothelial cells with ROS can result in alterations of many physiological process including stimulation of release of intracellular $\mathrm{Ca}^{+2}$ stores, release of polyunsaturated fatty acids via activation of phospholipases $\mathrm{A}_{2}, \mathrm{C}$ and $\mathrm{D}$, platelet-activating factor, protein phosphorylation and prostanoid synthesis, inhibition of agonist induced $\mathrm{Ca}^{+2}$ flux and inositol triphosphate liberation, depletion of ATP, NAD ${ }^{+}$ and reduced glutathione, accumulation of lysophopholipids, induction of c-myc and c-fos expression and alteration of vascular barrier function (Vane et al., 1990; Vercellotti et al., 1991; Elliot et al., 1992; Schilling and Elliot, 1992; Barchowsky et al., 1994; Natarajan, 1995). Considering the substantial potential for CYP1A induction in endothelial cells (Stegeman et al., 1982), the production of ROS during CYP1A uncoupling, the evidence of oxidative stress following CB treatment in culture (Toborek et al., 1995) and the correlation of early life-stage mortality stimulated by TCDD with endothelial CYP and ROS (Cantrell et al., 1996), ROS production stimulated by pHAHs may be an important initiator of endothelial cell pathology. 


\section{Appendix A}

3,3',4,4'-Tetrachlorobiphenyl Metabolism in Fish, Bird and Reptile Species and its Relationship with Cytochrome P4501A Inactivation and Reactive Oxygen Production 


\section{ABSTRACT}

Previous work in the fish model scup (Stenotomus chrysops) demonstrated that during the association of planar polychlorinated biphenyls with the CYP1A active site, reactive oxygen species (ROS) are produced as a result of catalytic uncoupling, culminating in oxidative inactivation of the enzyme. Here, we investigated 3,3',4',4-tetrachlorobiphenyl (TCB) metabolism and its relationship to CYP1A catalytic activity, CYP1A inactivation and ROS production liver microsomes from a series of fish (Anguilla rostrata, Fundulus heteroclitus, Psuedopleuronectes americanus, and Raja erinacea), bird (Gallus domesticus, Larus argentatus and Phalacrocorax auritus) and reptile (Chrysemys picta) species. For all species examined, TCB metabolism represented a very small proportion of the CYP1A catalytic activity, ethoxyresorufin O-deethylation (EROD); however, it was correlated strongly with EROD activity in all species except flounder. The rate of CYP1A inactivation varied between species. Chicken hepatic CYP1A was most susceptible to inactivation; however eel, flounder, killifish and cormorant liver microsomes all had significant decreases in EROD activity following incubation with TCB and NADPH. Inactivation was correlated negatively with TCB metabolism in the bird species $\left(\mathrm{r}^{2}=0.992\right.$, $\mathrm{p}<0.05$ ). ROS production by liver microsomes also was species dependent. In chicken and turtle liver microsomes, NADPH alone stimulated a high rate of ROS production, both $\mathrm{H}_{2} \mathrm{O}_{2}$ and $\mathrm{O}_{2}^{-\bullet}$. In both fish and bird species, NADPH-stimulated ROS production was correlated positively with EROD activity $\left(\mathrm{r}^{2}=0.770-0.845, \mathrm{p}<0.05\right.$ and $\mathrm{r}^{2}=0.952-0.959$, $\mathrm{p}<0.05$, respectively). TCB stimulated $\mathrm{H}_{2} \mathrm{O}_{2}$ production in liver microsomes of flounder, cormorant and gull; however, TCB decreased $\mathrm{H}_{2} \mathrm{O}_{2}$ production in the chicken liver microsomes. TCB stimulated $\mathrm{O}_{2}^{-\bullet}$ production in liver microsomes of flounder, killifish, cormorant and gull. Compared to the model species scup, only chicken had rates of ROS production and CYP1A inactivation as high. CYP1A inactivation appears to be dependent in part on the rate at which species metabolize TCB. 


\section{INTRODUCTION}

Polychlorinated biphenyls are ubiquitous in the global environment and present in tissues of fish, birds and mammals (see (Risebrough et al., 1968; McFarland and Clark, 1989)). Congeners that lack substitution at ortho sites (e.g. 3,3',4,4'-tetrachlorobiphenyl) can achieve a planar conformation similar to that of 2,3,7,8-tetrachlorodibenzo- $p$-dioxin (TCDD) (Safe et al., 1985). These planar halogenated aromatic hydrocarbons (pHAH) promote hepatocellular carcinoma, immunotoxicity, wasting syndrome and reproductive, endocrine and developmental toxicity (as reviewed in (Safe, 1994)). PHAH alter the expression of a number of genes, including cytochrome P4501A (CYP1A) genes, by activating the aryl hydrocarbon receptor (AhR) (Hankinson, 1995).

3,3',4'4,-Tetrachlorobiphenyl (TCB) induces CYP1A in a wide range of fish (Franklin et al., 1980; Melancon and Lech, 1983; Gooch et al., 1989; Monosson and Stegeman, 1991; Tyle et al., 1991; Lindstrom-Seppa et al., 1994; Newsted et al., 1995; Otto and Moon, 1995; Huuskonen et al., 1996; Sleiderlink and Boon, 1996; White et al., 1997a), bird (Dubois et al., 1995; Kennedy et al., 1996; Lorenzen et al., 1997), reptile (Schwen and Mannering, 1982; Jewell et al., 1989; Yawetz et al., 1998) and amphibian (Marty et al., 1992) species; however sensitivity to induction is species specific. In comparison, the ED50 calculated from 7-ethoxyresorufin O-deethylation (EROD) induction for administered doses of TCB has been estimated at $0.03 \mathrm{mg} / \mathrm{kg}$ in chicken embryo (Poland and Glover, 1977), 0.1 to $0.7 \mathrm{mg} / \mathrm{kg}$ in rainbow trout (Oncorhynchus mykiss) (Janz and Metcalfe, 1991; Newsted et al., 1995), $5 \mathrm{mg} / \mathrm{kg}$ in American eel (Anguilla rostrata) (Chapter 7), $5.8 \mathrm{mg} / \mathrm{kg}$ in C57BL/6J mice (Poland and Glover, 1977), and $150 \mathrm{mg} / \mathrm{kg}$ in Wistar rats (Leece et al., 1985). The EC50s for EROD induction by TCB in hepatocytes cultured from a number of bird species range over 4 orders of magnitude (Dubois et al., 1995; Kennedy et al., 1996; Lorenzen et al., 1997). Furthermore, in bird species, the susceptibility to CYP1A induction has been correlated with susceptibility to toxicity (Brunstrom and Reutergardh, 1986; Brunstrom, 1988; Brunstrom and Lund, 1988; Dubois et al., 1995; Kennedy et al., 1996; Lorenzen et al., 1997).

One possible route to toxicity is the metabolic activation of CYP1A substrates to reactive derivatives. That CYP1A1 is responsible for the metabolism of TCB has been established in rats (Ishida et al., 1991). Correlations of CYP1A catalytic activity and TCB metabolism support the conclusion that CYP1A4 metabolizes TCB in birds (Murk et al., 1994) and CYP1A metabolizes TCB in a fish (White et al., 1997b). Although rates of microsomal TCB metabolism in birds approach that seen in mammals, TCB metabolism is 
extremely slow in fish (Borlakoglu and Wilkins, 1993; Murk et al., 1994; White et al., 1997b). However, whether efficiently metabolized or not, bioactivation has not been found to be a significant avenue to pHAH toxicity (Safe, 1992).

Another route to toxicity may be stimulation of oxygen activation. TCB significantly increases the rate of ROS production by hepatic CYP1A in the fish model scup (Stenotomus chrysops) (Chapter 3). We have hypothesized that the production of ROS during catalytic uncoupling by TCB results in the formation and attack of $\mathrm{OH} \bullet$, leading to the inactivation of CYP1A (Chapter 3). This may be the mechanism by which pHAH stimulate oxidative stress (Faux et al., 1992; Alsharif et al., 1994; Park et al., 1996), as well as the mechanism of CYP1A protein loss following exposure to high doses of TCB seen in vivo in fish (Gooch et al., 1989; Newsted et al., 1995; White et al., 1997a) and in cultured hepatocytes of chickens and endothelial cells of pigs (Lambrecht et al., 1988; Sinclair et al., 1989; Stegeman et al., 1995).

Previous work has demonstrated a disparity in both TCB metabolism and TCBstimulated inactivation of CYP1A in scup and rats (Chapter 3), which suggested that the rate of inactivation may be related to the rate of TCB metabolism. Therefore, we investigated the relationship between TCB metabolism and inactivation of CYP1A in vitro, in a variety of fish, bird and reptile species. In addition, the potential for ROS production by liver microsomes of these species was examined. Within species groups, inactivation of CYP1A appears to be correlated negatively with the rate of TCB metabolism. The potential to produce ROS was correlated positively with CYP1A catalytic activity.

\section{MATERIALS AND METHODS}

Chemicals: 2',7'-Dichlorodihydrofluorescein diacetate, 7-ethoxyresorufin, and dihydroethidium were purchased from Molecular Probes (Eugene, OR). 3,3',4,4'Tetrachlorobiphenyl and 2,3,7,8-tetrachlorodibenzofuran were purchased from Ultra Scientific (N. Providence, RI). 3,3',4,4'-tetrachlorobiphenyl-Ring-UL-14C (52.1 $\mathrm{mCi} / \mathrm{mmol}$ ) was purchased from Pathfinder (St. Louis, MO). Analysis of the ${ }^{14} \mathrm{C}$ $3,3^{\prime}, 4,4^{\prime}-\mathrm{TCB}$ by GC/ECD and GC/MS revealed no hydrophobic contaminants (>99\% pure); small amounts of polar contaminants were removed by dissolving the TCB in hexane and extracting twice with $\mathrm{NaOH}$. All other reagents were purchased from Sigma (St. Louis, MO).

Animals: Killifish (Fundulus heteroclitus) were caught in Scorton Creek, MA, in June, 1996 and used in experiments in July, 1996. Killifish were held in flow-through 
seawater tanks at $14^{\circ} \mathrm{C}$ and maintained on a diet of TetraMin large flake food. Killifish ranged in size from 9 to $21 \mathrm{~g}$. Eight fish each were injected intraperitoneally with corn oil or a solution of 2,3,7,8-tetrachlorodibenzofuran $(10 \mathrm{nmol} / \mathrm{kg})$, a potent CYP1A inducer. Seven days following injection the fish were killed by decapitation. Livers were removed, and microsomes were made immediately. In each dose group, livers were pooled in twos to form 4 samples per group. Liver microsomes from benzo[a]pyrene treated eels (Anguilla rostrata) were prepared and characterized previously (Chapter 7). Flounder (Pseudopleuronectes americanus) and skate (Raja erinacea) liver samples were from animals environmentally exposed to halogenated and non-halogenated aromatic pollutants in Boston Harbor, MA. Chicken (Gallus domesticus), double crested cormorant (Phalacrocorax auritus), and herring gull (Larus argentatus) livers, both control and 3,3',4,4',5-pentachlorobiphenyl-treated, were generous gifts of Lori Feyk (Michigan State University). Microsomes from TCB- and $\beta$-naphthoflavone-treated turtles (Chrysemys picta) were prepared and characterized previously (Yawetz et 'al., 1998).

Microsome preparation: Microsomes were prepared from livers by differential centrifugation as before (Stegeman et al., 1979). Pellets were resuspended in buffer (50 $\mathrm{mM}$ TRIS, $\mathrm{pH} 7.4,1 \mathrm{mM}$ dithiothrietol, $1 \mathrm{mM}$ EDTA, 20\% glycerol) and frozen in liquid $\mathrm{N}_{2}$ until use. Protein content was determined using the bicinchoninic acid method (Smith et al., 1985), using bovine serum albumin as a standard.

Western blotting for CYP1A quantification: Immunoblotting procedures were modified from those previously described (Kloepper-Sams et al., 1987). Microsomal proteins (10-80 $\mu \mathrm{g} / \mathrm{lane})$ were resolved on $12 \%$ SDS-PAGE gels and electrophoretically transferred to nylon or nitrocellulose $(1 \mu \mathrm{m})$ membrane. The primary antibody was the mouse monoclonal antibody 1-12-3 (Park et al., 1986), raised against scup P450E (CYP1A; (Morrison et al., 1995)). MAb 1-12-3 is highly specific for CYP1A in fish and CYP1A1 in mammals but recognizes both CYP1A4 and CYP1A5 in chicken. The secondary antibody was alkaline phosphatase linked goat anti-mouse IgG (Biorad, Hercules, CA). The immunoreactive proteins on nitrocellulose membrane were visualized using nitro blue tetrazolium and 5-bromo-4-chloro-3-indoyl-phosphate (NBT/BCIP). The immunoreactive proteins on nylon membranes were visualized using enhanced chemiluminescence (Tropix, Bedford, MA). CYP1A content was quantified by densitometric analysis of video images (NIH Image, 1.60b5). Where appropriate, the CYP1A values are relative, reported as scup CYP1A equivalents. 
Enzyme assays: Microsomal ethoxyresorufin O-deethylation (EROD) was determined fluorometrically as before (Hahn et al., 1993), using a Cytofluor 2300 (Millipore) multiwell plate reader. TCB metabolism was assessed using the assay of Schnellman et al. (Schnellman et al., 1983), as modified by White et al., (1997b). Radioactivity was determined by liquid scintillation counting on a Beckman LS5000TD counter.

In vitro studies of CYP1A inactivation: The procedure was as described in Chapter 3 except that $0.1-0.3 \mathrm{mg}$ of microsomal protein was used in each reaction mixture. Inactivation was calculated by comparing EROD activity at 30 minutes in reaction mixtures containing TCB alone to that in reaction mixtures containing TCB+NADPH.

Peroxide and superoxide formation: $\mathrm{H}_{2} \mathrm{O}_{2}$ and $\mathrm{O}_{2} \cdot$ formation were determined as described in Chapter 3.

Statistics: Statistics were calculated using Microsoft Excel (Microsoft, Inc., Redmond, WA) and Stat-View for Macintosh (Abacus Concepts, Inc., Berkeley, CA). A Student's t-test was used to analyze inactivation (TCB vs. TCB+NADPH) and ROS production (NADPH vs. TCB+NADPH). To examine correlations between EROD activity, TCB metabolism, inactivation and ROS production, linear regression analyses were performed.

\section{RESULTS}

CYP1A content, EROD activity and TCB metabolism were determined in liver microsomes from bird, fish and reptile species in order to examine their relationship. The rate of TCB metabolism was very low in all species, compared to the rate of EROD (Table 1). When TCB metabolism was represented as a percentage of EROD activity, species varied widely in their rates of TCB metabolism. In the bird and turtle species, TCB metabolism represented a greater proportion of EROD activity than it did in fish (Table 1). However, in all species but flounder, the rate of TCB metabolism was correlated strongly with EROD activity (Table 1).

We examined the same fish, bird and reptile species for TCB-stimulated inactivation of CYP1A which has been described in the marine fish scup (White et al., 1997a; Chapter 3). To determine the level of inactivation, the rate of EROD activity in hepatic microsomal reaction mixtures containing $\mathrm{TCB}+\mathrm{NADPH}$ was compared to that in reaction mixtures containing only TCB following a 30 minute incubation. CYP1A inactivation was highly variable between species (Figure 1). Of the fish species, no one had as great a loss of 
TABLE 1

Comparison of CYP1A content, EROD activity and TCB metabolism in liver microsomes from bird, fish and reptile species

\begin{tabular}{|c|c|c|c|c|c|c|c|c|}
\hline \multirow[t]{2}{*}{ Species } & \multirow[t]{2}{*}{$\mathrm{n}$} & \multirow[t]{2}{*}{ Treatment } & \multirow{2}{*}{$\begin{array}{l}\text { CYP1A } \\
\text { (pmol/mg) }\end{array}$} & \multirow{2}{*}{$\begin{array}{c}\text { EROD } \\
\text { Activity } \\
\text { (pmol } / \mathrm{min} / \mathrm{mg} \text { ) }\end{array}$} & \multirow{2}{*}{$\begin{array}{l}\text { TCB Metabolism } \\
\text { (pmol/min/mg) }\end{array}$} & \multirow[t]{2}{*}{$\begin{array}{l}\text { TCB Metabolism } \\
\text { as a \% of EROD }\end{array}$} & \multicolumn{2}{|c|}{$\begin{array}{c}\text { TCB Metabolism } \\
\text { vs. EROD }\end{array}$} \\
\hline & & & & & & & $r^{2}$ & $\mathrm{p}<$ \\
\hline \multicolumn{9}{|l|}{ Fish } \\
\hline \multirow[t]{2}{*}{ Eel $(\text { A. rostrata })^{\mathrm{a}}$} & 4 & Control & $1 \pm 1$ & $59 \pm 26$ & $0.12 \pm 0.03$ & $0.2 \pm 0.1$ & 0.930 & 0.001 \\
\hline & 4 & Induced & $51 \pm 7$ & $466 \pm 194$ & $0.65 \pm 0.12$ & & & \\
\hline Flounder (P.americanus) & 5 & Environment & $22 \pm 7$ & $112 \pm 21$ & $0.14 \pm 0.02$ & $0.1 \pm 0.0$ & 0.000 & \\
\hline \multirow[t]{2}{*}{ Killifish (F.heteroclitus) } & 4 & Control & $3 \pm 1$ & $566 \pm 240$ & $0.12 \pm 0.02$ & $0.0 \pm 0.0$ & 0.915 & 0.001 \\
\hline & 4 & Induced & $21 \pm 8$ & $1385 \pm 290$ & $0.23 \pm 0.07$ & & & \\
\hline Scup $(S . \text { chrysops })^{\mathrm{b}}$ & 7 & Induced & $380 \pm 150$ & $4837 \pm 924$ & $0.34 \pm 0.08$ & $0.0 \pm 0.0$ & & \\
\hline Skate $(R$. erinacea $)$ & $3-4$ & Environment & $5 \pm 1$ & $201 \pm 84$ & $0.09 \pm 0.04$ & $0.1 \pm 0.1$ & 1.000 & 0.05 \\
\hline \multicolumn{9}{|l|}{ Birds } \\
\hline \multirow[t]{2}{*}{ Chicken (G. domesticus) } & 2 & Control & 1,2 & 131,480 & $0.4,0.7$ & $0.3 \pm 0.1$ & 0.840 & 0.005 \\
\hline & 7 & Induced & $19 \pm 5$ & $3658 \pm 1568$ & $10.9 \pm 2.9$ & & & \\
\hline \multirow[t]{2}{*}{ Cormorant (P. auritus) } & 4 & Control & $3 \pm 1$ & $182 \pm 64$ & $2.2 \pm 2.1$ & $0.9 \pm 0.6$ & 0.922 & 0.001 \\
\hline & 3 & Induced & $28 \pm 3$ & $1734 \pm 729$ & $12.8 \pm 8.0$ & & & \\
\hline \multirow[t]{2}{*}{ Gull (Largentatus) } & $3-6$ & Control & $3 \pm 1$ & $65 \pm 44$ & $0.5 \pm 0.2$ & $1.3 \pm 0.5$ & 0.978 & 0.001 \\
\hline & & Induced & $25 \pm 2$ & $337 \pm 114$ & $5.8 \pm 2.5$ & & & \\
\hline \multicolumn{9}{|l|}{ Reptile } \\
\hline Turtle $(C \text {. picta })^{\mathrm{c}}$ & 4 & Induced & $463 \pm 171$ & $80 \pm 23$ & $2.5 \pm 0.7$ & $3.2 \pm 0.4$ & 0.861 & 0.05 \\
\hline
\end{tabular}

a - CYP1A content and activity data from Chapter 7. b - All data from Chapter 3. c - CYP1A content and activity data from (Yawetz et al., in press). 


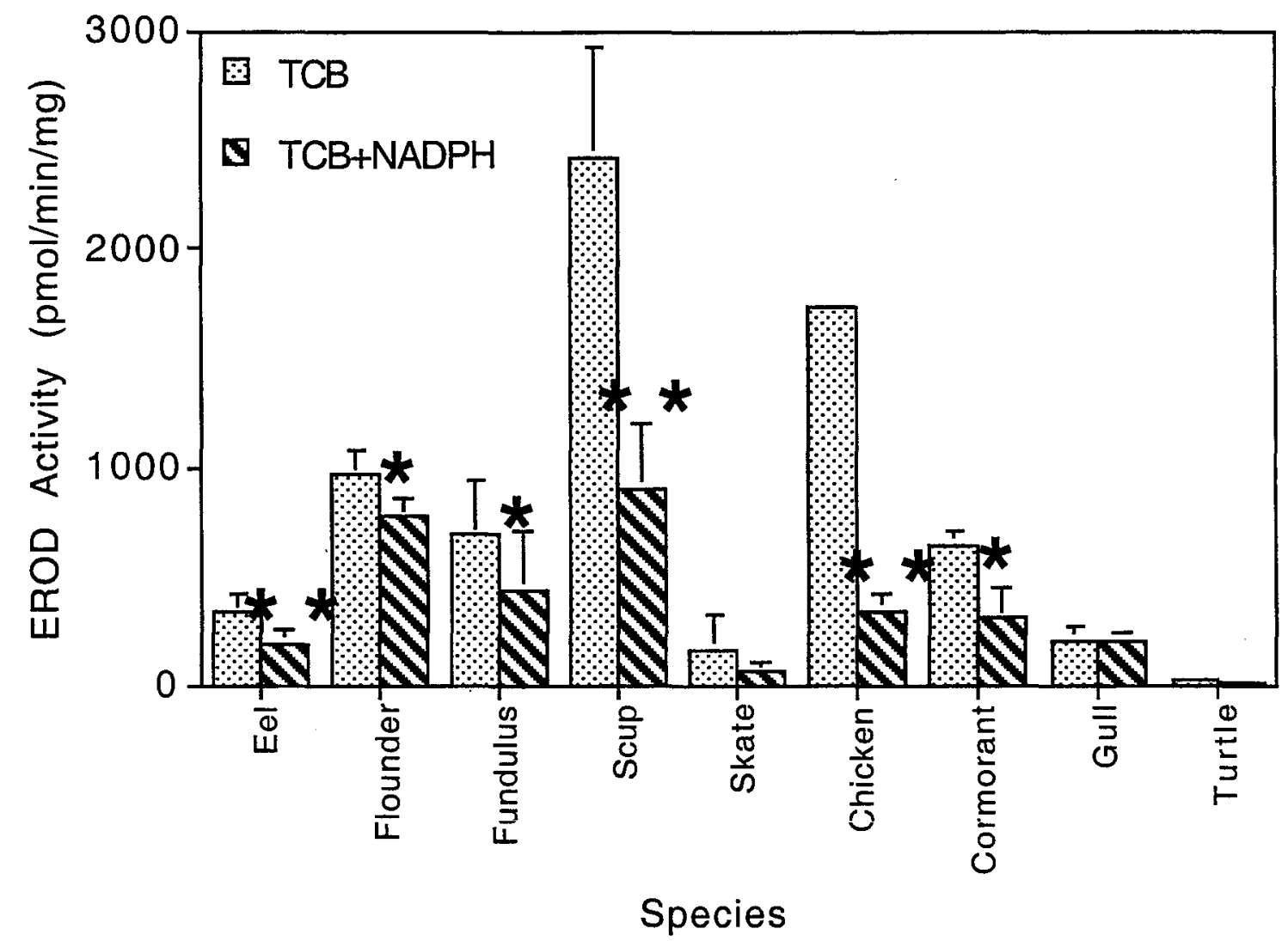

Figure 1. TCB-stimulated inactivation of hepatic microsomal CYP1A (EROD activity). Microsomes were incubated at $2 \mathrm{mg} / \mathrm{ml}$ in buffer ( $50 \mathrm{mM}$ TRIS, $0.1 \mathrm{mM}$ EDTA, pH 7.6) with combinations of the following additions: acetone $(5 \mu 1), \mathrm{NADPH}(1.8 \mathrm{mM})$, and TCB $(1.7 \mu \mathrm{M})$. Aliquots were removed from reaction mixtures at times zero, 10, 20 and 30 minutes and assayed for EROD fluorometrically over 5 minutes. Data shown here are from the 30 minute time point. EROD was constant in microsomes incubated with acetone or NADPH. Following an initial loss of EROD upon addition of TCB, EROD remained constant. There were linear losses of EROD during incubation with NADPH and TCB. Data are means \pm SD. 3-8 sets of microsomes. *Statistically different from the corresponding TCB incubation analyzed at 30 minutes (Student $\mathrm{t}$-Test, $\mathrm{p}<0.01$ ). 
activity due to inactivation as the model species scup; although there were statistically significant losses of EROD activity in eel, flounder and killifish liver microsomes (Figure 1). Of the bird species, chicken appeared to be highly sensitive to CYP1A inactivation (Figure 1). There was no inactivation of CYP1A in turtle liver microsomes (Figure 1). There was no significant relationship between the rate of TCB metabolism normalized for EROD activity and competitive inhibition of EROD activity by TCB (data not shown). However, both fish and bird species demonstrated a negative relationship between inactivation and TCB metabolism, with the relationship in the bird species being statistically significant (Figure 2).

Previous results in scup have demonstrated that TCB stimulates the production of ROS in liver microsomes, and it was hypothesized that those ROS may attack the protein resulting in inactivation (Chapter 3). Therefore, we examined ROS production in liver microsomes from the species analyzed in the inactivation assays. $\mathrm{H}_{2} \mathrm{O}_{2}$ and $\mathrm{O}_{2}{ }^{-}$production were measured by monitoring the oxidation of 2',7'-dichlorodihydrofluorescein diacetate (DCDFDA) to dichlorofluorescein (DCF) and dihydroethidium (HE) to ethidium, respectively. DCDFDA and HE oxidation were stimulated significantly by NADPH alone in chicken and turtle liver microsomes (Figure 3). In both fish and bird species, NADPH stimulated ROS production was correlated positively with EROD activity (Figure 4). TCB stimulated $\mathrm{H}_{2} \mathrm{O}_{2}$ production in flounder, cormorant and gull liver microsomes; however, TCB decreased $\mathrm{H}_{2} \mathrm{O}_{2}$ production in chicken liver microsomes. TCB increased $\mathrm{O}_{2}-\bullet$ production in the flounder, killifish, cormorant and gull liver microsomes. These increases in ROS production were not of the same magnitude as was seen in scup (Figure 3).

\section{DISCUSSION}

Planar HAHs are ubiquitous environmental contaminants that are known to be highly toxic (Safe, 1994). TCB both induces and suppresses the induction of CYP1A in several species (Lambrecht et al., 1988; Sinclair et al., 1989; Newsted et al., 1995; Stegeman et al., 1995; White et al., 1997a). Loss of CYP1A during incubation of scup liver microsomes with TCB+NADPH has been attributed to the formation and attack of ROS and may be involved in the decline in CYP1A seen in vivo (Chapter 3). In these studies we examined the inactivation of CYP1A and its relationship to TCB metabolism and ROS production in a variety of fish, bird, and reptile species. For all species examined, TCB metabolism represented a very small proportion of the CYP1A catalytic activity; however, it was correlated strongly with EROD activity, except in flounder. Susceptibility 


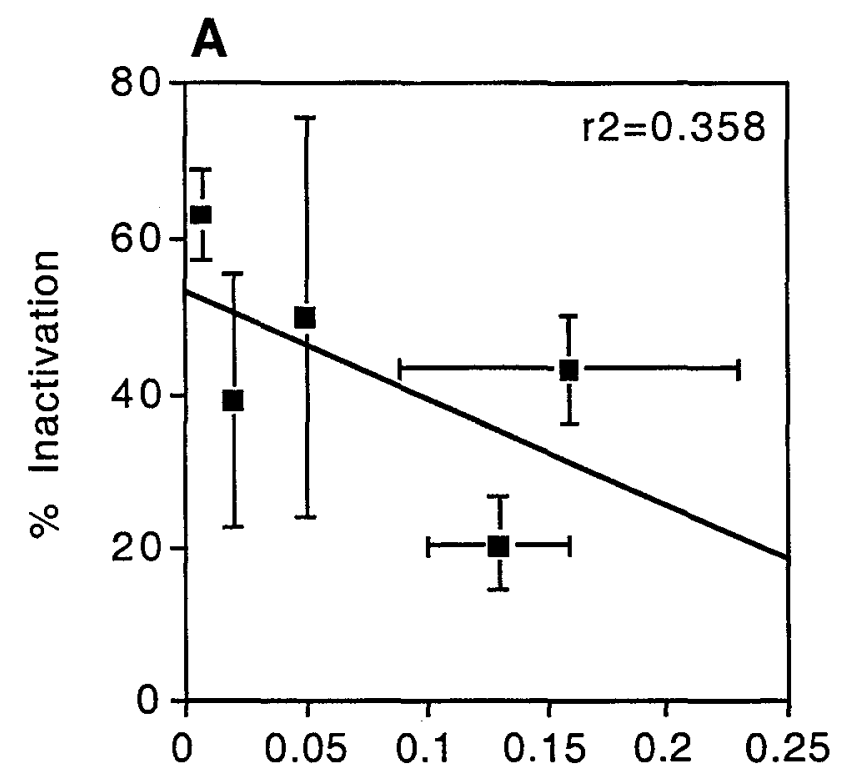

TCB Metabolism (\% of EROD Activity)

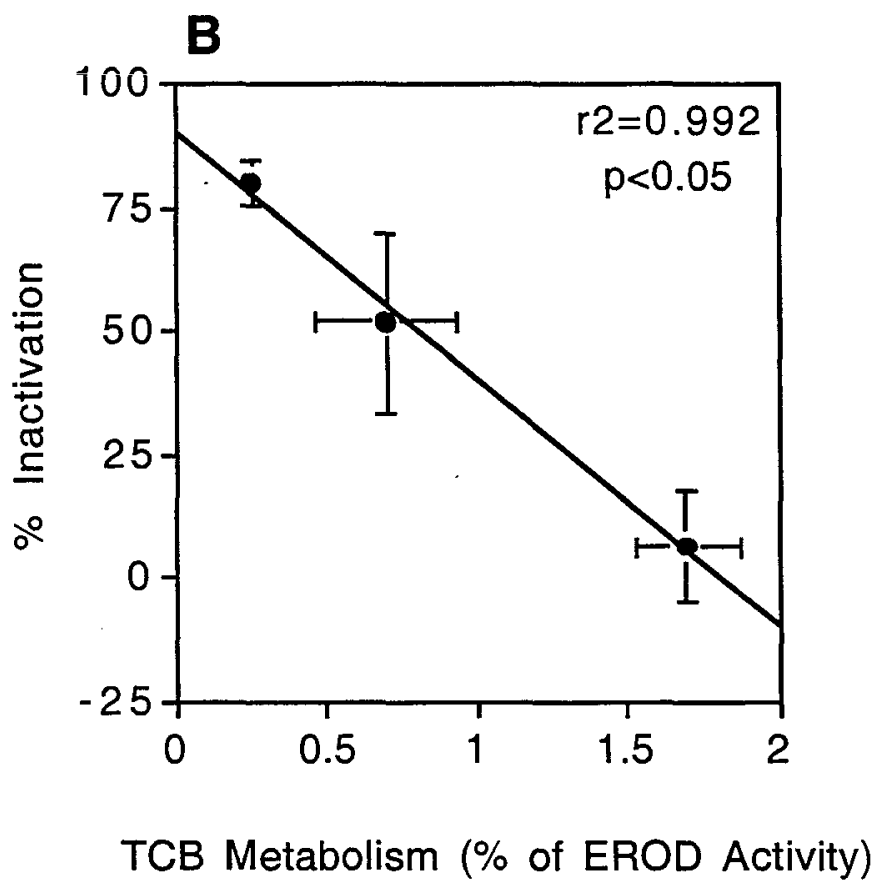

Figure 2. Correlation of TCB metabolism with inactivation of CYP1A catalytic activity. A) Fish liver microsomes. B) Bird liver microsomes. TCB metabolism has been normalized to the EROD activity in the microsomes. 
to inactivation varied among species with chicken being most sensitive but with eel, flounder, killifish and cormorant also having significant inactivation. Inactivation appeared to be negatively correlated with TCB metabolism. In both fish and bird species, NADPHstimulated ROS production was positively correlated with EROD activity. TCB further stimulated ROS production in liver microsomes of flounder, killifish, cormorant and gull; however, TCB decreased ROS production in the chicken liver microsomes. Compared to scup, only chicken had rates of ROS production and CYP1A inactivation as high. CYP1A inactivation appear to be dependent in part on the rate at which species metabolize TCB.

TCB Metabolism: This study and others have shown that fish do not metabolize chlorobiphenyls (CB) as readily as birds or mammals. A recent study confirmed that TCB is metabolized by the marine fish scup both in vivo and in vitro (White et al., 1997b). Here, all species of fish examined metabolized TCB at a rate of less than $1 \mathrm{pmol} / \mathrm{min} / \mathrm{mg}$ which represented between 0.01 and $0.2 \%$ of the EROD activity in these species. These very low rates of metabolism may be the reason why some studies have failed to detect $\mathrm{CB}$ metabolism in fish (Hutzinger et al., 1972; Herbst et al., 1978; Murk et al., 1994). However, selective loss of $\mathrm{CB}$ congeners in fish species indicated that biotransformation occurs in fish; selective loss of coplanar congeners TCB and 3,3',4,4',5pentachlorobiphenyl (Niimi and Oliver, 1983; de Boer et al., 1993) and non-coplanar congeners 2,2',5,5'-tetrachlorobiphenyl, 2,2',4,5,5'-pentachlorobiphenyl and 2,2',3,5,5',6-hexachlorobiphenyl (Boon et al., 1989; Elskus et al., 1994) has been described. Furthermore, trace amounts of metabolites of di- to pentachlorobiphenyls have been detected in several fish species (Metcalf et al., 1975; Sanborn et al., 1975; Melancon and Lech, 1976; Hinz and Matsumura, 1977; Herbst et al., 1978). Birds have been shown to metabolize a number of di- to pentachlorobiphenyls both in vitro (Borlakoglu and Wilkins, 1993) and by the selective loss of specific congeners (Borlakoglu et al., 1990). Analysis of congener composition following either environmental or experimental exposure to complex $\mathrm{CB}$ mixtures suggested that only congeners with at least one pair of adjacent unsubstituted meta-para carbons were metabolized by birds (Borlakoglu et al., 1990; Rozemeijer et al., 1991). However, liver microsomes from eider duck (Somateria mollissima) and common tern (Sterna hirundo) metabolize TCB at significant rates (0.6-1.4 and $21-47 \mathrm{pmol} / \mathrm{min} / \mathrm{mg}$, representing 2.9 and $4.0 \%$ of EROD activity) (Murk et al., 1994). Furthermore, all of the bird species in this study metabolized TCB at rates between 0.4 and $12.8 \mathrm{pmol} / \mathrm{min} / \mathrm{mg}$ which represented 0.3 to $1.3 \%$ of the EROD activity in these samples. TCB metabolism in liver microsomes from rats induced for CYP1A ranged from 
Figure 3. TCB-stimulated ROS production in liver microsomes. A) $\mathrm{H}_{2} \mathrm{O}_{2}$ production as assessed by oxidation of DCDFDA to DCF. B) $\mathrm{O}_{2}^{-\bullet}$ production as assessed by oxidation of $\mathrm{HE}$ to ethidium. In a 48-well plate, approximately $0.1 \mathrm{mg}$ of microsomal protein was diluted to $160 \mu \mathrm{l}$ with HBSS containing $5 \mu \mathrm{M}$ DCDFDA and $7.5 \mu \mathrm{M} \mathrm{HE}$ (final concentrations). Some reaction mixtures contained 200 units SOD. Following a fifteen minute incubation at $30^{\circ} \mathrm{C}, 1.7 \mathrm{nmol} \mathrm{TCB}$ in acetone or $5 \mu \mathrm{l}$ acetone was added. Reactions were initiated with NADPH $(1.7 \mathrm{mM})$. The rates of DCF and ethidium production were monitored fluorometrically over 5 minutes. Calculations were made using DCF and ethidium bromide as standards. Data are the means \pm S. D. from 3-8 sets of microsomes. *Statistically different from the corresponding NADPH+acetone incubation $(\mathrm{p}<0.05$, Student's t-Test). 

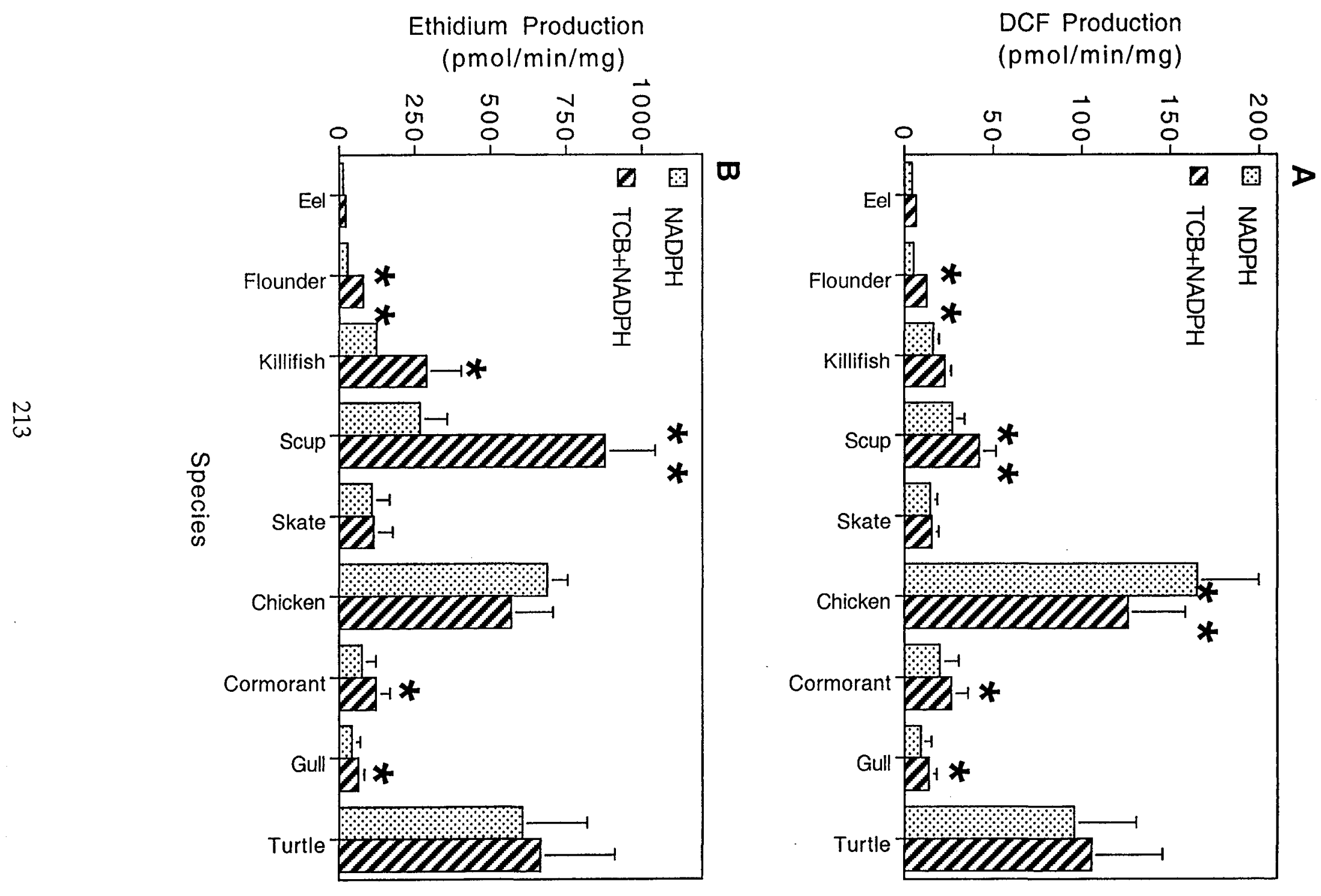

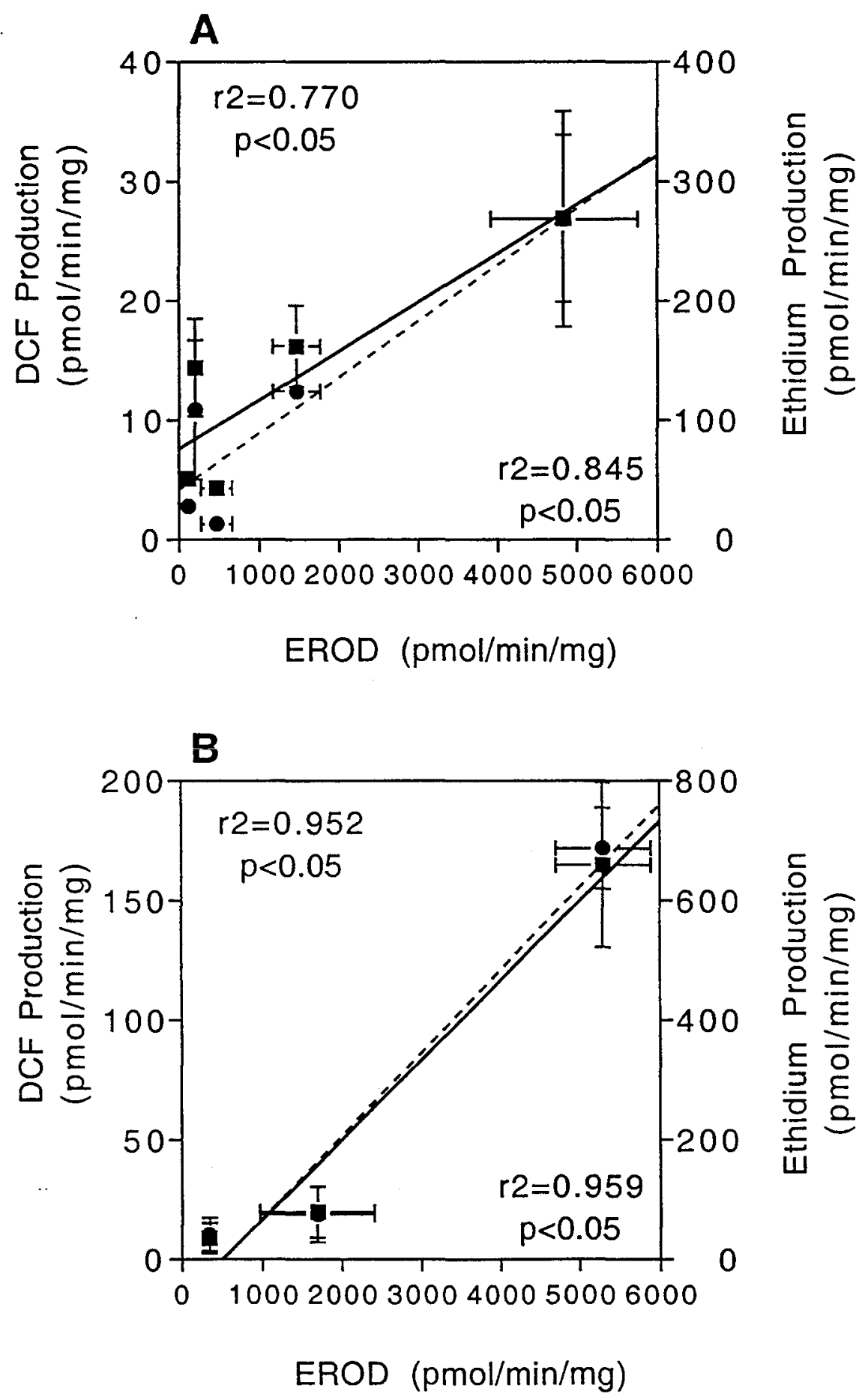

Figure 4. Correlation of ROS production with CYP1A catalytic activity. A) Fish liver microsomes. B) Bird liver microsomes. 
18-91 $\mathrm{pmol} / \mathrm{min} / \mathrm{mg}$, representing 4\% of EROD activity (Ishida et al., 1991; Murk et al., 1994).

Previous studies have determined the metabolite profiles of TCB in various species. In scup treated with $0.1 \mathrm{mg} \mathrm{TCB} / \mathrm{kg}$, 5-hydroxy-3,3',4,4'-tetrachlorobiphenyl (5-OHTCB) is the predominant metabolite in bile, constituting $85 \%$ of all metabolites, while 4hydroxy-3,3',4',5-tetrachlorobiphenyl (4-OH-TCB) constitutes $13 \%$ of the total (White et al., 1997b). This distribution appears to be dependent upon dose of TCB, with a dose of 5 $\mathrm{mg} \mathrm{TCB} / \mathrm{kg}$ resulting in a profile with similar amounts of 4-OH-TCB and 5-OH-TCB (White et al., 1997b). 5-OH-TCB is the predominant metabolite in bile of chickens (Klasson Wehler et al., 1990) and is the predominant metabolite produced by liver microsomes of the common tern and eider duck (Murk et al., 1994). In feces of mice and rats, 4-OH-TCB and 5-OH-TCB occur in nearly equal amounts (Yoshimura et al., 1987; Klasson Wehler et al., 1989).

CYP1As appear to be responsible for the metabolism of TCB. For most species in this study, TCB metabolism was correlated strongly with EROD activity. EROD activity is associated with CYP1A in fish (Klotz et al., 1983), CYP1A4 in birds (Rifkind et al., 1994), and CYP1A1 in mammals (Nerurkar et al., 1993). Induction and inhibition studies in scup have suggested that CYP1A is responsible for TCB metabolism in the fish scup (White et al., 1997b). Interestingly, the flounder showed no relationship between EROD activity and TCB metabolism. This may have resulted in part from the fact that a small number of samples with very similar TCB metabolism rates were analyzed. However, other studies have demonstrated a lack of CYP1A-like metabolism of CB congeners in flounder (Brown, 1992; Elskus et al., 1994). Along with the chicken, cormorant and gull examined in this study, positive correlation of EROD activity and TCB metabolism also has been demonstrated for the common tern and eider duck (Murk et al., 1994). In rats it is known that CYP1A1 metabolizes congeners with adjacent, unsubstituted ortho-meta carbons (Ishida et al., 1991).

TCB-Stimulated CYP1A Inactivation: TCB-mediated inactivation of CYP1A was described first in scup, where the phenomenon is quite strong (White et al., 1997a). Uncoupling of electron transfer and oxygen activation from mono-oxygenation during the interaction of TCB with CYP1A results in the release of $\mathrm{ROS}$, either $\mathrm{H}_{2} \mathrm{O}_{2}$ and $\mathrm{O}_{2}^{-\bullet}$, from the heme iron. $\mathrm{H}_{2} \mathrm{O}_{2}$ can be converted to the extremely reactive $\mathrm{OH} \cdot$ by the Fenton reaction with the reduced heme iron acting as the catalyst. That $\mathrm{OH} \bullet$ can attack the protein and disable it (Chapter 3. This oxidative mechanism of inactivation is hypothesized to 
occur during the in vitro metabolism of TCB and to be responsible for the loss of CYP1A protein in scup following exposure to a high dose of TCB (White et al., 1997a). Furthermore, in vitro oxidative inactivation is stimulated by several slowly metabolized CB congeners that are CYP1A substrates, including 2,3,3',4,4'-pentachlorobiphenyl, 3,3',4,4',5-pentachlorobiphenyl (PeCB) and 3,3',4,4',5,5'-hexachlorobiphenyl (Chapter $4)$.

Results from this study and others suggest that pHAH stimulated oxidative inactivation may occur in species other than scup. While CYP1A mRNA remains elevated in rainbow trout exposed to high doses of PeCB, CYP1A activity and protein both decrease at high doses (Newsted et al., 1995). Similarly, studies of cultured cells have demonstrated that chick embryo hepatocytes and porcine aorta endothelial cells exposed to high doses of TCB show losses of both EROD activity and CYP1A protein (Lambrecht et al., 1988; Sinclair et al., 1989; Stegeman et al., 1995). Studies of inactivation of CYP1A in liver microsomes of fish and birds show that the extent of TCB-mediated inactivation of CYP1A is species specific and may be related to the rate at which TCB is metabolized. A greater rate of TCB metabolism was correlated with a lesser rate of inactivation and a lesser rate of ROS production. A greater rate of TCB metabolism may reduce the extent of catalytic uncoupling thereby reducing the rate of production of ROS which could attack the protein.

However, data from the chicken do not fit this explanation entirely. Chickens have a greater concentration of $\mathrm{AhR}$, are more sensitive to CYP1A induction and are more susceptible to CB toxicity than other bird species (Brunstrom, 1988; Brunstrom and Lund, 1988; Dubois et al., 1995; Kennedy et al., 1996). While chicken liver microsomes had both one of the lowest rates of TCB metabolism and the greatest rate of inactivation, TCB did not enhance the production of ROS. Chicken liver microsomes had high levels of ROS production in the presence of NADPH alone with a slight reduction in the presence of TCB. Similarly, human CYP1A2 produced ROS at a high rate with NADPH alone, and the rate decreased substantially in the presence of TCB (Chapter 3). Unlike mammalian CYP1A1 and CYP1A2 (Dragnev et al., 1995), chicken CYP1A4 and CYP1A5 are induced in almost equal amounts by pHAH (Sinclair et al., 1997). As CYP1A5 possesses characteristics more like CYP1A2, then it may contribute more to the general production of ROS seen with NADPH alone. However, ROS production decreases only slightly in the presence of TCB in the chicken microsomes. While ROS production by CYP1A5 may decrease in the presence of TCB, the interaction of CYP1A4 with TCB may increase ROS 
production, finally resulting in the inactivation of CYP1A4. Studies with purified chicken CYP1As would be required to support this hypothesis.

PCB-Stimulated ROS Production: Evidence from studies in fish, birds and mammals indicate that CBs stimulate oxidative stress. Aroclor 1254 treatment stimulates hepatic lipid peroxidation in chickens, rats and guinea pigs (Combs and Scott, 1975; Kato et al., 1981; Dogra et al., 1988). Studies in fish have demonstrated an increase in antioxidant enzyme activity following exposure to TCB and PeCB (Otto and Moon, 1995; Palace et al., 1996). PeCB stimulates lipid peroxidation in kestrels (Hoffman et al., 1996), and TCB increases ROS production and lipid peroxidation in porcine pulmonary endothelial cells (Toborek et al., 1995).

Results from in vitro studies supports the hypothesis that pHAH stimulate ROS production through their interaction with CYP1A. While the extent of stimulation varied, TCB stimulated ROS production in a number of the species examined here. Previously, CYP1A from scup and rat were shown to produce ROS during their interaction with planar $\mathrm{CB}$ congeners (Chapter 4). Oxidation of bilirubin in chicken and rat liver microsomes was suggested to occur as a result of ROS formed during uncoupling of the CYP1A catalytic cycle by non-ortho CB congeners (Sinclair et al., 1986; DeMatteis et al., 1989). In rats, bilirubin oxidation has been shown to be catalyzed by CYP1A1 (DeMatteis et al., 1991). Thus, the correlation of CYP1A induction and oxidative stress may indicate that CYP1A induced through the AhR could be the immediate source of ROS in vivo.

Reptiles and Cytochromes P450: Information on CYP induction and CB metabolism in reptiles is scare. In both turtles and alligators, two bands are recognized by a polyclonal anti-mouse or anti-rat CYP1A1 (Jewell et al., 1989; Yawetz et al., 1998). 3Methylcholanthrene induced the slower migrating band in alligators (Jewell et al., 1989) and induced total P450, benzo[a]pyrene hydroxylase activity, and p-nitrophenetol Odeethylase activity in snakes (Schwen and Mannering, 1982). In the turtle, BNF, TCB and 2,3,3',4,4'-pentachlorobiphenyl also induced the slower migrating band (Yawetz et al., 1998). While EROD activities were low, they were correlated with the content of MAb-112-3 cross-reactive protein (Jewell et al., 1989; Yawetz et al., 1998). Furthermore, aryl hydrocarbon hydroxylase rates were substantial. We show here that a turtle species can metabolize TCB at rates comparable to those seen in birds. This study is the first to demonstrate a correlation between EROD activity and TCB metabolism in a reptile. Similar to the chicken, the oxidase activity in turtle liver microsomes was substantial. 
Initial studies in scup and rat suggested that not all species are equally susceptible to TCB mediated CYP1A inactivation. Here, we examined the relationship of the TCB metabolism to TCB-mediated inactivation of CYP1A and ROS production in a variety of species. Within groups of species, CYP1A inactivation appears to be negatively correlated with TCB metabolism. This supports earlier conclusions that TCB-mediated inactivation results from catalytic uncoupling and formation and attack of ROS. The results also demonstrate that ROS are produced by a variety of species. Formation of ROS by CYP1A may be linked to overt toxicity though damage to membranes (Bagchi et al., 1989; Simonian and Coyle, 1996), proteins (Davies, 1987; Kyle et al., 1989), and nuclei acids (Floyd et al., 1988; Simonian and Coyle, 1996) and through modification of the regulation of genes involved in several signal transduction pathways (Flohe et al., 1997). The stimulation of ROS production by pHAH may represent a pathway of toxicity that is common among diverse species. 


\section{REFERENCES}

Achard, F., Gilbert, M., Benistnat, C., Ben Slama, S., DeWitt, D. L., Smith, W. L. and Lagarde, M. (1997). Eicosapentaenoic and docosahexaenoic acids reduce PGH synthase 1 expression in bovine aortic endothelial cells. Biochem. Biophys. Res. Commun. 241: 513-518.

Ahmed, S. S., Napoli, K. L. and Strobel, H. W. (1995). Oxygen radical formation during cytochrome P450-catalyzed cyclosporine metabolism in rat and human liver microsomes at varying hydrogen ion concentrations. Mol. Cell. Biochem. 151: 131-140.

Alberts, B., Bray, D., Lewis, J., Raff, M., Roberts, K. and Watson, J. D. (1989). Molecular Biology of the Cell. New York, Garland Publ., Inc.

Alexander, R. W. (1995). Hypertension and the pathogenesis of atherosclerosis: Oxidative stress and the mediation of arterial inflammatory response: A new perspective. Hypertension 25: 155-161.

Alsharif, N. Z., Lawson, T. and Stohs, S. J. (1994). Oxidative stress induced by 2,3,7,8tetrachlorodibenzo- $p$-dioxin is mediated by the aryl hydrocarbon $(\mathrm{Ah})$ receptor complex. Toxicology 92: 39-51.

Alsharif, N. Z., Schlueter, W. J. and Stohs, S. J. (1994). Stimulation of NADPHdependent reactive oxygen species formation and DNA damage by $2,3,7,8$ tetrachlorodibenzo-p-dioxin in rat peritoneal lavage cells. Arch. Environ. Contam. Toxicol. 26: 392-7.

Anderson, A. A., Fletcher, T. C. and Smith, G. M. (1981). Prostaglandin biosynthesis in the skin of the plaice, Pleuronectes platessa L. Comp. Biochem. Physiol. 70C: 195-199.

Andersson, T. and Forlin, L. (1992). Regulation of the cytochrome P-450 enzyme system in fish. Aquat. Toxicol. 24: 1-20.

Ando, J. and Kamiya, A. (1993). Blood flow and vascular endothelial cell function. Frontiers Med. Biol. Engng. 5: 245-264.

Angel, P. and Karin, M. (1991). The role of Jun, Fos, and AP-1 complex in cell proliferation and transformation. Biochim. Biophys. Acta 1072: 129-157.

Arnone, M. I., Zannini, M. and Di Lauro, R. (1995). The DNA binding activity and the dimerization ability of the thyroid transcription factor 1 are redox regulated. J. Biol. Chem. 270: 12048-12055.

Auclair, C., De Prost, D. and Hakim, J. (1978). Superoxide anion production by liver microsomes from phenobarbital treated rat. Biochem. Pharmacol. 27: 355-358.

Aust, S. D., Roerig, D. I. and Pederson, T. C. (1972). Evidence for superoxide generation by NADPH-cytochrome $c$ reductase of rat liver microsomes. Biochem. Biophys. Res. Commun. 47: 1133-1137. 
Baboir, B. M. (1978). Oxygen-dependent microbial killing by phagocytes. N. Engl. J. Med. 298: 659-668.

Baeuerle, P. A. (1991). The inducible transcription activator NF-kappaB: Regulation by distinct protein subunits. Biochim. Biophys. Acta 1072: 63-80.

Baeuerle, P. A. and Henkel, T. (1994). Function and activation of NF-kappaB in the immune system. Annu. Rev. Immunol. 12: 141-179.

Bagchi, M., Prasad, M. R., Engelmean, R. M. and Das, D. K. (1989). Effects of free radicals on the fluidity of myocardial membranes. Free Rad. Res. Commun. 7: 375-380.

Baird, W. M., Chemerys, R., Grinspan, J. B., Mueller, S. N. and Levine, E. M. (1980). Benzo[a]pyrene metabolism in bovine aortic endothelial and bovine lung fibroblastlike cell cultures. Cancer Res. 40: 1781-1786.

Baker, S. J., Markowitz, S., Fearon, E. R., Willson, J. K. and Vogelstein, S. (1990). Suppression of human colorectal carcinoma cell growth by wildtype p53. Science 249: $912-915$.

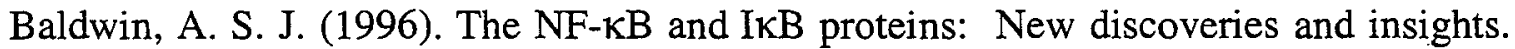
Annu. Rev. Immunol. 14: 649-681.

Ballard, D. W., Bohnlein, E., Hoffman, J. A., Bogerd, H. P., Dixon, E. P., Franze, B. R. and Greene, W. C. (1989). Activation of the interleukin-2 receptor alpha gene: regulatory role for DNA-protein interactions flanking the kappa B enhancer. $\mathrm{New}$ Biol. 1: 183-92.

Ballard, D. W., Walker, W. H., Doerre, S., Sista, P., Molitor, J. A., Dixon, E. P., Peffer, N. J., Hannink, M. and Greene, W. C. (1990). The v-rel oncogene encodes a $\mathrm{\kappa B}$ enhancer binding protein that inhibits NF- $\mathrm{KB}$ function. Cell 63: 803814.

Bandyopadhyay, G., Dutta, J. and Ghosh, S. (1982). Synthesis of diene prostaglandins in freshwater fish. Lipids 17: 755-758.

Barchowsky, A., Williams, M. E., Benz, C. C. and Chepenik, K. P. (1994). Oxidantsensitive proteins phosphorylation in endothelial cells. Free Rad. Biol. Med. 16: 771-777.

Barker, C. W., Fagan, J. B. and Pasco, D. S. (1994). Down-regulation of P4501A1 and P4501A2 mRNA expression in isolated hepatocytes by oxidative stress. J. Biol. Chem. 269: 3985-3990.

Beckman, B. and Mustafa, T. (1992). Arachidonic acid metabolism in gill homogenate and isolated gill cells from rainbow trout, Oncorhynchus mykiss: The effect of osmolality, electrolytes and prolactin. Fish Physiol. Biochem. 10: 213-222. 
Beg, A. A., Sha, W. C., Bronson, R. T., Ghosh, S. and Baltimore, D. (1995). Embryonic lethality and liver degeneration in mice lacking the RelA component of NF-kappaB. Nature 376: 167-170.

Berndtson, A. K. and Chen, T. T. (1994). Two unique CYP1 genes are expressed in response to 3-methylcholanthrene treatment in rainbow trout. Arch. Biochem. Biophys. 310: 187-195.

Bernhoft, A., Hektoen, H., Skaare, J. U. and Ingebrigtsen, K. (1994). Tissue distribution and effects of hepatic xenobiotic metabolising enzymes of $2,3,3^{\prime}, 4,4^{\prime}-$ pentachlorobiphenyl (PCB-105) in cod (Gadus morhua) and rainbow trout (Oncorhynchus mykiss). Environ. Poll. 85: 351-359.

Beutler, E. (1975). Catalase. Red Cell Metabolism: A manual of biochemical methods. New York, Grune and Stratton. 89-90.

Beyer, J., Sandvik, M., Skare, J. U., Egaas, E., Hylland, K., Waagbo, R. and Goksoyr, A. (1997). Time- and dose-dependent biomarker responses in flounder (Platichthys flesus L.) exposed to benzo[a]pyrene, 2,3,3',4,4',5-hexachlorobiphenyl and cadmium. Biomarkers 2: 35-44.

Beyer, W. F. and Fridovich, I. (1987). Effect of hydrogen peroxide on the iron containing SOD of Escherichia coli. Biochemistry 26: 1251-1257.

Black, S. D. and Coon, M. J. (1986). Comparative structures of P-450 cytochromes. Cytochrome P-450: Structure, Mechanism, and Biochemistry. New York, P.R. Ortiz de Montellano. 161-216.

Blech, D. M. and Borders, C. L., Jr. (1983). Hydroperoxidase anion, HO2-, is an affinity reagent for the inactivation of yeast $\mathrm{Cu}, \mathrm{Zn}-\mathrm{SOD}$ : modification of one histidine per subunit. Arch. Biochem. Biophys. 224: 579-586.

Bol, J., Van den Berg, M. and Seinen, W. (1989). Interactive effects of PCDD's, PCDF's and PCB's as assessed by the E. L. S.-bioassay. Chemosphere 19: 899-906.

Bondy, S. C. and Naderi, S. (1994). Contribution of hepatic cytochrome P450 systems to the generation of reactive oxygen species. Biochem. Pharmacol. 48: 155-159.

Bonkovsky, H. L., Healey, J. F., Bement, W. J., Sinclair, P. R., Sinclair, J. F. and Shedlovsky, S. F. (1984). Effect of uroporphyrinogen on the spectral measurement of cytochrome P450. Biochem. Pharmacol. 33: 499-502.

Boon, J. P., Eijgenraam, F., Everaarts, J. M. and Duinker, J. C. (1989). A structureactivity relationship (SAR) approach towards metabolism of PCBs in marine animals from different trophic levels. Mar. Environ. Res. 27: 159-176.

Borlakoglu, J. T. and Wilkins, J. P. G. (1993). Metabolism of di-, tri-, tetra-, penta- and hexachlorobiphenyls by hepatic microsomes isolated from control animals and animals treated with Aroclor 1254, a commercial mixture of polychlorinated biphenyls (PCBs). Comp. Biochem. Physiol. 105C: 95-106. 
Borlakoglu, J. T., Wilkins, J. P. G., Walker, C. H. and Dils, R. R. (1990). Polychlorinated biphenyls (PCBs) in fish-eating sea birds-III. Molecular features and metabolic interpretations of PCB isomers and congeners in adipose tissue. Comp. Biochem. Physiol. 97C: 173-177.

Breen, A. P. and Murphy, J. A. (1995). Reactions of oxyl radicals with DNA. Free Rad. Biol. Med. 18: 1033-1077.

Brittebo, E. B. (1994). Metabolic activation of the food mutagen Trp-P-1 in endothelial cells of heart and kidney in cytochrome P450-induced mice. Carcinogenesis 15: 667-672.

Brown, J. A. and Bucknall, R. M. (1986). Antidiuretic and cardiovascular actions of prostaglandin E2 in the rainbow trout, Salmo gairdneri. Gen. Comp. Endocrinol. 61: 330-337.

Brown, J. F. (1992). Metabolic alterations of PCB residues in aquatic fauna: distributions of cytochrome P4501A- and P4502B- like activities. Marine Environ. Res. 34: 261-266.

Brunstrom, B. (1988). Sensitivity of embryos from duck, goose, herring gull, and various chicken breeds to 3,3',4,4'-tetrachlorobiphenyl. Poult. Sci. 67: 52-57.

Brunstrom, B. and Lund, J. (1988). Differences between chick and turkey embryos in sensitivity to $3,3^{\prime}, 4,4^{\prime}$-tetrachlorobiphenyl and in concentration/affinity of the hepatic receptor for 2,3,7,8-tetrachlorodibenzo-p-dioxin. Comp. Biochem. Physiol. 91C: 507-512.

Brunstrom, B. and Reutergardh, L. (1986). Differences in sensitivity of some avian species to the embryotoxicity of a PCB, 3,3',4,4'-tetrachlorobiphenyl, injected into the eggs. Environ. Pollution (Series A) 42: 37-45.

Buchmann, A., Zigler, S., Wolf, A., Robertson, L. W., Durham, S. K. and Schwartz, M. (1991). Effects of polychlorinated biphenyls in rat liver: correlation between primary subcellular effects and promoting activity. Toxicol. Appl. Pharmacol. 111: 454-468.

Buhler, D. R., Yang, Y. H., Dreher, T. W., Miranda, C. L. and Wang, J. L. (1994). Cloning and sequencing of the major rainbow trout constitutive cytochrome $\mathrm{P} 450$ (CYP2K1): identification of a new cytochrome P450 gene subfamily and its expression in mature rainbow trout liver and trunk kidney. Arch. Biochem. Biophys. 312: 45-51.

Cagen, L. M., Quershi, Z. and Nishimura, H. (1983). Synthesis of prostaglandin E2 and prostaglandin F2 $\alpha$ by toadfish red blood cells. Biochem. Biophys. Res. Commun. 110: $250-255$.

Campbell, W. B., Gebremedhin, D., Pratt, P. F. and Harder, D. R. (1996). Identification of epoxyeicosatrienoic acids as endothelium-derived hyperpolarizing factors. Circ. Res. 78: 415-423. 
Cantrell, S. M., Lutz, L. H., Tillitt, D. E. and Hannink, M. (1996). Embryotoxicity of 2,3,7,8-tetrachlorodibenzo- $p$-dioxin (TCDD): The embryonic vasculature is a physiological target for TCDD-induced DNA damage and apoptotic cell death in medaka (Orysias latipes). Toxicol. Appl. Pharmacol. 141: 23-34.

Capdevila, J. H., Karara, A., Waxman, D. J., Martin, M. V., Falck, J. R. and Guengerich, F. P. (1990). Cytochrome P450 enzyme specific control of the regioand enantiofacial selectivity of the microsomal arachidonic acid epoxygenase. $J$. Biol. Chem. 265: 10865-10871.

Capdevila, J. H., Wei, S., Yan, J., Karara, A., Jacobson, H. R., Falck, J. R., Guengerich, F. P. and DuBois, R. N. (1992). Cytochrome P-450 arachidonic acid epoxygenase. Regulatory control of the renal epoxygenase by dietary salt loading. J. Biol. Chem. 267: 21720-6.

Capdevila, J. H., Zeldin, D., Makita, K., Karara, A. and Falck, J. R. (1995). Cytochrome P450 and the metabolism of arachidonic acid and oxygenated eicosanoids. Cytochrome P450: Structure, Mechanism and Biochemistry. New York, Plenum Press. 443-471.

Capobianco, A. J., Chang, D., Mosialos, G. and Gilmore, T. D. (1992). p105, the NFkappaB p50 precursor protein, is one of the cellular proteins complexed with the vRel oncoprotein in transformed chicken spleen cells. J. Virol. 66: 3758-3767.

Capobianco, A. J., Simmons, D. L. and Gilmore, T. D. (1990). Cloning and expression of a chicken c-rel cDNA: unlike p59v-rel, p68c-rel is a cytoplasmic protein in chicken embryo fibroblasts. Oncogene 5: 257-265.

Carpenter, H. M., Fredrickson, L. S., Williams, D. E., Buhler, D. R. and Curtis, L. R. (1990). The effect of thermal acclimation on the activity of arylhydrocarbon hydorxylase in rainbow trout (Oncorhynchus mykiss). Comp. Biochem. Physiol. 97C: $127-32$.

Celander, M., Buhler, D. R., Forlin, L., Goksoyr, A., Miranda, C. L., Woodin, B. R. and Stegeman, J. J. (1996). Immunochemical relationships of cytochrome P4503A-like proteins in teleost fish. Fish Physiol. Biochem. 15: 323-332.

Cha, S. (1975). Tight-binding inhibitors-I. Kinetic behavior. Biochem. Pharmacol. 24: $2177-2185$.

Chang, C.-Y. and Puga, A. (1998). Constitutive activation of the aromatic hydrocarbon receptor. Mol. Cell. Biol. 18: 525-535.

Chang, J. P., Jobin, R. M. and Wong, A. O. L. (1993). Intracellular mechanisms mediating gonadotropin and growth hormone release in the goldfish, Carassius auratus. Fish Physiol. Biochem. 11: 25-33.

Chen, Q. and Cederbaum, A. I. (1997). Menadione cytotoxicity to Hep G2 cells and protection by activation of nuclear factor-kB. Mol. Pharmacol. 52: 648-657. 
Cheng, Y.-C. and Prusoff, W. H. (1973). Relationship between the inhibition constant $\left(\mathrm{K}_{\mathrm{i}}\right)$ and the concentration of inhibitor which causes 50 per cent inhibition $\left(\mathrm{I}_{50}\right)$ of an enzymatic reaction. Biochem. Pharmacol. 22: 3099-3108.

Chien, S., Li, S. and Shyy, J. Y.-J. (1998). Effects of mechanical forces on signal transduction and gene expression in endothelial cells. Hypertension 31(part 2): $162-$ 169.

Choi, E. J., Toscano, D. G., Ryan, J. A., Riedel, N. and Toscano, W. A. (1991). Dioxin induces transforming growth factor- $\alpha$ in human keratinocytes. J. Biol. Chem. 266: 9591-9597.

Chomczynski, P. (1992). One-hour downward alkaline capillary transfer for blotting of DNA and RNA. Anal. Biochem. 201: 134-139.

Civitareale, D., Saiardi, S. and Falasca, P. (1994). Purification and characterization of thyroid transcription factor 2. Biochem. J. 304: 981-985.

Cohen, G. (1985). Oxidative stress in the nervous system. Oxidative Stress. London, Academic Press Inc. 383-401.

Combs, C. F. and Scott, M. L. (1975). Polychlorinated biphenyl-stimulated selenium deficiency in the chick. Poult. Sci. 54: 1152-1158.

Connor, K., Safe, S., Jefcoate, C. R. and Larsen, M. (1995). Structure-dependent induction of CYP2B by polychlorinated biphenyl congeners in female SpragueDawley rats. Biochem. Pharmacol. 50: 1913-1920.

Cressman, D. E., Greenbaum, L. E., Haber, B. A. and Taub, R. (1994). Rapid activation of post-hepatectomy factor/nuclear factor kappa B in hepatocytes, a primary response in the regenerating liver. J. Biol. Chem. 269: 30429-30435.

Crone, C. (1986). Modulation of solute permiability in microvascular endothelium. Federation Proc. 45: 77-83.

Da Costa, E. G. and Curtis, L. R. (1995). Bioaccumulation of dietary 2,2',4,4',5,5'hexachlorobiphenyl and induction of hepatic arylhydrocarbon hydroxylase in rainbow trout (Oncorhynchus mykiss). Environ. Toxicol. Chem. 14: 1711-1717.

Das, K., Engelman, R. M., Liu, X., Maity, S., Rousou, J. A., Flack, J., Laksmipati, J., Jones, R. M., Prasad, M. R. and Deaton, D. W. (1992). Oxygen-derived free radicals and hemolysis during open-heart surgery. Mol. Cell. Biochem. 111: 7786.

Davies, K. J. A. (1986). Intracellular proteolytic systems may function as secondary antioxidant defenses: an hypothesis. J. Free Rad. Biol. Med. 2: 155-173.

Davies, K. J. A. (1987). Protein damage and degradation by oxygen radicals I. General aspects. J. Biol. Chem. 262: 9895-9901. 
Davies, K. J. A., Delsignore, M. E. and Lin, S. W. (1987). Protein damage and degradation by oxygen radicals II. Modification of amino acids. J. Biol. Chem. 262: $9902-9907$.

Davies, K. J. A., Lin, S. W. and Pcifici, R. E. (1987). Protein damage and degradation by oxygen radicals IV. Degradation of denatured proteins. J. Biol. Chem. 262: 99149920.

de Boer, J., Stronck, C. J. N., Traag, W. A. and van der Meer, J. (1993). Non-ortho and mono-ortho substituted chlorobiphenyls and chlorinated dibenzo- $p$-dioxins and dibenzofurans in marine and freshwater fish and shellfish from the Netherlands. Chemosphere 26: 1823-1842.

Dees, J. H., Masters, B. S. S., Muller-Eberhard, U. and Johnson, E. F. (1982). Effect of $2,3,7,8$-tetrachlorodibenzo- $p$-dioxin and phenobarbital on the occurrence and distribution of four cytochrome P-450 isozymes in rabbit kidney, lung, and liver. Cancer Res. 42: 1423-1432.

DeMatteis, F., Dawson, S. J., Boobis, A. R. and Comoglio, A. (1991). Inducible bilirubin-degrading system rat liver microsomes: role of cytochrome P450IA1. Mol. Pharmacol. 40: 686-691.

DeMatteis, F., Harvey, C., Reed, C. and Hempenius, R. (1988). Increased oxidation of uroporphyrinogen by an inducible liver microsomal system. Possible relevance to drug-induced uroporphyria. Biochem. J. 250: 161-169.

DeMatteis, F., Trenti, T., Gibbs, A. H. and Greig, J. B. (1989). Inducible bilirubindegrading system in the microsomal fraction of rat liver. Mol. Pharmacol. 35: 831838 .

Deryckere, F. and Gannon, F. (1994). A one-hour minipreparation technique for extraction of DNA-binding proteins from animal tissues. Biotechniques 16: 405.

Diliberto, J. J. (1997). Role of CYP1A2 in hepatic sequestration of dioxin: Studies using CYP1A2 knock-out mice. Biochem. Biophys. Res. Commun. 236: 431-433.

Dogra, S., Fisher, J. G., Cojocel, C., Greim, H., Regel, U., Oesch, F. and Robertson, L. W. (1988). Long-term effects of commercial and congeneric polychlorinated biphenyls on ethane production and malondialdehyde levels, indicators of in vivo lipid peroxidation. Arch. Toxicol. 62: 369-374.

Dragnev, K. H., Nims, R. W., Fox, S. D., Lindahl, R. and Lubet, R. A. (1995). Relative potencies of induction of hepatic drug-metabolizing enzyme genes by individual PCB congeners. Toxicol. Appl. Pharmacol. 132: 334-342.

Dubois, M., Pfohl-Leszkowicz, A., Grosse, Y. and Kremers, P. (1995). DNA adducts and $\mathrm{P} 450$ induction in human, rat, and avian liver cells after exposure to polychlorobiphenyls. Mutat. Res. 345: 181-190. 
Dushay, M. S., Asling, B. and Hultmark, D. (1996). Origins of immunity: Relish, a compound Rel-like gene in the antibacterial defense of Drosophila. Proc. Natl. Acad. Sci. USA 91: 10285-10289.

Edwards, R. J., Murray, B. P., Singleton, A. M. and Boobis, A. R. (1991). Orientation of cytochromes P450 in the endoplasmic reticulum. Biochemistry 30: 71-6.

Ekstrom, G., Cronholm, T. and Ingelman-Sundberg, M. (1986). Hydroxyl-radical production and ethanol oxidation by liver microsomes isolated from ethanol-treated rats. Biochem. J. 233: 755-761.

Ekstrom, G. and Ingelman-Sundberg, M. (1986). Mechanisms of lipid peroxidation dependent upon cytochrome P450 LM2. Eur. J. Biochem. 158: 195.

Ekstrom, G. and Ingelman-Sundberg, M. (1989). Rat liver microsomal NADPHsupported oxidase activity and lipid peroxidation dependent on ethanol-inducible cytochrome P450 (P-450IIE1), Biochem. Pharmacol. 38: 1313-1319.

Eliasson, E., Johansson, I. and Ingelman-Sundberg, M. (1990). Substrate-, hormone-, and cAMP- regulation of cytochrome P450 degradation. Proc. Natl. Acad. Sci. USA 87: 3225-229.

Elliot, S. J., Mezaros, J. G. and P., S: W. (1992). Effect of oxidant stress on calcium signaling in vascular endothelial cells. Free Rad. Biol. Med. 13: 635-650.

Elskus, A. A., Pruell, R. and Stegeman, J. J. (1992). Endogenously-mediated, pretranslational suppression of cytochrome P4501A in PCB-contaminated flounder. Mar. Environ. Res. 34: 97-101.

Elskus, A. A., Stegeman, J. J., Gooch, J. W., Black, D. E. and Pruell, R. J. (1994). Polychlorinated biphenyl congener distributions in winter flounder as related to gender, spawning site, and congener metabolism. Environ. Sci. Technol. 28: 401407.

Engwall, M. B., Brunstrom, B., Brewer, A. and Norrgren, L. (1994). Cytochrome P4501A induction by a coplanar PCB, a PAH mixture and PCB-contaminated sediment extracts following microinjection of rainbow trout sac-fry. Aquat. Toxicol. 30: 311-324.

Escalante, B., Sessa, W. C., Falck, J. R., Yadagiri, P. and Schwartzman, M. (1990). Cytochrome P450-dependent arachidonic acid metabolites, 19- and 20hydroxyeicosatetraenoic acids, enhance sodium-potassium ATPase activity in vascular smooth muscle. J. Cardiovasc. Pharmacol. 16: 438-443.

Esposito, F., Cuccovillo, F., Morra, F., Russo, T. and Ciminio, F. (1995). DNA binding activity of the glucocorticoid receptor is sensitive to redox changes in intact cells. Biochim. Biophys. Acta 1260: 308-314.

Estabrook, R. W., Kawano, S., Werringloer, J., Kuthan, H., Tsuji, H., Graf, H. and Ullrich, V. (1979). Oxycytochrome P450: its breakdown to superoxide for the formation of hydrogen peroxide. Acta Biol. Med. Ger. 38: 423. 
Estabrook; R. W., Shet, M. S., Fisher, C. W., Jenkins, C. M. and Waterman, M. R. (1996). The interaction of NADPH-P450 reductase with P450: an electrochemical study of the role of the flavin mononucleotide-binding domain. Arch. Biochem. Biophys. 333: 308-315.

Fahay, M. P. (1978). Biological and fisheries data on American eel, Anguilla rostrata (LaSueur). Technical Series Report, Sandy Hook Laboratory, Northeast Fisheries Center, No. 17, Highlands, N.J., National Marine Fisheries Service/National Oceanic and Atmospheric Administration,

Falck, J. R., Manna, S., Moltz, J., Chacos, N. and Capdevila, J. (1983). Epoxyeicosatrienoic acids stimulate glucagon and insulin release from isolated rat pancreatic islets. Biochem. Biophys. Res. Commun. 114: 743-749.

Falckh, P. H. J., Wu, Q. K. and Ahokas, J. P. (1997). CYP4T1-a cytochrome P450 expressed in rainbow trout (Oncorhynchus mykiss) liver. Biochem. Biophys. Res. Commun. 236: 302-305.

Farin, F. M., Pohlman, T. H. and Omiencinski, C. J. (1994). Expression of cytochrome P450s and microsomal epoxide hydrolase in primary cultures of human umbilical vein endothelial cells. Toxicol. Appl. Pharmacol. 124: 1-9.

Faux, S. P., Francis, J. E., Smith, A. G. and Chipman, J. K. (1992). Induction of 8hydroxydeoxyguanosine in Ah-responsive mouse liver by iron and Arocior 1254. Carcinogenesis 13: 247-250.

Fernandez-Salguero, P. M., Hilbert, D. M., Rudikoff, S., Ward, J. M. and Gonzalez, F. J. (1996). Aryl-hydrocarbon receptor-deficient mice are resistant to 2,3,7,8tetrachlorodibenzo-p-dioxin-induced toxicity. Toxicol. Appl. Pharmacol. 140: 173179.

Fitzpatrick, F. A. and Murphy, R. C. (1989). Cytochrome P450 metabolism of arachidonic acid: formation and biological actions of "epoxygenase"-derived eicosanoids. Pharmacol. Rev. 40: 229-241.

Flohe, L., Brigelius-Flohe, R., Saliou, C., Traber, M. G. and Packer, L. (1997). Redox regulation of NF-kappa B activation. Free Rad. Biol. Med. 22: 1115-1126.

Floyd, R. A., West, M. S., Eneff, K. L., Hogsett, W. E. and Tingey, D. T. (1988). Hydroxyl free radical mediated formation of 8-hydroxyguanine in isolated DNA. Arch. Biochem. Biophys. 262: 266-272.

Forlin, L. and Lidman, U. (1978). Effects of Clophen A50, 4-, 2,5,2',5'-tetra and $2,4,5,2^{\prime}, 4$ ',5'-hexachlorobiphenyl on the mixed-function oxidase system of rainbow trout (Salmo gairdnerii Rich.) liver. Comp. Biochem. Physiol. 60C: 193197. 
Franklin, R. B., Elcombe, C. R., Vodicnik, M. J. and Lech, J. J. (1980). Comparative aspects of hepatic monooxygenase induction in rat and rainbow trout by several PCB isomers. Microsomes, Drug Oxidations and Chemical Carcinogenesis. New York, Academic Press. 833-836.

Freeman, B. A. and Crapo, J. D. (1982). Free radicals and tissue injury. Lab. Invest. 47: 412-426.

Fulton, D., Mahboubi, K., McGiff, J. C. and Quilley, J. (1995). Cytochrome P450dependent effects of bradykinin in the rat heart. Brit. J. Pharmacol. 114: 99-102.

Fulton, D., McGiff, J. C. and Quilley, J. (1992). Contribution of NO and cytochrome P450 to the vasodilator effect of bradykinin in the rat kidney. Brit. J. Pharmacol. 107: $722-725$.

Gaido, K. W., Maness, S. C., Leonard, L. S. and Greenlee, W. F. (1992). 2,3,7,8Tetrachlorodibenzo- $p$-dioxin-dependent regulation of transforming growth factors$\alpha$ and $-\beta 2$ expression in a human keratinocyte cell line involves both transcriptional and post-transcriptional control. J. Biol. Chem. 34: 24591-24595.

Ganey, P. E., Sirois, J. E., Denison, M., Robinson, J. P. and Roth, R. A. (1993). Neutrophil function after exposure to polychlorinated biphenyls in vitro. Environ. Health Perspect. 101: 430-434.

Gerritsen, M. E. (1987). Functional heterogeneity of vascular endothelial cells. Biochem. Pharmacol. 36: 2701-2711.

Gillette, J. R., Brodie, B. B. and LaDu, B. N. (1957). The oxidation of drugs by liver microsomes: on the role of TPNH and oxygen. J. Pharmacol. Exp. Ther. 119: $532-540$.

Girotti, A. W. (1985). Mechanisms of lipid peroxidation. Free Rad. Biol. Med. 1: 87-95.

Goetz, F. W., Smith, D. C. and Krickl, S. P. (1982). The effects of prostaglandins, phosphodiesterase, and cyclic AMP on ovulation of brook trout, Salvelinus fortinalis, oocytes. Gen. Comp. Endocrinol. 48: 154-160.

Goldstein, J. A. and Linko, P. (1984). Differential induction of two 2,3,7,8tetrachlorodibenzo- $p$-dioxin-inducible forms of cytochrome P-450 in extrahepatic versus hepatic tissues. Mol. Pharmacol. 25: 185-191.

Gonder, J. C., Proctor, R. A. and Will, J. A. (1985). Genetic differences in oxygen toxicity are correlated with cytochrome P450 inducibility. Proc. Natl. Acad. Sci. 82: 6315-6319.

Gonzalez, F. J. and Lee, Y.-H. (1996). Constitutive expression of hepatic cytochrome P450 genes. FASEB J. 10: 1112-1117. 
Gooch, J. W., Elskus, A. A., Kloepper-Sams, P. J., Hahn, M. E. and Stegeman, J. J. (1989). Effects of ortho and non-ortho substituted polychlorinated biphenyl congeners on the hepatic monooxygenase system in scup (Stenotomus chrysops). Toxicol. Appl. Pharmacol. 98: 422-433.

Gooch, J. W. and Matsumura, F. (1983). Characteristics of the hepatic monooxygenase system of the goldfish (Carassius auratus) and its induction with B-naphthoflavone. Toxicol. Appl. Pharmacol. 68: 380-391.

Gradin, K., McGuire, J., Wenger, R. H., Kvietikova, I., fhitelaw, M. L., Toftgard, R., Tora, L., Gassmann, M. and Poellinger, L. (1996). Functional interference between hypoxia and dioxin signal transduction pathways: competition for recruitment of the Arnt transcription factor. Mol. Cell. Biol. 16: 5221-5231.

Gray, E. S. (1988). Sexual patterns of monooygenase functions in the liver of marine teleosts and the regulation of activity by estradiol. Biology. Wood Hole, MIT/ WHOI, 154.

Gray, E. S., Woodin, B. R. and Stegeman, J. J. (1991). Sex differences in hepatic monooxygenases in winter flounder (Pseudopleuronectes americanus) and scup (Stenotomus chrysops) and regulation of P450 forms by estradiol. J. Exper. Zool. 259: 330-342.

Gruebele, A., Zawaski, K., Kaplan, D. and Novak, R. F. (1996). Cytochrome P4502E1and cytochrome P4502B1/2B2-catalyzed carbon tetrachloride metabolism: effects on signal transduction as demonstrated by altered immediate-early (c-Fos and cJun) gene expression and nuclear AP-1 and NF- $\mathrm{KB}$ transcription factor levels. Drug Metab. Dispo. 24: 15-22.

Gruger, E. H., Jr., Hruby, T. and Karrick, N. L. (1976). Sublethal effects of structurally related tetrachloro-, pentachloro-, and hexachlorobiphenyl on juvenile coho salmon. Environ. Sci. Technol. 10: 1033-1037.

Guehmann, S., Vorbrueggen, G., Kalkbrenner, F. and Moelling, K. (1992). Reduction of a conserved Cys is essential for Myb DNA-binding. Nucleic Acids Res. 20: 22792286.

Guengerich, F. P. (1978). Destruction of heme and hemoproteins mediated by liver microsomal reduced nicotinamide adenine dinucleotide phosphate-cytochrome $\mathrm{P}$ 450 reductase. Biochemistry 17: 3633-3639.

Guengerich, F. P. and Johnson, W. W. (1997). Kinetics of ferric cytochrome P450 reduction by NADPH-cytochrome $\mathrm{P} 450$ reductase: Rapid reduction in the absence of substrate and variations among cytochrome P450 systems. Biochemistry 36: 14741-14750.

Guengerich, F. P. and Strickland, T. W. (1977). Metabolism of vinyl chloride: Destruction of the heme of highly purified liver microsomal P-450 by a metabolite. Mol. Pharmacol. 13: 993-1004. 
Guiney, P. D., Smolowitz, R. M., Peterson, R. E. and Stegeman, J. J. (1997). Correlation of 2,3,7,8-tetrachlorodibenzo-p-dioxin induction of cytochrome P4501A in vascular endothelium with toxicity in early stages of lake trout. Toxicol. Appl. Pharmacol. 143: 256-273.

Gutteridge, J. M. C. (1986). Iron promoters of the Fenton reaction and lipid peroxidations can be released from haemoglobin by peroxides. FEBS Lett. 201: 291-295.

Hahn, M. E. and Chandran, K. (1996). Accumulation of uroporphyrin and heptacarboxylporphyrin associated with cytochrome P4501A induction in fish hepatoma cells exposed to Ah receptor agonists, including 2,3,7,8tetrachlorodibenzo-p-dioxin and planar chlorobiphenyls. Arch. Biochem. Biophys.

Hahn, M. E., Lamb, T. M., Schultz, M. E., Smolowitz, R. M. and Stegeman, J. J. (1993). Cytochrome P4501A induction and inhibition by 3,3',4,4'tetrachlorobiphenyl in an Ah receptor-containing fish hepatoma cell line (PLHC-1). Aquat. Toxicol. 26: 185-208.

Hahn, M. E. and Stegeman, J. J. (1994). Regulation of cytochrome P4501A1 in teleosts: sustained induction of CYP1A1 mRNA, protein, and catalytic activity by $2,3,7,8-$ tetrachlorodibenzofuran in the marine fish Stenotomus chrysops. Toxicol. Appl. Pharmacol. 127: 187-198.

Halliwell, B. (1993). The role of oxygen radicals in human disease, with particular reference to the vascular system. Haemostasis 23 (suppl 1): 118-126.

Hankinson, O. (1995). The aryl hydrocarbon receptor complex. Ann. Rev. Pharmacol. Toxicol. 35: 307-340.

Harder, D. R., Campbell, W. B. and Roman, R. J. (1995). Role of cytochrome P-450 enzymes and metabolites of arachidonic acid in the control of vascular tone. $J$. Vasc. Res. 32: 79-92.

Hardwick, J. P., Song, B.-J., Huberman, E. and Gonzalez, F. J. (1987). Isolation, complementary DNA sequence, and regulation of rat hepatic lauric acid $\omega$ hydroxylase (cytochrome P-450 LA $\omega$ ). Identification of a new P-450 gene family. J. Biol. Chem. 262: 801-810.

Hayashi, S.-I., Hajiro-Nakanishi, K., Makino, Y., Eguchi, H., Yodoi, J. and Tanaka, H. (1997). Functional modulation of estrogen receptor by redox state with reference to thioredoxin as a mediator. Nucleic Acids Res. 25: 4035-4040.

Hazinski, T. A., Noisin, E., Hamon, I. and DeMatteo, A. (1995). Sheep lung cytochrome P4501A1 (CYP1A1): cDNA cloning and transcriptional regulation by oxygen tension. J. Clin. Invest. 96: 2083-2089.

Hecker, M., Bara, A. T., Bauersachs, J. and Busse, R. (1994). Characterization of endothelium-derived hyperpolarizing factor as a cytochrome P450-derived arachidonic acid metabolite in mammals. J. Physiol. 481: 407-414. 
Hektoen, H., Bernhoft, A., Ingebrigtsen, K., Skaare, J. U. and Goksoyr, A. (1994). Response of hepatic xenobiotic metabolizing enzymes in rainbow trout (Oncorhynchus mykiss) and cod (Gadus morhua) to 2,3,7,8-tetrachlorodibenzo-pdioxin (2,3,7,8-TCDD). Aquat. Toxicol. 28: 97-106.

Henderson, R. J., Bell, M. V. and Sargent, J. R. (1985). The conversion of polyunsaturated fatty acids to prostaglandins by tissue homogenate of the turbot, Scophtalmus maximus (L.). J. Exp. Biol. Ecol. 85: 93-99.

Herbst, E., Scheunert, I., Klein, W. and Korte, F. (1978). Uptake and conversion of 2,5,4'-trichlorobiphenyl- ${ }^{14} \mathrm{C}, 2,4,6,2^{\prime}, 4^{\prime}$-pentachlorobiphenyl- ${ }^{14} \mathrm{C}$ and chloroalkylene-9-14 $\mathrm{C}$ by goldfish after a single water treatment. Chemosphere 7 : 221-230.

Herman, C. A., Zimmerman, P. R. and Doolittle, K. D. (1979). Prostaglandin synthesis in goldfish heart, Carassius auratus. Gen. Comp. Endocrinol. 54: 478-485.

Hesse, S. and Wolff, T. (1977). In vitro interactions of di-, tetra- and hexa-chlorobiphenyl with rabbit liver monooxygenase. Biochem. Pharmacol. 26: 2043-2047.

Hinz, R. and Matsumura, F. (1977). Comparative metabolism of PCB isomers by three species of fish and the rat. Bull. Environ. Contam. Toxicol. 18: 631-639.

Hodgson, E. K. and Fridovich, I. (1975). The interaction of bovine erythrocyte superoxide dismutase with hydrogen peroxide: inactivation of the enzyme. Biochemistry 14: 5294-5299.

Hoffer, A., Chang, C. Y. and Puga, A. (1996). Dioxin induces transcription of fos and jun genes by Ah receptor-dependent and -independent pathways. Toxicol. Appl. Pharmacol. 141: 238-247.

Hoffman, D. J., Melancon, M. J., Klein, P. N., Rice, C. P., Eisemann, J. D., Hines, R. K., Spann, J. W. and Pendleton, G. W. (1996). Developmental toxicity of PCB $126\left(3,3^{\prime}, 4,4^{\prime}, 5\right.$-pentachlorobiphneyl) in nestling American kestrels (Falco sparverius). Fundam. Appl. Toxicol. 34: 188-200.

Hornig, B. and Drexler, H. (1997). Endothelial function and bradykinin in humans. Drugs 54: $42-47$.

Hsieh, H.-J., Cheng, C.-C., Wu, S.-T., Chiu, J.-J., Wung, B.-S. and Wang, D. L. (1998). Increase of reactive oxygen species (ROS) in endothelial cells by shear flow and involvement of ROS in shear-induced c-fos expression. J. Cell. Physiol. 175: $156-162$.

Hsu, S. Y. and Goetz, F. W. (1993). Cellular mechanisms for orthovanadate-, phorbol ester-, and calcium ionophore-stimulated prostagladin production in brook trout (Salvelinus fontinalis) follicles. Biol. Reprod. 48: 1202-1209. 
Huang, R.-P. and Adamson, E. D. (1993). Characterization of the DNA-binding properties of the early growth response-1 (Egr-1) transcription factor: evidence for modulation by a redox mechanism. DNA Cell Biol. 12: 265-273.

Huguet, C., Crepieux, P. and Laudet, V. (1997). Rel/NF- $\mathrm{KB}$ transcription factors and IKB inhibitors: Evolution from a unique common ancestor. Oncogene 15: 29652974.

Hungate, R. E. (1969). A roll tube methods for cultivation of strict anearobes. Methods of Microbiology. New York, Academic Press. 117-132.

Hutzinger, O., Nash, D. M., Safe, S., DeFreitas, A. S. W., Norstrom, R. J., Wildish, D. J. and Zitko, V. (1972). Polychlorinated biphenyls: metabolic behavior of pure isomers in pigeons, rats, and brook trout. Science 178: 312-313.

Huuskonen, S., Lindstrom-Seppa, P., Koponen, K. and Roy, S. (1996). Effects of nonortho-substituted polychlorinated biphenyls (congeners 77 and 126) on cytochrome P4501A and conjugation activities in rainbow trout (Oncorhynchus mykiss). Comp. Biochem. Physiol. 113C: 205-213.

Ikeda, T., Honjo, K., Hirota, Y. and Onodera, T. (1993). Isolation of the chicken NF-kB p65 subunit-encoding cDNA and characterization of its products. Gene 133: 237242.

Imai, Y. (1979). Reconsituted O-dealkylase systems containing various forms of liver microsomal cytochrome P-450. J. Biochem. 86: 1697-1707.

Ingelman-Sundberg, M. (1986). Cytochrome P-450 organization and membrane interactions. Cytochrome P-450 Structure, Mechanism, and Biochemistry. New York, Plenum Press. 119-160.

Ip, Y. T., Reach, M., Engstrom, Y., Kadalayil, L., Cai, H., Gonzales-Crespo, S., Tatei, $\mathrm{K}$. and Levine, M. (1993). Dif, a dorsal-related gene that mediates an immune response in Drosophila. Cell 75: 753-763.

Ireland, R. C., Li, S.-Y. and Dougherty, J. J. (1995). The DNA binding of purified Ah receptor heterodimer is regulated by redox conditions. Arch. Biochem. Biophys. 319: 470-480.

Ishida, C., Koga, N., Hanioka, N., Saeki, H. K. and Yoshimura, H. (1991). Metabolism in vitro of $3,4,3^{\prime}, 4^{\prime}$ - and $2,5,2^{\prime}, 5^{\prime}$-tetrachlorobiphenyl by rat liver microsomes and highly purified cytochrome P450. J. Pharmacobio.-Dyn. 14: 276-284.

James, M. O. and Little, P. J. (1981). Polyhalogenated biphenyls and phenobarbital: evaluation as inducers of drug metabolizing enzymes in the sheepshead, Archosargus probatocephalus. Chem.-Biol. Inter. 36: 229-248. 
Janz, D. M. and Metcalfe, C. D. (1991). Nonadditive interactions of mixtures of 2,3,7,8TCDD and 3,3'4,4'-tetrachlorobiphenyl on aryl hydrocabon hydroxylase induction in rainbow trout. Chemosphere 23: 467-472.

Janz, D. M. and Metcalfe, C. D. (1991). Relative induction of aryl hydrocarbon hydroxylase by $2,3,7,8-\mathrm{TCDD}$ and two coplanar PCBs in rainbow trout (Oncorhynchus mykiss). Environ. Toxicol. Chem. 10: 917-923.

Jeffery, E. H. and Mannering, G. J. (1982). Interaction of constitutive and phenobarbitalinduced cytochrome $\mathrm{P} 450$ isoenzymes during sequential oxidation of benzphetamine. Mol. Pharmacol. 23: 748.

Jensen, S. (1966). Report of a new chemical hazard. New Scientist 32: 612.

Jenzer, H., Kohler, H. and Broger, C. (1987). The role of hydroxyl radicals in irreversible inactivation of lactoperoxidase by excess $\mathrm{H}_{2} \mathrm{O}_{2}$. Arch. Biochem. Biophys. 258: 381-390.

Jewell, C. S. E., Cummings, L. E., Ronis, M. J. J. and Winston, G. W. (1989). The hepatic microsomal mixed-function oxygenase (MFO) system of Alligator mississippiensis: Induction by 3-methycholanthrene (3-MC). Xenobiotica 19: 1181-1200.

Jiang, W. G., Bryce, R. P., Horrobin, D. F. and Mansel, R. E. (1998). Regulation of tight junction permeability and occludin expression by polyunsaturated fatty acids. Biochem. Biophys. Res. Commun. 244: 414-420.

Juchau, M. R., Bond, J. A. and Benditt, E. P. (1976). Aryl 4-monooxygenase and cytochrome P-450 in the aorta: Possible role in atherosclerosis. Proc. Natl. Acad. Sci. USA 73: 3723-3725.

Kafafi, S. A., Afeefy, H. Y., Ali, A. H., Said, H. K., Abd-Elazem, I. S. and Kafafi, A. G. (1993). Affinities for the aryl hydrocarbon receptor, potencies as aryl hydrocarbon hydroxylase inducers and relative toxicities of polychlorinated biphenyls. A congener specific approach. Carcinogenesis 14: 2063-2071.

Kao, K. R. and Hopwood, N. D. (1991). Expression of a mRNA related to c-rel and dorsal in early Xenopus laevis embryos. Proc. Natl. Acad. Sci. 88: 2697-2701.

Kaplan, L. A. E., Schultz, M. E., Schultz, R. J. and Crivello, J. F. (1991). Nitrosodiethylamine metabolism in the viviparous fish Poeciliopsis : Evidence for the existence of liver P450pj activity and expression. Carcinogenesis 12: 647-652.

Kappus, H. (1987). Oxidative stress in chemical toxicity. Arch. Toxicol. 60: 144-149.

Karuzina, I. I. and Archakov, A. I. (1994). Hydrogen peroxide-mediated inactivation of microsomal cytochrome P450 during monooxygenase reactions. Free Rad. Biol. Med. 17: 557-567. 
Kato, N., Kawai, K. and Yoshida, A. (1981). Effect of dietary level of ascorbic acid on the growth, hepatic lipid peroxidation and serum lipids in guinea pigs fed polychlorinated biphenyls. J. Nutr. 111: 1727-1733.

Kennedy, S. W., Lorenzen, A., James, C. A. and Collins, B. T. (1993). EthoxyresorufinO-deethylase and porphyrin analysis in chicken embryo hepatocyte cultures with a fluorescence multi-well plate reader. Anal. Biochem. 211: 102-112.

Kennedy, S. W., Lorenzen, A., Jones, S. P., Hahn, M. E. and Stegeman, J. J. (1996). Cytochrome P4501A induction in avian hepatocyte cultures: A promising approach for predicting the sensitivity of avian species to in ovo toxic effects of halogenated aromatic hydrocarbons. Toxicol. Appl. Pharmacol. 141: 214-230.

Kimura, S., Gonzalez, F. J. and Nebert, D. W. (1986). Tissue-specific expression of the mouse dioxin-inducible $\mathrm{P}_{1} 450$ and $\mathrm{P}_{3} 450$ genes: differential transcriptional activation and mRNA stability in liver and extrahepatic tissues. Mol. Cell. Biol. 6: 1471-1477.

Klasson Wehler, E., Bergman, A., Brandt, I., Darnerud, P. O. and Wachtmeister, C. A. (1989). 3,3',4,4'-Tetrachlorobiphenyl excretion and tissue retention of hydroxylated metabolites in the mouse. Drug Metab. Dispos. 17: 441-448.

Klasson Wehler, E., Brunstrom, B., Rannug, U. and Bergman, A. (1990). 3,3',4,4'Tetrachlorobiphenyl: metabolism by the chick embryo in ovo and toxicity of hydroxylated metabolites. Chem.-Biol. Inter. 73: 121-132.

Kloepper-Sams, P. J., Park, S. S., Gelboin, H. V. and Stegeman, J. J. (1987). Specificity and cross-reactivity of monoclonal and polyclonal antibodies against cytochrome P450E of the marine fish scup. Arch. Biochem. Biophys. 253: 268278.

Kloepper-Sams, P. J. and Stegeman, J. J. (1992). The effect of temperature acclimation on the expression of cytochrome P4501A mRNA and protein in the fish Fundulus heteroclitus. Arch. Biochem. Biophys. 299: 38-46.

Kloepper-Sams, P. J. and Stegeman, J. J. (1994). Turnover of hepatic microsomal cytochrome P4501A protein and heme in B-naphthoflavone-induced Fundulus heteroclitus. Molec. Mar. Biol. Biotechnol. 3: 171-183.

Klotz, A. V., Stegeman, J. J. and Walsh, C. (1983). An aryl hydrocarbon hydroxylating hepatic cytochrome P-450 from the marine fish Stenotomus chrysops. Arch. Biochem. Biophys. 226: 578-592.

Klotz, A. V., Stegeman, J. J., Woodin, B. R., Snowberger, E. A., Thomas, P. E. and Walsh, C. (1986). Cytochrome P-450 isozymes from the marine teleost Stenotomus chrysops: their roles in steroid hydroxylation and the influence of cytochrome $b_{5}$. Arch. Biochem. Biophys. 249: 326-338. 
Knoepfel, L., Steinkuhler, C., Carri, M.-T. and Rotilio, G. (1994). Role of zinccoordination and of the the glutathione redox couple in redox susceptibility of human transcription factor SP1. Biochem. Biophys. Res. Commun. 201: 871-877.

Koga, N., Beppu, M. and Yoshimura, H. (1990). Metabolism in vivo of 3,4,5,3',4'pentachlorobiphenyl and toxicological assesment of the metabolite in rats. $J$. Pharmacobio.-Dyn. 13: 497.

Krogh, A. (1959). The Anatomy and Physiology of the Capillaries. New York, Hafner.

Kurzban, G. B. and Strobel, H. W. (1986). Preparation and characterization of FADdependent NADPH-cytochrome P450 reductase. J. Biol. Chem. 261: 7824-7830.

Kuthan, H., Tsuji, H., Graf, H. and Ullrich, V. (1978). Generation of superoxide anion as a source of hydrogen peroxide in a reconstituted monooxygenase system. FEBS Lett. 91: 343-345.

Kuthan, H. and Ullrich, V. (1982). Oxidase and oxygenase function of the microsomal cytochrome P-450 monooxygenase system. Eur. J. Biochem. 126: 583-588.

Kwak, E. L., Larochelle, D. A., Beaumont, C., Torti, S. V. and Torti, F. M. (1995). Role for NF- $\mathrm{KB}$ in the regulation of ferritin $\mathrm{H}$ by tumor necrosis factor-alpha. $J$. Biol. Chem. 270: 15285-15293.

Kyle, M. E., Nakae, D., Sakaida, I., Serroni, A. and Farber, J. L. (1989). Protein thiol depletion and the killing of cultured hepatocytes by hydrogen peroxide. Biochem. Pharmacol. 38: 3797-3805.

Laethem, R. M., Balazy, M., Falck, J. R., Laethem, C. L. and Koop, D. R. (1993). Formation of 19(S)-, 19(R), and 18(R)-hydroxyeicosatetraenoic acids by alcoholinducible cytochrome P450 2E1. J. Biol. Chem. 268: 12912-12918.

Lake, J. L., McKinney, R., Lake, C. A., Osterman, F. A. and Heltshe, J. (1995). Comparison of patterns of polychlorinated biphenyl congeners in water, sediment and indigenous organisms from New Bedford Harbor, Massachusetts. Arch. Environ. Contam. Toxicol. 29: 207-230.

Lambrecht, R. W., Sinclair, P. R., Bement, W. J. and Sinclair, J. F. (1988). Uroporphyrin accumulation in cultured chick embryo hepatocytes: comparison of 2,3,7,8-tetrachlorodibenzo-p-dioxin and 3,4,3',4'-tetrachlorobiphenyl. Toxicol. Appl. Pharmacol. 96: 507-516.

Lane, D. P. (1992). P53, gaurdian of the genome. Nature 358: 15-16.

Leece, B., Denomme, M. A., Towner, R. and Li, S. M. A. (1985). Polychlorinated biphenyls: correlation between in vivo and in vitro quantitative structure-activity relationships. J. Toxicol. Environ. Health 16: 379-388. 
Leu, J. H., Lee, M. S., Chen, K. T:, Change, G. D., Chou, C. K. and Huang, C. J. (1996). Genomic structure of carp mitogen-activated protein kinase kinase 1 gene. Biochim. Biophys. Acta 1306: 133-136.

Lewis, D. F. V., Ioannides, C. and Parke, D. V. (1994). Molecular modelling of cytochrome CYP1A1 - a putative access channel explains differences in induction potency between the isomers benzo[a]pyrene and benzo[e]pyrene, and 2- and 4acetylaminofluorene. Toxicol. Lett. 71: 235-243.

Lewis, D. F. W. and Lake, B. G. (1996). Molecular modelling of CYP1A subfamily members based on an alignment with CYP102: rationalization of CYP1A substrate specificity in terms of active site amino acid residues. Xenobiotica 26: 723-753.

Li, X., Leung, L. K., Spear, B. T. and Glauert, H. P. (1996). Activation of hepatic NFKB by phenobarbital in rats. Biochem. Biophys. Res. Commun. 229: 982-989.

Li, Y., Leung, L. K., Glauert, H. P. and Spear, B. T. (1996). Treatment of rats with the peroxisome proliferator ciprofibrate results in increased liver NF- $\mathrm{kB}$ activity. Carcinogenesis 17: 2305-2309.

Li, Z. S. and Furness, J. B. (1991). Constitutive and inducible nitric oxide synthase incorporate molecular oxygen into both nitric oxide and citrulline. J. Biol. Chem. 266: 23790-23795.

Lindstrom-Seppa, P., Korytko, P. J., Hahn, M. E. and Stegeman, J. J. (1994). Uptake of waterborne 3,3',4,4'-tetrachlorobiphenyl and organ and cell-specific induction of cytochrome P4501A in adult and larval fathead minnow Pimephales promelas. Aquat. Toxicol. 28: 147-167.

Loosemore, M., Light, D. R. and Walsh, C. (1980). Studies on the autoinactivation behavior of pure, reconstituted phenobarbital-induced cytochrome P-450 isozyme from rat liver. J. Biol. Chem. 255: 9017-9020.

Lorentzen, R. J. and Ts'o, P. O. P. (1977). Benzo[a]pyrenedione/benzo[a]pyrenediol oxidation-reduction couples and the generation of reactive reduced molecular oxygen. Biochem. 16: 1467-1473.

Lorenzen, A., Kennedy, S. W., Bastein, L. J. and Hahn, M. E. (1997). Halogenated aromatic hydrocarbon-mediated porphyrin accumulation and induction of cytochrome P4501A in chicken embryo hepatocytes. Biochem. Pharmacol. 53: 373-384.

Lorenzen, A., Shutt, J. L. and Kennedy, S. W. (1997). Sensitivity of common tern (Sterna hirundo) embryo hepatocyte cultures to CYP1A induction and porphyrin accumulation by halogenated aromatic hydrocarbons and common tern egg extracts. Arch. Environ. Contam. Toxicol. 32: 126-134.

Lusska, A., Shen, E. and Whitlock, J. P. (1993). Protein-DNA interactions at a dioxinresponsive enhancer. Analysis of six bona-fide DNA binding sites for liganded Ah receptor. J. Biol. Chem. 268: 6575-6580. 
Ma, Q. and Whitlock, J. P. (1996). The aromatic hydrocarbon receptor modulates the Hepa 1c1c7 cell cycle and differentiated state independently of dioxin. Mol. Cell Biol. 16: 2144-2150.

Manchester, D. K., Parker, N. B. and Bowman, C. M. (1984). Maternal smoking increases xenobiotic metabolism in placenta but not in umbilical vein endothelium. Pediatric Res. 18: 1071-1075.

Manjunath, G. S. and Dufresne, M. J. (1988). Evidence that 2,3,7,8-tetrachlorodibenzo-pdioxin induces NADPH cytochrome $c(\mathrm{P} 450)$ reductase in rat hepatoma cells in culture. Cell. Biol. Internat. Reports 12: 41-51.

Mannaerts and Veldhoven, V. (1993). Metabolic pathways in mammalian peroxisomes. Biochimie 75: 147-158.

Marty, J., Riviere, J. L., Guinaudy, M. J., Kremers, P. and Lesca, P. (1992). Induction and characterization of cytochromes P450IA and -IIB in the newt, Pleurodeles waltl. Ecotoxicol. Environ. Safety 24: 144-154.

Matheson, N. R. and Travis, J. (1985). Differential effects of oxidizing agents on human plasma alpha1-proteinase inhibitor and human neutrophil myeloperoxidase. Biochemistry 24: 1941-1945.

McConkey, D. J., Hartzill, P., Duddy, S. K., Hakansson, H. and Orrenius, S. (1988). 2,3,7,8-Tetrachlorodibenzo-p-dioxin kills immature thymocytes by $\mathrm{Ca}^{2+}$-mediated endonuclease activation. Science 242: 256-259.

McCord, J. M. and Fridovich, I. (1968). The reduction of cytochrome $c$ by milk xanthine oxidase. J. Biol. Chem. 243: 5753-5760.

McCord, J. M. and Fridovich, I. (1969). Superoxide dismutase: an enzymic function for erythrocuprein. J.Biol. Chem. 244: 6049-6055.

McFarland, V. A. and Clark, J. U. (1989). Environmental occurrence, abundance, and potential toxicity of polychlorinated biphenyl congeners: Considerations for a congener-specific analysis. Environ. Health Perspect. 81: 225-239.

McMurry, T. J. and Groves, J. T. (1986). Metalloporphyrin models for cytochrome P450. Cytochrome P450: Structure, Mechanism and Biochemistry. New York, Plenum Press. 1-28.

Melancon, M. J. and Lech, J. J. (1976). Isolation and identification of a polar metabolite of tetrachlorobiphenyl from bile of rainbow trout exposed to ${ }^{14} \mathrm{C}$-tetrachlorobiphenyl. Bull. Environ. Contam. Toxicol. 15: 181-188.

Melancon, M. J. and Lech, J. J. (1983). Dose-effect relationship for induction of hepatic monooxygenase activity in rainbow trout and carp by Aroclor 1254. Aquat. Toxicol. 4: 51-61. 
Metcalf, R. L., Sanborn, J. R., Lu, P.-Y. and Nye, D. (1975). Laboratory model ecosystem studies of the degradation and fate of radiolabeled tri-, tetra-, and pentachlorobiphenyl compared with DDE. Arch. Environ. Contam. Toxicol. 3: 151-165.

Meyer, B. K., Pray-Grant, M. G., Vanden Heuvel, J. P. and Perdew, G. H. (1998). Hepatitis $B$ virus $X$-associated protein 2 is a subunit of the unliganded aryl hydrocarbon receptor core complex and exhibits transcriptional enhancer activity. Mol. Cell: Biol. 18: 978-988.

Meyer, M., Pahl, H. L. and Baeuerle, P. A. (1994). Regulation of the transcription factors NF-kB and AP-1 by redox changes. Chem. Biol. Interact. 91: 91-100.

Miller, F. N. and Sims, D. E. (1986). Contractile elements in the regulation of macromolecular permeability. Federation Proc. 45: 84-88.

Miller, M. R., Hinton, D. E. and Stegeman, J. J. (1989). Cytochrome P-450E induction and localization in gill pillar (endothelial) cells of scup and rainbow trout. Aquat. Toxicol. 14: 307-322.

Miranda, C. L., Wang, J.-L., Chang, H.-S. and Buhler, D. R. (1990). Multiple effects of $3,4,5,3^{\prime}, 4^{\prime}, 5^{\prime}$-hexachlorobiphenyl administration on hepatic cytochrome P450 isozymes and associated mixed-function oxidase activities in rainbow trout. Biochem. Pharmacol. 40: 387-390.

Misra, H. P. and Fridovich, I. (1972). The role of superoxide anion in the autoxidation of epinephrine and a simple assay for superoxide dismutase. J. Biol. Chem. 247: 3170-3175.

Miwa, G. T. and Lu, A. Y. H. (1986). The topology of the mammalian cytochrome P450 active site. Cytochrome P450: Structure, Mechanism and Biochemistry. New York, Plenum Press. 77-88.

Miyamoto, S. and Verma, I. M. (1995). Rel/NF-kappa B/I kappa B story. Adv. Cancer Res. 66: 255-292.

Monosson, E. and Stegeman, J. J. (1991). Cytochrome P450E (P450IA) induction and inhibition in winter flounder by 3,3',4,4'-tetrachlorobiphenyl: Comparison of response in fish from Georges Bank and Narragansett Bay. Environ. Toxicol. Chem. 10: 765-774.

Morehouse, L. A., Thomas, C. E. and Aust, S. D. (1984). Superoxide generation by NADPH-cytochrome P-450 reductase: the effect of iron chelators and the role of superoxide in microsomal lipid peroxidation. Arch. Biochem. Biophys. 232: 366377.

Morrison, H. G., Oleksiak, M. F., Cornell, N. W., Sogin, M. L. and Stegeman, J. J. (1995). Identification of cytochrome P450 1A (CYP1A) genes from two teleost fish, toadfish (Opsanus tau) and scup (Stenotomus chrysops), and phylogenetic analysis of CYP1A genes. Biochem. J. 308: 97-104. 
Morrison, H. G., Weil, E. J., Karchner, S. I., Sogin, M. L. and Stegeman, J. J. (1998). Molecular cloning of CYP1A from Fundulus heteroclitus, and phylogenetic analysis of CYP1A genes: Update with new sequences. Comp. Biochem. Physiol. in Press:

Morse, W. M. (1978). Biological and fisheries data on scup, Stenotomus chrysops (Linnaeus). Technical Series Report, Sandy Hook Laboratory, Northeast Fisheries Center, No. 12, Highlands, N.J., National Marine Fisheries Service/National Oceanic and Atmospheric Administration,

Muller, C. W., Rey, F. A. and Harrison, S. C. (1996). Comparison of two different DNA-binding modes of the NF-kappa B p50 homodimer. Nat. Struct. Biol. 3: 224227.

Murk, A., Morse, D., Boon, J. and Brouwer, A. (1994). In vitro metabolism of 3,3',4,4'tetrachlorobiphenyl in relation to ethoxyresorufin-O-deethylase activity in liver microsomes of some wildlife species and rat. Eur. J. Pharmacol. 270: 253-261.

Mustafa, T. and Strivastava, K. C. (1989). Prostaglandins (eicosanoids) and their role in ecothermic organisms. Adv. Comp. Environ. Physiol. 5: 157-207.

Natarajan, V. (1995). Oxidants and signal transduction in vascular endothelium. J. Lab. Clin. Med. 125: 26-37.

Nebert, D. W. (1994). Drug metabolism and signal transduction: possible role of Ah receptor and arachidonic acid cascade in protection from ethanol toxicity. Exs. 71: 231-40.

Needleman, P., Turk, J., Jakschik, B. A., Morrison, A. R. and Lefkowith, J. B. (1986). Arachidonic acid metabolism. Annu. Rev. Biochem. 55: 69-102.

Nelson, D. R. (1997). A table of species distribution for the various CYP families. http://drnelson.utmem.edu,

Nelson, D. R. and Strobel, H. W. (1988). On the membrane topology of vertebrate cytochrome P-450 proteins. J. Biol. Chem. 263: 6038-6050.

Nerurkar, P. V., Park, S. S., Thomas, P. E., Nims, R. W. and Lubet, R. A. (1993). Methoxyresorufin and benzyloxyresorufin: Substrates preferentially metabolized by cytochromes P4501A2 and 2B, respectively, in the rat and mouse. Biochem. Pharmacol. 46: 933-943.

Newsted, J. L., Giesy, J. P., Ankley, G. T., Tillitt, D. E., Crawford, R. A., Gooch, J. W., Jones, P. D. and Denison, M. S. (1995). Development of toxic equivalency factors for PCB congeners and the assessment of TCDD and PCB mixtures in rainbow trout. Environ. Toxicol. Chem. 15: 861-871.

Niimi, A. J. and Oliver, B. G. (1983). Biological half-lives of polychlorinated biphenyl (PCB) congeners in whole fish and muscle of rainbow trout (Salmo gairdneri). Can. J. Fish. Aquat. Sci. 40: 1388-1394. 
Oakley, G. G., Devanaboyina, U.-S., Robertson, L. W. and Gupta, R. C. (1996). Oxidative DNA damage induced by activation of polychlorinated biphenyls (PCBs): Implications for PCB-induced oxidative stress in breast cancer. Chem. Res. Toxicol. 9: 1285-1292.

Ohnishi, T., Posner, J. B. and Shapiro, W. R. (1992). Vasogenic brain edema induced by arachidonic acid: Role of extracellular arachidonic acid in blood-brain barrier dysfunction. Neurosurgery 30: 545-551.

Okuda, Y., Kawashima, K., Sawada, T., Tsurumaru, K., Asano, M., Suzuki, S., Soma, M., Nakajima, T. and Yamashita, K. (1997). Eicosapentaenoic acid enhances nitric oxide production by cultured human endothelial cells. Biochem. Biophys. Res. Commun. 232: 487-491.

Oleksiak, M. F., Parker, C., Stegeman, J. J. and Zeldin, D. (1998b). Baculovirus expression and characterization of novel cytochromes P450 2N1 and 2N2 highly expressed in killifish heart and brain. Arch. Biochem. Biophys. Submitted:

Oleksiak, M. F., Zeldin, D. and Stegeman, J. J. (1998a). In vitro expression of a novel cytochrome P450, CYP2P3: an early vertebrate arachidonic acid catalyst. Proc. Natl. Acad. Sci., USA Submitted:

Oliw, E. H., Guengerich, F. P. and Oates, I. A. (1982). Oxygenation of arachidonic acid by hepatic monooxygenases. Isolation and metabolism of four epoxide intermediates. J. Biol. Chem. 257: 3771-3781.

Olnes, M. J., Verma, M. and Kurl, R. N. (1994). 2,3'7,8'-Tetrachlorodibenzo-p-dioxinmediated gene expression in the immature rat thymus. Exp. Clin. Immunogenet. 11: 102-109.

Omura, T. and Sato, R. (1964). The carbon monoxide-binding pigment of liver microsomes. J. Biol. Chem. 239: 2370-2378.

Ortiz de Montellano, P. R. (1986). Oxygen activation and transfer. Cytochrome P-450. Structure, Mechanism, and Biochemistry. 217-271.

Ortiz de Montellano, P. R., David, S. K., Ator, M. A. and Tew, D. (1988). Mechanismbased inactivation of horseradish peroxidase by sodium azide. Formation of mesoazidoprotoporphyrin IX. Biochemistry 27: 5470-5476.

Otto, D. M. E. and Moon, T. W. (1995). 3,3',4,4'-Tetrachlorobiphenyl effects on antioxidant enzymes and glutathione status in different tissues of rainbow trout. Pharmacol. Toxicol. 77: 281-287.

Overby, L. H., Nishio, S., Weir, A., Carver, G. T., Plopper, C. G. and Philpot, R. M. (1992). Distribution of cytochrome P450 1 A1 and NADPH-cytochrome P450 reductase in lungs of rabbits treated with 2,3,7,8-tetrachlorodibenzo- $p$-dioxin: Ultrastructural immunolocalization and in situ hybridization. Mol. Pharmacol. 41: 1039-1046. 
Pajor, A. M., Stegeman, J. J., Thomas, P. and Woodin, B. R. (1990). Feminization of the hepatic microsomal cytochrome P-450 system in brook trout by estradiol, testosterone, and pituitary factors. J. Exper. Zool. 253: 51-60.

Palace, V. P., Klaverkamp, J. F., Lockhart, W. L., Metner, D. A., Muir, D. C. G. and Brown, S. B. (1996). Mixed-function oxidase enzyme activity and oxidative stress in lake trout (Salvelinus namaycush) exposed to 3,3',4,4',5-pentachlorobiphneyl (PCB-126). Environ. Toxicol. Chem. 15: 955-960.

Pang, X. P., Ross, N. S., Park, M., Juillard, G. J., Stanley, T. M. and Hershman, J. M. (1992). Tumor necrosis factor-alpha activates nuclear factor kappa B and induces manganous superoxide dismutase and phosphodiesterase mRNA in human papillary thyroid carcinoma cells. J. Biol. Chem. 267: 12826-12830.

Park, J.-Y., Shigenaga, M. K. and Ames, B. N. (1996). Induction of cytochrome P4501A1 by 2,3,7,8-tetrachlorodibenzo-p-dioxin or indole(3,2-b)carbazole is associated with oxidative DNA damage. Proc. Natl. Acad. Sci., USA. 93: 23222327.

Park, S. S., Miller, H., Klotz, A. V., Kloepper-Sams, P. J., Stegeman, J. J. and Gelboin, H. V. (1986). Monoclonal antibodies to liver microsomal cytochrome P450 E of the marine fish Stenotomus chrysops (scup): Cross-reactivity with 3methylcholanthrene induced rat cytochrome P-450. Arch. Biochem. Biophys. 249: 339-350.

Parke, D. V., Ioannides, C. and Lewis, D. (1991). The role of the cytochromes P450 in the detoxication and activation of drugs and other chemicals. Can. J. Physiol. Pharm. 69: 537-549.

Parkinson, A. (1996). Biotransformation of xenobiotics. Casarett and Doull's Toxicology. The Basic Science of Poisons. McGraw-Hill Inc. 5th, ed. 113-186.

Parkinson, A., Cockerline, R. and Safe, S. (1980). Polychlorinated biphenyl isomers and congeners as inducers of both 3-methylcholanthrene- and phenobarbitone-type microsomal enzyme activity. Chem.-Biol. Inter. 29: 277-289.

Parkinson, A., Robertson, L., Safe, L. and Safe, S. (1980). Polychlorinated biphenyls as inducers of hepatic microsomal enzymes: structure-activity rules. Chem.-Biol. Interact. 30: 271-285.

Parkinson, A., Safe, S. H., Robertson, L. W., Thomas, P. E., Ryan, D. E., Reik, L. M. and Levin, W. (1983). Immunochemical quantitation of cytochrome P-450 isozymes and epoxide hydrolase in liver microsomes from polychlorinated or polybrominated biphenyl-treated rats. J. Biol. Chem. 258: 5967-5976.

Parkinson, A., Thomas, P. E., Ryan, D. E., Gorsky, L. D., Shively, J. E., Sayer, J. M., Jerina, D. M. and Levin, W. (1986). Mechanism of inactivation of rat liver cytochrome P-450c by 2-bromo-4'-nitroacetophenone. J. Biol. Chem. 261: 1148711495. 
Partridge, R. S., Monroe, S. M., Parks, J. K., Johnson, K., Parker Jr., W. D., Eaton, G. R. and Eaton, S. S. (1994). Spin trapping of azidyl and hydroxyl radicals in azide-inhibited rat brain submitochondrial particles. Arch. Biochem. Biophys. 310: 210-217.

Pearson, J. D. (1991). Endothelial cell biology. Radiology 179: 9-14.

Peterson, R. E., Theobald, H. M. and Kimmel, G. L. (1993). Developmental and reproductive toxicity of dioxins and related compounds: cross-species comparisons. Crit. Rev. Toxicol. 23: 283-335.

Pfisterer, P., Annweiler, A., Ullmer, C., Corcoran, L. M. and Wirth, T. (1994). Differential transactivation potential of Octl and Oct 2 is determined by additional Bcell-specific activities. EMBO J. 13: 1655-1663.

Piette, J., Piret, B., Bonizzi, G., Schoonbroodt, S., Merville, M.-P., Legrand-Poels, S. and Bours, V. (1997). Multiple redox regulation in NF- $\mathrm{KB}$ transcription factor activation. Biol. Chem. 378: 1237-45.

Pinkus, R., Weiner, L. M. and Daniel, V. (1996). Role of oxidants and antioxidants in the induction of AP-1, NF-kappaB, and glutathione S-transferase gene expression. $J$. Biol. Chem. 271: 13422-13429.

Pinto, A., Abraham, N. G. and Mullane, K. M. (1987). Arachidonic acid-induced endothelium-dependent relaxations of canine coronary arteries: contribution of a cytochrome P450 dependent pathway. J. Pharmacol. Exp. Ther. 240: 856-863.

Pinto, A. N., Abraham, G. and Mullane, K. M. (1986). Cytochrome P-450-dependent monooxygenase activity and endothelial-dependent relaxations induced by arachidonic acid. J. Pharmacol. Exp. Ther. 236: 445-451.

Pognonec, P., Kato, H. and Roeder, R. G. (1992). The Helix-Loop-Helix/Leucine repeat transcription factor USF can be functionally regulated in a redox-dependent manner. J. Biol. Chem. 267: 24563-24567.

Poland, A. and Glover, E. (1977). Chlorinated biphenyl induction of aryl hydrocarbon hydroxylase activity: a study of the structure-activity relationship. Mol. Pharmacol 13: 924-938.

Poland, A. and Glover, E. (1980). 2,3,7,8-tetrachlorodibenzo-p-dioxin: segregation of toxicity with the Ah locus. Mol. Pharmacol. 17: 86-94.

Poland, A., Teitelbaum, P. and Glover, E. (1989). [ $\left.{ }^{125} \mathrm{I}\right] 2$-Iodo-3,7,8-trichlorodibenzo-pdioxin-binding species in mouse liver induced by agonists for the Ah receptor: characterization and identification. Mol. Pharmacol. 36: 113-120.

Poland, A., Teitelbaum, P., Glover, E. and Kende, A. (1989). Stimulation of in vivo hepatic uptake and in vitro hepatic binding of [ $\left.{ }^{125} \mathrm{I}\right] 2$-iodo-3,7,8-trichlorodibenzop-dioxin by the administration of agonists for the Ah receptor. Mol. Pharmacol. 36: 121-127. 
Porter, T. D. and Coon, M. J. (1991). Cytochrome P450: Multiplicity of isoforms, substrates and catalytic and regulatory mechanisms. J. Biol. Chem. 266: 13469472.

Proctor, K. G., Capdevila, J. H., Flack, J. R., Fitzpatrick, F. A., Mullane, K. M. and McGiff, J. C. (1989). Cardiovascular and renal actions of cytochrome P-450 metabolites of arachidonic acid. Blood Vessels 26: 53-64.

Pruell, R. J., Norwood, C. B., Bowen, R. D., Boothman, W. S., Rogerson, P. F., Hackett, M. and Butterworth, B. C. (1990). Geochemical study of sediment contamination in New Bedford Harbor, Massachusetts. Mar. Environ. Res. 29: 77102.

Puntarulo, S. and Cederbaum, A. I. (1998). Production of reactive oxygen species by microsomes enriched in specific human cytochrome P450 enzymes. Free Rad. Biol. Med. 24: 1324-1330.

Rainwater, R., Parks, D., Anerson, M. E., Tegetmeyer, P. and Mann, K. (1995). Role of cysteine residues in regulation of p53 function. Mol. Cell. Biol. 15: 3892-3903.

Rashba-Step, J. and Cederbaum, A. I. (1994). Generation of reactive oxygen intermediates by human liver microsomes in the presence of NADPH and NADH. Mol. Pharmacol. 45: 150-157.

Reinke, L. A., Bailey, S. M., Rau, J. M. and McCay, P. B. (1994). Oxygen radical formation in well-washed rat liver microsomes: spin trapping studies. Free Radic. Res. 20: 51-60.

Riddick, D. S., Park, S. S., Gelboin, H. V. and Marks, G. S. (1990). Effects of 4-alkyl analogues of 3,5-diethoxycarbonyl-1,4-dihydro-2,4,6-trimethylpyridine on hepatic cytochrome $\mathrm{P} 450$ heme, apoproteins and catalytic activities following in vivo administration in rats. Mol. Pharmacol. 37: 130-136.

Rifkind, A. B., Gannon, M. and Gross, S. S. (1990). Arachidonic acid metabolism by dioxin-induced cytochrome P-450: a new hypothesis on the role of P-450 in dioxin toxicity. Biochem. Biophys. Res. Commun. 172: 1180-1188.

Rifkind, A. B., Kanetoshi, A., Orlinick, J., Capdevila, J. H. and Lee, C. (1994). Purification and biochemical characterization of two major cytochrome P-450 isoforms induced by 2,3,7,8 tetrachlorodibenzo-p-dioxin in chick embryo liver. $J$. Biol. Chem. 269: 3387-3396.

Rifkind, A. B., Lee, C., Chang, T. K. H. and Waxman, D. J. (1995). Arachidonic acid metabolism by human cytochrome $\mathrm{P} 450 \mathrm{~s} 2 \mathrm{C} 8,2 \mathrm{C} 9,2 \mathrm{E} 1$, and $1 \mathrm{~A} 2$ : regioselective oxygenation and evidence for a role for CYP2C enzymes in arachidonic acid expoxygenation in human liver microsomes. Arch. Biochem. Biophys. 320: 380389. 
Risebrough, R. W., Rieche, P., Peakall, D. B., Herman, S. G. and Kirven, M. N. (1968). Polychlorinated biphenyls in the global ecosystem. Nature 220: 10981102.

Robinson, J. P., Carter, W. O. and Narayanan, P. K. (1994). Oxidative product formation analysis by flow cytometry. Methods Cell. Biol. 41: 437-447.

Rodman, L. E., Shedlofsky, S. I., Swim, A. T. and Robertson, L. W. (1989). Effects of polychlorinated biphenyls on cytochrome P450 induction in the chick embryo hepatocyte culture. Arch. Biochem. Biophys. 275: 252-262.

Rowley, A. F., Knight, J., Lloyd-Evans, P., Holland, J. W. and Vickers, P. J. (1995). Eicosanoids and their role in immune modulation in fish-a brief overview. Fish Shellfish Immunol. 5: 549-567.

Rozemeijer, M. J. C., Boon, J. P., Duiven, P., van der Meer, J., van der Saint, J. S. J., Swennen, C., Murk, A. J., Berg, J. H. J. and Brouwer, A. (1991). The effect of 3,3',4,4'-tetrachlorobiphenyl and Clophen A50 on the hepatic monooxygenase system of eider ducklings (Somateria mollisima) with indication for structure related biotransformation of CB-congeners. Mar. Environ. Res. 207-211.

Rushmore, T. H., Morton, M. R. and Pickett, C. B. (1991). The antioxidant response element: Activation by oxidative stress and identification of the DNA consensus sequence required for functional activity. J. Biol. Chem. 266: 11632-11639.

Safe, S. (1990). Polychlorinated biphenyls (PCBs), dibenzo-p-dioxins (PCDDs), dibenzofurans (PCDFs), and related compounds: environmental and mechanistic considerations which support the development of toxic equivalency factors (TEFs). CRC Crit. Rev. Toxicol. 21: 51-88.

Safe, S. (1992). Toxicology, structure-function relationship, and human and environmental health impacts of polychlorinated biphenyls: progress and problems. Environ. Health Perspect. 100: 259-268.

Safe, S., Bandiera, S., Sawyer, T., Robertson, L., Sae, L., Parkinson, A., Thomas, P. E., Ryan, D. E., Reik, L. M., Levin, W., Denomme, M. A. and Fujita, T. (1985). PCBs: Structure function relationships and mechanism of action. Environ. Health Perspect. 60: 47-56.

Safe, S. H. (1994). Polychlorinated biphenyls (PCBs): environmental impact, biochemical and toxic responses, and implications for risk assessment. Crit. Rev. Toxicol. 24: 87-149.

Sakai, H., Park, S. S. and Kikkawa, Y. (1992). Differential oxidase activity of hepatic and pulmonary microsomal cytochrome P-450 isozymes after treatment with cytochrome P-450 inducers. Biochem. Biophys. Res. Commun. 187: 1262-1269.

Sakai, N., Tanaka, M., Adachi, S., Miller, W. L. and Nagahama, Y. (1992). Rainbow trout cytochrome-P-450c17 (17-alpha-Hydroxylase/ 17,20-Lyase) - cDNA cloning, enzymatic properties and temporal pattern of ovarian P-450c17 messenger RNA expression during oogenesis. FEBS Lett. 301: 60-64. 
Sanborn, J. R., Childers, W. F. and Metcalf, R. L. (1975). Uptake of three polychlorinated biphenyls, DDT, and DDE by the green sunfish, Lepomis cyanellus Raf. Bull. Environ. Contam. Toxicol. 13: 209.

Sawyer, T. and Safe, S. (1982). PCB isomers and congeners: induction of aryl hydrocarbon hydroxylase and ethoxyresorufin $\mathrm{O}$-deethylase enzyme activities in rat hepatoma cells. Toxicol. Lett. 13: 87-94.

Schilling, W. P. and Elliot, S. J. (1992). $\mathrm{Ca}^{2+}$ signaling mechanisms of vascular endothelial cells and their role in oxidant-induced endothelial cell dysfunction. Am. J. Physiol. 262: H1617-H1630.

Schlezinger, J. J., Parker, C., Zeldin, D. L. and Stegeman, J. J. (1998). Arachidonic acid metabolism in the marine fish Stenotomus chrysops (scup) and the effects of CYP1A induction. Arch. Biochem. Biophys. 353: 265-275.

Schmidt, K. N., Amstad, P., Cerutti, P. and Baeuerle, P. A. (1995). The roles of hydrogen peroxide and superoxide as messengers in the activation of trascription factor NF-kappaB. Chem. Biol. 2: 13-22.

Schnellman, R. G., Putnam, C. W. and Sipes, I. G. (1983). Metabolism of $2,2^{\prime}, 3,3^{\prime}, 6,6^{\prime}$-hexachlorobiphenyl and 2,2',4,4',5,5'-hexachlorobiphenyl by human hepatic microsomes. Biochem. Pharmacol. 32: 3233-3239.

Schreck, R., Albermann, K. and Baeuerle, P. A. (1992). Nuclear factor kappa B: an oxidative stress-responsive transcription factor of eukaryotic cells (a review). Free Rad. Res. Commun. 17: 221-227.

Schreck, R., Rieber, P. and Baeuerle, P. A. (1991). Reactive oxygen intermediates as apparently widely used messengers in the activation of the NF- $\mathrm{KB}$ transcription factor and HIV-1. EMBO J. 10: 2247-2258.

Schuetz, E. G., Schuetz, J. D., Thompson, M. T., Fisher, R. A., Madariage, J. R. and Strom, S. C. (1995). Phenotypic variability in induction of P-glycoprotein mRNA by aromatic hydrocarbons in primary human hepatocytes. Mol. Carcinog. 12: 6165 .

Schuetz, E. G., Wrighton, S. A. and Guzelian, P. S. (1984). Induction of cytochrome P450 by glucocorticoids in rat liver. I. Evidence that glucorticoids and pregnenolone 16-alpha-carbonitrile regulate de novo synthesis of a common form of cytochrome P450 in cultures of adult rat hepatocytes and in liver in vivo. J. Biol. Chem. 259: 1999-2006.

Schwartzman, M. L., Balazy, M., Masferrer, J., Abraham, N. G., McGiff, J. C. and Murphy, R. C. (1987). 12(R)-Hydroxyicosatetraenoic acid: A cytochrome P450dependent arachidonate metabolite that inhibits $\mathrm{Na}^{+}, \mathrm{K}^{+}$-ATPase in the cornea. Proc. Natl. Acad. Sci. USA 84: 8125-8129. 
Schwen, R. J. and Mannering, G. J. (1982). Hepatic cytochrome P-450-dependent monooxygenase system of the trout, frog and snake. III. Induction. Comp. Biochem. Physiol. 71B: 445-453.

Sen, C. and Packer, L. (1996). Antioxidant and redox regulation of gene transcription. FASEB J 10: 709-720.

Shatwell, K. P. and Segal, A. W. (1996). NADPH Oxidase. Int. J. Biochem. Cell Biol. 28: 1191-1195.

Shertzer, H. G., Bechtel, M. A., Dalton, T. P., Meyer, D. C., Sonntag, D., Dixon, K., Robinson, L. J., Nebert, D. W. and Puga, A. (1998). TCDD causes a sustained oxidative stress response in CB57BL/6J mice. Toxicol. Sci. 42: 385.

Shimada, T. and Sawabe, Y. (1983). Activation of 3,4,3',4'-tetrachlorobiphenyl to protein bound metabolites by the rat liver cytochrome P-448-containing monooxygenase system. Toxicol. Appl. Pharmacol. 70: 486-493.

Shneider, A. M., Mann, K. K., Schneider, V. M., Sonenshein, G. E. and Sherr, D. H. (submitted). Activation of the aryl hydrocarbon receptor/transcription factor induces NF-KB/Rel.

Sies, H., Koch, O. R., Martino, E. and Boveris, A. (1979). Increased biliary glutathione disulfide release in chronically ethanol-treated rats. FEBS Lett. 103: 287-290.

Sif, S. and Gilmore, T. D. (1993). NF-kappaB p100 is one of the high-molecular-weight proteins complexed with the v-Rel oncoprotein in transformed chicken spleen cells. J. Virol 67: 7612-7617.

Simonian, N. A. and Coyle, J. T. (1996). Oxidative stress and neurodegenerative diseases. Annu. Rev. Pharmacol. Toxicol. 36: 83-106.

Sinclair, P., Frezza, J., Sinclair, J., Bement, W., Haugen, S., Healey, J. and Bonkovsky, H. (1989). Immunochemical detection of different isoenzymes of cytochrome P450 induced in chick hepatocyte cultures. Biochem. J. 258: 237-245.

Sinclair, P. R., Bement, W. J., Bonkovsky, H. L., Lambrecht, R. W., Frezza, J. E., Sinclair, J. F., Urquhart, A. J. and Elder, G. H. (1986). Uroporphyrin accumulation produced by halogenated biphenyls in chick embryo hepatocytes: reversal of the accumulation by piperonyl butoxide. Biochem. J. 237: 63-71.

Sinclair, P. R., Gorman, N., Walton, H. S., Sinclair, J. F., Lee, C. A. and Rifkind, A. B. (1997). Identification of CYP1A5 as the CYP1A enzyme mainly responsible for uroporphyrinogen oxidation induced by $\mathrm{Ah}$ receptor ligands in chicken liver and kidney. Drug Metab. Dispo. 25: 779-783. 
Skaare, J. U., Jensen, E. G., Goksoyr, A. and Egaas, E. (1991). Response of xenobiotic metabolizing enzymes of rainbow trout (Oncorhynchus mykiss) to the mono-ortho substituted polychlorinated PCB congener 2,3',4,4',5-pentachlorobiphenyl, PCB118 , detected by enzyme activities and immunochemical methods. Arch. Environ. Contam. Toxicol. 20: 349-352.

Sleiderlink, H. M. and Boon, J. P. (1996). Temporal induction pattern of hepatic cytochrome P4501A in thermally acclimated dab (Limanda limanda) treated with 3,3',4,4'-tetrachlorobiphenyl (CB 77). Chemosphere 32: 2335-2344.

Smith, A. G., Carthew, P., Clotheir, B., Constantin, D., Francis, J. E. and Madra, S. (1995). Synergy of iron in the toxicity and carcinogenicity of polychlorinated biphenyls (PCBs) and related chemicals. Toxicol. Lett. 82-83: 945-950.

Smith, P. K., Krohn, R. I., Hermanson, G. T., Mallia, A. K., Gartner, F. H., Provenzano, M. D., Fujimoto, E. K., Goeke, N. M., Olson, B. J. and Klenk, D. C. (1985). Measurement of protein using bicinchoninic acid. Anal. Biochem. 150: 76-85.

Smolowitz, R. M., Hahn, M. E. and Stegeman, J. J. (1991). Immunohistochemical localization of cytochrome P450IA1 induced by 3,3',4,4'-tetrachlorobiphenyl and by 2,3,7,8-tetrachlorodibenzofuran in liver and extrahepatic tissues of the teleost Stenotomus chrysops (scup). Drug Metab. Dispos. 19: 113-123.

Song, B. J., Gelboin, H. V., Park, S. S., Yang, C. S. and Gonzalez, F. J. (1986). Complementary DNA and protein sequences of ethanol-inducible rat and human cytochrome P450s. Transcriptional and post-transcriptional regulation of the rat enzyme. J. Biol. Chem. 261: 16689-16697.

Stadtman, E. R. and Berlett, B. S. (1991). Fenton chemistry. Amino acid oxidation. J. Biol. Chem. 266: 17201-17211.

Stegeman, J. J. (1981). Polynuclear aromatic hydrocarbons and their metabolism in the marine environment. Polycyclic Hydrocarbons and Cancer. New York, Academic Press. 1-60.

Stegeman, J. J. (1987). Monooxygenase systems in marine fish. Pollutant Studies in Marine Animals. Boca Raton, Florida, CRC Press. 65-.

Stegeman, J. J. (1989). Cytochrome P450 forms in fish: catalytic, immunological and sequence similarities. Xenobiotica 19: 1093-1110.

Stegeman, J. J. (1993). Cytochrome P450 forms in fish. Cytochrome P450. SpringerVerlag. 279-291.

Stegeman, J. J., Binder, R. L. and Orren, A. (1979). Hepatic and extrahepatic microsomal electron transport components and mixed-function oxygenases in the marine fish Stenotomus versicolor. Biochem. Pharmacol. 28: 3431-3439. 
Stegeman, J. J. and Hahn, M. E. (1994). Biochemistry and molecular biology of monooxygenases: Current perspectives on the forms, function and regulation of cytochromes P450. Aquatic Toxicology: Cellular, Molecular and Biochemical Perspectives. Boca Raton Fla, Lewis. 87-206.

Stegeman, J. J., Hahn, M. E., Weisbrod, R., Woodin, B. R., Joy, J. S., Najibi, S. and Cohen, R. A. (1995). Induction of cytochrome P450 1A1 by aryl hydrocarbon receptor agonists in porcine aorta endothelial cells in culture, and CYP1A1 activity in intact cells. Mol. Pharmacol. 47: 296-306.

Stegeman, J. J. and Kloepper-Sams, P. J. (1987). Cytochrome P-450 isozymes and monooxygenase activity in aquatic animals. Environ. Health Perspect. 71: 87-95.

Stegeman, J. J., Miller, M. R. and Hinton, D. E. (1989). Cytochrome P450IA1 induction and localization in endothelium of vertebrate (teleost) heart. Mol. Pharmacol. 36: 723-729.

Stegeman, J. J., Morrison, H. G., Soballa, V., Jacob, J. and Doehmer, J. (1996). Catalytic properties of a teleost cytochrome P4501A1 (Scup CYP1A1) expressed in V79 cells. XIth International Symposium on Microsomes and Drug Oxidations, Los Angeles,

Stegeman, J. J., Woodin, B. R., Klotz, A. V., Wolke, R. E. and Orme-Johnson, N. R. (1982). Cytochrome P-450 and monooxygenase activity in cardiac microsomes from the fish Stenotomus chrysops. Mol. Pharmacol. 21: 517-526.

Stegeman, J. J., Woodin, B. R., Park, S. S., Kloepper-Sams, P. J. and Gelboin, H. V. (1985). Microsomal cytochrome P-450 function in fish evaluated with polyclonal and monoclonal antibodies to cytochrome P-450E from scup (Stenotomus chrysops). Mar. Environ. Res. 17: 83-86.

Stegeman, J. J., Woodin, B. R. and Waxman, D. J. (1990). Structural relatedness of mammalian cytochromes P450 IIB and cytochrome P450B from the marine fish scup (Stenotomus chrysops). FASEB J. 4: A739.

Stern, J. O., Peisach, J., Blumberg, W. E., Lu, A. I. H. and Levin, W. (1973). A low temperature EPR study of partially purified soluble cytochromes P-450 and P-448 from rat liver microsomes. Arch. Biochem. Biophys. 156: 404-413.

Steward, R. (1987). Dorsal, an embryonic polarity gene in Drosophila, is homologous to the vertebrate proto-oncogene, c-rel. Science 238: 692-694.

Stohs, S. J. (1990). Oxidative stress induced by 2,3,7,8-tetrachlorodibenzo-p-dioxin (TCDD). Free Rad. Biol. Med. 9: 79-90.

Stohs, S. J., Al-Bayati, Z. F., Hassan, M. Q., Murray, W. J. and Mohammadpour, H. A. (1986). Glutathione peroxidase and reactive oxygen species in TCDD-induced lipid peroxidation. Adv. Exp. Med. Biol. 197: 357-365. 
Stohs, S. J., Shara, M. A., Alsharif, N. Z., Wahba, Z. Z. and Al-Bayati, Z. A. F. (1990). $2,3,7,8$-Tetrachlorodibenzo- $p$-dioxin-induced oxidative stress in female rats. Toxicol. Appl. Pharmacol. 106: 126-135.

Strivastava, K. C. and Mustafa, T. (1984). Arachidonic acid metabolism and prostaglandins in lower animals. Mol. Physiol. 5: 53-60.

Sundseth, S. S., Alberta, J. A. and Waxman, D. J. (1992a). Sex-specific growth hormone-regulated transcription of the cytochromes $\mathrm{P} 4502 \mathrm{C} 11$ and $2 \mathrm{C} 12$ genes. $J$. Biol. Chem. 267: 3907-3914.

Sundseth, S. S. and Waxman, D. J. (1992b). Sex dependent expression and clofibrate inducibility of cytochrome P450 4A fatty acid $\omega$-hydroxylases. J. Biol. Chem. 267: 3915-3921.

Suzuki, K., Tsuchida, J., Yamamoto, T. and Inoue, J. (1998). Identification and expression of the Xenopus homolog of mammalian p100-NFKB2. Gene 206: 1-9.

Suzuki, K., Yamamoto, T. and Inoue, J. (1995). Molecular conling of cDNA encoding the Xenopus homolog of mammalian RelB. Nuc. Acids Res. 23: 4664-4669.

Suzuki, Y., HJ, F. and A, S. (1997). Oxidants as stimulators of signal transduction. Free Rad. Biol. Med. 22: 269-285.

Takahashi, M., Tanaka, M., Sakai, N., Adachi, S., Miller, W. L. and Nagahama, Y. (1993). Rainbow trout ovarian cholesterol side-chain cleavage cytochrome-P450 (P450scc) - cDNA cloning and messenger RNA expression during oogenesis. FEBS Lett. 319: 45-48.

Takamo, T., Iyazaki, Y. M. and Araki, R. (1988). Interaction of 1,1,1-trichloroethane with the mixed-function oxidation system in rat liver microsomes. Xenobiotica 18: 1457.

Tanabe, S. (1985). Distribution, behaviour and fate of PCBs in the marine environment. Lecture by the member awarded the Okada prize of the Oceanographical Society of Japan for 1985. J. Oceanogr. Soc. Japan 41: 358-370.

Tanaka, M., Telecky, T. M., Fukuda, S., Adachi, S. and Chen, S. (1992). Cloning and sequence analysis of the cDNA encoding $\mathrm{P}-450$ aromatase (P450arom) from a rainbow trout (Oncorhynchus mykiss) ovary: relationship between the amount of P450arom mRNA and the production of oestradiol-17 $\beta$ in the ovary. J. Mol. Endocrinol. 8: 53-61.

Tannahill, D. and Wardle, F. C. (1995). Control of axis formation in Xenopus by the NFКB-IкB system. Int. J. Dev. Biol. 39: 549-558.

Thiemermann, C. (1991). Biosynthesis and interaction of endothelium-derived vasoactive mediators. Eicosanoids 4: 187-202. 
Thirman, M. J., Albrecht, J. H., Krueger, M. A., Erickson, R. R., Cherwitz, D. L., Park, S. S., Gelboin, H. V. and Holtzman, J. L. (1994). Induction of cytochrome P4501A1 and formation of toxic metabolites of benzo[a]pyrene by rat aorta: a possible role in atherogenesis. Proc. Natl. Acad. Sci., USA 91: 5397-5401.

Tian, Y., Ke, S., Rabson, A. B. and Gallo, M. A. (1998). Interaction between the Ah receptor (AhR) and NF-kB signal transduction pathway. Toxicol. Sci. 41: 68.

Tillitt, D. E., Ankley, G. T., Verbrugge, D. A., Giesy, J. P., Ludwig, J. P. and Kubiak, T. J. (1991). H4IIE rat hepatoma cell bioassay-derived 2,3,7,8-tetrachlorodibenzop-dioxin equivalents in colonial fish-eating waterbird eggs from the Great Lakes. Arch. Environ. Contam. Toxicol. 21: 91-101.

Toborek, M., Barger, S. W., Mattson, M. P., Espandiari, P., Robertson, L. W. and Hennig, B. (1995). Exposure to polychlorinated biphenyls causes endothelial cell dysfunction. J. Biochem. Toxicol. 10: 219-226.

Tsyrlov, I. B., Goldfarb, I. S. and Gelboin, H. V. (1993). Enzyme-kinetic and immunochemical characteristics of mouse cDNA-expressed, microsomal, and purified CYP1A1 and CYP1A2. Arch. Biochem. Biophys. 307: 259-266.

Tyle, H., Egsmose, M. and Harrit, N. (1991). Mixed-function oxygenase in juvenile rainbow trout exposed to hexachlorobenzene or 3,3',4,4'-tetrachlorobiphenyl. Comp. Biochem. Physiol. 100C: 16́1-164.

Urquhart, A. J. and Elder, G. H. (1987). Hexachlorobenzene-induced oxygen activation by mouse liver microsomes: Comparison with phenobarbitone and 20methylcholanthrene. Biochem. Pharmacol. 36: 3795-3796.

van der Oost, R., Goksoyr, A., Celander, M., Heida, H. and Vermeulen, N. P. E. (1996). Biomonitoring of aquatic pollution with feral eel (Anguilla anguilla) II. Biomarkers: pollution-induced biochemical responses. Aquat. Toxicol. 36: 189222.

van der Oost, R., Stumalay, K., Goksohr, A., Vindimian, E., van den Brink, P., Heida, H. and Vermeulen, N. P. E. (1995). Relationships between bioaccumulation of organic trace pollutants (PCBs, OCPs and PAHs) and biochemical markers in feral eel (Anguilla anguilla): a multi-variant analysis. 8th International Symposium on Pollutant Responses in Marine Organisms., Monterey, CA,

Van Praag, D., Parber, S. J., Minkin, E. and Primor, N. (1987). Production of eicosanoids by the killifish gills and opercular epithelia and their effect on active transport of ions. Gen. Comp. Endocrinol. 67: 50-57.

Vander, A. J., Sherman, J. H. and Luciano, D. S. (1990). Human Physiology: The Mechanisms of Body Function. New York, McGraw Hill Publishing Co.

Vane, J. R., Anggard, E. E. and Botting, R. M. (1990). Regulatory functions of the vascular endothelium. New Eng. J. Med. 323: 27-36. 
VanRollins, M. (1990). Synthesis and characterization of cytochrome P-450 epoxygenase metabolites of eicosapentaenoic acid. Lipids 25: 481-490.

VanRollins, M., Baker, R. C., Sprecher, H. W. and Murphy, R. C. (1984). Oxidation of docosahexaenoic acid by rat liver microsomes. J. Biol. Chem. 259: 5776-5783.

VanRollins, M., Frade, P. D. and Carretero, O. A. (1988). Oxidation of 5,8,11,14,17eicosapentaenoic acid by hepatic and renal microsomes. Biochim. Biophys. Acta 966: 133-149.

Vercellotti, G. M., Severson, S. P., Duane, P. and Moldow, C. F. (1991). Hydrogen peroxide alters signal transduction in human endothelial cells. J. Lab. Clin. Med. 117: $15-24$.

Verma, I. M., Stevenson, J. K., Schwartz, E. M., Van Antwerp, D. and Miyamoto, S.

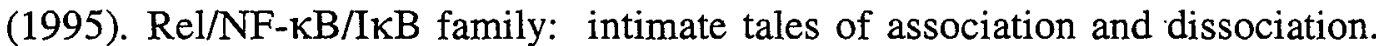
Genes Dev. 9: 2723-2735.

Voorman, R. and Aust, S. D. (1987). Specific binding of polyhalogenated aromatic hydrocarbon inducers of cytochrome P-450d to the cytochrome and inhibition of its estradiol 2-hydroxylase activity. Toxicol. Appl. Pharmacol. 90: 69-78.

Voorman, R. and Aust, S. D. (1988). Inducers of cytochrome P-450d: influence on microsomal catalytic activities and differential regulation by enzyme stabilization. Arch. Biochem. Biophys. 262: 76-84.

Wade, M. G. and Van Der Kraak, G. (1993). Arachidonic acid and prostaglandin E sub(2) stimulate testosterone production by goldfish testis in vitro. Gen. Comp. Endocrinol. 90: 109-118.

Wahba, Z. Z., Lawson, T. A., Murray, W. J. and Stohs, S. J. (1989). Factors influencing induction of DNA single strand breaks in rats by $2,3,7,8$-tetrachlorodibenzo- $p$ dioxin. Toxicology 58: 57-69.

Wales, N. A. M. and Gaunt, T. (1985). Hemodynamic, renal and steroidogenic actions of prostaglandins E1, E2, A2, F2 $\alpha$ in European eels. Gen. Comp. Endocrinol. 62: 327-334.

Walker, M. K. and Peterson, R. E. (1991). Potencies of polychlorinated dibenzo-p-dioxin, dibenzofuran, and biphenyl congeners, relative to 2,3,7,8-tetrachlorodibenzo- $p$ dioxin, for producing early life stage mortality in rainbow trout (Oncorhynchus mykiss). Aquat. Toxicol. 21: 219-238.

Wang, W. L., Porter, W., Burghardt, R. and Safe, S. H. (1997). Mechanism of inhibition of MDA-MB-468 breast cancer cell growth by 2,3,7,8-tetrachlorodibenzo-p-dioxin. Carcinogenesis 18: 925-933.

Wasylyk, C. and Wasylyk, B. (1993). Oncogenic conversion of Ets affects redox regulation in vivo and in vitro. Nucleic Acids Res. 21: 523-529. 
Waterman, M. R., John, M. E. and Simpson, E. R. (1986). Regulation of synthesis and activity of cytochrome P450 enzymes in physiological pathways. Cytochrome P450: Structure, Mechanism, Biochemistry. New York, Plenum Press. 345-386.

Watkins, P. B., Wrighton, S. A., Schuetz, E. G., Maurel, P. and Guzelian, P. S. (1986). Macrolide antibiotics inhibit the degradation of the glucocorticoid-responsive cytochrome P-450p in rat hepatocytes in vivo and in primary monolayer culture. $J$. Biol. Chem. 261: 6264-6271.

Waxman, D. and Azaroff, L. (1992). Phenobarbital induction of cytochrome P-450 gene expression. Biochem. J. 281: 577-592.

Weber, C., Erl, W., Pietsch, A., Strobel, M., Ziegler-Heitbrock, H. W. L. and Weber, P. C. (1994). Antioxidants inhibit monocyte adhesion by suppressing nuclear factor$\mathrm{kB}$ mobilization and induction of vascular cell adhesion molecule-1 in endothelial cells stimulated to generate radicals. Arterioscler. Thromb. 14: 1665-1673.

Weber, P. C. (1990). The modification of the arachidonic acid cascade by $n-3$ fatty acids. Advances in prostaglandin, thromboxane, and leukotriene research. New York, Raven Press. 232-240.

Weiss, C., Kolluri, S. K., Kiefer, F. and Gottlicher, M. (1996). Complementation of Ah receptor deficiency in hepatoma cells: negative feedback regulation and cell cycle control by the Ah receptor. Exp. Cell Res. 226: 154-163.

White, J. A., Guo, Y.-D., Baetz, K., Beckett-Jones, B., Bonasoro, J., Hsu, K. E., Dilworth, F. E., Jones, G. and Petkovich, M. (1996). Identification of the retinoic acid-inducible all trans retinoic acid 4-hydroxylase. J. Biol. Chem. 271: 2992229927.

White, R. D., Shea, D., Solow, A. R. and Stegeman, J. J. (1997a). Induction and posttranscriptional suppression of hepatic cytochrome P4501A1 by 3,3',4,4'tetrachlorobiphenyl. Biochem. Pharmacol. 53: 1029-1040.

White, R. D., Shea, D. and Stegeman., J. J. (1997b). Metabolism of the aryl hydrocarbon receptor agonist 3,3',4,4'-tetrachlorobiphenyl by the marine fish scup (Stenotomus chrysops) in vivo and in vitro. Drug Metab. Dispos. 25: 564-572.

Wilhelmsen, K. C., Eggleton, K. and Temin, H. M. (1984). Nucleic acid sequences of the oncogene $\mathrm{V}$-rel in reticuloendotheliosis virus strain $\mathrm{T}$ and its cellular homolog, the proto-oncogene c-rel. J. Virol. 52: 172-182.

Wu, S., Moomaw, C. R., Tomer, K. B., Falck, J. R. and Zeldin, D. C. (1996). Molecular cloning and expression of CYP2J2, a human cytochrome P450 arachidonic acid epoxygenase highly expressed in heart. J. Biol. Chem. 271: 34603468. 
Wu, S., Weina, C., Murphy, E., Gabel, S., Tomer, K. B., Foley, J., Steenbergen, C., Falck, J. R., Moomaw, C. R. and Zeldin, D. C. (1997). Molecular cloning, expression, and functional significance of a cytochrome P450 highly expressed in rat heart myocytes. J. Biol. Chem. 272: 12551-12559.

Xie, Q. W., Kashiwabara, Y. and Nathan, C. (1994). Role of transcription factor NFkB/Rel in induction of nitric oxide synthase. J. Biol. Chem 269: 4705-4708.

Yang, Y., Wang, J. and Buhler, D. R. (1996). Cloning and characterization of a new cytochrome P450 from rainbow trout. Mar. Environ. Res. 42: 27.

Yao, K. S. and O'Dwyer, P. J. (1995). Involvement of NF-KB in the induction of NAD(P)H:quinone oxidoredutase (DT-diaphorase) by hypoxia, oltipraz and mitomycin C. Biochem. Pharmacol. 49: 275-282.

Yao, Y., Hoffer, A., Chang, C.-Y. and Puga, A. (1995). Dioxin activates HIV-1 gene expression by an oxidative stress pathway requiring a functional cytochrome $\mathrm{P} 450$ CYP1A1 enzyme. Envrion. Health Perspect. 103: 366-371.

Yawetz, A., Woodin, B. R. and Stegeman, J. J. (1998). Cytochromes P450 (CYP) in liver of the turtle Chysemys picta picta and the induction and partial purification of CYP1A-like proteins. Biochim. Biophys. Acta. 1381: 12-26.

Yeh, G. C., Lopaczynska, J., Poore, C. M. and Phang, J. A. (1992). A new functional role for P-glycoprotein: Efflux pump for benzo[a]pyrene in human breast cancer MCF-7 cells. Cancer Res. 52:

Yoshimura, H., Yonemoto, Y., Yamada, H., Koga, N., Oguri, K. and Saeki, S. (1987). Metabolism in vivo of 3,4,3',4'-tetrachlorobiphenyl and toxicological assessment of the metabolites in rats. Xenobiotica 17: 897-910.

Yu, B. P. (1994). Cellular defenses against damage from reactive oxygen species. Physiol. Rev. 74: 139-162.

Zabel, E. W., Walker, M. K., Hornung, M. W., Clayton, M. K. and Peterson, R. E. (1995). Interactions of polychlorinated dibenzo- $p$-dioxin, dibenzofuran and biphenyl congeners for producing rainbow trout early life stage mortality. Toxicol. Appl. Pharmacol. 134: 204-213.

Zacharewski, T. R., McCallum, G. P., Stegeman, J. J. and Bend, J. R. (1996). Hepatic cytochrome $\mathrm{P} 4501 \mathrm{~A}$ as a biomarker for hydrocarbon and oxidant pollutants in fish: Relevance of identification of specific mechanism(s) of induction and potential effects on homeostasis. Environmental Toxicology and Risk Assessment: Transboundary Issues in Pollution-Air, Surface and Groundwater. Philadelphia, American Society for Testing and Materials. 165-187.

Zeldin, D. C., Plitman, J. D., Kobayashi, J., Miller, R. F., Snapper, J. R., Falck, J. R., Szarek, J. L., Philpot, R. M. and Capdevila, J. H. (1995). The rabbit pulmonary cytochrome P450 arachidonic acid metabolic pathway: Characterization and significance. J. Clin. Invest. 95: 2150-2160. 
Zetter, B. R. (1981). The endothelial cells of large and small blood vessels. Diabetes 30: 24-28.

Zhang, Q.-Y., Ding, X. and Kaminsky, L. S. (1997). cDNA cloning, heterologous expression, and characterization of rat intestinal CYP2J4. Arch. Biochem. Biophys. 340: 270-278.

Zhou, G. and Kuo, M. T. (1997). NF-kappaB-mediated induction of mdr1b expression by insulin in rat hepatoma cells. J. Biol. Chem. 272: 15174-15183. 